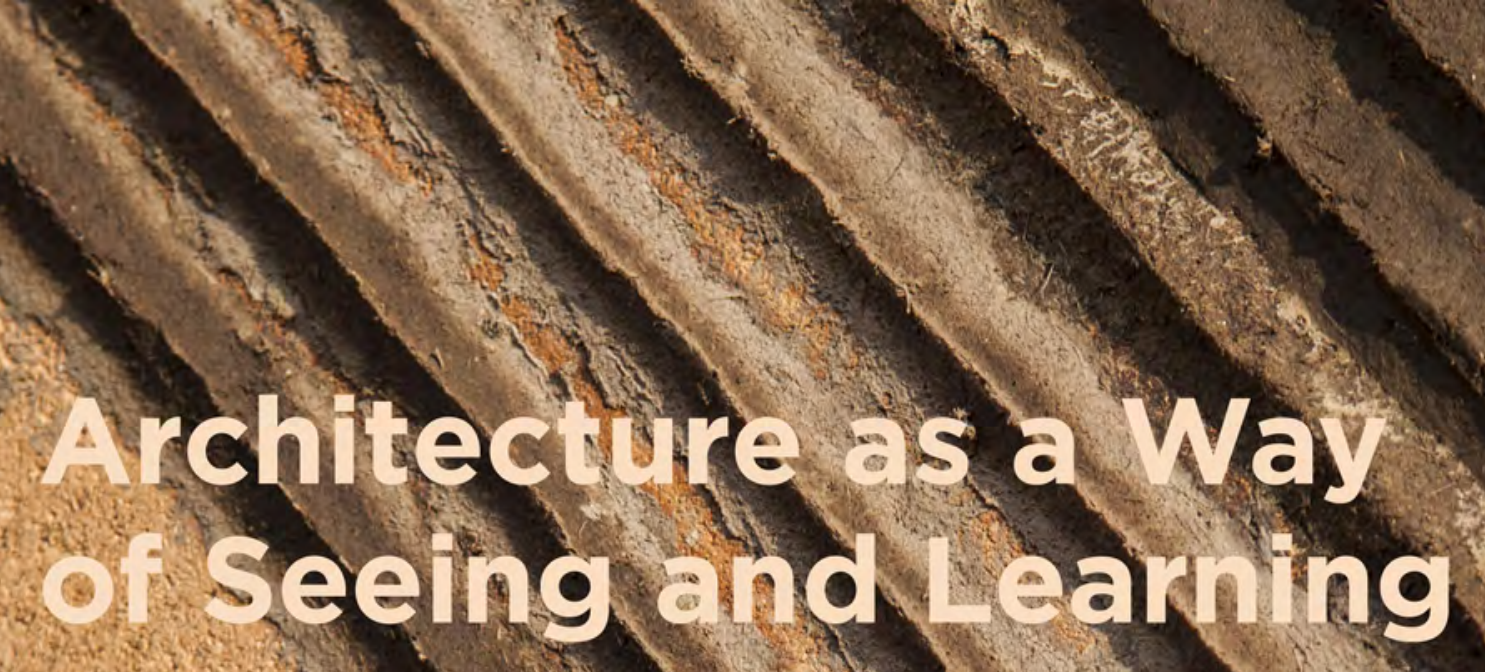

The buil environment as an added educator

In East African refugee camps
Nerea Amorós Elorduy

In Est Aftcan refuc
Nerea Amorós Elorduy 
Architecture as a Way of Seeing and Learning 


\section{Series Editors:}

Murray Fraser,

The Bartlett School of Architecture, UCL

Jonathan Hill,

The Bartlett School of Architecture, UCL

Lesley Lokko,

African Futures Institute, Ghan

Since the Renaissance a number of architect-scholars have created methods of intellectual scrutiny of architectural design that rely upon the interplay of drawings, models, textual analysis, intellectual ideas and cultural insights. Yet there is still no cohesive framework or outlet for design research in architecture. This innovative book series - still the only or of knd - showcases the very best proponents of architectural design

Featuring work from Early Career Researchers and leading architect-scholars in practice and academia, books in the series vary in tone and structure, covering aspects such as design method, visual representation, reasoned critique, social processes and strategies for action. The series is deliberately inclusive to encourage a vibrant, novel retical research with creative propositions expressed through drawings, models or texts; indeed, it is the symbiotic interplay between these components that forms the basis for design research in architecture. Now is a fertile time for design research and this book series acts as the heart of these investigations.

\section{Architecture as a Way of} Seeing and Learning

The built environment as

an added educator in

East African refugee camps

Nerea Amorós Elorduy 
Text $\odot$ Nerea Amorós Elorduy, 2021

Images $\odot$ Author and copyright holders named in captions, 202

Nerea Amorós Elorduy has asserted her right under the Copyright, Designs and

Patents Act 1988 to be identified as author of this work.

A CIP catalogue record for this book is available from The British Library.

This book is published under a Creative Commons Attribution-Non-Commercial

4.0 International licence (CC BY-NC 4.0). This licence allows you to share and adapt the work for non-commercial use providing attribution is made to the author and publisher (but not in any way that suggests that they endorse you or your use of the work) and any changes are indicated. Attribution should include the following information:

Elorduy, N.A. 2021. Architecture as a Way of Seeing and Learning: The built environment as an added educator in East African refugee camps. London, UCL Press. https://doi.org/10 $.14324 / 111.9781800080119$

Further details about Creative Commons licences are available at http://creativecommons .org/licenses/

Any third-party material in this book is published under the book's Creative Common licence unless indicated otherwise in the credit line to the material. If you would like to re-use any third-party material not covered by the book's Creative Commons licence, you will need to obtain permission directly from the copyright holder.

ISBN: 978-1-80008-012-6 (Pbk.)

ISBN: 978-1-80008-011-9 (PDF)

DOI: https://doi.org/10.14324/111.9781800080119 vii List of figures

xv Foreword

xvii Acknowledgements

Introduction: the spatial and educational paradox of the long-term refugee camp

Foregrounding built and learning

environments

The refugee's role

Integrating theory and practice Architecture as a way of seeing and learning

Long-term refugee camps

are proto-urban learning

11 The urban turn: informality, co-modification and

13 The long-term camp and the nascence of the urban turn

18 Co-modification

19 Assemblage thinking

20 East African urban turn - a way forward?

25 Ever-evolving assemblages: the built environment of seven East African long-term camps

25 The beginning of refugee encampment policies in Eastern Africa

26 The continuation of encampment and its effects on young children
29 Complex, heterogeneous and ever-evolving encampment territories

33 Varied and changing learning environments

34 A constellation of refugee camp assemblages

67 Interactive and static spatial characteristics

82 Ever-changing, proto-urban, learning assemblages

95 Refugee-led spatial interventions: observed, imagined and speculated 96 The power of place-making

101 Observed quiet encroachment

and everyday life practices Refugee-imagined radical

incrementalism

127 Speculated transversal spatial

appropriations

incrementalism

153 Conclusions: through the eyes of an architect

Contributing to research by architectural design

$\begin{array}{ll}157 & \text { Situating refugee studies } \\ 158 & \text { Looking for real alternatives }\end{array}$ to camps

161 Glossary

167 Acronyms

169 Bibliograph

189 Index 
List of figures

1 Figure l.1 Nyabiheke refugee camp, Gatsibo, Western Province, Rwanda. September 2015. @ Amorós Elorduy.

7 Figure I.2 Diagram of all the actor included in this research. @ Amorós Elorduy.

12 Figure 1.1 Map of the African continent showing the East African Rift with the current locations of internally tered with the United Nations High tered with the United Nations High Commissioner for Refugees (UNHCR) and the International Organization for Migration. @ Amorós Elorduy.

14 Figure 1.2 Diagram of the literature reviewed in this chapter showing th growth of refugee camp studies' texts from the 1970s onwards (coinciding with the growth of registered refugees globally) and the incorporation of built environment experts into the discussion. The diagram high lights three main points of inflexion relevant to this study: Barbara HarrelBond's push for a refugee studies centre at Oxford University Giorgio Agamben's Homo Sacer book and Michel Agier's discussion on camps as cities. @ Amorós Elorduy.
25 Figure 2.1 Kiziba refugee camp, Karongi district, Western region, Rwanda. September 2017. @ Amorós Elorduy.

27 Figure 2.2 Infographic showing the location of all the camps I had identified as 'long-term refugee camps' in the region, highlighting that most UNHCR-registered refugees are in exile for more than 10 years, and only $40 \%$ of them settle in camps. Data sources: Nicholas in camps. Data sources: Nicholas Haysom and Nadine Walicki. Haysom and Nadine Walicki. 'Protracted Displacement: Uncertain Commissioned Report, Humanitarian Policy Group and Overseas Development Institute, London, 2015.๑ Amorós Elorduy

30 Figure 2.3 Map of East Africa (including the southern part of Sudan and Eastern Congo) with the 66 long-term camps I had identified in the region highlighting nation states' borders. The graphic shows the names of all 66 camps, their the names of all 66 camps, their they hosted as of December 2016. ○ Amorós Elorduy. 
32 Figure 2.4 Maps of East Africa and the African continent showing the three main conflict areas that feed the refugee camps in East Africa: Horn of Africa, the Great Lakes
region and South Sudan. $\odot$ Amorós Elorduy.

35 Figure 2.5 Map of Uganda showing the location of current refugee camps (or groups of camps), and their demographics. @ Amorós Elorduy.

37 Figure 2.6 Maps and diagrams of the country the landscape and the the count camp scales or Nakivale, Kyangwal and Kyaka ll refugee camps. These maps show the relative position of the camps in respect to Kampala and the country's borders (country scale), nearest population hubs an main transportation arteries (lan scape scale) and the different zonin and circulation arteries (camp scale). ○ Amorós Elorduy.

38 Figure 2.7 Maps and diagrams of Nakivale on the Rift, country, landscape and camp scales. On the camp scale, the maps show the location of visited formal and non-formal early childhood development (ECD) centres and also three different villages, their grain, density, pattern of habitation and location of one formal or nonformal learning environments. Th villages I have chosen are representtive of the three zones that cosentNive
Kashojwa villages in Base Camp zone and Isanja vill ○ Amorós Elorduy.

40 Figure 2.8 From top to bottom and left to right: Nakivale's main road at Juru zone, the road passing through Base Camp zone and at paths at Rubondo zone. August 2016 (c) Amorós Elorduy.

42 Figure 2.9 Maps and diagrams of Kyangwali on the Rift, country landscape and camp scales On the landscale, the maps show the the camp visited formal and non-forman of visited for centres and also two different villages, their grain, density, pattern of or non-formal learning environor non-formal learning environment. The villages I have chosen are representative of the two zones that compose Kyangwali: Nugurue in zone $\mathrm{A}$ and Malembo in zone $\mathrm{B}$ ๑ Amorós Elorduy.

44 Figure 2.10 Kyangwali refugee camp. Top: main road at Kasonga on zone A. Bottom left: path in Ngurue zone A. Bottom right: main road at Rwenyawawa zone B. August 2016. ๔ Amorós Elorduy.

46 Figure 2.11 Maps and diagrams of Kyaka II on the Rift, country, landscape and camp scales. On the camp scale, the maps show the location of visited formal and non-formal ECD centres and also two different villages, their gra pattern of habitation and location of one formal or non-formal learning environments. The villages I have chosen are representative of the two main types of urban grain present in the camp: the trading centre type represented by Bukere village and the farmland type represented by Bujubuli village. @ Amorós Elorduy.

48 Figure 2.12 Kyaka II refugee camp Top: road at SweSwe Zone. Bottom left: path through the fields Alfajiri village path through the fields, Alfajiri village in Bujubuli zone. Botor main path connecting Buliti with Bukere zones. August 2016. @ Amorós
Elorduy.

Figure 2.13 Map of Kenya showing the location of refugee camps (or groups of camps) and their demo-
graphics. @ Amorós Elorduy.

51 Figure 2.14 Maps and diagrams of the country, landscape and camp scales of Kakuma. These maps show the relative position of the camp in respect to Nairobi and the country's borders (country scale), nearest population hubs and main transportation arteries (landscape scale) and the different zoning and circulation arteries (camp scale). ๑) Amorós Elorduy.

52 Figure 2.15 Kakuma refuge camp. Top: Kakuma phase I main commercial road. Bottom left: right: secondary path phase I. September 2016. @ Amorós Elorduy.

53 Figure 2.16 Kakuma refugee camp. Bottom left: Mapor Kakuma showing the areas that flood during the rainy season. Top and bottom right: Photographs of the seasonal rivers/ flood-prone areas called 'lagga' between Kakuma phases I and II. September 2016. @ Amorós Elorduy.

54 Figure 2.17 Maps and diagrams of Kakuma on the Rift, country, landscape and camp scales. On the camp scale, the maps show the camp visited formal and non-formal $O C D$ visited formal and non-formal ECD centres and also three different zones, their grain, density, pattern of habitation and location of one formal or non-formal learning environments. The areas I have chosen are representative of Kakuma phases I, II and III. ๑ Amorós Elorduy.

57 Figure 2.18 Map of Rwanda showing the location of refugee camps and their demographics. @ Amorós Elorduy.

58 Figure 2.19 Maps and diagrams of the country, the landscape and the camp scales of Kiziba, Kigeme and Mugombwa in Rwanda. These maps show the relative position of the camps in respect to Kigali and the country's borders (country scale), country's borders (country scale), nearest population hubs and main scale) and the different $z$ in 
circulation arteries (camp scale) ○ Amorós Elorduy.

59 Figure 2.20 Kiziba refugee camp. Top: kitchen constructions. Bottom left: children playing between houses. Bottom right: overview of the camp. September 2015. @ Amorós Elorduy.

60 Figure 2.21 Maps of Kiziba on the Rift, country, landscape and camp scales. On the camp scale, the maps
show the location of visited formal show the location of visited formal and also the qurter level showing its grain, de nsity, pattern of habitation and location of one formal Elorduy.

63 Figure 2.22 Kigeme refuge camp. Top: general view of shelters at Kigeme B. Bottom left: vegetable patch at Kigeme B. Bottom right: path in Kigeme A. September 2015. ○ Amorós Elorduy.

64 Figure 2.23 Maps and diagrams of Kigeme on the Rift, country, landscape and camp scales. On the cam scale, the maps show the location of visited formal and non-formal ECD centres and also the quarter leve showing its grain, density, pattern of habitation and location of one formal ○ Amorós Elorduy.

67 Figure 2.24 Mugombwa refuge camp. Top: Mugombwa's main road the camp's centre and formal ECD centre. September 2017. Bottom lef: east-facing shelters. Bottom righ west-facing shelters. September 2015 ๑ Amorós Elorduy.

68 Figure 2.25 Maps and diagrams of Mugombwa on the Rift, country, landscape and camp scales. On the camp scale, the maps show the location of visited formal and non-forma ECD centres and also the quarter level showing its grain quarter pattern of habitation and density, pattern of habitation and location ○ Amorós Elorduy.

70 Figure 2.26 Location within Eas Africa, 2.26 Location within East Africa, detailed maps and dates of establishment of my seven case studies. Nakivale (est.198), Kyangwal (est. 1964) and Kyaka II (est. 1983) in Southwest Uganda; Kakuma (est. 1992) in Northwest Kenya; and Kiziba (est. 1997), Kigeme (est. 2005) and Mugombwa (est. 2013) in Rwanda. (c) Amorós Elorduy.

72 Figure 2.27 Diagram showing the spatial relationships on the country, landscape and camp scales of Nakivale, Kyangwali, Kyaka II Kakuma, Kiziba, Kigeme and Mugombwa. @ Amorós Elorduy.

74 Figure 2.28 Infographic showin the variability within the camp scale across my seven case studies (the diverse villages and quarters). Specifically it shows: three villages at Nakivale portraying the camp's three zones (Ruholo village in Rubondo zone the village in Kigali and Kashoje villages in Base Camp zone, and Isanja in Juru zone); two villages at Kyangwali, Ngurue in zone $\mathrm{A}$ and Malembo in zone $\mathrm{B}_{\text {i }}$ two villages at Kyaka II, Bukere trading centre in Bukere zone and Bujubuli in Buliti zone; three zones at Kakuma, one per phase; the encounter of four quarters in $\mathrm{Kizib}$ encounter of four quarters in Kiziba, quarters $2,4,5$ and 8 ; the encounter of four quarters in Kigeme, quarters $3,4,5$ and 6 ; and the centre of
Mugombwa covering portions of Mugombwa covering portions of all quarters except quarters 7 and 8 .

79 Figure 2.29 Diagram of the open areas and the porosity of differen villages in my seven case studies. From top to bottom and left to right (organised from most to leas permeable): Ruhoko (Nakivale), Ngurue (Kyangwali), Isanja (Nakivale), Malembo (Kyangwali), Buliti (Kyaka II), Bukere (Kyaka II), Kiziba, Kigeme, Mugombwa, Kakuma phase III, Kakuma phase II, Kakuma phase and Base Camp (Nakivale). @ Amorós Elorduy.

95 Figure 3.1 Two neighbours at Kiziba refugee camp rebuilding an old shelter from scratch on land appropriter from the canp apronegotiations with direct local hosts. negot rionswith ir ๑ Amorós Elorduy
97 Figure 3.2 Commercial strip in Kakuma phase III. Kakuma refugee camp, September 2016. @ Amorós Elorduy.

101 Figure 3.3 Sample of methods of spatial data collection. Map orientation (left) and sketching (right). Rwandan camps, September 2015. ๑ Amorós Elorduy.

102 Figure 3.4 Man repairing the tarp roof to his home in Kiziba. Kiziba refugee camp, September 2017. ๑) Amorós Elorduy.

104 Figure 3.5 Adapted homes. Top: two-storey home in Rubondo zone, Nakivale refugee camp, August 2016. Bottom (from left to right): Base Camp, Nakivale refugee camp, August 2016; Mugombwa refugee camp, September 2015; and Juru zone, Nakivale refugee camp, August 2016. ๑ Amorós Elorduy.

06 Figure 3.6 Diagrams showing the Congolese refugee homes in the Rwandan refugee camps and the main activities happening during the day and the night within and around them. Left: axonometric overview of homes in Kiziba quarter 2 with day activities. Right: top-down axonometric view of one house in jiziba quarter 2 showing the sleeping arrangements. @ Amorós Elorduy.

108 Figure 3.7 Diagrams showing the South Sudanese refugee homes in 
the Southwest Ugandan refugee camps and the main activities happening during the day and the night within and around them. Left: axonometric overview of homes in Ngurue village in Kyangwali showing daily activities. Right: top-down axonometric view of one house in Ngurue village in Kyangwali showing the sleeping arrangements. @ Amorós Elorduy.

111 Figure 3.8 Religious facilities. Top: mosque on Kiziba's outskirts, Kizib mosque on Kimp's Bottom from left to right: church Bottom cam left to right: chur in Kiziba's quarter 8, Kiziba refuge camp, September 2015, Isanja Baptist church, lsanja village, Juru zone, Nakivale refugee camp, August 2016; mosque in Kakuma phase II, Kakuma refugee camp, September 2016. ○ Amorós Elorduy.

112 Figure 3.9 Kiziba's non-formal ECD initiatives taking place in refugee an direct local host-built churches o the camp's outskirts. Kiziba refuge camp, September 2015. @ Amorōs Elorduy.

113 Figure 3.10 Commercial activities in Kakuma. Top: small business in Kakuma phase II. Bottom: two commercial roads in Kakum phase I. Kakuma refugee September 2016. @ Amorós Elordu

14 Figure 3.11 One of Kigeme's homebased initiatives in quarter 5 . Kigeme refugee camp, September 2017 ○ Amorós Elorduy

115 Figure 3.12 Photographs of Kigem home-based ECD initiatives in qua ters 4 and 5. Kigeme refugee camp September 2017. @ Amorós Elorduy.

116 Figure 3.13 Photographs of homebased ECD initiatives in Mugombwa quarters 5, 6 and 7. Mugombwa refugee camp, September 2015 ○ Amorós Elorduy

120 Figure 3.14 Diagram showing the elements that Domecaregiversidentified as problematic for young children's as problematic for young children's learning in my case studies. Data during fieldwork. Amoros Elorduy.

121 Figure $3.15(A+B)$ Before-and-after photomontage of pavement and drainage solutions in Kiziba refuge camp. @ Amorós Elorduy.

123 Figure $3.16(A+B)$ Before-and-after photomontage of the formal ECD centre in Kiziba quarter 8, with new windows manufactured in the camp. @ Amorós Elorduy.

124 Figure $3.17(A+B)$ Before-and-after photomontage of classroom interio in the maternelle in Kiziba quarte 4, with new windows and ceiling ๑) Amorós Elorduy.

126 Figure 3.18 Home interiors in the Rwandan refugee camps,
September 2015 and 2017. @ Amorós Elorduy.

128 Figure 3.19 (composition workshop $1^{\text {st }}$ day) Inception workshop in Kiziba refugee camp. Left page: adult participants engaged in a discussion about the common and open spaces young children currently use as playground. Right page clockwise: discussing the photomontages: listing the diverse need montages; listing the diverse needs and qualities for each of the location identified; the diverse locations for potential child-friendly spaces (CFS) identific marken model; children and adult participants identifying current and potential playgrounds for young children in the camp. Kiziba refugee camp, 5 September 2017. OAmorós Elorduy.

130 Figure 3.20 Diverse uses of mud colours and other natural pigment in the decoration of home interior and exteriors in Kiziba refugee camp, September 2015 and 2017. @ Amorós Elorduy.

132 Figure 3.21 First day of learning the imigongo technique. Left page: applying the dung-and-ash mixture to a preprepared wooden frame. Right page, from top to bottom and left to right: studying the different traditional imigongo designs and their meanings preparinga wooden fram with a geometric fram wooden frame an imigongo design; refuge filming the dung-and-ash application with their mobile phones; and an imigongo artisan teaching a group from the youth arts club. Kiziba refugee camp, 6September 2017. @ Amorós Elorduy.

134 Figure 3.22 Imigongo learning process. Left page: sanding the sundried dung-and-ash wooden boards. Right page, from top to bottom and left to right: sun-drying the wooden boards with the top layer of dungboards with the top layer of dung-
and-ash mixture already applied. sanding mixture already applied; mixture anplying first cotand-ash mud be, applying a first coat of grey manting; and the finished board. Kiziba refugee camp, 7-15 September 2017. @ Amorós
Elorduy.

136 Figure 3.23 Mural-making process on the first and second walls of the maternelle site. Left page: a geometric piece during the sun-drying process. Right page, from top to bottom and left to right: usual number of children surrounding the mural-making process during their break time; detail of corner between first and second walls; the application of the mixture should be done by adding water to the mixture; an overview of the first and second walls at maternelle in the afternoon. Kiziba refugee camp, 8 and 9 September 2017. ๑ Amorós Elorduy.

138 Figure 3.24 First steps of the mural-making process on the neighbourhood site. Left page: two of the 
walls at the neighbourhood mural site during the process of sun-drying the dung-and-ash mixture. Right pa bottom left: the neighbourhood site prior to the mural-making activity. Bottom right: imigongo artisan, community mobiliser and owner of one of the homes to get an imigongo mural on its walls discussing the potential outcomes portrayed in the photomontages. Kiziba refugee cam 11 and 12 September 2017 . ๑ Amoros Elorduy.

140 Figure 3.25 Painting process on first and second walls at neighbourhood site. Left page: morking bourhood site. Left page: working atmosphere. Right page: painting process (hrough layers) applied after sanding the sun-dried dung-and-as mixture. Application of base coat in dark grey mud, application of othe colours, application of detailing in black, and final detail. Kiziba refuge camp, 12 and 13 September 2017 ๑ Amorós Elorduy.
142 Figure 3.26 Finished murals. Left page: neighbourhood site with it three murals. Right page, bottom left two walls at maternelle's entrance bottom right: mural facing maternelle's playground. Kiziba refugee camp, 15 September 2017. @ Amorós Elorduy.

144 Figure 3.27 Public interest design studio workshops. Left page: discussion around findings and potential design guidelines for home-based ECD spaces in the Rwand home-base ECD spaces in the Rwandan refuge camps. Kigeme refugee camp 6 November 2017. Right page: session to discuss the findings and in the Congus in Rwanda Kizie ruge camps in Rwanda. Kiziba refugee camp, Amorós Elorduy

153 Figure C.1 Children playing with bottle tops on the street. Kizib refugee camp, September 2015 ๑) Amorós Elorduy.
Foreword

My architectural work in the refugee also attempted - but failed - to develop a camps of Rwanda incited me to start a $\mathrm{PhD}$ at the beginning of 2015 on the role the built environment had on encamped children's development I began work in the country as an intern with the United Nations Children's Fund (UNICEF) as part of Rwanda's national Early Childhood Development Task Force ${ }^{1}$ in February 2011 I contributed to develop an incremental, modular design for early childhood development (ECD) centres. This initial prototype was subsequently tested in difin 2011 and $2012^{2}$ and went on to become in 2011 and $2012^{2}$ and went on to become the basis for the first work of Active Socia Architecture (ASA) Studio, the architecspeculative collaboration between the NHCR and the School of Architecture in Rwanda, where I lectured from 2011 to 2014. Such cooperation intended to investigate the potential of having local creative minds continuously involved in the well-being of camp inhabitants and their local hosts rather than resorting to one-time foreign common practice. In 2014, we sold ASA Studio, and I went on to undertake this research.

The PhD research project that inspired this book explored the role of architecture, refugees and built environment professionals in the making and maintenance of refugee camps in East Africa. It was inithe 2012, which built more than 20 of these the design of ECD centres had on young centres across rural Rwanda from 2012 to children's development. However, as I 2014. ASA Studio worked for UNICEF and began to search for case studies, I became the United Nations High Commissioner aware of the lack of information on educafor Refugees (UNHCR) to develop two ECD tional facilities, child development and the centres in the two newest refugee camps built environment within refugee camps in at the time: one in Kigeme and one in East Africa. ${ }^{5}$ also realised it is necessary Mugombwa. ${ }^{4}$

to emphasise the socio-political role of the

These ECD centres were the first built environment within refugee camps. built interventions I had developed in a Prompted by both realisations, I decided refugee camp setting. Each experience to focus my research on investigating the refugee camp setting. Each experience to focus my research on investigating the examined the potential role of architec- kaleidoscopic and multi-authored built ture, participary proceses and 
rather than focus on a technical apprais of formal educational facilities alone.

This book is a study of the whole built

environment of seven refugee camps in

Southwest Uganda, Northwest Kenya an

Rwanda as a learning source for youn

children. It shows that there is a need for a

more focused, inclusive and participatory approach towards refugee assistance. This that the built environment, its creation and development have on humanitarion policy and practice, on geopolitics, on the study and prefuce, on gapolics, on the study the lives of encamped refugees and the direct local hosts, especially young chilchecto dren. Principally, with this book, I tried to test if and how archiecture and the built enver ives of those inhabiting and surrounding Afre long

With this book, I do not expect or hope to suddenly transform refugee cam planning and refugee education policies and practices. I desire to inject a sense of urgency into the topics concerning the built environment, the refugees' voice, the development of young children and the need to decolonise the study and practice of refugee assistance in these East African camps.

Ministry of Education Government of Rwanda, Integrated early childhood development strate-

gic plan 2011-2016, 5 . in June 2012; ASA developed a second itera-
tion of the model in Nyabiondo, Bugesera, in October 2012

were both lecturers at the Department. We Architecture at the College of Science and Technology a the University of Rwanda (Former
KIST) at the time

This improvement of the refugee educational
facilities coincided with the Rwanda Ministry of Education taking over the coordination of education within the camps. In addition, since
2015 , UNICEF is using ASA's design of ECD centres to develop ECD centres at Mahama efugee camp, established in April 2015 in the At the time of writing

database that agglomerated the world's refugee camps, their position and size and the number 列 and reports that accumulate information on specific ongoing emergencies.
Acknowledgements

This book is the result of a collective effort the three and a half years of $\mathrm{PhD}$ research made possible thanks to the generosity of a fun adventure and a possibility with his many individuals and institutions. I first want to thank UCL Press for promoting high-quality open-source publications and for accepting this work for publication under a relevant series.

I was able to undertake my research full-time thanks to a scholarship award from the La Caixa Foundation, which generously sponsored two years of my $\mathrm{PhD}$ work In addition, the fieldwork trips, which constituted the bulk of my research, were made possible thanks to the Architecture Research Fund and the Bartlett Studen Conference Fund from the Bartlett Faculty of the Built environment at UCL, the travel bursary of the British Association for International and Comparative Education and the Beacon Bursary from UCLCulture. I was also lucky to be accompanied on this research journey by some incredibly talented people. Joan Amorós was a source of energy, happiness, logistical mastery and gifted filming and photographing skills during most of the fieldwork trips. Lloyd Price, Mary Dain and Mercé Torrelles brought their expertise and vitality to the field and to the writing table. Thanks also to Marta Elorduy for being an unparalleled hard worker and for her reviews, patience and advice, and to Matt Smiths, who made ard work, serenity ands ured all my trips.

Many other family, PhD colleagues, ds of friends and selfless strangers also helped this research with ideas ion hosting my team and and providing avice and support at all tages of the process.

I would like to express my gratitude Professors Murray Fraser and Jonathan Hill for their tireless work at developing excellence in research by architectural design. I would also like to thank Professor Camillo Boano and Dr Tejendra Pherali for contributing with incredibly valuable nsights and guidance. I also express my gratitude to the staff at the Bartlett School of Architecture.

My research assistants have been critical to this research. They volunteered their time and accompanied me on long trips over bumpy dirt roads, walking tirelessly to visit refugee homes and remote ECD centres and accompanying young chilwillingness and their aim of improving their own countries have and continue to be a source of in to Flavia Gwiza Frank Bagenzi, Yves Twizeyimana, Murwanashyaka Shaffy, dren on transect walks. Their vitality and 
Aziz Farid, Emmanuel Nyirikindi, Thierry of the Prime Minister (Uganda) and the raguha, Mugabo Medard, Theophile Department for Refugee Affairs for grant Uwayezu, Jackson Opolot, Moses Magala, ing me access to all the camps visited. My Justicia Tegyeka, Tiffanie Kateizi, Etta deepappreciation also goes to the College Madette, Dolphine Kerubo, Asya Esajee, of Science and Technology in Rwanda, to Victor Iyakaremye, Lydia Kanakulya and the Ugandan Martyrs University and to Moses Mawa.

the head of department, Dr Mark Olweny

This research was also made possi- and the University of Nairobi, especially ble by the UNHCR Rwanda and Uganda, Professor Musau Kimeu.

UNICEF Rwanda and Kenya, the Lutheran My biggest recognition and appre-

World Federation in Kenya, and the Windle ciation goes to all the refugee parents,

Trust in Uganda to whom I would like to caregivers, mother leaders, youth and com

offer my thanks. Very special thanks go munity mobilisers, elected can and comoffer my thanks. who believed in me in 2011 and have Kyaka II Kakuma Kiziba, Kigeme and ho believed in me in 2011 and have Kyaka Il, Kakma, Kiziba, Kigeme and whe genein order to make his reserch and other ouslyopened work a possibility. I am deeply gratefulto and playgrounds to my research team, wo full o two full weeks in Kiziba working hand with us and enjoyed their participation in in hand with refugees and my team of the diverse activities we developed. I wish research assistants. Thanks too to the them the best as they continue to work to former Ministry of Disaster Management improve their lives and those of the youngand Refugee Affairs (Rwanda), the Office est camp inhabitants. 
Introduction the spatial and educational paradox of the long-term refugee camp

At the beginning of 2020, 66 long-term built environments affect their learning refugee camps' existed along the East and development.

African Rift. ${ }^{2}$ Some, such as Nakivale in

Southwest Uganda, were established

I started to work designing and evalu-

ating early childhood development (ECD)

refugees lived in these camps in 2020 , camps-in Rwanda in 2011 when also began

with roughly half a million of them being teaching at the country's first school of

younger than six years old ${ }^{3}$ Over the architecture. Like many professionals

years, millions of children have been involved in humanitarian assistance, I want

born and have grown up in these camps. to understand the impact of my work and Yet, it is unknown how their surrounding ensure that I provide what the users of my

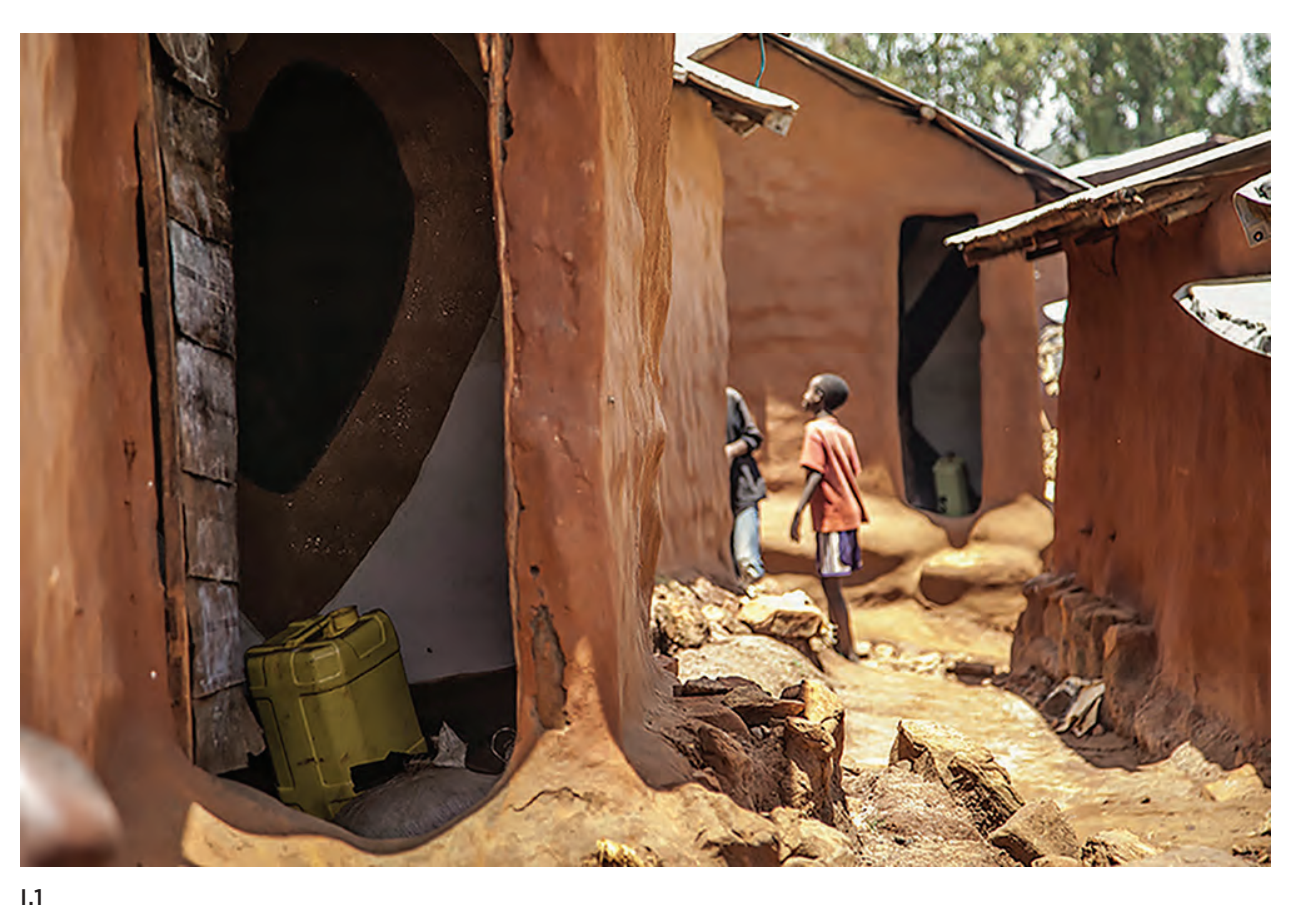


designs want and need. In 2015, I decided I realised that I needed to shift focus
investigate how the architecture of the and explore the whole built environmen Cal ECD facilities in the long-term and explore the whole built environmen affected young chit- of the camps - both inside and outside the formal schooling facilities - if I was to former architecture undergraduates at ing the young refugees. Unfortunately, the ECD centres of the Congolese camps the camps' spaces seemed to be forming in Rwanda - which my architectural firm mostly negative skills, attitudes and behavActive Social Architecture (ASA) had iours. That insight made me want to explore built -I realised that their weight on young further how architecture could transform children's learning was relatively small. what were meagre learning environments The homes, streets, common areas and public sanitation facilities carried the public sanit. young refugees.

Indeed, is it not the case that we al remember the feeling of the floor where we played with our siblings when we were young? And how tall the counters were to help her cook? That recognition made me recall this quote from Peter Zumthor that highlights how unforgettable our first experiences with architecture are

There was a time when I experienced rchitecture without thinking about Sometimes I can almost feel a particular door handle in my hand, a piece of metal shaped like the back of a spoon. I used to take hold of it when I went into my aunt's garden. That door handle still seems to $\mathrm{me}$ like a special sign of entry into a world of the sound of the gravel under my feet, th soft gleam of the waxed oak staircase, Ican hear the heavy front door closing me as I walk along the dark corridor and mer the kitchen the only really brigh lit room in the house', ronments-Over the years I have noticed an extreme lack of information about African camps, especially in their built environments. I have indeed suffered from it when trying to develop my work. Apart fro a few academic works such Apant Chad 5 Bran Junsent Siddiqi ${ }^{7}$ about for from European scholars-about the camps built realm through a socio-political lens. Moreover, the refugee's voice is missing in most studies, humanitarian policies and interventions, which suffer from an excess of standardised guidelines and toolkits. thought it was time to create contextualised knowledge - nuanced, situated and particithe East African long-term camps to help decolonise the refugee studies field and refugee assistance.

\section{into stimulating added educators.}

Foregrounding built and learning enviof schol ars - wha, there is a shortage built environments. These works become almost non-existent when concernin learning settings and when looking at the patory - to describe, study and transform to uncovise the refugee studies field and
I tackled the task by using architecture as a means to create new knowledge collectively, include more local voices an speculate - through highly participator approaches - on how to improve the curren educational landscape for the million of young children living in these camps. Besides, while practising - especially building ECD facilities - in the refugee camps, was faced with the moral dilemma of contributing to their creation and maintenance. Participatory approaches help me reflect on the highly political role of practising in on the highly pol
the camps.?

In this book, the reader will find an architect's take on the questions that many academics and humanitarian workersare already asking ${ }^{10}$ Is it relevant to look camps through an urban lens and focus on their built environment? Which analytical benefits can architectural and design tools provide to refugee assistance? And which advantages can assemblage thinking and situated knowledges bring about in analysing, understanding and transforming long-term refugee camps?

With this work, I want to build upon what Bran Jansen calls a modest urban turn $^{\prime 11}$ in refugee camp studies, the emerging attention on the built environment in the last decade. This body of literature aims to bring nuance and contextualisation to the field, focusing on the camps' urbanity. Especially, the Middle Eastern cases are gaining from the new centrality of the uable insight about push-pull factors for forced migration, concepts of belonging and the relationships betwe olonging

refugees and direct local hosts and is contributing to exploring the role of the refugees in their own assistance in these settings. Alas, this attention has not yet reached the least visible cases in Eastern Africa. Studies, policies and strategies in the region have for decades largely ignored the built environment's relevance, assuming it as a contextual side topic. This disregard might be due in part to the insufficient humanitarian funding, a focus ${ }^{12}$ mostly on what is perceived to be life-saving and resulting from the humanitarian and the space of led the scholarship on camps for decades ${ }^{13}$ You might be wondering why You might be wondering why am ested in the built environment as a learning resouce foryoungchildritarian would become long term living and would become long term living and learning environments for millions of young children. In fact, my personal experience shows that many camp planners in the region still hardly foresee the physical infrastructures they design as permanent devices. Instead, they mainly plan camps as efficient tools for movement control, epidemic prevention, food distribution and temporary shelter.

Moreover, as camp spaces have been considered non-places, limbo and transitional for decades, not only the built environment but also matters such as child development and everyday life have been left aside. In addition, as humanitarian educational programmes lack enough unding and suffer from an overarching Anglo-European bias - mainly due

promote a narrow approach to education,

(n)


emphasising formal schooling with stand- included architects and designer $\mathrm{s}^{20}$ since ards devised in Geneva and overlooking the 1970s.

the learning that happens outside the The body of learning environment school environment. Moreover, as ECD works I reflect upon, and I want to collabohas only recently gathered momentum rate with, consider education and learning in refugee assistance, ${ }^{14}$ the information environments as complex, nuanced and available on learning environments for contextualised - as tools that can be both young children is mostly technical, with freeing and oppressive. Especially when an excess of standards and construction there are unbalanced power relations, guidelines focused on formal educational conflict and extreme deprivation - such as facilities alone.

What really should trigger your interest are the impacts of this neglect It is now internationally acknowledged that no Internationaly ack dren's initial years are critical for the socio-emotional, cognitive and physical development. Ihas also been proven th children absorb from experiencing the them. The built environment holds a potential that we must understand. ${ }^{16}$ Knowing which spatial qualities are relevant to young which spatial qualities are relevant to young
children's learning can inform policies and interventions as ECD gains momentum an new alternatives to camps are being buil. It is a matter that affects millions of young humans globally, and the long-term ca show that it will continue to do so.

To understand to what degree camps from post-structuralist literature that has, over the years, widened the conception of learning, describing it as diverse, composed of direct content-based education and learning by experience. ${ }^{17}$ Since the 1950 s, wor in the learning environments field has increasingly studied the built and natural environments outside the school setting is, by nature, interdisciplinary $\mathrm{y}^{19}$ and has the case of refugee camps - education and learning environments can harm and be used as a tool of the powerful to repress traditional knowledge. ${ }^{21}$

The refugee's role-Not surprisingly The refuges's rolegiven the decades-long humanitarian conthere is an extreme lack finvolvement there is an extreme lack of involvement of refugees and surrounding populations in Africa. ${ }^{22}$ This lack of engagement is exac erbated by a shortage of aid for long-term crises, poor humanitarian institutional memory due to the continuous movement of personnel and short-term funding, restrictive host government policies and economic and geopolitical stakes. In $\mathrm{m}$ experience, it is also because most humanitarian relief workers - which count few built environment professionals in their talking about the built environment as relevant factor in their work.

Despite refugees not being included in the official management and construcmakers, eamps, hey are their primar term. Yet, there is scarce reserch about indoctrinat ond the powerful to repress, planning the refugee camp spaces in Eas ranks - are unfamiliar with thinking and tion of the camps, they are the construc- refugee-led actions. Due to my long-term engagement in the topic, have been fortunate to observe the refugee-led spatial appropriations in Rwanda's long-term refugee camps since 2011. ${ }^{23}$ In particular I have experienced it in real time in the Mugombwa refugee camp, as I have been involved there from its establishment in 2013.

For the same reasons as those stated above, the refugees' perspective is lacking in knowledge production cycles. Academi and practice rely heavily on foreign-led and practicestly helo-Europan-led ers and institutions - based to often on short-term engaments in the field. The perceptions, views and actions field'. The perceptions, views and actions of the encamped and their direct local hosts, works - mainly women - are still largely works - main
overlooked.

In this book, I want to shed some light o the effects that the inclusion of the refugees voice - both adults and children - can have for the discussion about refugee assistance, particularly focusing on the built and learning environments. As part of my researc and practice journey, together with my teams, we have collected respondents proposals to make the camps stimulating child-friendly learning environments. ${ }^{24}$ The analysis of the information I gathered and created exposes the refugees' crucial role in the production of the camps' built environments and the relevance of their voice to transform the long-term camps and develop real alternatives to camps.

rating theory and practice-I strive to stand aware of my baggage and inheren biases throughout my work, creating a constant dialogue with my peers, assistants, informants and contexts. My identity as a young female architect born and raised in Barcelona affects access to certain areas and people, the types of responses I obtain, the information I collect and its analysis. It also limits my position as I seek to decolonise refugee camp research ${ }^{25}$ and camp management, as well as architectural design and research in the region. I try to challenge assumptions-the readers' mine and those of the humanitarian system/host government assemblages.

Specifically, writing this book, I was the new deal and the 'collective experiKnow and Dona Haraway's 'Situated Feming The Science Question in Peminism of Partial and the Privilege.'2 Both authors state that optimal policies cannot be universal or extracted from partial information and views - a common trait amongst humanitarian policies; they should be context specific and draw from various factors. They require local actors' participation to contextualise data and existing knowledge and tailor solutions best suited to their environment. It was relevant to involve refugees, direct local hosts, local artists, architects, academics, institutions, and foreign participants' in order to achieve my goals.

The collective experiment I have tried to undertake is rooted in a post-structural conception of the built environment and
the world. I have used assemblage thinking ${ }^{28}$ to grasp the interconnectedness of ing changing nature This theory bas helped 
me understand seven long-term refugee camps in East Africa as proto-urban settlements and learning assemblages continuous evolution. It has allowed detail and contextualisation, opening the door to create situated bits of knowledge to contend narratives of camps as solely humanitarian spaces, as spaces of exception, limbo and non-places.

Architecture as a way of seeing and learning $-\mathrm{My}$ experience is that architecture can be - and should more often - used as an exploratory and analytic . lo sude the reader about this book.
spatial experimentations that I describe

In the first chapter, 'The urban turn: nformality, co-modification and assemblage, I explain how the long-term camp prevalence triggered an urban turn in refugee camp studies at the end of the twe tieth century. The urban turn comprises a body of works that use post-structu list urban theory to explore the camps power dynamics. I outline the possibilities this movement provides for the study of the phenomenon in East Africa. I make a case for studying the long-term camps a typology in its own right as proto-urban draw from works that analyse the embodiment of Lefebvre's 'right to the city' in urban settings in former colonies - particularly in Sub-Saharan Africa - through local perspectives. I reference Asef Bayat's concept of the 'quiet encroachment of the ordinary' 29 James Scott's notions of 'everyday life' and 'survival practices', ${ }^{\prime 0}$ Teres
Caldeira's 'peripheral urbanisation ${ }^{31}$ and dgar Pieterse's 'radical incrementalism'. In the following two chapters, I try convey to the reader the considerable challenges that children face living in the long-term refugee camps that I describe and how they extract both positive and negative learning from their surroundings. I lead the reader through a multi-scalar spatial mapping and analysis of Nakivale Kyangwali, Kyaka II, Kakuma, Kiziba Kigeme and Mugombwa refugee camps. These and Mugombwa refugee camps. the principal conflict areas in three of (the Horn of Africa, the Great Lakes and South ${ }^{2}{ }^{23}$ enco states, 12 refugee origins, six decades of stes, 12 refugee origins, six decades of physical characteristics. These long-term phyicalcharacteristics. These longterm refugee campsinclude various ages, sizes, population densities, regional climates, geographies and host country refuge policies. Moreover, these camps host large proportions of young children.

Particularly, in the chapter 'Everevolving assemblages: the built environmen of seven East African long-term camps, map, dissect and finally reassemble the seven camps spatial characteristics on regional, country and landscape scales. It becomes apparent how their evolution influences, and is influenced by, a complex array of factors, including the education of young children living in these camps and the refugees' agency. I present to the reader six spatial characteristics of the camps as relevant to their evolution: growing heterogeneity and complexity, growing heterogeneity and complexity, becoming porosity, land scarciy an

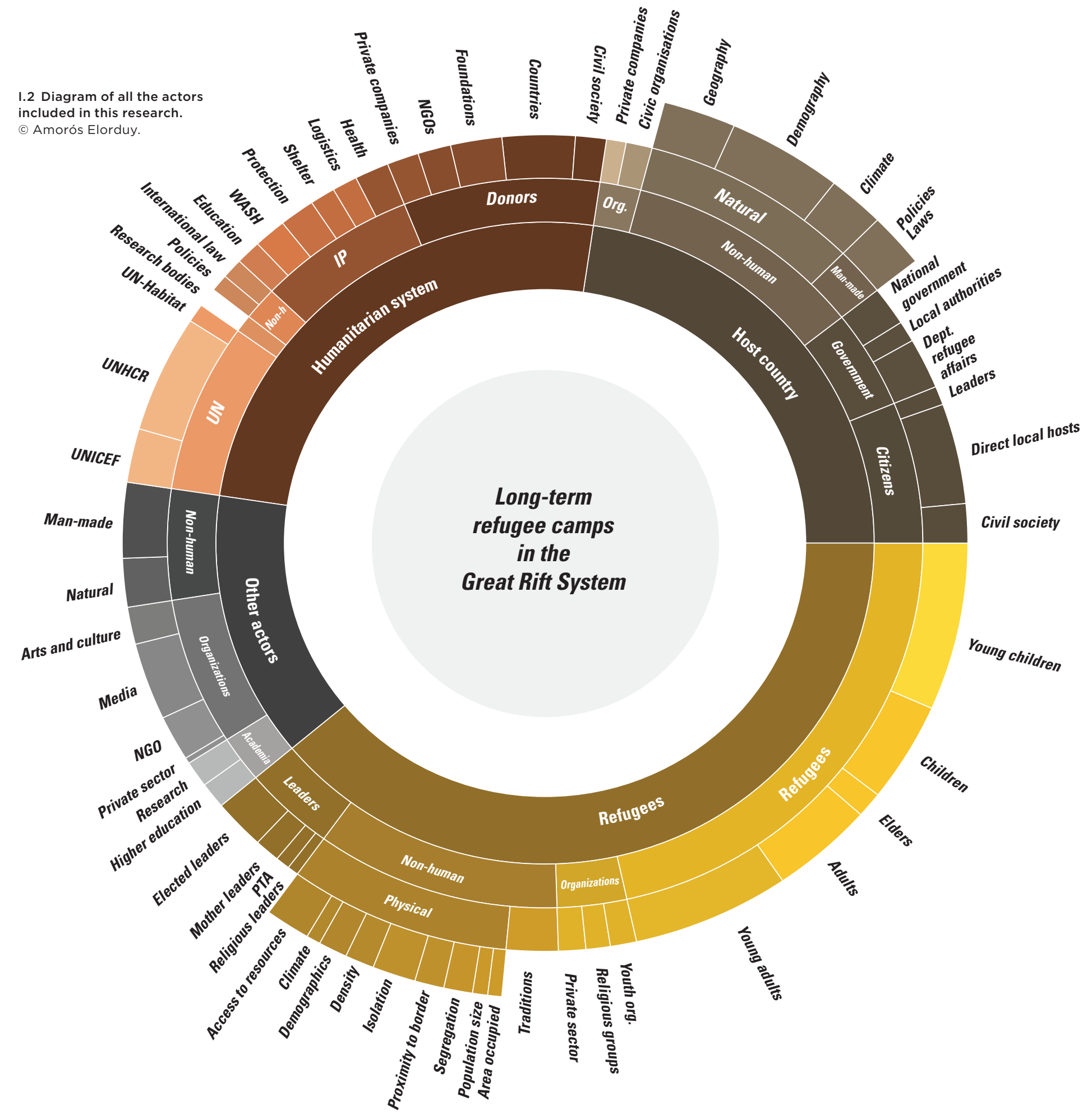


soils, and isolation and proximity to the incrementalism' in order to begin the transborder. These characteristics contribute to formation of the camps into stimulating make the long-term camps ever-changing, learning environments. ${ }^{37}$

proto-urban and learning assemblages for young children.

The collective experiment I recount in

Exploring an architecture of opportu- this book complies specifically with refugee nity, in the third chapter, 'Refugee-led spatial Bond emphasised the need to research the interventions: observed, imagined and humanitarian system's anti-participatory speculated', I bring to light the prominent ideologies and practices, ${ }^{38}$ which still position of refugees in the spatial reproduc- persist. David Turton took this idea further tion of long-term camps and their effects on with his assertion that research on the young children's learning. For example, I subject of refugees and migrant popula show how the camp administrations disre- tions should, in addition to causing popula-

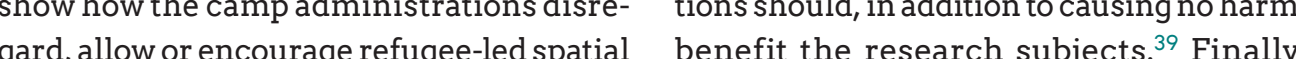
grd, al pinally, approprian quesled spatialing that analysing the current quiet encroachment research on this topic should be rigorous and everyday spatial transformations that and benefitacademia, policy developmen

action research (PAR) methods using

architectural tools allowed refugees to get Long-term refugee camps are protoinvolved in, and become informed about, urban learning environments-I believ decision-making processes regarding their that by the end of the book, the reader will built environments and young children's agree with me that its topic and approach learning. When pedagogist Paulo Freire are both timely and vital. It is of the utmos first introduced PAR, he also introduced the importance to explore the proto-urbanity theory of 'conscientisation' - a process by of long-term camps and their effect on which participants learn to perceive the lifelong learning as new 'alternatives to social, political and economic forces that camps ${ }^{\prime 41}$ are created. It is also necessary influence them and learn to take action that humanitarian strategies recognise the against the oppressive components of such centrality of refugees and direct local hosts forces. ${ }^{35}$ Through Lefebvre's 'transduction' on young children's learning and in the methodology, '[to] introduce "rigour in production and maintenance of refugee invention and knowledge in utopia" as assistance strategies. We are in dire need for a way of avoiding "irresponsible ideal- case-specific theories, policies and interism" ${ }^{\prime \prime \prime}, 36$ I tested the speculative potential ventions based on research grounded on of architecture to create new knowledge iterative, multi-stakeholder, participar on how campscould become better learning knowledge creation processes. Moreover, environments I us ar hitecture to inng tivise what Edgar Pieterse terms 'radical ECD, will benefit from considering the whole built environment as one of its various relevant tools, and from includin local creative minds, arts and crafts, both as a universal language and as tools to involve more actors and create positive change. $\mathrm{My}_{\mathrm{Y}}$ work might be of use to policy and practice on several fronts, including new refugee assistance strategies, refugee ECD, longterm camp maintenance in East Africa an research by architectural design.

I expect to persuade the reader that more contextualised, inclusive and participatory approach towards creating and coordinating spatial strategies of ring and assistance is attainable. An architecture assistance is attainable. An archlecture of oppor unity could inprove the lives of those inhabiting the long-term refuge camps and the newly created alternatives to camps. camps in East Africa into vibrant schools without walls.

Notes

By 'long-term refugee camps', I mean those that have lasted more than three years and
host more than 5,000 refugees from the so called protracted refugee situations. These called in Uganda). I encompass refugee settlements and camps because of their primary role in physically containing refugees, even they distinguish between the two terms stating that settlements leave more freedom to refugees.
Macgregor, 'History of the development of the East African Rift System' 2015 UNHCR, 'Population statistics', 2020, population figures updated for the end of 2018 . Herz, From Camp to City; Herz, 'Refugee camp in Chad.

Hilhorst and Jansen, 'Humanitarian space as

7. arena', $2010 .^{2}$.

Siddiqi, 'L'historire
toire non identifie'
Fresia and Von Kanel, Beyond space of exception?', 2015

e becomes a medium for politics. Refugee camps are probably the most direct translation
of politics into space. Any political strategy or decision has immediate consequence on a
spatial dimension in the camp And any spatian spatial dimension in the camp. And any spatial
modification, on whatever scale, immediately resonates on a political and demographic level. The camp is politics having become space'.
Herz, 'Refugee camps or ideal-cities in dust dirt',2005, 318 .

. Jansen, 'The protracted refugee camp', 2015; Minca, 2015; Herz, 'Refugee camps or ideal refuge', 2014; Grbac, 'Civitas, polis, and urbs'. Ramadan, 'Spatialising the refugee camp', 2013, Agier, 'Aterword
tell us', 2016.

1. Jansen, 'The protracted refugee camp', 2015,1 aid have different approacheses and goals. While former tends to rely on quick fixes for emerthe latter focuses on sustainable approaches for long-term solutions and works in more stable ing their positions, affording the recognition of education as a necessary tool in humanitarian

relief.
3. On the one hand, humanitarian publications lead the "humanitarian space and space of protection
reading. These works apply a structuralist and technocratic approach to the creation, maintenance and representation of refugee camps and
frame the camps' physical spaces as of almost purely apolitical protection. On the other hand European political scientists, anthropologists and sociologists initiated the 'space of exception
and non-place' reading during the 1990s. Many
Euro-American academics and mainstream media publications still use it.

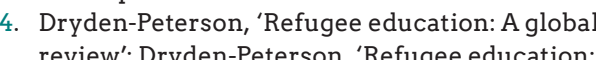
The crossroads of globalization' education UNICEF, 'Building better brains' Montessori, The Absorbent Mind; Dewey, Dewey; Coombs, World Educational Crisis. Ward and Fyson, Streetwork: The Exploding Bronfenbrenner, The Ecology of Human
Development. 
20. Ward, 'The child in the city', 1978; David and
Weinstein 'The built environment and chil Weinstein, "The buil
dren's development.

dren's development?
Bush and Saltarelli, The Two Faces of Education in Ethnic Conflict; UNESCO, 'The hidden crisis', Paulson, Easfation, Conflict and Development youths?' 2005.

23. I first visited Nyabiheke, Kiziba and Gihembe efugee camps in August 2011 for a project to mprove primary education facilities in the
camps with UNICEF and UNHCR Rwanda.

24. With $\mathrm{my}$ research team, we asked responden about their opinions to improve young chilwhole settlement - the streets, common spaces whd WASH facilities ( (2) the homess and (3) the
educational facilities - ECD, pre-primary and eductional
maternelle.

maternelle.
25. Smith, Decolo

Smith, Decolonizing Methodologies

of research?', 1998

Mille Plateaux: Capitalisme et Schizophrén Assemblage theory presumes that a fixed, social world does not exist. It rejecects the interpretation of the social and natural worlds as made up of finite and definable organisms and generalisation and a synthesis to facilitate analysis. Assemblage theory proposes instead that natural and social formations are assemblages composed of other complex configurations, an that in turn create more extended configuratio

29. Bayat, "From "dangerous classes" to "quiet
rebels"', 2000; Bayat 'The auiet encroach of the ordinary' 2007
0. Scott, Preface'.

Pieterse, City Futures includes Rwanda, Burundi, Eastern Democratic Republic of Congo (DRC) and Uganda, particuBurundi's internal wars (1950s-ongoing), Eastern DRC's decades-long internal and external conflicts (1960s-ongoing) and Uganda's Sudan conflicts include South Sudan, Suda and Uganda, specifically: Uganda-Sudan (1960s-1980s), the South of Sudan conflict The Horn of Africa conflict includes mainly Somalia, Ethiopia and Eritrea and Djibouti: conflicts (1990s-ongoing), Eritea- internal (1990s-ongoing) and Eritrea's and Ethiopia's authoritarian regimes (1990s-ongoing). Nakivale (est. 1958). Kyangwali (est 1904) and Kyaka II (est. 1983) in Southwest Uganda; Kakuma (est. 1992) in Northwest Kenya; and Mugombwa (est. 2013) in

36. Lefebvre in Petcou and Petrescu, 'R-URBAN or how to co-produce a resil

Harrell-Bond, Imposing Aid,

Turton, 'Refugees, forced resettlers and othe forced migrants'

, The dual imperative in

UNHCR, 'Policy on alte

protection and solutions 'UNCR policy on refuge
The urban turn | informality, co-modification and assemblage

The study of refugee camps started Amongst existing works, there are mainly in earnest in the 1980s and currently three conceptualisations of the physical holds a sizeable and varied body of space of refugee camps: as a humanitarian works. However, not all the contexts, space and a space of protection, as a space camps and topics receive the same of ention and non-place and a relatively attention. The built environment is still new conceptualisation as a proto-urban a surprisingly elusive topic, and most space On the one hand, humanitarian pub-

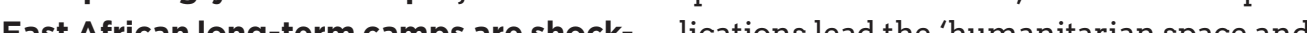
ingly understudied in a field packed with space of protection' reading The and ingly unders lo European philosophers, social scientists apply a structuralist and technocratic and

the built environmen has not gained traction in the field until recently and why its professionals seem to have failed to collaborate in its study. Some causes might stem from the compartmentalisation of both academic studies and humanitarian practice. For example, architecture and urban planning studies are usually historical, theoretical and archival investigations, with architectural design research incorporated only recently. Moreover, humanitarian practice and refugee camp studies tend to think of the built environment and its professionals as just technical support to other programm rather than relevant in their own right.

Despite a lack of focus on the built environment, it is inevitable for most refugee camp studies to touch upon it in one way or another, as encampment is a spatial answer to humanitarian assistance. proaintaining and representing refugee camps. They frame the camps spaces as almost purely apolitical pritical scientis, anthropologisand logistsinitated the 'space of exception and ench mon

Both conceptualisations are partial fepresentans and are insufficient to characterise, study and manage long-term refugee camps nowadays. These ncomplete views simplify the spatial complexity and variability of refugee camps to depict an abstract and universalised 'camp' whose analysis can produce broadly transferable knowledge and generate global policy recommendations. These structuralist conceptualisations are useful to a degree in international refugee assistance and advocacy strategies. Yet, they tend to miss 


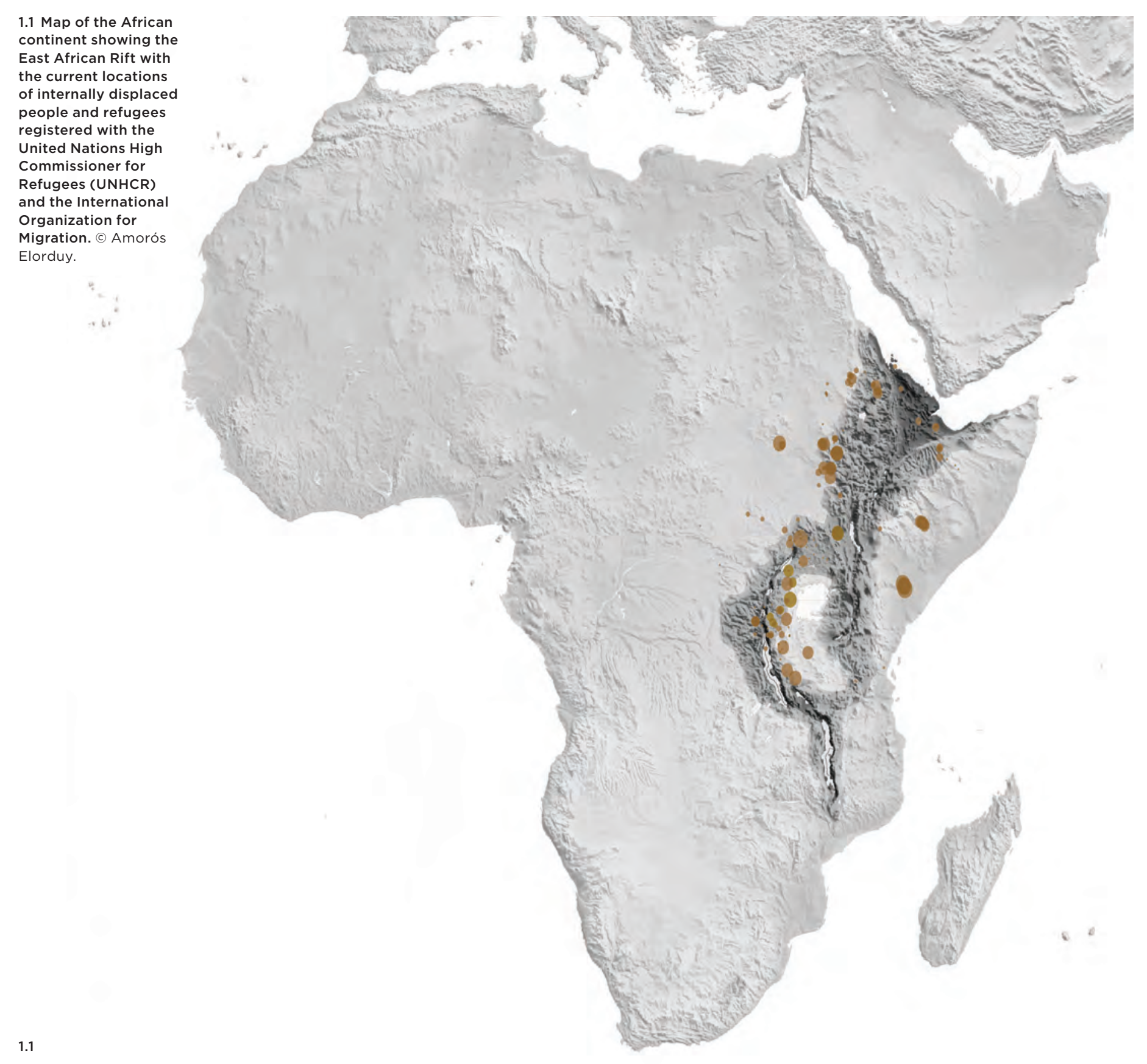

out on the diversity of actors that create, maintain and reproduce the long-term cam spaces and overlook their influence o inhabitants and direct local hosts, especially the effects on young children's learning. Since the early 2000s, an 'urban turn' in the literature has presented camps as what 1 call 'proto-urban spaces'. Post-structuralist authors from varied disciplines lead this branch of works, which include -in addition to humanities and social sciences academics - geographers, architects and urban planners, with a relevant representation authors that aim at decolonising the field Urban turn works are especially prevalent in highly virit. campsin Leanon, and bing to campsin Lebanon, and ing to the for the complexify viablity andoverlapping The urban turn approach renders visible The urban turn approach renders visible hereft of agency and overlooked under discourses of humanitarian spaces and spaces courses of hum

In the following pages, I lead the reader through the evolution of the camp space conceptions in academic discourse and in humanitarian practice, which derived in the current urban turn. I highlight thre cross-cutting themes on spatial modifcations and place-making in vulnerable urban settlements, which also apply to the refugee camp: informality, co-modification and assemblage thinking. To conclude, discuss how an urban turn could benefit East African refugee camps, specifically its long-term ones.

The long-term camp and the nascence of the urban turn-Refugee camps have for decades been studied from either a structuralist or a humanitarian standpoint. Both narratives have generalised and simplified the 'camp, the 'refugee' and 'education' nto easily managed concepts. These works explain camp life as a relationship between two main actors: the poor and powerless refugees and the either harsh or saviour camp management. The limits of these frameworks for the analysis of refugee camps surfaced in the late 1990 s as long-term camps became prevalent and development and umanitarian efforts started to intermingle.4 The 66 existing Est Africon refugee camp model failing math a tran refor rasing caces of control and confinem. Long archical and totalising definitions.

The vast majority of camps become long term due to geopolitics, long-lasting conflicts and a lack of plausible durable solutions for refugees. ${ }^{5}$ As camps prolong in time, they pose threats to refugees and their surrounding communities. Despite this, the humanitarian system/host government assemblage continues to replicate this model, partly due to global politics and socio-economic factors, and partly due to assumptions rooted in incomplete and biased information.

The long-term camps pose a paradox that ripples through socio-political, spatial and educational fields. These camps are sites of humanitarian assistance, conflict, political action and everyday life. These camps are a transitional solution turned camps 


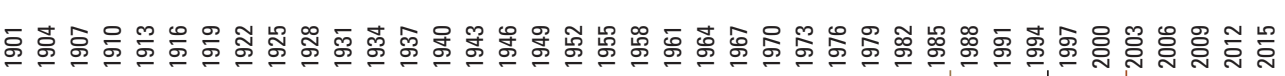
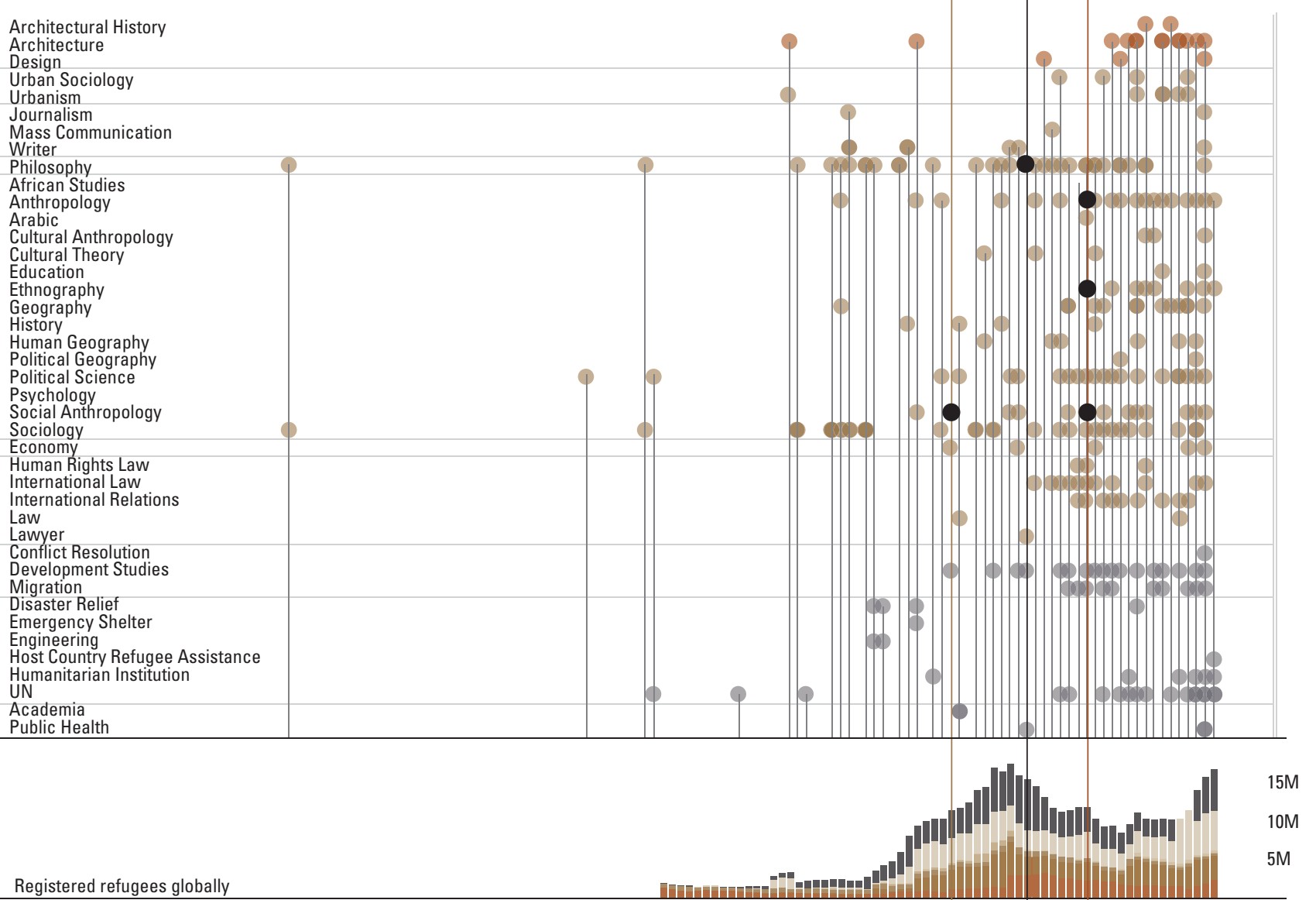

Registered refugees globally

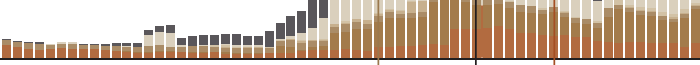

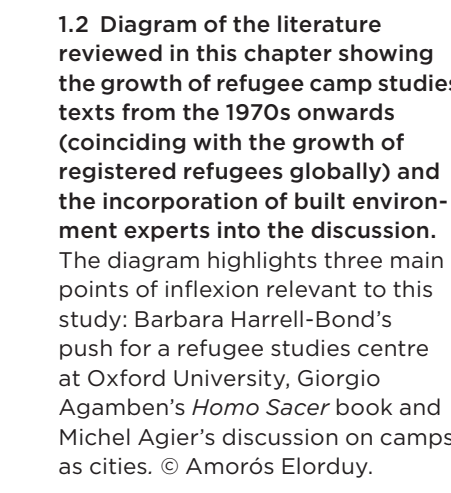
crippled, as camps prevent refugees from
furthering that education or its use for not-some have never been problem. They result from a continuous environments. ${ }^{6}$ They cultivate socioco-modification camp-inhabitant-neigh- political and economic interactions, and bour, not just the outcome of humanitarian within them, refugees and their direct local planners and host government policies. In hosts consistently exercise their Lefebvrian this book, East African long-term camps 'right to the city'.7 They are also learning are cosmopolitan; they are proto-urban environments. Yet, the learning that young children gain from them is rather negative, and the formal education provided is the gainful work. ${ }^{2}$ The long-term camps are

Why call them proto-urban rather than thoroughly urban? Despite the move by some academics and humanitarians to recognise these as not just 'humanitarian' spaces or 'limbo', many researchers and practitioners, including most host governments, are reluctant to admit them asurba ognition could legitimise these spaces as ogniman peritizens Thecurrent and heringsto ascize in ${ }^{\prime}$ ' politicl states that host them and the accountability of the humanitarian organisations that de facto govern them. Besides, my experience, the information I have collected on them the information I have collected on them and the literature on the topic demonstrate that these settings political community is not fully formed. There is no real refugee representation in the camps management. These camps are not a polis, not yet.

These camps suffer from limited biased - both geographically and disciplinary - and inconsistent information insufficient to build sturdy and contextualised frameworks to develop appropriate policies. Being understudied affects the lesser-known camps, such as those in

the Middle East and a scarcity of resources cause this weak pool of knowledge..$^{10}$ Besides, the current explosion of big data and remote sensing technologies ${ }^{11}$ facilitate the generation of information on understudied camps. Yet, they promote an outsider standpoint. The lack of situated knowledges, the topdown perspective of the Euro-American lenses and the heightened visibility of the Middle East cases tend to guide mainstream thought, inform humanitarian practise and policy, and influence further studies globally. The humanitarian system's lack of ros. The humanitarian sys-

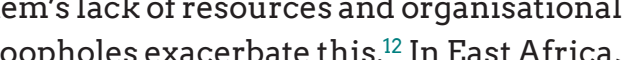
int fer that ferlex views f humanitaian institutional memory In respons to In response to the long-term camp raphers, anthropologists, geographers, architects and urbanists began a body of 'multidisciplinary, multi-scalar, multisited ${ }^{14}$ studies. These works promoted an increasingly post-structuralist understanding of the long-term camps, associating their particular socio-spatial organisation with different urban life forms. This move afforded the consideration of these settlements as complex proto-urban assemblages where all components are agents of change. ${ }^{15}$ Paraphrasing cultural anthropologist Bram Jansen, these works created an Southwest Uganda and Rwanda particularly. A lack of interest and political motivation accessibility hurdles, limited pre-existin information, a dominance of European-

[This shift not] only highlight[ed] the mergence of vibrant and diverse markets, cosmo of vibrant and diverse markets, 
in places deemed bleak and dependent. It social life and system of power that exis d how the academic gaze has nowhere else. These are paradoxical devices, moved beyond emergency epistemes and hybrids that, for lack of an appropriate term humanitarian and normative discourses, to I shall call city-camps (camps-villes).... It recognise "normalisation of the geography constitutes a "relatively large, dense, and of the camp", in which people settle down, permanent settlement of socially heteroengage in economic lives and re-form a geneous individuals", creates opportunities political body ${ }^{\prime 16}$

By the mid-2000s, refugee camp studies scholars started to explore the built environment as a transformative force. Increasing since the early 2010s, this line of enquiry enabled the inclusion of the concent'urbar higlighting the agency of both the refugee highlighting the agency of both the refuge camps' bulltenvironments and their inhabtiants. These works dwell in the camp complexity, bringing out the insufficiency coursesto definand courses to define and study them. Moreove these studies denounce the humanitaria/ most government assemblage's inertia to maintain power relationships and assumptions. This awareness is a necessary step towards analysing

As sociologists Giovanni Picker and
the powerful. Silvia Pasquetti point out, ${ }^{17}$ Michel Agier's work Between War and City: Towards a Urban Anthropology of Refugee Camps kick-started the discussion about the analytical benefits of drawing from comparative literature on cities to study the camps. Agier states that the long-term camps become functional cities due to the complexity and length of the economic and social agreements they trigger:

... the camps gradually become the sites of an enduring organisation of space for encounters, exchanges and reworkings of identity among all who live there. In camps produces cities, "de la ville", if on considers the city from the point of view of camp become a city in the sense of a space camp become a city in the sense of a space thron sociability, an urbs, and indeed in

The hypothesis of a camp as a city allowed researchers to study long-term refugee camps as 'city-like, with complex social arrangements and economic activities. Philosopher Zygmunt Bauman returns to the refugees their human subjectivity, of which they have been expropriate by the dominant discourses'.21

Most scholars agree on some generic city traits that relate to the long-term refugee camps' urbanity such as size, density, heterogeneity and social hierarchies. However, the contested definition of 'city' complicates its use as an analytic tool. ${ }^{22}$ Particularly, in regions of the third growing numbers of urban scholars challenge the use of the terms'city', 'metropolis' and 'megacities' as Euro-American constructs. ${ }^{23}$ Amongst refugee studies schon structs. ${ }^{2} \mathrm{Amongst}$ refugee studies scholars, 'city' to analyse camps and instead explores this sense, the humanitarian device of the its essential complexity.... Can the refuge suggests that with this consideration, 'Agie urban wave, as is the African continent the idea of camps as urban-like, political to new spatial forms of assistance. ${ }^{36}$ In 2016 , and identity-creating places..$^{24} \mathrm{I}$ align with the international community recognised Manuel Herz and call them proto-urban..$^{25}$ the complexity, length of existence and Once the 'city' dispute was acknowl- variability of conditions amongst refugees edged and urban turn works focused on and refugee camps with the signing of the urban traits, they allowed a growing body New York Declaration for Refugees and of authors such as Claudio Minca, ${ }^{26}$ Iris Migrants which included the proposal of a $\mathrm{Katz}_{,}{ }^{27}$ Romola Sanyal, ${ }^{28}$ Peter Grbac ${ }^{29}$ and Global Compact on Refugees and facilitated many other ${ }^{30}$ to bridge the gap between the development of the Comprehensive humanitarian spaces and urban environ- Refugee Response Framework (CRRF) ${ }^{37}$ The ments. These texts borrow from urban CRRFaims to welcome refugees in national

theory, urban planning and architecture. policies, providing a more contextualised These increasingly post-structural studies unveil the myriad pofuman and non human actors that participate in camps' evolution. They create space for discussions about camp inhabitants' agency and their role in the camps' spatial re-production. For example, in his work Civitas, Polis, and Urbs, Grbac defends that conceiving refugee camps as urban spaces can allow the inhabitants agency to be fully acknowledged. ${ }^{31}$ The geographer Sanyal elaborates on that by suggesting that refugees' actions 'transgress the boundaries of
place and non-place'.32 Both authors focus place and non-place' ${ }^{32}$ Both authors focus
on Palestinian refugee camps and try to on Palestinian refugee camps and try to
respond to the camps' preconceptions as anomalies, violations, non-places and ghe toes expressed by structuralist studies.

This urban turn in academia began to influence humanitarian refugee assistance practice from the $2010 \mathrm{~s}^{33}$ when the international community started to acknowledge the relevance of the physical space on refugee assistance and the protracted nature of refugee camps. ${ }^{34}$ In 2014 the humanitarian accepted an Alternative to Camps prafted and seeking new'durable solutions' connected .

Looking at the refugee camps through the lenses of post-structural urban theory affords an onderstanding of the camss built olitical, social, conomic and educationations within the camps and their broader networks werks issurs informali, co-m lage then, $c 0$-modification and assemas a fluid, elastic and adapt informality as a fluid, elastic and adaptative means of creating, not as opposed to formality in the urban. I assume co-modification as natural in the urban realm, particularly as the multiple human and non-human actors are agents of change and influence each other. Finally, I conceive ssemblage thinking as a post-structural framework for analysing social complexty, emphasising non-linear approaches exchangeability and interconnectedness ${ }^{39}$

Informality-Geographer Romola Sanyal has been instrumental in the inclusion of informality as a line of enquiry in the to social systems based on mutability, 
study of refugee camps and refugee setand mention informal processes of contlements in urban areas 40 Borrowing from struction while not dwelling on them.
urban planners and theorists such as Nazer Alsayyad ${ }^{41}$ and AbdouMaliq Simone, Sanyal applies notions of urban informality and decolonisation to describe and study the socio-political, economic and physical connotations of long-term spaces of refuge. She outlines parallels between settlements, sustaining that the boundaries between the global and the urban marginal are blurring. Her work aims to demystify the universal and enericideas that prift the univingat thesent refugee spaces solely as Agambean bare Another geographer, Diana Martin compares urban informality and long-term ncampment spaces following anthropologist Arjun Appadurai's steps. Martin uses the suffix '-scape' to coin the term 'camp-
scapes', , $^{4}$ which 'gives the idea of fluidity, scapes', ${ }^{\prime 4}$ which 'gives the idea of fluidity,
of something elastic. It indicates dispersal of something elastic. It indicates dispersal and non-static boundaries. The notion of
"campscape" seems to better render the "campscape" seems to better render the in its relation with its surroundings as the exception has transcended the camp's shape'.45 In addition, anthropologist Ilana Feldman, while not mentioning informality per se, describes the informal development processes of long-term refugee camps in the Middle East. ${ }^{46}$

In the East African context, economic studies are the only ones looking at informality, and they have little regard Anooradha Iyer Siddiqi's works $s^{49}$ about the Kenyan camps-the most visible of the Eas African camps-look at their developmen
Co-modification-The inclusion of poststructuralist logics in refugee camp studies has allowed diverse types of power and variety of actors into the discussion. It has afforded refugees, direct local hosts and the built environment to show their agency as they exercise what philosopher and sociologist Henri Lefebvre called the 'right to the city'. This notion discussed how city space and inhabitants are co-constitutiv and use their agency to modify each ${ }^{2}$ In tuse heir agency to modify each other. physica alter the identity of refugees, surrounding commines, host governments and the pereption others have of them. Urban turn literature presentsco-modification in three discrete fields: political, economic an ciocultura.

In the political arena, the discussion in African soil explores the contested role of space as an actor that enhances or tame refugees' political aspirations and negotiations. One example of this is Elisabeth Holzer's work. She explains how Liberian refugees - particularly women - appropriated Buduburam refugee camp's open spaces ${ }^{51}$ to demonstrate against its administrators. ${ }^{52}$ As a consequence of this occupation, the humanitarian institutions' perception of these refugees changed from victims to political dissidents with implications for their asylum status. Another example is Manuel Herz's work about Western Sahara's camps in Tindouf Tindouf. He sustains how these camps' pher the
United Nations High Commissioner for Refugees - allowed Saharawi refugees to 'build' a Saharawi state with ministrie These health and education services would have been unthinkable before the exile. ${ }^{53}$ In Tanzania, both Liisa Malkki's ${ }^{54}$ and Simon Turner's works ${ }^{55}$ focus on the misconceptions held by the humanitarian system, host governments and the media about refugees. Particularly, Malkki reflects on the refugees' heterogeneity and how the physical setting influenced their cultural and political identity In her case study in northern Tanzania, developed a more robust conception of deir Burundian identity than their un their Burund an identiy than their urba

In the economic arena, Peter Mwang Kagwanja and Marc-Antolne Perouse de Montclos study the socio-economic opportunities that Dadaab's built environments, their geographic location and their media visibility afforded..$^{56}$ Rahul Oka presents these same camps' informal economy as a result and necessity of the humanitarian aid operation and the physical spaces it created in Kenya. ${ }^{57}$ Alexander Betts and his team developed a similar work for the camps in Southwest Uganda in 2015.

In the sociocultural arena, a remarkable topic is the interaction between refugee camps and neighbouring communities. For example, Holzer points out how in Buduburam, 'the influx of people and resources transformed the camp environ and surrounding villages into an urban space. In the ensuing years, Buduburam became host to a diverse array of nationalities 59

In the Rwandan, Southwest Ugandan and Northwest Kenyan camps that I describe here, there is a continuous co-modification between studies, policies, physical spaces, laws, media, aid, refugees, camps, authorities, regulations, culture, geography, traditions and education. I focus primarily on how the co-modifications between camp inhabitant, direct local hosts, built environment and natural environment affect young children's learning. In these camps, learning environments come to the fore as main characters in young children's learning especially their learning by experience. Precisely the informal learning environments - homes, streets and common areas - gain responsibility in the of children born and raised in these long term camps.

Assemblage thinking-It is unsurprising that the notion of 'assemblage', put forward by Deleuze and Guattari in the late 1980 s, ${ }^{60}$ emerged strongly amongst urban turn studies. The first works that applied assemblage thinking to refugee camps focused on the Palestinian camps in Lebanon and began in the mid-2000s. ${ }^{61}$ For example, Adam Ramadan described the Palestinian refugee camps as assemblages of human and non-human actors, analysing time-space particularities with a critical take on Agamben's 'space of exception'.62 Also, political scientist Nasser Abourahme developed a reading of the camp as a material assemblage that brings subjects and objects, people and things into mutually . blage. For example, siddiqi and Ansem- 
Pieris use it to analyse long-term refugee out: refugee leadership, gangs, religious camps in Kenya and Sri Lanka, respec- leaders and commercial lobbies. Particularly ively. ${ }^{64}$ Anthropologist Julie Marie Peteet in the education field, assemblage thinkin highlights the interconnectedness and unveils the hegemony of non-formal and assemblic nature of camps, which draws informal educational systems and facilitie from culture and traditions in countries of that operate in addition to, or instead of, the origin and the routes refugees have taken humanitarian system's formal ones. and merges that with the camps' contextual situations. She describes the Palestinian refugee camps in Lebanon as 'profoundly shaped by and referenced to places of origin and residence, multiple boundaries, and routes of travel between them'.65

Critics of assemblage thinking state

that it can easily fall in relativism and fail to acknowledge enough power differences. However, Ramadan, Peteet and Abourahme show that the theory enables them to and between assemblages. As Ramadan puts it, 'in absence of a single sovereign, puts it, 'in absence of a single sovereign,
different actors and organisations in the different actors and organisations in the compete for power and influence camps compete for power and influence among the population through force of arms, provision of services and resources retical approach brings to the fore differe types of power and agency hidden under humanitarian and structural accounts. Assemblage thinking affords authors to move away from binomial conventions such as powerful-vulnerable, state-individual and humanitarian system-refugee victim.

By questioning the conventionally powerful - the humanitarian system and the host country - and using situated bits of knowledge, studies can help unveil hidden power dynamics. For example, in the seven camps I describe in depth in the next two chapters, different power struggles stan
East African urban turn - a way
forward?-Since the urban turn appeared there is a growing interest in the human and social dimensions of refugee camps built environments. Studies worldwide are starting to draw from compordwide are ture on ture on urban theory, urban planning an architecture. However, works on hyper-vis On the urban turn into practice. One of the issues with the urban turn in refugee studies is the evasive definition the question of uhether defining capser camps as urban might ease their study an benefit refugees and the assistance given to them. Besides, there is resistance - mainly by the humanitarian system/host government assemblage - to accept these space as urban, since the term 'urban' conveys normalcy and permanence. ${ }^{67}$

Most long-term camps in Eastern Africa were established before the humanitarian camp planning guidelines were in place. Their material evolution assimilates in many ways that of informal settlements in the region. Therefore, it is fitting to study them through an urban lens. They have responding to material ment patterns, responding to material means, geograis cow to prinarian aid is slow to incort developed organic settlem. They have length of exile, humanitarian system's resources and refugees' daily activities that have modified and continue to change these spaces. In the particular examples portrayed in this book, ${ }^{69}$ Uganda follows a settlement rather than a camp model, ${ }^{70}$ and humanitarian planning was not introduced in the camps in Rwanda and Kenya until 2005 with the establishment of Kigeme and Kakuma phase III

This particular urban turn study incorporates human and non-human actors previously bereft of voice into the conversation. It might help understand biases and assumptions, power imbases and assum refuge assistonce policies - policies tha refugee assistance policies-policies that use spatial strategies as their go to tool to Giving centraliy to the urbay Giving centrality to the urban may allow a better understanding of the built environment as a powerful and socially charged tool and its use to tackle oppression and improve assistance, young children's learning and refugee livelihoods. The three cross-cutting issues extracted from post-structural urban theory -informality, co-modification and assemblage thinking - highlight the built environment as a critical factor influencing life in the camps. These post-structural lenses underline the relevance of the camps' built environments as added educators, bringing to the fore refugees' actions on youn children's learning.

The ensemble of urban turn works and the current humanitarian system's discussions about diversifying spatial strategies f assistance ${ }^{71}$ are opening up to nuege and various voices, providing an path to take, which is more empathic and contextualised.

Notes Diven and Latstsen, The Culture of Exception ties', 2004

(a) Jansen, I call the 'urban turn' the epistemic and ontological shift that occurred in refugee
camp studies that associated long-term refugee camp studies that associated long-term refug
camps with urbanisation. The inclusion of geographers, architects, urban planners and urban theorists into the study of refugee camps 'The protracted refugee camp' 2015

Diken, 'From refugee camps to gated commu-
nities', 2004: Diken and Laustsen, 'The camp', ${ }_{2006}$ nities 2006 . The development-aid divide owed to the differ-
ent approaches and goals of the humanitarian and development modes of aid. While the former relies on quick fixes for emergenc
situations, usually in fragile contexts, the later focuses on sustainable approaches for long-term solutions and works in more stable countries. With the acknowledgement of the of the refugee crises and with the adoption of the sustainable development goals by the international community, these two modes the mid-2000s, the approximation of both aid approaches afforded the recognition of education as a necessary tool in humanitarian relief camps' camps.' peldman, 'What is a camp?', 2014; Jansen, 'The
protracted refugee camp', 2015; Napier-Moore, Iuse the term 'urbas'to

Iuse the term 'urban' to mean 'within or of
distinctly demarcated human settlements' specifically use the term 'proto-urban' borrow Ing from Manuel Herz who usesit to refer to
the long-term refugee camps in the Western Shara. Herz, 'Refugee camps of the Western
She Sahara', 2013, 383

Lefebvre, Le Droit à La Ville. Tho tend to prevent them fromp refugees work, and it was not until the late 2010 s when some camps started to provide some form of
secondary education and vocational training 
opportunities. Dryden-Peterson, 'Refugee edu-

Jansen, 'The accidental city' 2009: Agier and Lecadet, Un Monde de Camps; Feldman,
is a camp?', 2014; Jansen, 'The protracted

refugee camp', 2015.

the camps that receive a lot of media attentract more focus and funp ps in Kenya, often visible to the international community and enStreetMap, 'Hu

manitarian Openstreetmap 12. Loescher, 'The UNHCR at 50', 26-7.

Agler, Afterword: What contemporary camps
tell 2016,461 .

15. Grbac, 'Civitas, polis, and urbs'; Sanyal,

'Refugees and the city', 2012

. Tansen, 'The protracted refugee camp', 2015, 1 .
Picker and Pasquetti, 'Durable camps', 2015.

Agier, 'Between war and city', 2002.

Banyal, 'Refugees and the city', 2012, 634 . modernity', 2002, 34

23. Pincent-Gerse, 'Grasping et al., Translating the City.

Pieterse, 'Introduction: Rogue urbanisms', 20

Simone, 'Movement: The Zawiyyah as the city'

Malkki, Purity and Exle

the Western Sahara',

Minca, 'Geographies of the camp', 2015.

27. Katz, 'Between bare life and everyday life', 2017.

city'.

. Abourahme, 'Assembling and spilling-over',
2015; Abourahme and Hilal 'The production of space'; Peteet, Landscape of Hope and Despair Petti and Hilal, 'Architecture of exile'; Isin and

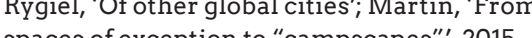

spaces of exception to "campscapes",
1. Grbac, 'Civitas, polis, and urbs', 4 .

32. Sanyal, 'Squatting in camps',2011, 880.

3. The United Nations High Commissioner for

to camps has prompted collaboration between
the UNHCR and UN-Habitat for the establish-

Kenya. UN-Habitat is applying practices it

implementation of Kalobeye.
UNHCR, 'Protracted refugee situations', The search for practical solutionst'; UNHCR,
Protracted refugee situations: Revisiting the

problem,
35. UNHCR, Policy on alternatives to camps. Rwanda, 'Mahama refugee camp, one year
on'; Ennead et al.,' Rethinking refugee on'; Ennead et al., 'Rethinking refugee

37. Communities'.

for Refugees and Migrants; UNHCR,

'Comprehensive refugee response framework'

8. Iveson and Fincher, "'Just diversity" in the city
of differencec', 408 ,

9. 'Both assemblage t

to say about the spatial dimensions of power an politics. That is because both approaches are ways, how they hold together, somewhat precariously, how they reach across or mold space and how they fall apart'. Müller, 'Assemblages Sanyal 'Urbanizing refuge',

Roy and AlSayyad, Urban Informality 2. Simone, 'Cities and change',
4. Sanval, 'Urbanizing refuge', 2014; Sanyal,
'Refugees and the city' 2012 . Appadurai, 'Grassroots globalization and research imagination', 2000.

4. Martin,' 'From spaces of exception to "camp

46. Feldman, 'What is a camp?', 2014.

7. Oka, 'Unlikely cities in the desert', 2011; Oka, Coping with the refugee wait', 2014; Betts an Jansen, 'The accidental city', 2009; Jansen, 'The protracted refugee camp', 2015 Siddiqi, 'L'historire architecturale d'un terriLefebvre, Le Droit à La Ville. 1. Buduburam is a long-term refugee camp estab-
lished in 1989 in hanana to host refugees fleeing
the Liberian civil war

Herz, From Camp to City.
Malkki, Purity and Exile.

Malkki, Purity and Exile.

Kagwanja and Pérouse de Montclos, 'Refugee
Karters of

camps or cities?', 2000.

51. Oka,'Unlikely cities in the desert', 2011

B. Hetts and Omata, Refugee Economies.

camp?', 2013, 852 .
0. Deleuze and Guattari, $A$ Thousand Plateaus. 1948-68' 2. Ramadan, 'Spatialising the refugee camp', 2013 .
3. Abourahme, 'Assembling and spilling-over',

$2015,200$.
Siddiqi, 'L'historire architecturale d'un territoire non identifie'; Pieris, 'Encamp ments' 2014 65. Peteet, Landscape of Hope and Despair, 25. 66. Ramadan, 'Spatialising the refugee camp', 2013,72 modernity', 2002; Jansen, 'The protr refugee camp', 2015; Grbac, 'Reimagining the refugee camp as the city',

$\mathrm{m}$, 'Aid and the perpetuation of refuge

presented in this book are and Kyaka a (1) (est), Kyangingwali (est. 1964) Kakuma (est. 1992) in Northwest Kenya and Mugombwa (est. 2013) in Rwanda.
0. The Ugandan government and UNHCR call country 'settlements' 'A "settlement" in the from a "camp" in that it is of a more permanen nature (characterised by infrastructure such as schools, hospitals, brick buildings, boreholes self-sufficient over time. "Camps" are often spontaneous and temporary creations (struc lmost exclusively depend on relief handout Bagenda, Naggaga and Smith, 'Land problems in Nakivale settlement', 5. However, even if more loosely contained than in other countr so-called settlements.

1. UNHCR, 'The implementation of UNHCR's policy on refugee protection and solutions in camps; United Nations, New York Declaration camps; United Nations, New York DCR,
for Refugees and Migrants; UNHCR, 


\section{Ever-evolving the built environment assemblages \\ of seven East African \\ long-term camps}

The beginning of refugee encampment policies in Eastern Africa-Simultaneously inhabited by different nomad and sedentary

cultures, Eastern Africa has experienced

regional and global migrations for millen-

nation states with permanent and impermeable political borders. Due to the 1951 refugee con

nia. ${ }^{1}$ Mobility patterns across the continen

Influenced by their European colonis-

ers, some of the soon-to-be-independent

the nation states began to house these refu-

colonial partition of Sub-Saharan Africa in gees in specially devised isolated rulal

the late nineteenhcentury. The liberion settements in the late 1950s. This move from European colonial rule created new supposed a change in former settlement

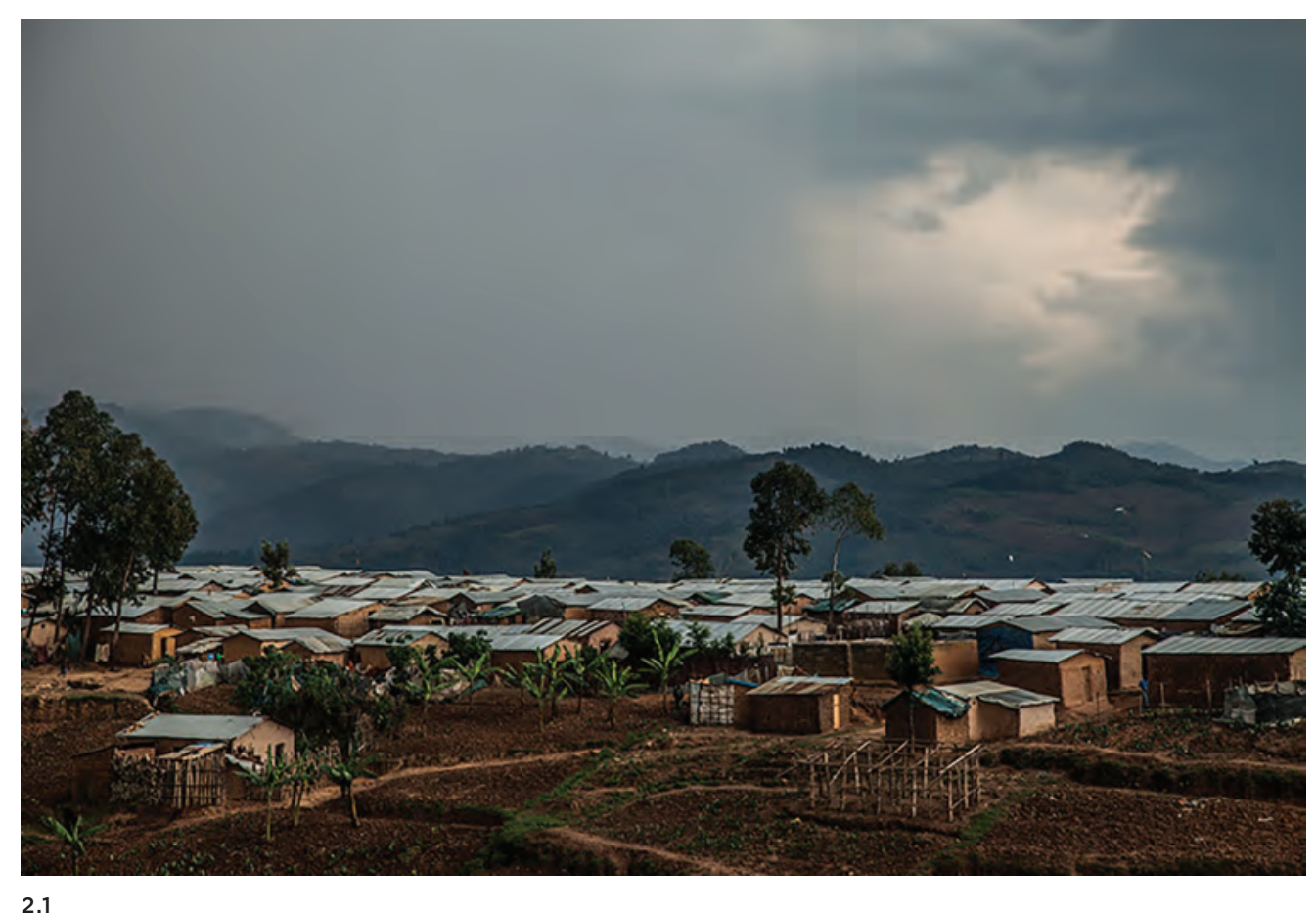


patterns that usually saw migrants settled creation, ${ }^{10}$ the UNHCR has presented the tiations and struggles. ${ }^{3}$ In the early 1960s, matic means to assist them. ${ }^{11}$ The UNHCR due mostly to new conflicts in the young has contributed to building hundreds countries, East African refugee numbers of camps over the decades. New camp grew exponentially, ${ }^{,}$and the United Nations continue to sprout up, despite renowned High Commissioner for Refugees (UNHCR) scholars and even the UNHCR ${ }^{12}$ its own became involved in the region's refugee Handbookfor Emergencies advises against assistance. ${ }^{5}$ The UNHCR consolidated and large, planned camps - expressing since standardised the refugee settlements the 1980s, in texts and policies, what established in some countries by colonis- was already evident on the ground. The

proReconstruction

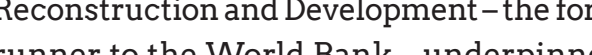
the UNHCR's ration behind encanping refuge popultions on the contineVillagisation implied that upooting and condensing populations in 'villages ${ }^{\prime 7}$ would ensure the agricultural and technological development desired by both the Bank and the new states' governments. ${ }^{8}$ As is evident the new states' governments. ${ }^{8}$ As is evident in numerous studies, these social engineering strategies and theories failed. Despite that, the UNHCR borrowed from these and other spatial forms of extortion happening at the time - concentration camps, prisoners of war camps and forced labour camps - to With these large isal refugee settlements. UNHCR aimed to instil a sense of belong ing to refugees and to ease their assistance, economic independence and control..$^{9}$ These agricultural camps evolved into the planned solated camps that we are used to seeing in the mainstream media.

majority of refuges choose to self-settle in urban centres, amps becom ellf-settle and appear to cause more problemsterm solutions for both ruges and direct local colut

The reasons why containment strategies prevail-albeit with small modifications over time - above other policies are the primary focus of numerous refugee camp studies. ${ }^{15}$ Some causes are the internationa community's geopolitical interests and $\mathrm{mis}$ trust in African governments - largely a post-colonial hangover, the large number of refugees, the overlapping long-term conflicts and the humanitarian system's biases triggered by lack of contextualised knowledge. Some of these biases include, for example, that displacement is temporary - contradicted by increasing refugee flows and long-lasting displacement ${ }^{16}$-and that refugees are a smooth fabric with no agency and not enough skill that needs to be contained and controlled to be assisted. Some scholars defend the idea that encampments are maintained because they justify the humanitarian aid system's work the the humanitarian system taks's work. The humanitarian system takes over hos The continuation of encampment and its states respo effects on young children-Ever since its releasing them from the so-called refugee

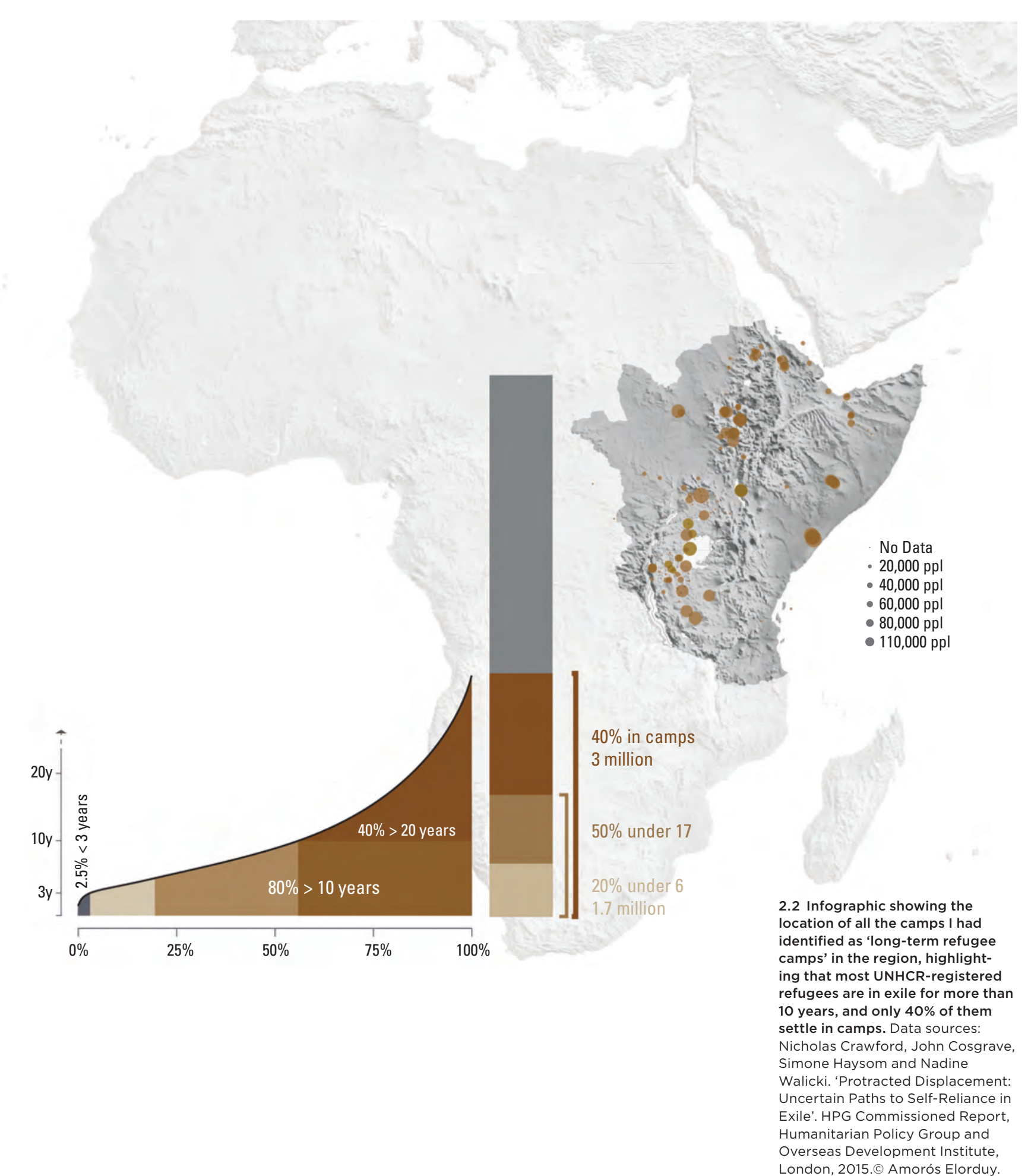


burden-a burden disproved by numerous between existing and incoming populations conomists and humanitarian researchers. ${ }^{17}$ and improved the country's infrastructur During the late 1980s and throughout where the refugees settled, which usually the 1990s, the UNHCR-led international wasclose to the borders where infrastructure community imposed refugee encamp- was weaker. Nevertheless, eventually, the ment as a condition for African countries to humanitarian system ended up imposing its receive humanitarian and development aid. encampment model of assistance. ${ }^{20}$ Despite the UNHCR's push for encampment, Guinea's and Malawi's situations are until the 1990s, many African host coun- amongst several, ${ }^{21}$ including Zambia ${ }^{22}$ tries promoted rather welcoming policies and Tanzania, ${ }^{23}$ which illustrate how to neighbouring refugees according to cus- transnational powers and internationa tomary practices and 'solidarity' between humanitarian aid transformed Africa's formerly colonised peoples..$^{18}$ However, pre-existing refugee assistance strateas host countries began to have political gies. In many cases, this evolution from as host countries began to have political gies. In many cases, this evolution from and economic problems and displacement government-managed policies that spanned years and decades, they became tended to encourage self-settlement to a system where transnational institution Some countries fought the establish- managed isolated planned camps caused ment of large, isolated, planned camps on power imbalances. Moreover, large and their soil. For example, Malawi maintained its isolated refugee camps had negative conpre-existent policies until 1987. It welcomed sequences for refugees and direct local hundreds of thousands of Mozambican hosts. ${ }^{24}$ The camps tended to reduce the refugees since the early 1980s, peaking at freedom, agency and self-determination 1.2 million in $1990 .{ }^{19}$ Initially, Mozambican of refugees and their direct local hosts, refugees were encouraged to settle spontane- which frequently caused power struggles ously, and refugee integration was evolving between those two groups and the regiona well, covered by the Malawian government. governments. ${ }^{25}$ If we look at education for However, due to intricate national and example, for decades, the large camps isointernational affairs, in 1986-7, the country lated the young refugees from national reluctantly acceded to foreign aid, which education programmes. Camps left children forced the creation of camps. at the hands of the resource-scarce UNHCR

Another example of this is Guinea education section with its standardised low(Conakry). Between 1989 and 1999, the West quality programmes and monitoring. ${ }^{26}$ African country welcomed half a million As the humanitarian-development Liberian and Sierra Leonean refugees with an divide narrows, information and technology open self-settlement approach, and accepted become more accessible ${ }^{27}$ and the UNHCR humanitarian aid solely if the UNHCR acknowledges the protracted nature of directed it to reinforce its national infrastruc- refugee situations, refuge assistare of ture where refugees freely chose to settle refugee situations, refugee assistance is This strategy strengthened relationships gated vision seems to be positive, as it matches the reality on the ground. Most are they becoming, underlining how their of the refugee camps established in East architectures affect young children. For Africa have not been dismantled and have some, it is the first published account of become long term. However, despite efforts their history. I then dissect and reassemto move away from isolated and temporary ble their spaces on regional, country and planned camps into alternatives to camps landscape scales to understand patterns and assistance in urban areas, the humani- and similar behaviours. I explain six spatial tarian system continues to rely on physical characteristics of all seven settlements containment globally. ${ }^{28}$ Even if aiming to which influence their evolution and affect equalise relationships with direct local the young refugees living in them: three hosts and hiding under different labels, interactive characteristics - growing hetspatial containment strategies continue. The step from policy intopractice is not ringing a structural change to encampment strategies Under different labels, the ment strategles. Under containment and isolation of refugees into specifically designedzonescontinues. That is due in significant part to the inertia of host governments and hum national actors. Yet, $I$ believe, it is also due to the unbalanced relevance given to advocacy efforts and politics rather than utilising more spatial knowledge. While the information is there, in the everyday running of the camps, policies do not tap into it. Having, and using, the physical information about these settlements and understanding how they change over time and how they affect camp inhabitants - especially young children and their support networks - can improve refugee assistance theory and practice. The use of contextualised knowledge can inform decisions in long-term camps and new interventions. That is what I have tried to achieve, on a small scale, and what I explain in the following sections.

In this chapter, Ifirst describe Nakivale Kyangwali, Kyaka IL Kakuma, Kiziba, Kigeme and Mugombwa refugee camps, how they were first established and what interactive characteristics - growing heterogeneity and complexity, co-functioning/ ing-and threess and ever becomthe land proxim to the boder ithen discuss and impact this situat linowledge has for mpact this situated knowledge has for and refuge assistance in the regio (fig)

Complex, heterogeneous and everevolving, heterogeneous and everEast African Rift is a teortores-The and red Sea to the southern tip derle valleys as well as sandy hot and dry planes usually scarcely inhabited by nomadic pastoralists characterise the Rift. The UNHCR and host the porous borders of the different nation tates along the Rift in relatively underpopulated lands where it is usually challenging to live. However, owing to environmental pressures and the camps' economic and social opportunities, the population in and around them grows, putting pressure on the land use.

The three areas I describe in this book-Southwesteas I describe in this governments establish the camps close to 


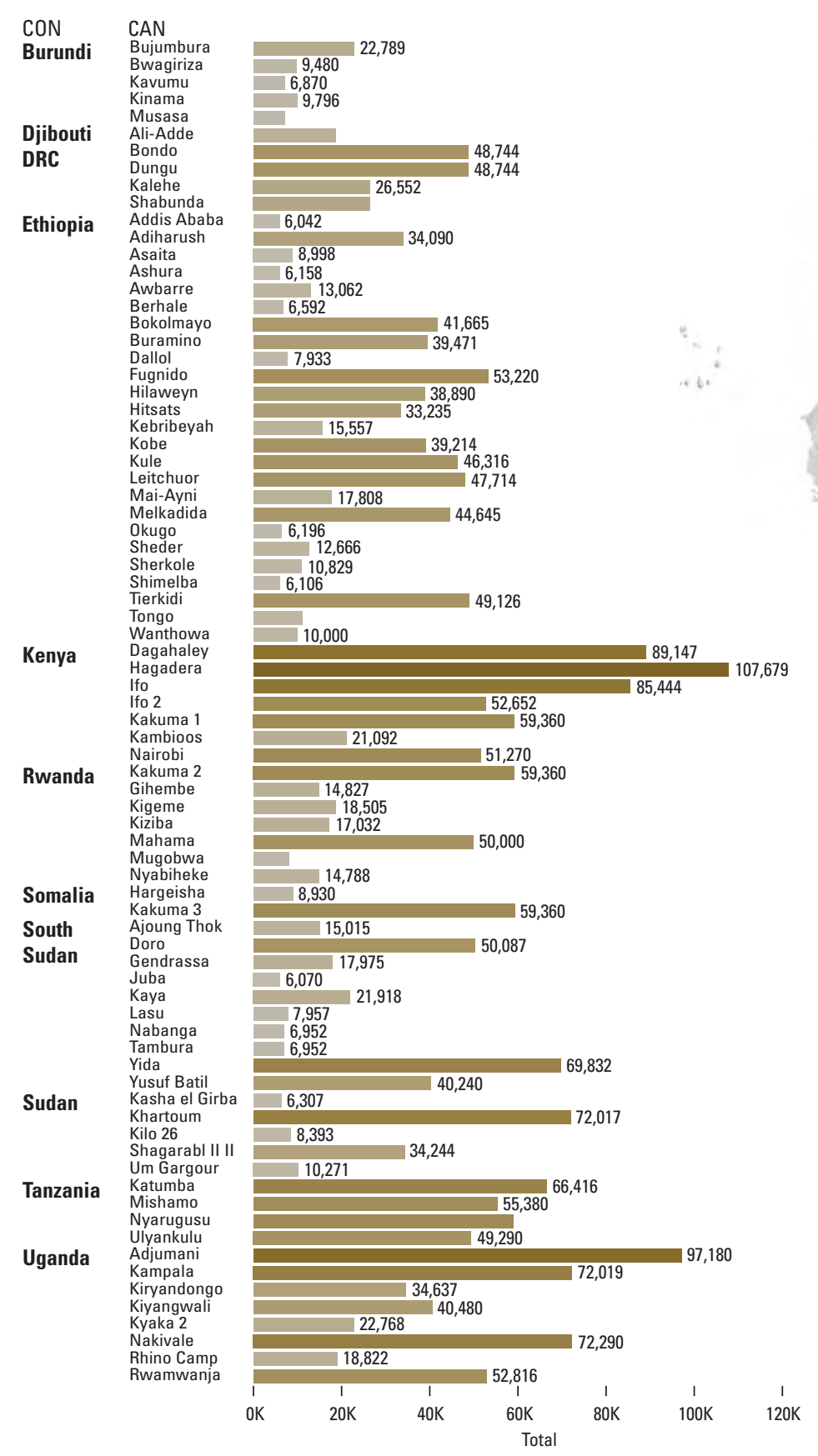

2.3

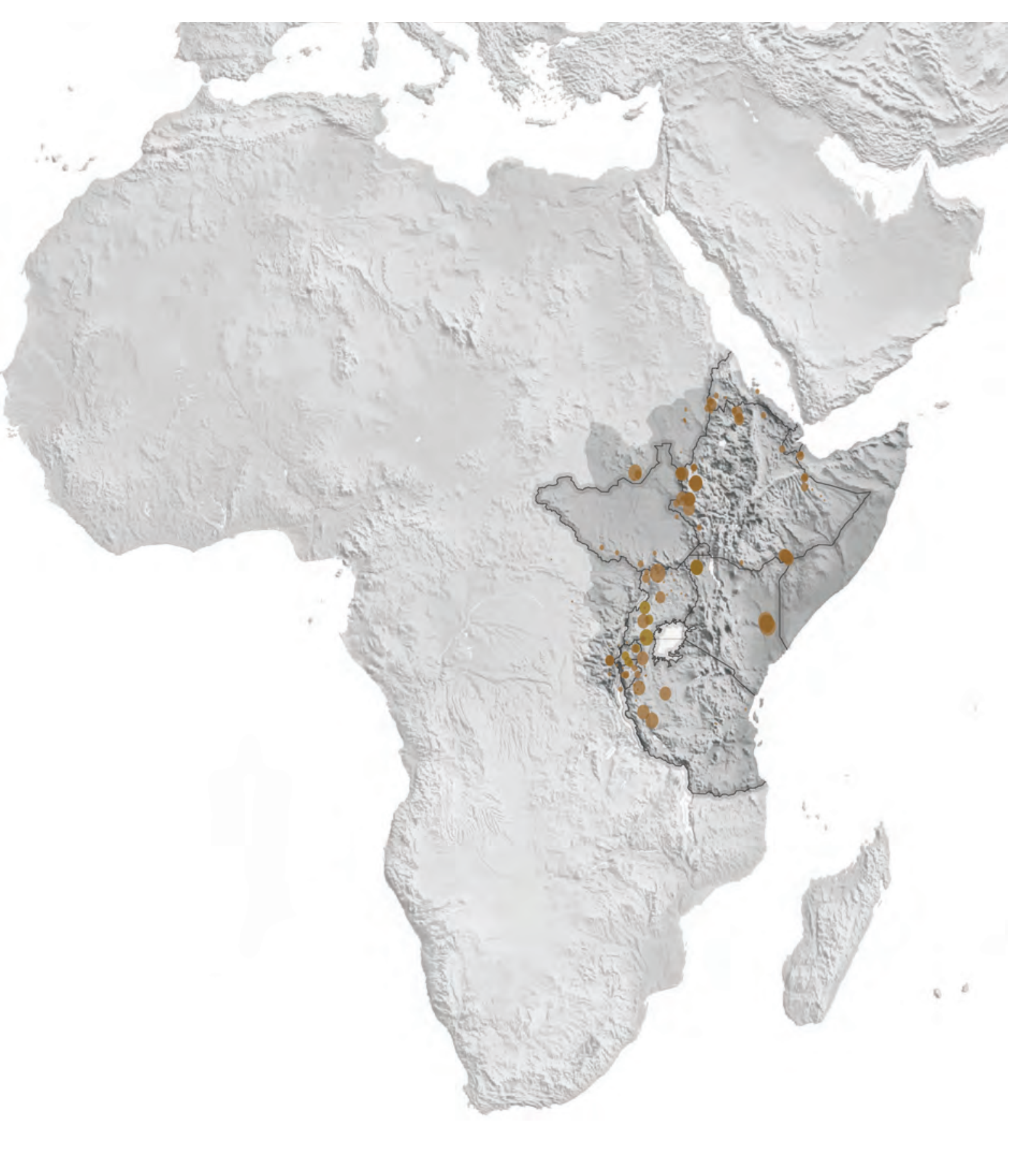

2.3 Map of East Africa (including Eastern Congo) with the 66 In the region highlighting nation states' borders. The graphic shows the names of all 66 camps, of refugaes they hosted as of
of December 2016. $\odot$ Amorós 
Refugee Origins Main conflict areas Horn of Africa

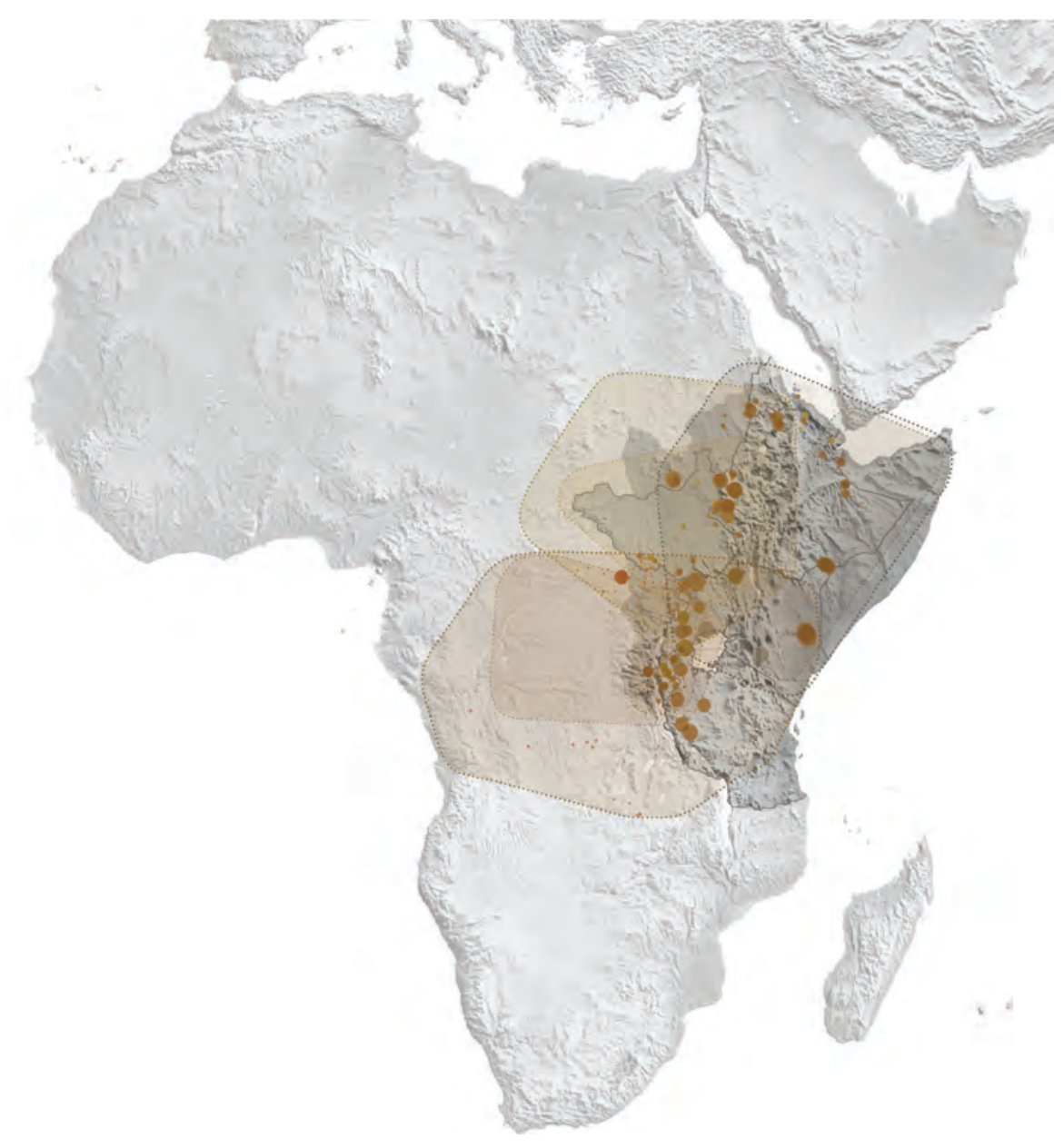

2.4

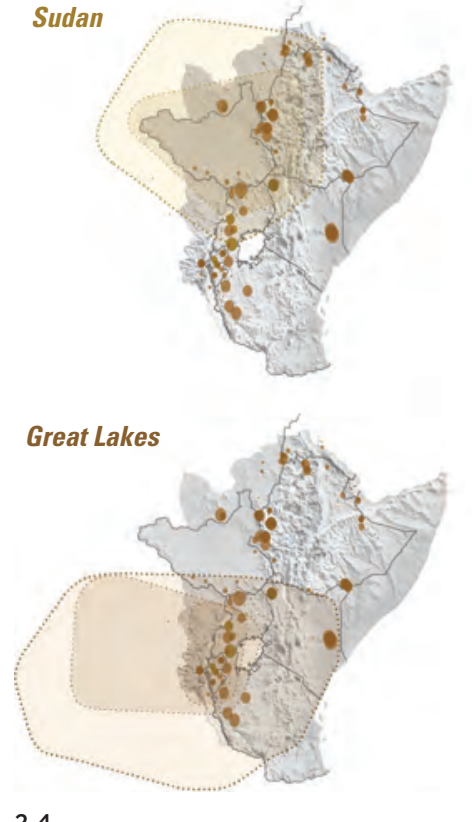

and Rwanda - reflect the Rift's heterogene- the conflicts that constrained them to flee, ity. They represent diverse conflicts and and variable international and media visrefugee policies; cultural, ethnic and lin- ibility. ${ }^{29}$ The seven camps I present her guistic abundance; material, formal and host refugees originating from three of the structural richness of vernacular architec- principal conflict areas in the region - the tures; and wealth of child-rearing practices Horn of Africa, the Great Lakes and South and concentions of education. Uganda, Sudan (fig 2.4). They encos and South and conceptions of education. Uganda, Sudan (fig. 2.4). They encompass diverse Kenya and Rwanda have different assistance lengths of existence, varied sizes and popucountries of origin of the refugees they host, geographies. feed the refugee OAmorós Elorduy.
In this chapter, the possible refugee are learning environments for young chilcamp assemblage combinations in the dren. What do I mean by that? East Africa's region come to light. The description and long-term refugee camps are cosmopolitan analysis of the different camps elucidate and cultivate socio-political and economic how these environments came to be - or interactions, and within them, refugees to become - and their effects on young and their direct local hosts continuously children's learning. In Southwest Uganda, exercise their Lefebvrian 'right to the city'. I present Nakivale (established in 1958), However, they are not yet a polis, and as I Kyangwali (created around 1964) and Kyaka explain in the chapter 'The urban turn: inforII (established in 1983). All three are medium mality, co-modification and assemblage', I to large in terms of both the area covered and the population size, but they are low and the population size, but they are low in population density. Located in subtropmainly inhabited by Eastern Democratic Republic of Congo (DRC) refuges, with Repure varion some variation amongst their minority crom is situated on a flooding like geography and hosts refugees from 11 different nationalities. In northern Kenya, I focus on Kakuma refugee camp (estabI focus on Kakuma refugee camp (estab-
lished in 1992). This camp hosts refugees from 11 nations, and it is placed in a deser area with seasonal floods. It has grown in four clearly defined phases which reflec conflict outbursts in the region. In Rwanda I present the camps of Kiziba (establishe in 1996), Kigeme (established in 2005) and Mugombwa (established in 2014). All three camps host solely Eastern DRC refugees and are characterised by being small in terms of size and population. They occupy hilltops with steep slopes and have extremely high densities of inhabitation. ${ }^{30}$

ategorise them as proto-urban.

These settlements are the result of the relationships between numerous human and non-human actors. They all have different demographics, densities of habitation, erface areasocupiedandsociopolitical hey sit Heterogeneity is he norm. They are in continuous evolution, asallsencent ow than a

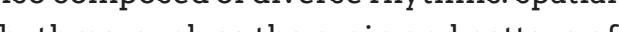
hom such as the grin and pattern of 作 sal and the spatial segregation of uses and different population groups; and temporal rhythms, such as the everyday human activities and the seasons with their floods, droughts and harvests.

A particularly relevant rhythm for this book is children's lifelong learning. Learning varies across ages, through the seasons and the daily activities according to access to direct content-based education and learning by experience. Learning also varies according to the environment where it is developed both directly and indirectly. At Varied and changing learning environ- devectly. At ments-Long-term refugee camps pluri-authored, polyrhythmic and everchanging proto-urban assemblages that 
some examples. On the regional scale, the in Southwest Uganda and Kakuma, refuleeing routes and the geographic and climatic context of the camps affect young located too far from where the children live. children's learning mostly indirectly. For They are only open for a few hours in the instance, long fleeing routes means being morning, and they sometimes teach in a further from conflict, but it also usually language that the children do not undermeans different languages and culture in the stand. ${ }^{34}$ The refugees lead the non-formal host country. On the country scale, closeness initiatives that aim to bridge these educato the borders causes insecurity, reducing tional gaps. Community groups, mother children's chances of free play and increas- leaders, churches and madrassas, someing insecurity and potential kidnapping and times in liaison with smaller and local NGOs, conflict within the camp On the landscape create spaces and mobilise human resources scale, the camp's boundaries have a relevant towards young children's learning 35 The role. For example, the porous Ugandancamps most overlooked but most influential and their position close to surrounding spaces for young children's learning are and their por populations incentive good relationships the informal ${ }^{37}$ nng settings: streets, between both groups with common educa- shared spaces, homes and WASH facilitonal facilties that serve both refugees and ties. These environments and the activities direct local hosts. On the camp scale, some developed in them are the principal influrelevant variables are size, density, grain, ence on their emotional, social and physical outline and pattern, which architect Kevin development." As John Dewey pointed Lynch has focused on in his studies about out and literature in the learning environhow the urban environment's conditions ment field sustains, children extract skills, affect child psychology. For example, the behaviours and attitudes and learn conten density of habitation and the growth patterns within and through those informal learnin the Rwandan camps provide ideal spaces ing environments. ${ }^{40}$ These three categorie for curiosity and imaginative play, which is resulted from the review of post-structura relevant to indirect learning. ${ }^{32}$

On the building scale, I focus on three assemblages of learning environments: formal, non-formal and informal. The formal facilities - ECD centres - and the contentbased education they provide are usually tions (NGOs) and UN agencies, funded by international donors, built in somewh permane structures and with a set curriculum, grades and accreditation once complet ${ }^{33}$ These facilities do not meet all the needs of the refugees. Particularly learning environent literature, specifically mist and education expert Philip Hall Coombs, ${ }^{44}$ and various edited volumes.

\section{constellation of refugee}

Southwest Uganda: middle-sized, lowdensity, multi-ethnic camps and unmarked from neighbouring countries long before the works of architects Colin Ward, ${ }^{41} \mathrm{Kevin}$ Lynch $^{42}$ and Allison and Peter Smithson, borders-Ugandic camps and un marked
2.5 Map of Uganda showing the
location of current refugee che (or groups of camps), and their

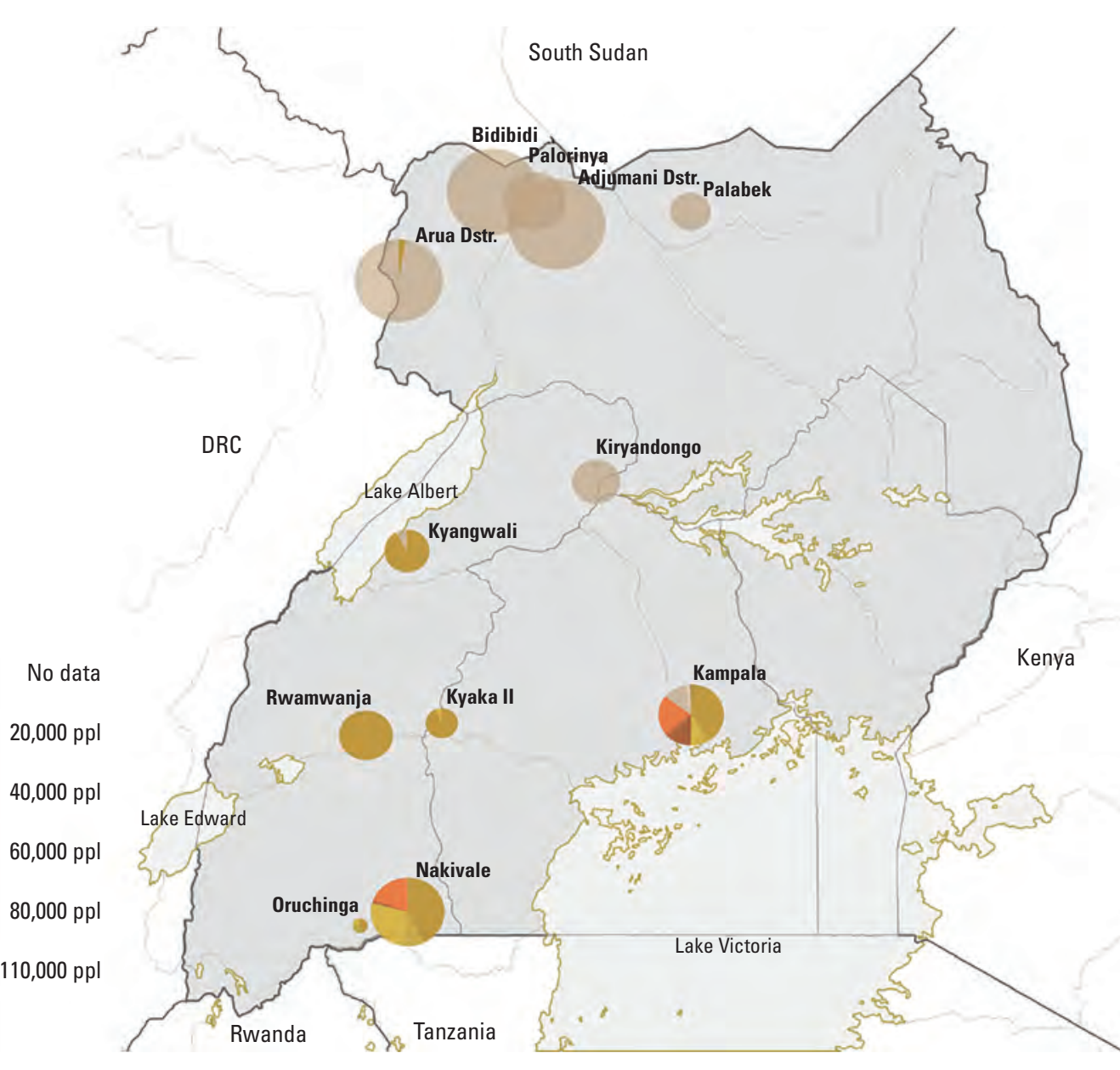

its independence from the British Empire, were considered temporary residents. After before the UNHCR started working in the Uganda's independence, the Office of the continent ${ }^{46}$ From the mid-1950s, the British Prime Minister (OPM) and the UNHCR ${ }^{47}$ conEmpire began to house refugees - most tinued the British policy of planned refugee of whom were Batutsi pastoralists from settlements with some modifications ${ }^{48}$ They Rwanda - in planned settlements. These altered the pre-existing settlements, allocatwere close to Uganda's southern borders ing a plot of land per refugee family for their where land was available and where refu- self-sustainability aslater expressed in the gees could quickly return home. In these Refugees Act 2006 (fig. 2.5).49

vast unmarked landscames, lu moved around, grazed their herds and the media and even the refugees generally 
praise the Ugandan refugee settlement the first examples of refugee encampment policy. However, it has drawbacks. It technically allows refugees to move and work. Yet, British Protectorate of Uganda acquired it still places them in rural camps usually the land where Nakivale sits from the isolated from economic and transportation Omugabe - the King of the Ankole - to hubs, making it difficult to exercise those host refugees fleeing the Rwandan freedoms. Moreover, many of these refugee Revolution. ${ }^{57}$ That was then the Ankole settlements are close to the country's region, ${ }^{58}$ in the district now known as borders, putting both refugees and their Isingiro, close to Mbarara. ${ }^{59}$ In the late direct local hosts in danger due to cross-bor- 1950 s, this was a scarcely populated area, der conflicts and rebel incursions. ${ }^{50}$ Lastly, and Nakivale's closeness to the border was they tend to lack marked boundaries, which, supposed to facilitate the return home of due to the lowing demand for land across the Rwandan refugees 60 However, this due to the gras flicts with the camps' direct local hosts 52 out the six decades of Nakivale's existen In February 2020, Uganda was hosting most notably in the 1980 a a 1990 s, when In Febr $1,411,098$ registered refugees and asylum attacks on Rwandan refugees happene seekers mainly from neighboung nation more easily and often (ig. 2.7).

states: South Sudan, DRC and Rwanda. Initially, there were no specific plots Most of them lived in 28 refugee camps. ${ }^{34}$ allocated per family for 'self-sufficient' Two-thirds were younger than 18 years of agriculture - as is the method now - an age, and 20 per cent were younger than six the boundaries of the settlement were years of age. ${ }^{55}$

The Southwest region, which shares borders with Eastern DRC, Rwanda and Northern Tanzania, hosts the oldest camps in the country, and it is mostly populated by
Eastern DR Congolese refugees. ${ }^{56}$ Camps in Eastern DR Congolese refugees. ${ }^{56}$ Camps in the Southwest region provide more extensive pieces of land than those in the West Nile sub-region - an area historically mophy and multiple lakes create porous borders that facilitate the inconspicuous crossing of goods and people, including refugees and even rebels (fig. 2.6).

unmarked, allowing refugees to graze their cattle on the surrounding land. This lack of marked boundaries and lack of title deed caused conflicts with the neighbourin Baru and Bahima populations over time. At the end of February 2020, Nakival housed 127,951 refugees and asylum seekers in 185 square kilometres on the shores of Lake Nakivale. ${ }^{63}$ The settlement is made up of 79 villages divided into three zones: Juru, Base Camp and Rubondo. ${ }^{64}$ In Base Camp - the oldest most central and populated zone - refugees have named its different villages. Names such as Little Congo, Kigali, Mogadishu Nakivale: old, large and thinly spread on and Sudan-according to the people that dry borderland-Nakivale is the oldest inhabit them-now appear in the reports settlement that I present here and one of and plans of the UNHCR and the various

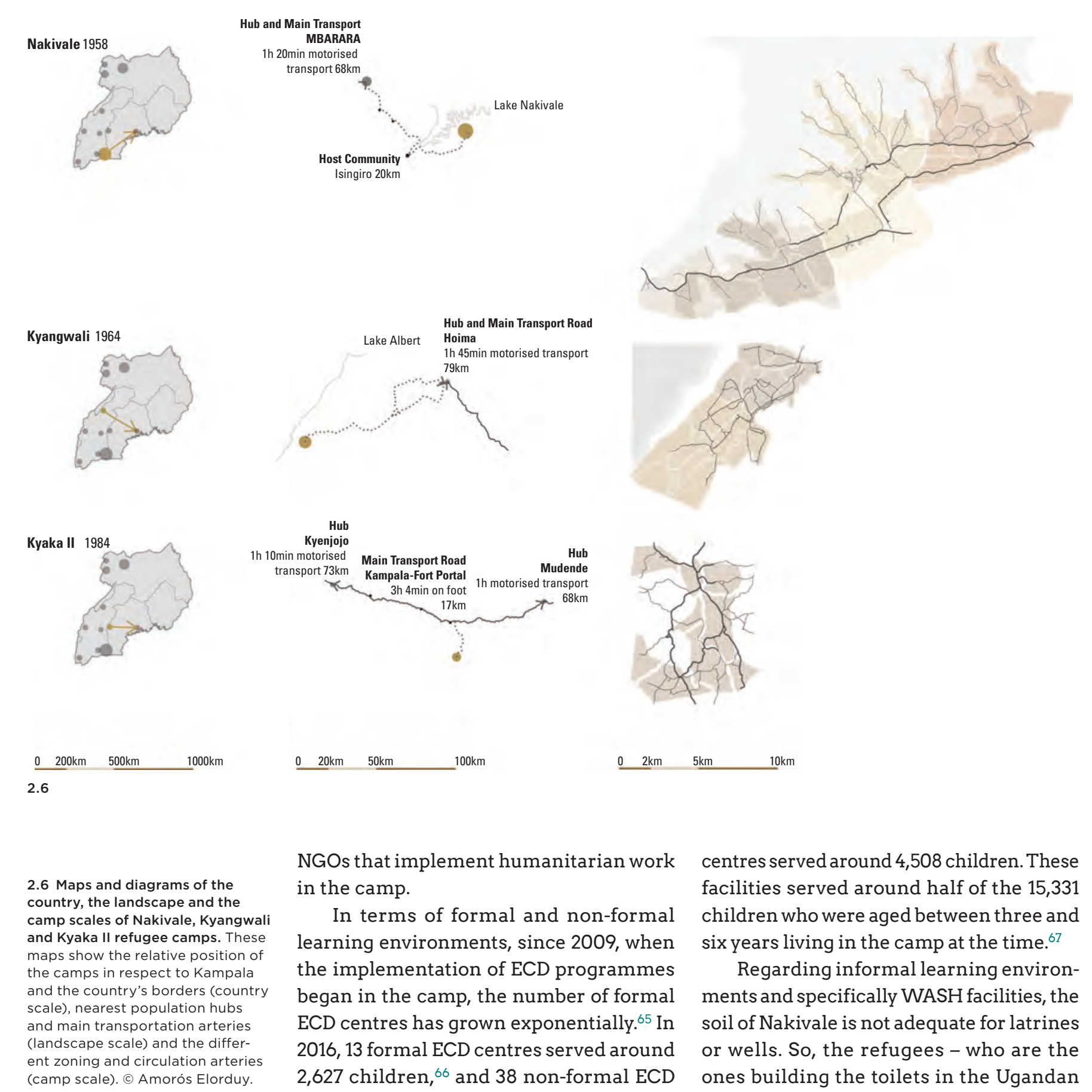


Nakivale
1958

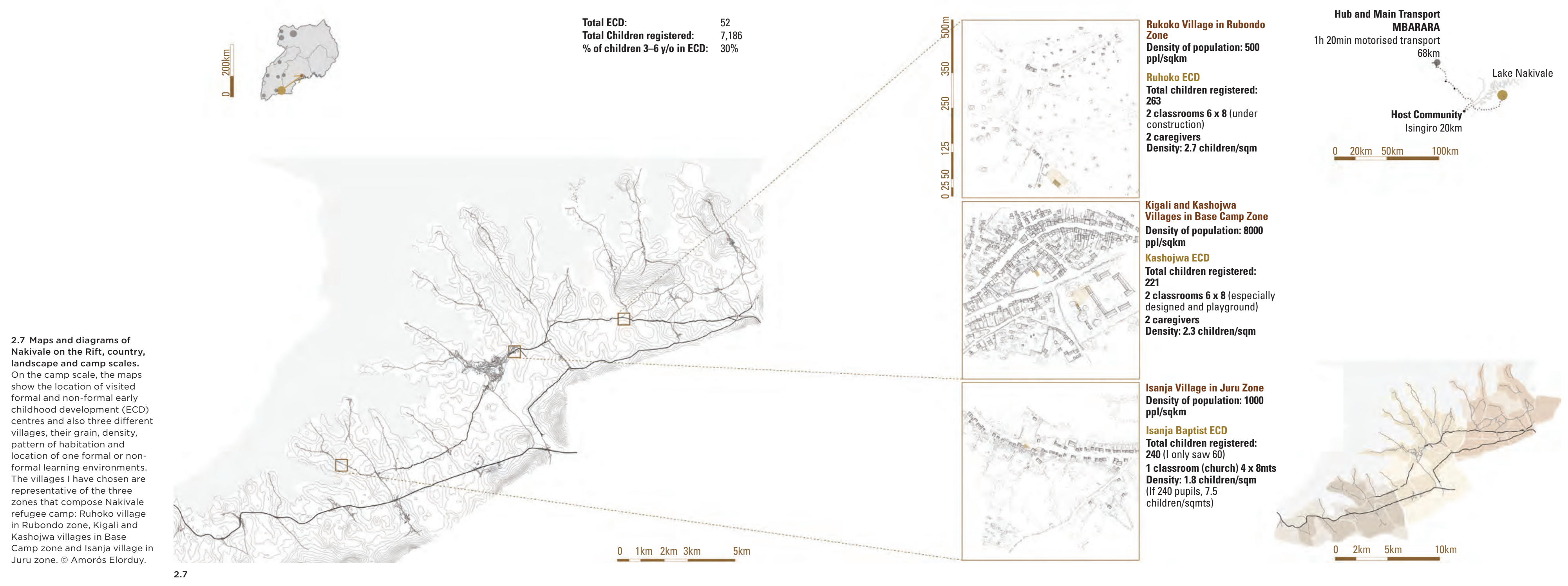




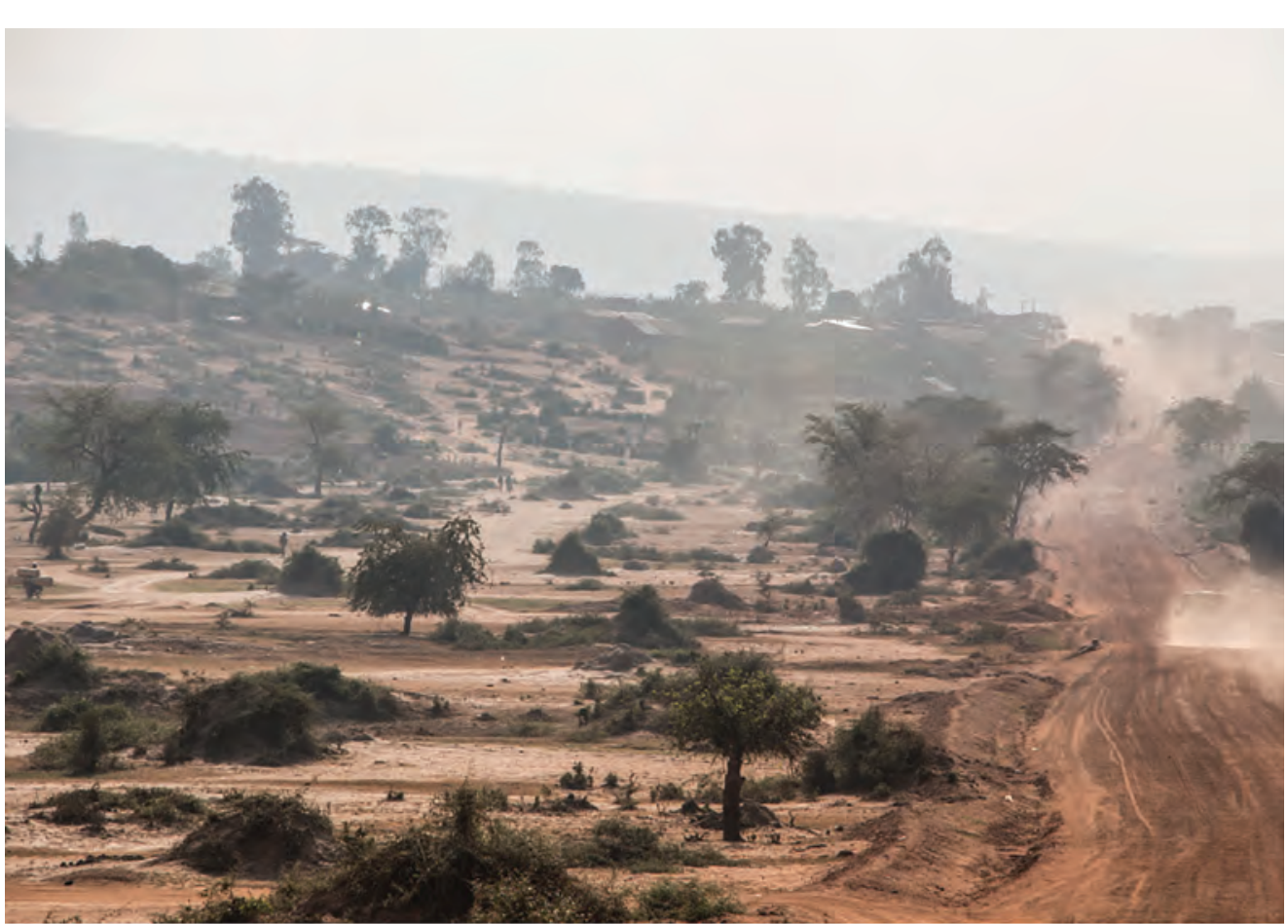

camps-resort to building latrines on termite mounds when possible.

The rhythm of everyday life varies amongst the 79 different villages. The diver sity of population densities, longevity and gees must travel to get to the ECD centres, essential services and shops. Access to basic services is especially complicated in the newest and most remote Rubondo zone, which suffers from population fluctuations and considerable distances from outside transportation and market hubs (fig. 2.8). ${ }^{68}$

Kyangwali: elastic and porous on a jungle-like border lake-After Uganda's independence, the government estabindependence, the government established six new refugee setlements in the Southwest. These initially hosted the Rwandan Batutsi escaping the Rwandan Revolution ${ }^{70}$ and Eastern DR Congolese or diverse ethnicities escaping violence following the assassination of Patrice Lumumba in $1961 .^{71}$ The Ugandan government established the Kyangwali refugee camp in $1964^{12}$ at the shores of Lake Albert-a natural border with Eastern DRC and 89 kilometres from the town of Hoima in Western Uganda. ${ }^{73}$ From 1994 to 1995 , most of the Rwandans repatriated, ${ }^{74}$ leaving the camp almost empty until 1997 when a new wave of Eastern DR Congolese arr

The current 89 square kilometres intended for the refugees in Kyangwali - not consistently demarcated until $1967^{76}$ - hosted 120,626 refugees in February 2020, ${ }^{, 7}$ mostly from Eastern DRC..$^{78}$ Almost 24,000 of those were children younger than six

years of age.
Kyangwali has an undulated geograwhich are very favourable factors for agriculture. Its right soil conditions, porous unmarked borders and fluctuations in refugee population sometimes lead to land conflicts between the camp inhabitants and the growing numbers of surrounding settlers. ${ }^{7}$

The camp consists of 16 villages each with between 10 and 20 blocks of homes. ${ }^{80}$ Refugees arrive in waves, and those define village creation and organs those define ing refuges usually by onisation, separating refugees usually by origin. ${ }^{8}$ The camp che in Kasonga village dministrative centre in Kasonga village and several small trading areas at each In centre.

In terms of formal and non-formal learning environments, in 2016, the camp had 11 formal and 6 non-formal ECD centres - around one per village. ${ }^{33} \mathrm{~A}$ total 2,200 children, 27 per cent of the 7,900 ECD-aged children, attended these centres. Regarding informal learning environments, specifically common areas and streets, the situation at the buffer zones has changed radically in the last four years (2016-2020). In 2016, Kyangwali had a third of its February 2020 population, going from 36,713 to 120,626 mainly during 2018 and 2019. The density of habitation in 2016 was relatively low, especially in the 'buffer' villages of Mukunyu and Malembo that were almost unoccupied. ${ }^{84}$ In terms of WASH facilities, the towns in the Kasonga area have more boreholes and access to health points than the newer villages of the Rwenyawawa zone with scarcer points and taps, which are close to the trading centres and helth points (fig 210$)^{85}$ zone, the road passing through Base Camp zone and at paths
at Rubondo zone. August 2016 . 
Kyangwali
1964

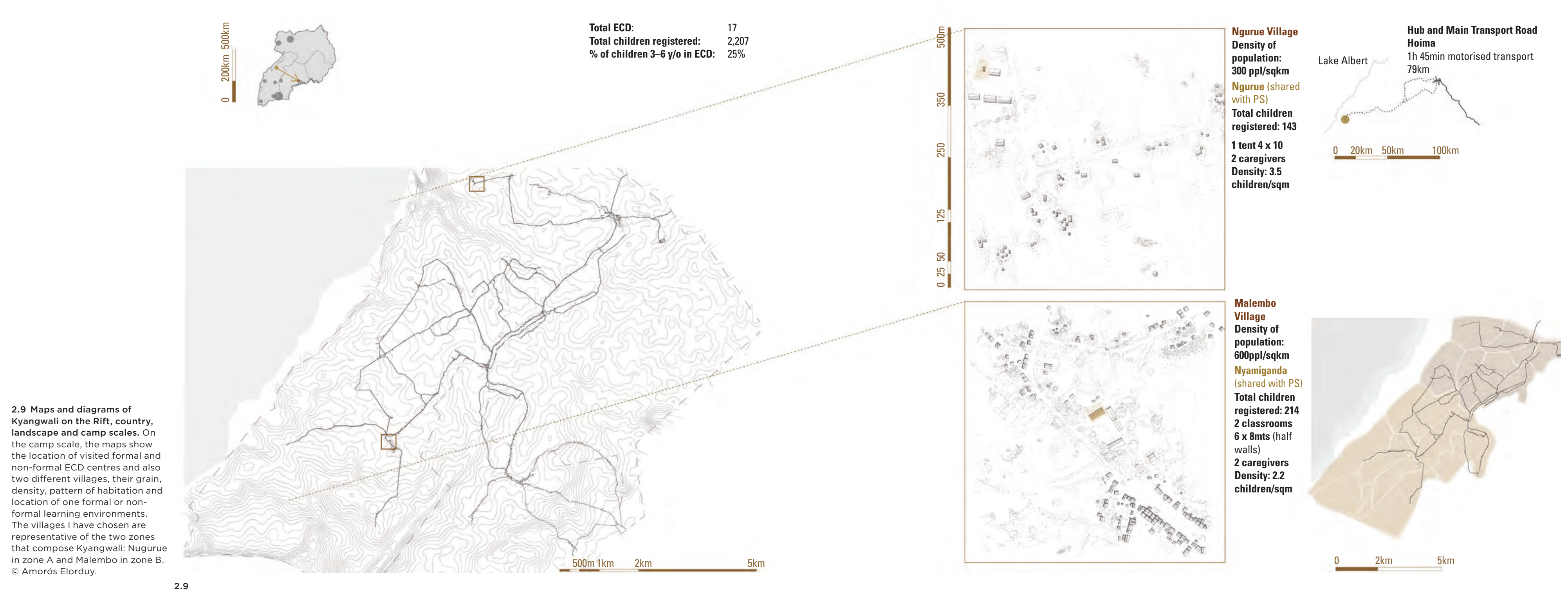



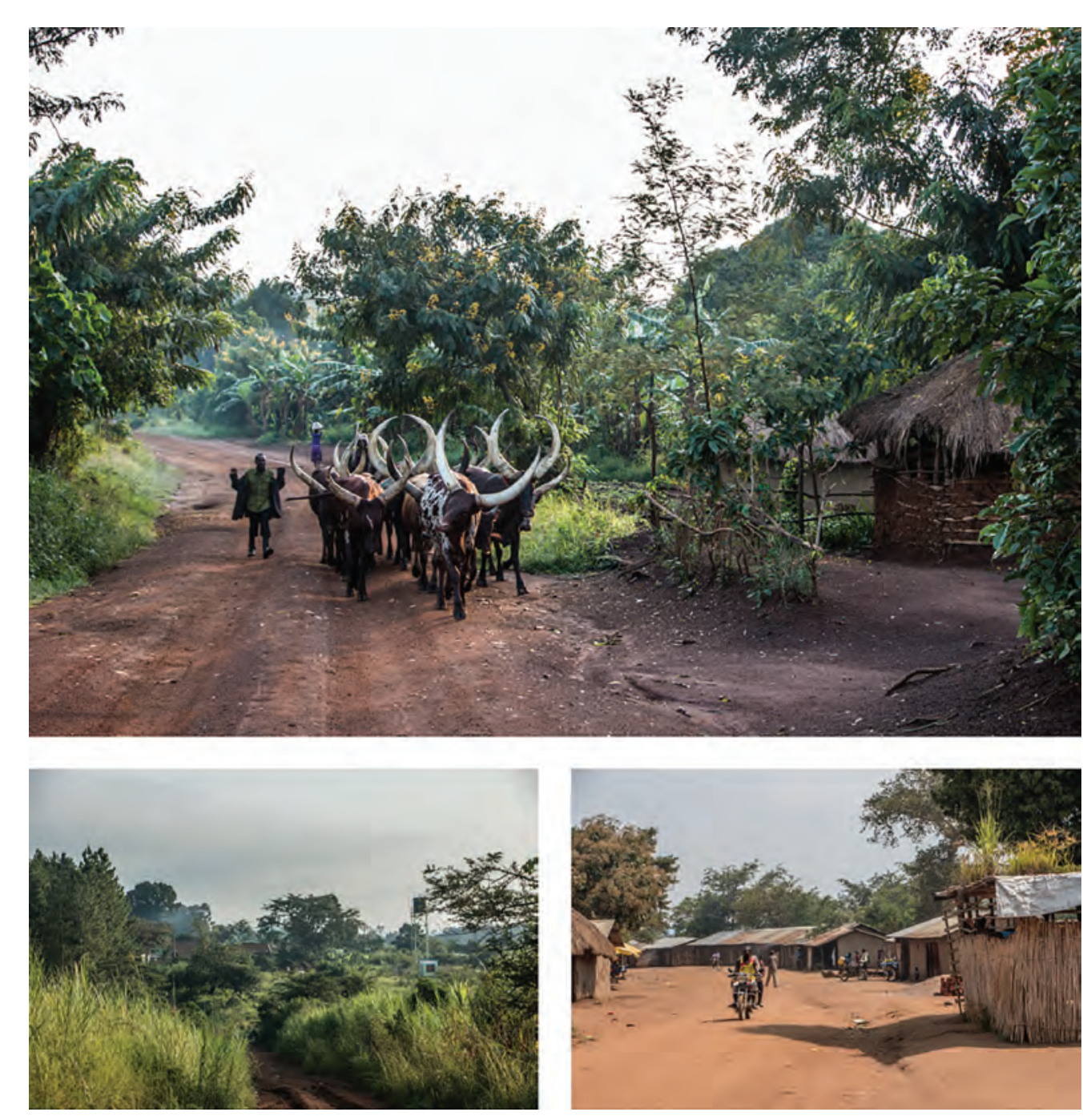

Kyaka II: a pluri-nuclear, spider-like Ugandan government established Kyaka size..$^{90}$ In 2016, it had nine zones ${ }^{91}$ and II in May 1983 in the Kyenjojo District as 26 villages, with an average of 731 people Banyarwanda people - both economic migrants who had arrived throughout the century and Batutsi refugees from the 1960s who had previously avoided the planned camps - were forcibly moved into camps under Milton Obote..$^{86}$ Most of the Batuts refugees repatriated in 1994. From 1996 onwards, Kyaka II began to host Rwandan Bahutu, Burundians, Eastern DR Congoles and a small number of Ethiopian and Somali refugees. Between 2005 and 2006, Kyaka II than 17,000 inhabitants. The increase was due to the transfer of refugees from Kyaka I which closed in 2005, and to a significant influx of Eastern DRC refugees caused by a guerrilla conflict in the region. ${ }^{87}$ It again quadrupled its population from 2018 to 2020 due to conflict and the Ebola epidemic
North Kivu in Eastern DRC (fig. 2.11). North Kivu in Eastern DRC (fig. 2.11). In February 2020, the camp was hosting 123,086 refugees, ${ }^{88}$ mainly from Eastern DRC. Twenty-five per cent of those were children younger than six years of per village. ${ }^{92}$

In terms of formal and non-formal learning environments, in 2016, Kyaka II had 30 formal and non-formal ECD centres attended by 2,819 children, which was 33 per cent of the settlement's total population of young children aged between three and six years..$^{93}$ The humanitarian system leads and funds the formal centres, while Ugandan nationals, and coalitions of nationls and refugees run private non-formal rning (a) the serter in the setlement (he be 2,000 metres, 4 and 78 per cent of the families have access toprivate latrines. In terms of homes and commercial trading centres, Kyaka II suffers considerable fluctuations, affecting the diverse areas with some established and well-developed trading centres and other zones that are relatively poor and desolate (fig. 2.12). 

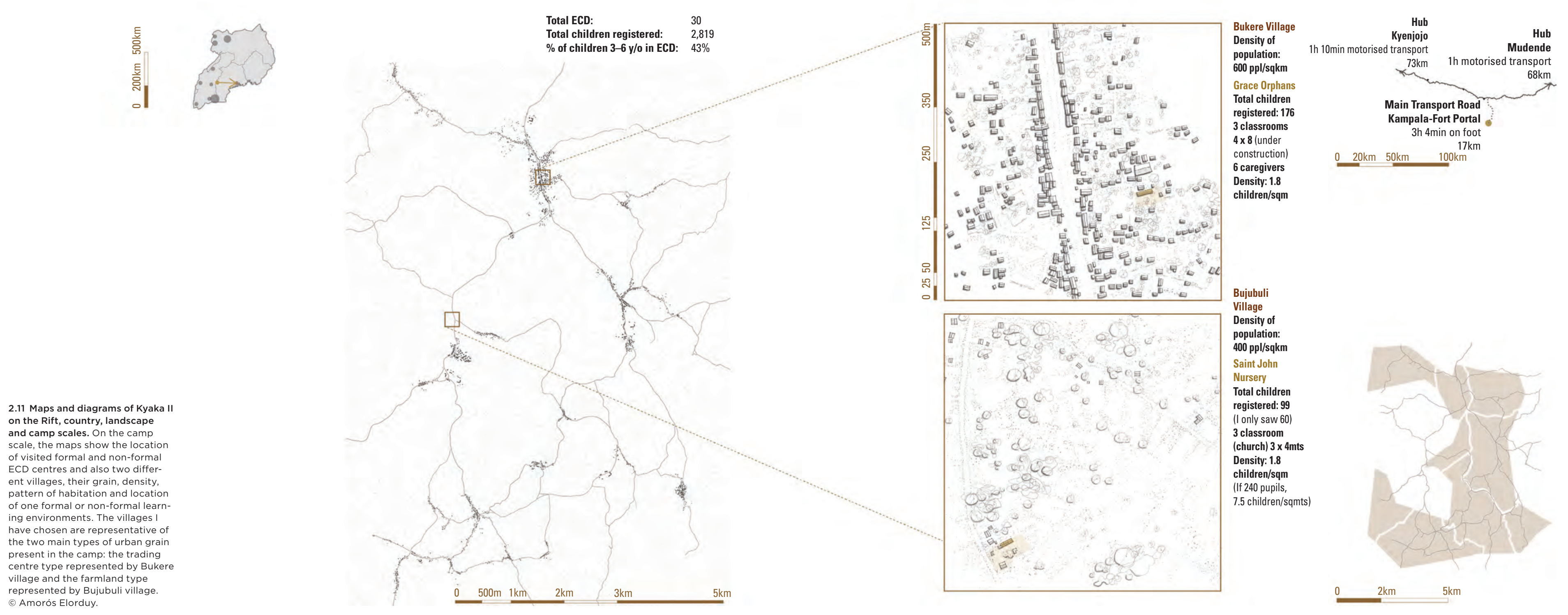

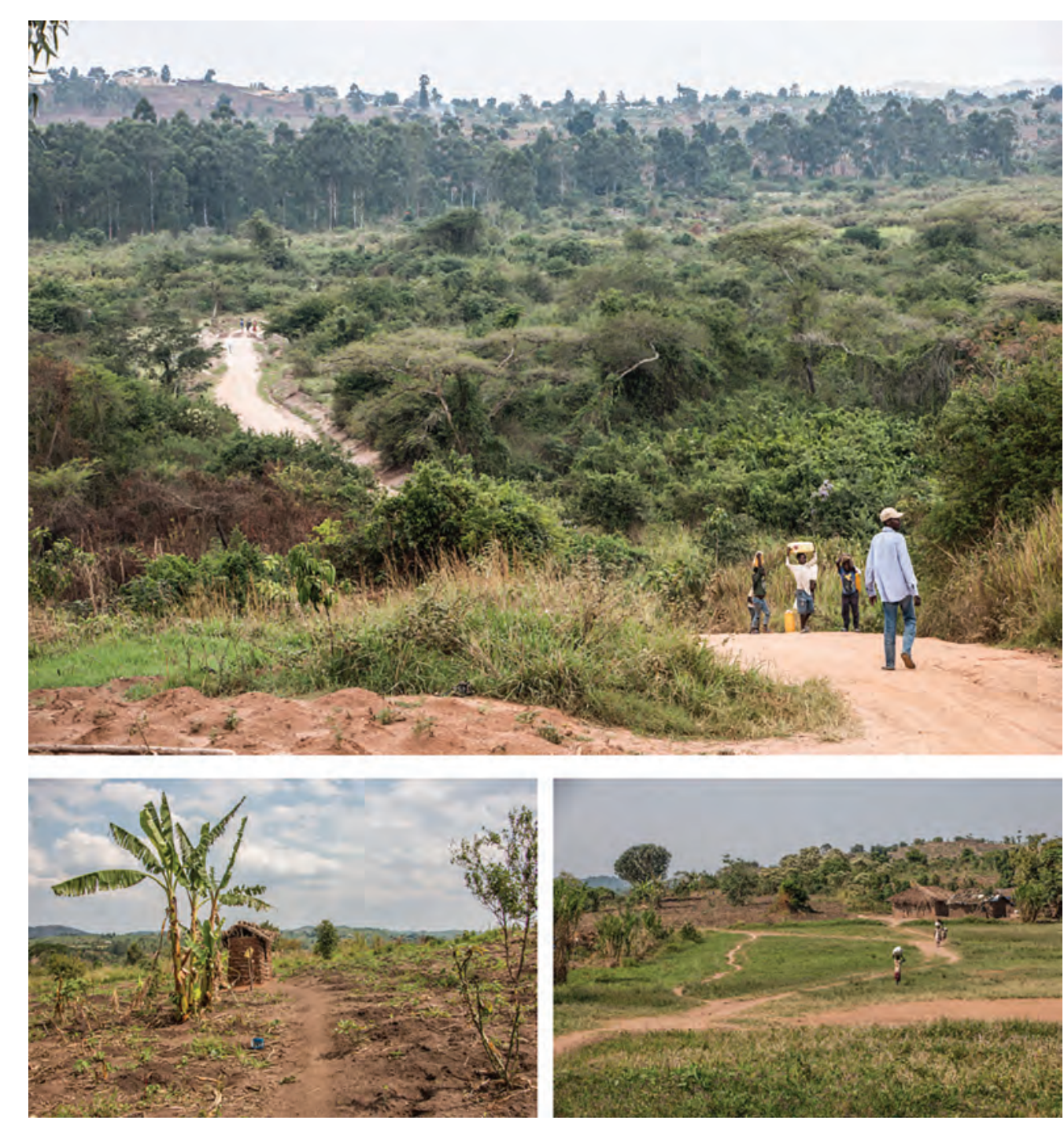

Northeast Kenya: a multi-ethnic, phased, refugees to the vast rural camps between and increasingly grid-like camp on desert 1995 and $1997 .{ }^{103}$ In addition, in 1995, the plains-In the early 1990s with the growing Kakuma and Dadaab camps re-accommoconflicts in Somalia ${ }^{95}$ and South Sudan, 96 dated refugees from the unplanned ones Kenya began hosting large numbers of refu- close to the Somali border such as Liboi. ${ }^{104}$ gees. From 1992 to 1993 UNHCR supported These movements contributed to the cos-

the country in the creation of nineteen refugee mopolitanism in Kakuma and the camps camps. ${ }^{97}$ The Kenyan government - like its Ugandan neighbour - inherited its refugee assistance policies from the British Empire. These policies were, and are still, based on spatial segregation, allegedly to govern refugees and reduce conflict, and to some degree also related to the refugees' $k$ inship ties and their different times and points of entry into Kenya (fig. 2.13).98

Initially, two different encampment strategies took place in Kenya. One was Hagadera, Ifo, Dagahaley and Liboi-sizable in population and surface, placed in desert areas close to Kenya's northern borders, and isolated from any political or economic activities. The other was the constellation of multiple coastal camps, relatively small and placed within or around bustling urban areas and on the trade routes along the coast. Initially, the government placed most of the Nuer and Dinka Sudanese in the northwest camp of Kakuma and Thika and Ruiru camps close to Nairobi. The coastal camps ${ }^{99}$ and the large camps up north in Mandera ${ }^{100}$ and Garissa Counties ${ }^{101}$ hosted most of the heterogeneous Somali refugees. ${ }^{102}$

The coastal camps' informal growth and the refugees' lobbying to be resettled to third countries caused friction with their local hosts and the Kenyan government. Consequently the governmentclosed these camps and either repariated or resetted in the Dadaab complex.

At the end of February 2020, Kenya hosted 492,802 refugees in five rural camps: the three surviving Dadaab camps, still running after the Kenyan government forced repatriation of the Somali refugeesios and Kalobeyei in 2017.106

lorren landscape around hem and $t$ other factors, these camps have become her lo The Tomala and hor Kenyaw Sudan and Uganda. 107 The rural camps segregate refugees by origin and ethnicity and also separate administrators from refugees in their master plans. The compounds of the UNHCR and their implementing partners (NGOs) are located away from the refugees in permanent buildings surrounded by turdy fences, barbed wire and guards. 108 The discrepancy between the planning guidelines outlined by the UNHCR's Emergency Handbook ${ }^{109}$ and the practical measures that the UNHCR implements in the Kenyan context is glaringly obvious. Planners disregard refugees' necessary participation and consultation and the importance of maintaining former traditional settlement patterns and relatraditional settlement patterns and relaandbook 


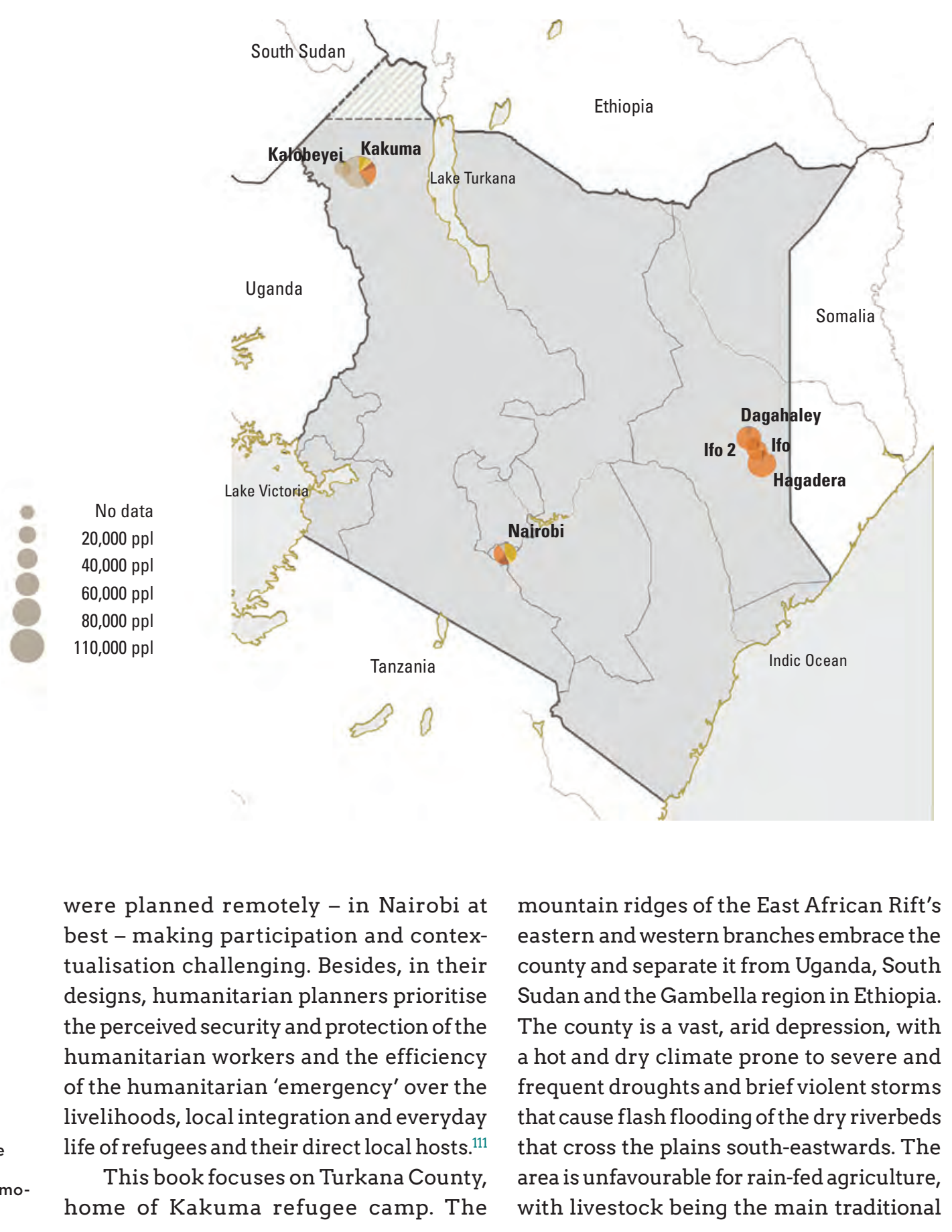

Kakuma
1991

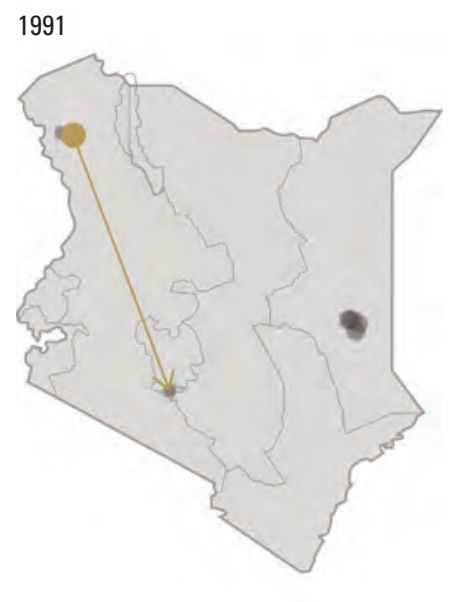

$\frac{0}{2.14}$

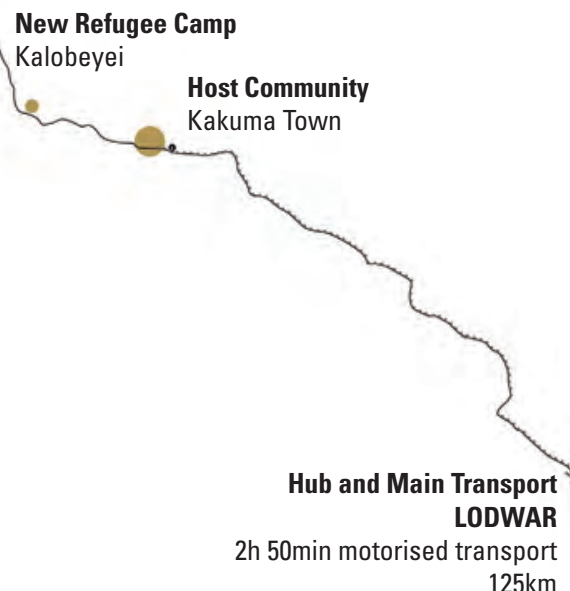

$1000 \mathrm{~km}$

$\underline{0} \quad 20 \mathrm{~km} \quad 50 \mathrm{~km}$

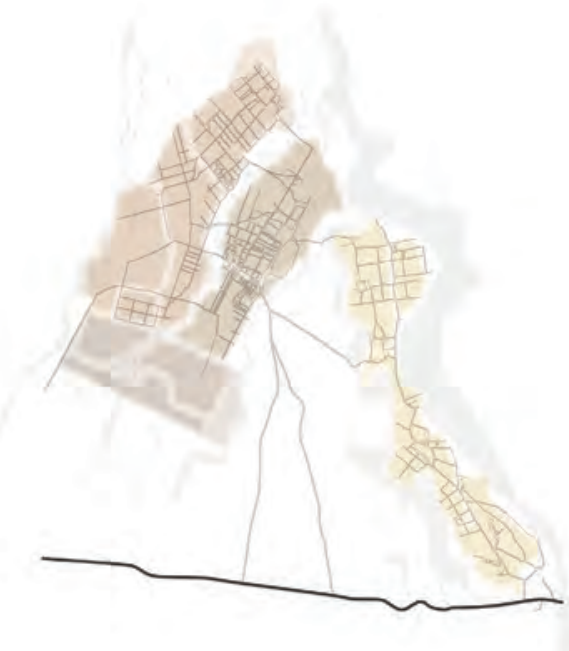

$5 \mathrm{~km}$

activity for most of the Turkana, the seminomadic pastoralists the area for generations (fig. 2.14).112

water and other resources around Kakuma. Lack of water is damaging the Turkana's livelihoods and putting a strain on their relationship with the refugees. ${ }^{119}$ Conflict Kakuma: from organic and dense to a also erupts amongst refugees, due mostly planned low-density grid-The UNHCR to politically and ethnically triggered vioand the Kenyan government established lence. Sometimes, these disputes mirror Kakuma refugee camp in July $1992^{113}$ to the larger-scale clashes that take place in house 10,000 Sudanese refugees ${ }^{114}$ in an the refugees' countries of origin. ${ }^{120}$

area separated from Kakuma town by the Kakuma grows in phases through seasonal River Tarach. ${ }^{115}$ However, the size expansion grids filled with new refugees and population of the camp have grown and their shelters over time and is crisssince its creation, reflecting the region's crossed by dry riverbeds that flash flood conflicts, especially those in nearby South seasonally. The camp's coarse urban grain

2.14 Maps and diagrams of the
country. landscape and camp scales of Kakuma. These maps camp in respect to Nairobi and the country's borders (country scale, nearest poplatation hubs and main
transportation arteries (landscape
scale) scale) and the different zoning and circulation arteries (camp scale). 2.13 Map of Kenya showing the
location of refugee camps (or location of refugee camps (or
groups of camps) and their de
graphics. $A$ Amorós Elorduy home of Kakuma refugee camp. The rea is unfavourable for rain-fed agriculture,
Sudan. At the end of February 2020, has certain areas reserved for housing and Kakuma housed 194,914 refugees from 11 others earmarked for services. The oldest, nation states"17 and consisted of phases I, Kakuma phase I, has the highest population II, III and IV that covered approximately density and an organic structure of small 12 square kilometres (fig 2.15) 118 intricate streets lined with tall thorny The large population in addition to fences separating the densely built residenthe increasing drought, is draining the tial compounds. Here, distances betwen 


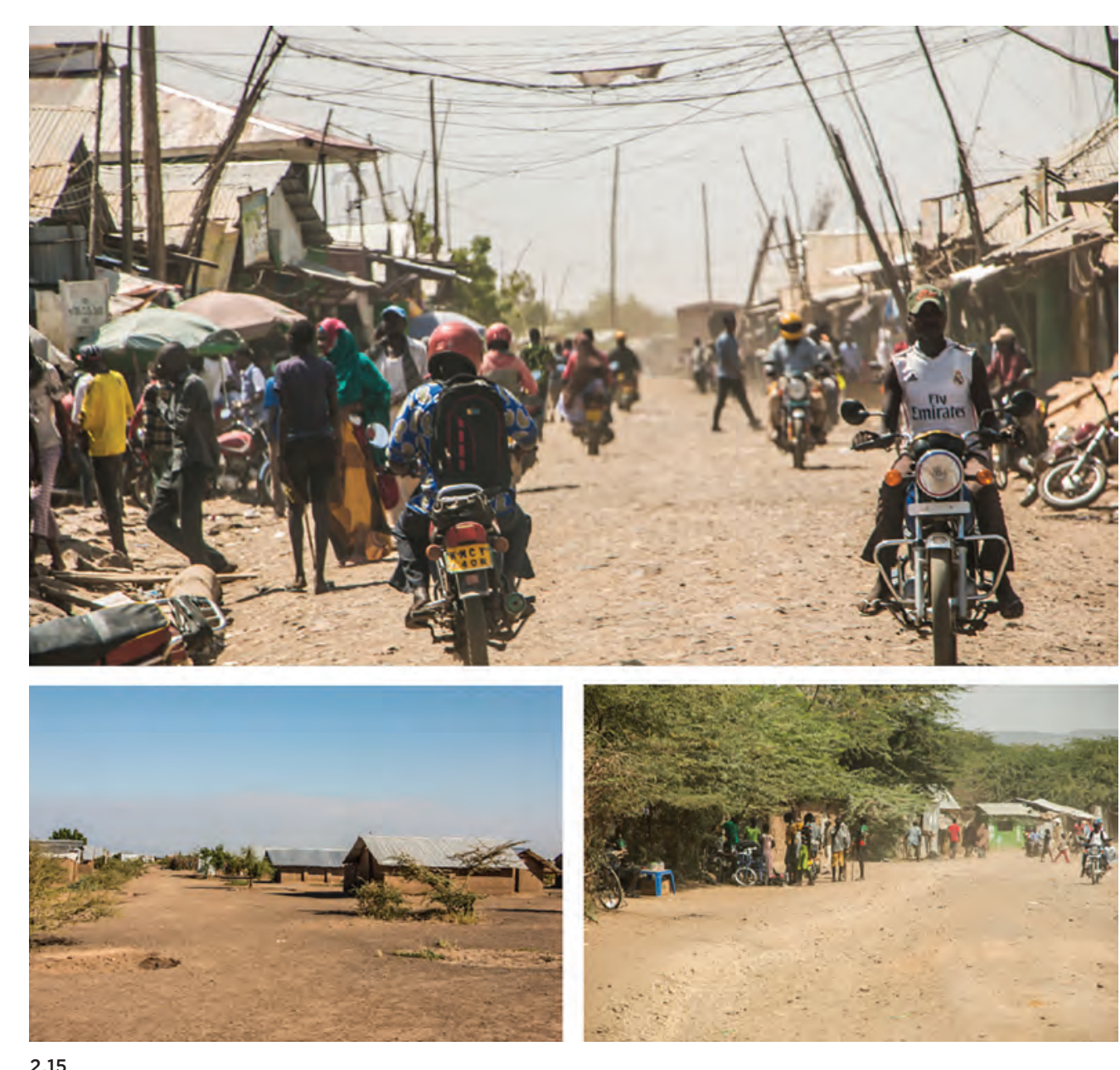
Top: Kakuma phase I main com-
mercial road. Bottom left: road in Kakuma phase III. Bottom righ phase l. September 2016 .
OAmorós Elorduy.

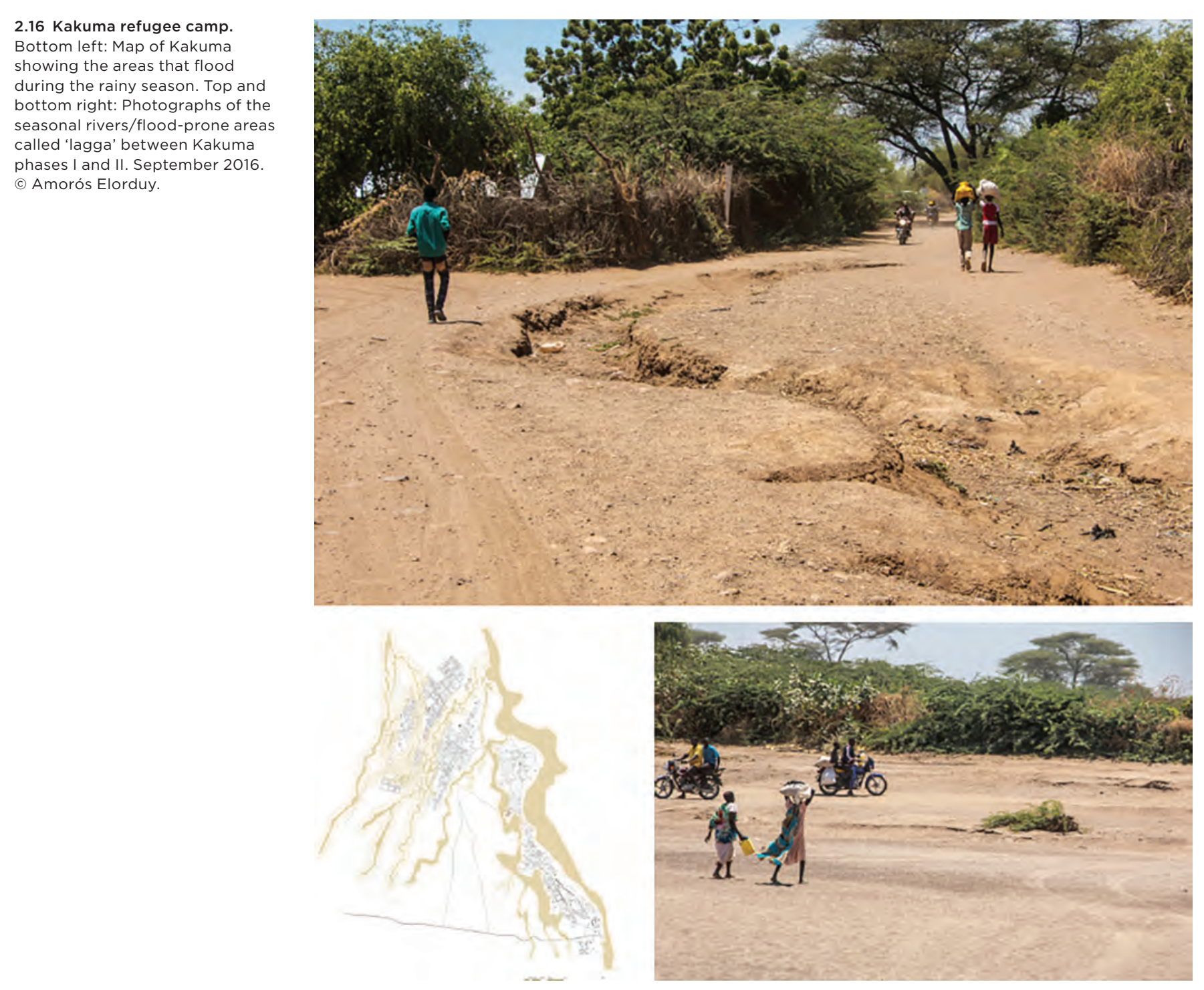

216 

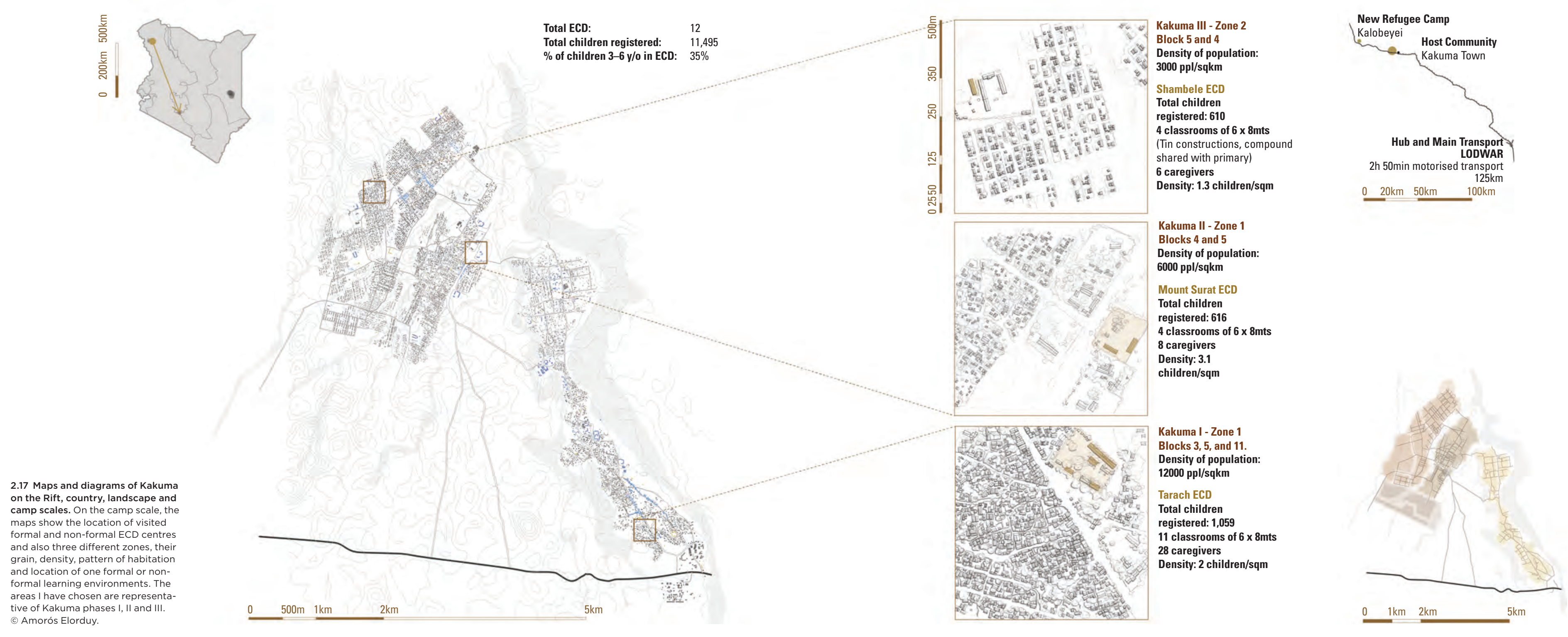
homes and services are relatively short. wider roads and a lower population density Kakuma phase I has some longitudinal Distances to schools and water points are (he noise and dust of fast motorbikes and trucks bringing in goods under messy heaps of electric cables passing overhead. These roads are filled with buyers, pedestrians, bicycles and childre This phase accommodates refugees from different nationalities and ethnic groups, mainly Ethiopians, Eritreans and Rwandans. There is one particular zone that refugees named'Hong Kong' due to its density, noise and messiness, and the name now appears in NGOs' accounts and maps.

The Kenyan governmentopened Kakum phase II in 1998, primarily to house Somali (c) is still predominantly Somali. Lagga - dry is still predominantly Somali. Lagga-dry
riverbeds that flash flood in the rainy riverbeds that flash flood in the rainy
season-separate its mid-density grid from season-separate its mid-density grid from Kakuma phases III and I. The floods have a considerable effect on the foundationless mud houses and the infrastructure that seasonally becomes severely damaged (fig. 2.16) Kakuma phase Ill resulted from the consolidation in 2009'121 of the first iterations of phases III and IV, which were established in 1999 and the early 2000s, respectively. ${ }^{122}$ The current Kakuma phase III has a low-density grid, with wide, open and dusty roads. It in 2014 for a new influx of South Sudanese refugees. It has hosted Burundians and vulnerable Somalis since 2015. The latter came from the attempted dismantling of the Dada III and IV feel drier and dustier than Kakum phase I, since they have much less vegetation longer in these newer phases.

There are 12 formal ECD centres across all Kakuma's phases,', several churches and madrassas per phase, two Furah centres ${ }^{125}$ and four Waldorf initiatives ${ }^{126}$ that some young refugee children attend durin out-of-school hours. Due to the sandy soil and recurrent floods, several of the school's foundations suffer from a lack of stability that creates cracks and destroys the poorly built facilities Regarding informal poornin environments, particuly WASH facilities the soll in Kakuma dos not facilitate the construction of proper nothe primarly family own are primarily family owned. In terms of housing, prep of sol also makesitchallenging to pepar ity especially in flood-prone areas (fig 217). Rwanda: small-sized, dense and steep most densely populated countries on th African continent, ${ }^{127}$ and land availability is a concern. The vast majority of the Rwandan population still lives in rural respective agricultural plots are sparsely and somewhat homogeneously distributed throughout the hills, leaving valleys and wetlands for agriculture. ${ }^{128}$ The hills have traditionally constituted an administrahomes dispersed on their slopes (fig. 218) In 1996, in the aftermath of the id 2 r in the afterm Rwanda, he government (primarily funded Congolese camps-Rwanda is one of th areas. Scattered homes surrounded by their tive and social unit that pulls together the Rwanda the

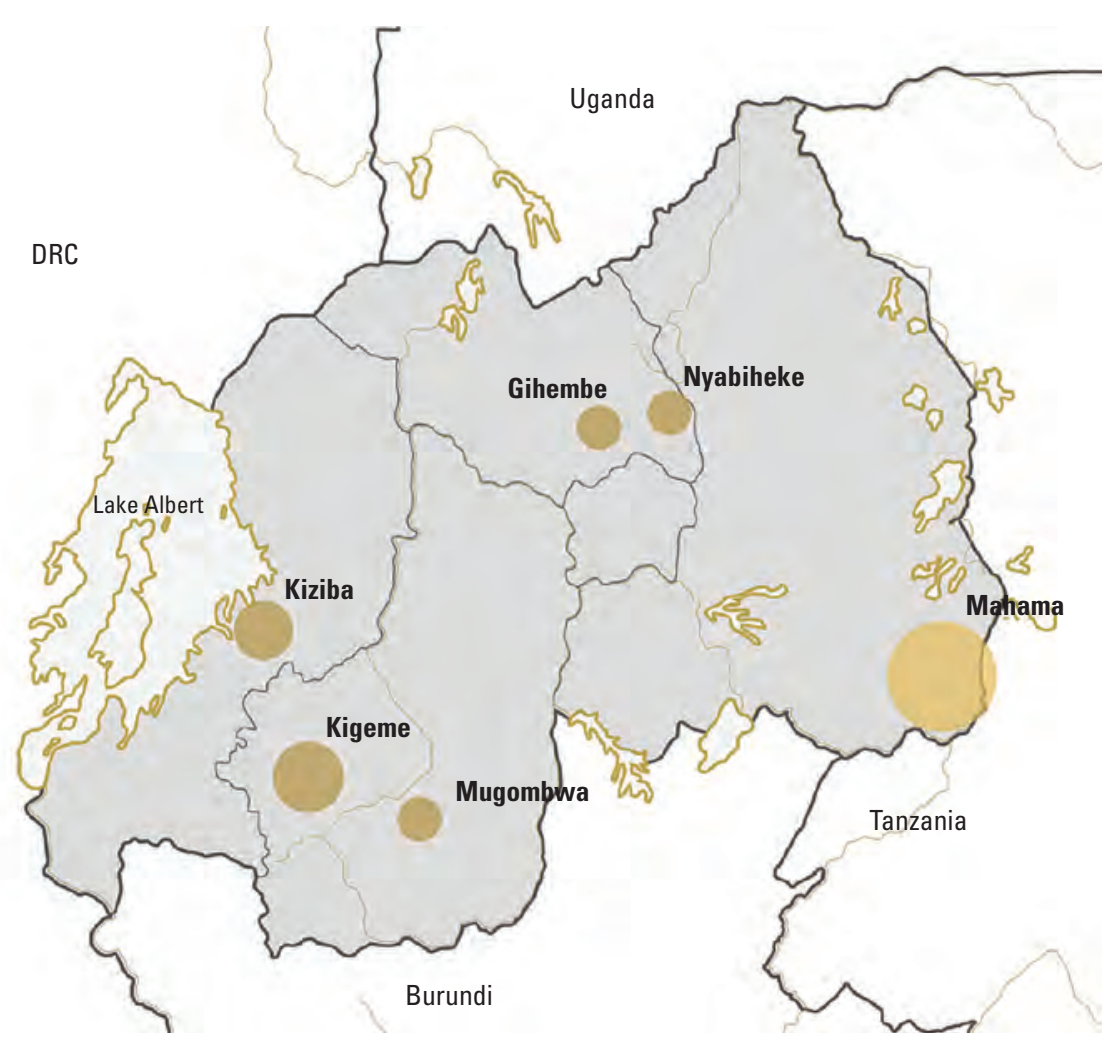

Policy of Regrouped Settlement Sites in the of hills are the size of a small- to mediumRural Areas of Rwanda, 129 widely known as sized village with a similar organisation to the Imidugudu Policy. ${ }^{130}$ Imidugudu means a planned imidugudu. ${ }^{133}$ One of the main 'villages' in Kinyarwanda. This policy was differences between both settlement pata villagisation strategy similar to those terns is their materiality. Until 2013, the main implemented by the World Bank during the driver behind the camps' materiality was 1960s and 1970s in other African countries with no great success. ${ }^{131}$ The government initially presented this policy as an emergency strategy to resettle all the returnees that reached the already overpopulated country 132 The involvement of UNHCR in country 2.18 Map of Rwanda showing the
location of refugee camps and heir demegraphics. $\odot$ Amor the spatiality of the probably inluenced camps in the country that perched on top
At the end of February 2020, there were 149,289 refugees in Rwanda living in six come from Eastern DRC and Burundi. Those who do not manage to go to Kigali, Congolese and one for Burundians. Most refugees-especially the Congolese speak heir supposed temporariness. ${ }^{134}$ camps. ${ }^{355}$ Most refugees in the country are housed in camps, five established for 
Kiziba
1996

Hub and Main Transpor
Kibuye ths walking down

inis

${ }_{2005}^{K}$

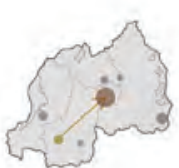

Mugombwa

2013

sins

$\frac{0 \quad 100 \quad 200 \quad 500 k m}{2.19}$

$$
\begin{gathered}
\text { Kibuye 4hs walking down } \\
\text { (4.5-5hs up) } \\
20 \mathrm{~km} \&>80 \mathrm{~m} \text { es elevation }
\end{gathered}
$$
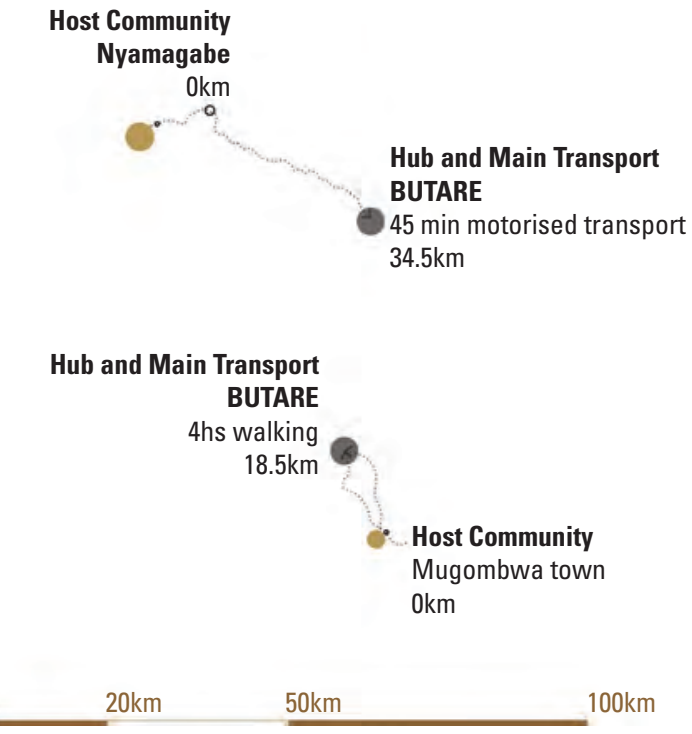

$50 \mathrm{~km}$ ${ }^{100 \mathrm{~km}}$

$34.5 \mathrm{~km}$
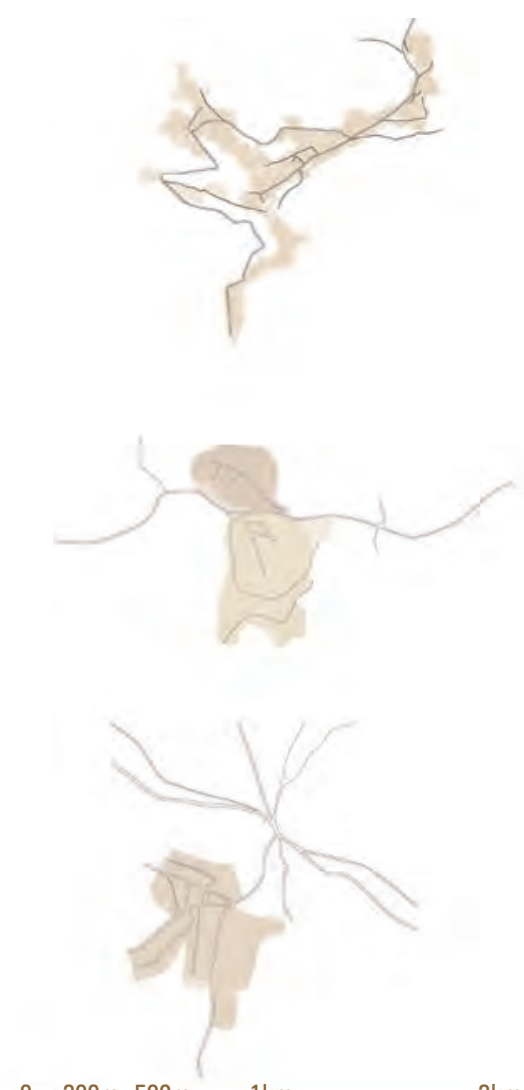

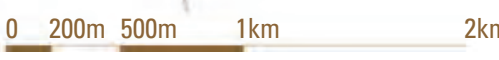

Kinyarwanda, the local language, and are Kiziba: along a ridge, isolated and negoethnically and historically tied to their host tiating expansion-The first significan country. Approximately 16 per cent of all registered influx of Eastern DRC refugees the refugees in the country are children into Rwanda was related to the First Congo younger than six years of age, ${ }^{136}$ and more War, which lasted from 1996 to $1997.7^{138}$ than 54 per cent of the camps' populations These refugees were initially encamped are younger than 17 years of age. These chil- in Umubano and Mudende refugee camps, dren spend most of their time out of school close to Rwanda's north-western border roaming the streets - school usually lasts town of Gisenyi. This location made the for four hours in the morning, and not all camps susceptible to border incursions. children attend Rwanda is closely tied to They were attacked sevder incursions. child ant and Burundi into its borders (fig. 2.19).137 in the Karongi District in December 1996

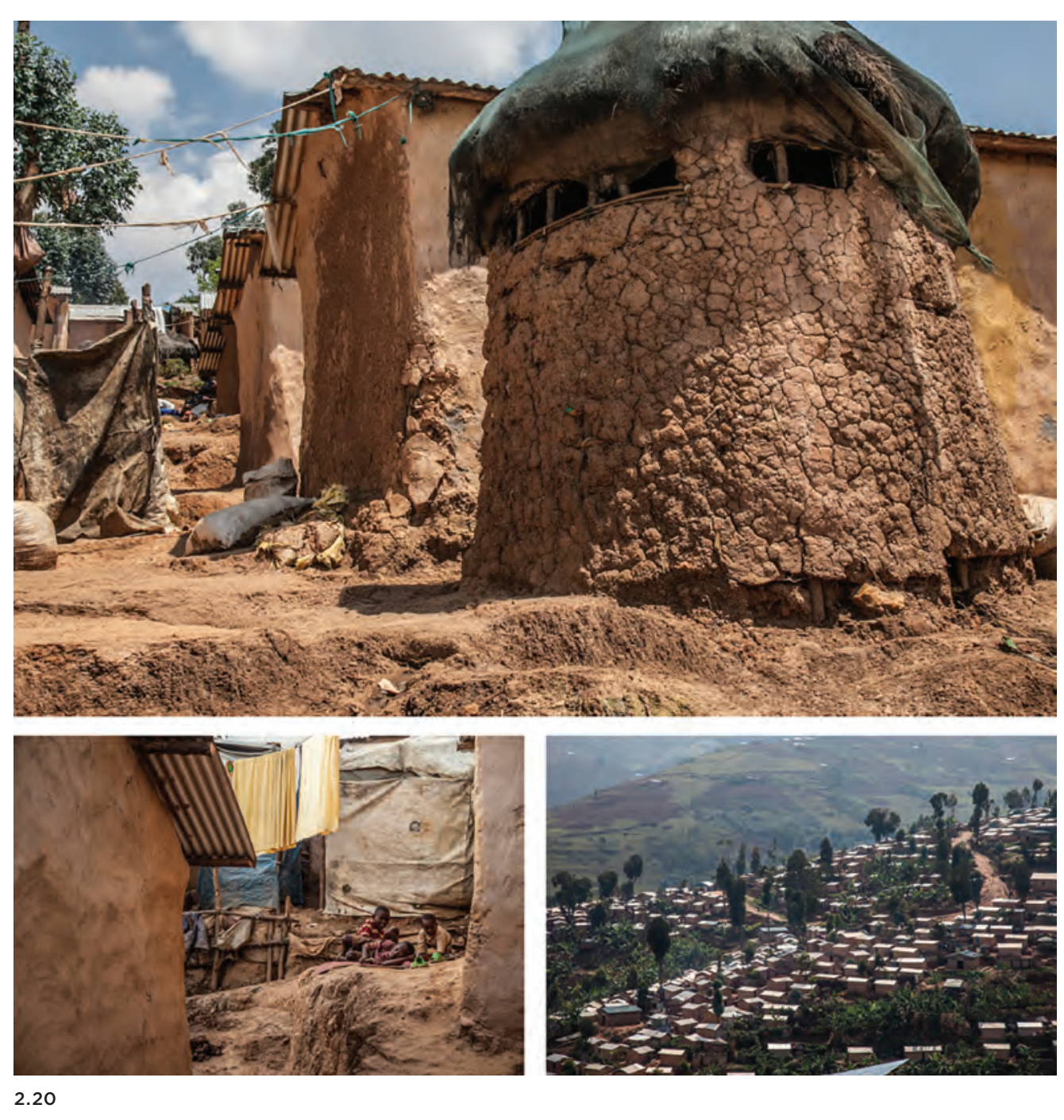

2.20 Kiziba refugee camp. Top:
kitchen constructions. Bottom le children playing between houses.
Bottom right: overview of the camp. S S

and Gihembe close to the central town Byumba in December 1997 (fig. 2.20).139 natural border with Eastern DRC. The main

metres below, on the shores of Lake Kivu, a of the camps in Rwanda. In February 2020, it hub, the health centre and the market. hosted 17,043 refugees in 28 hectares, with These facilities grow along the hillcrest, a higher density than Manila, the world's on a path that runs longitudinally southa higher density than Manila, the world's on a path that runs longitudinally southdensest city. It lies on a ridge, a two-hour wards through the camp. Kiziba's shelters
walk from Kibuye town, which sits 500 crowd the sides of this main path, and as the 

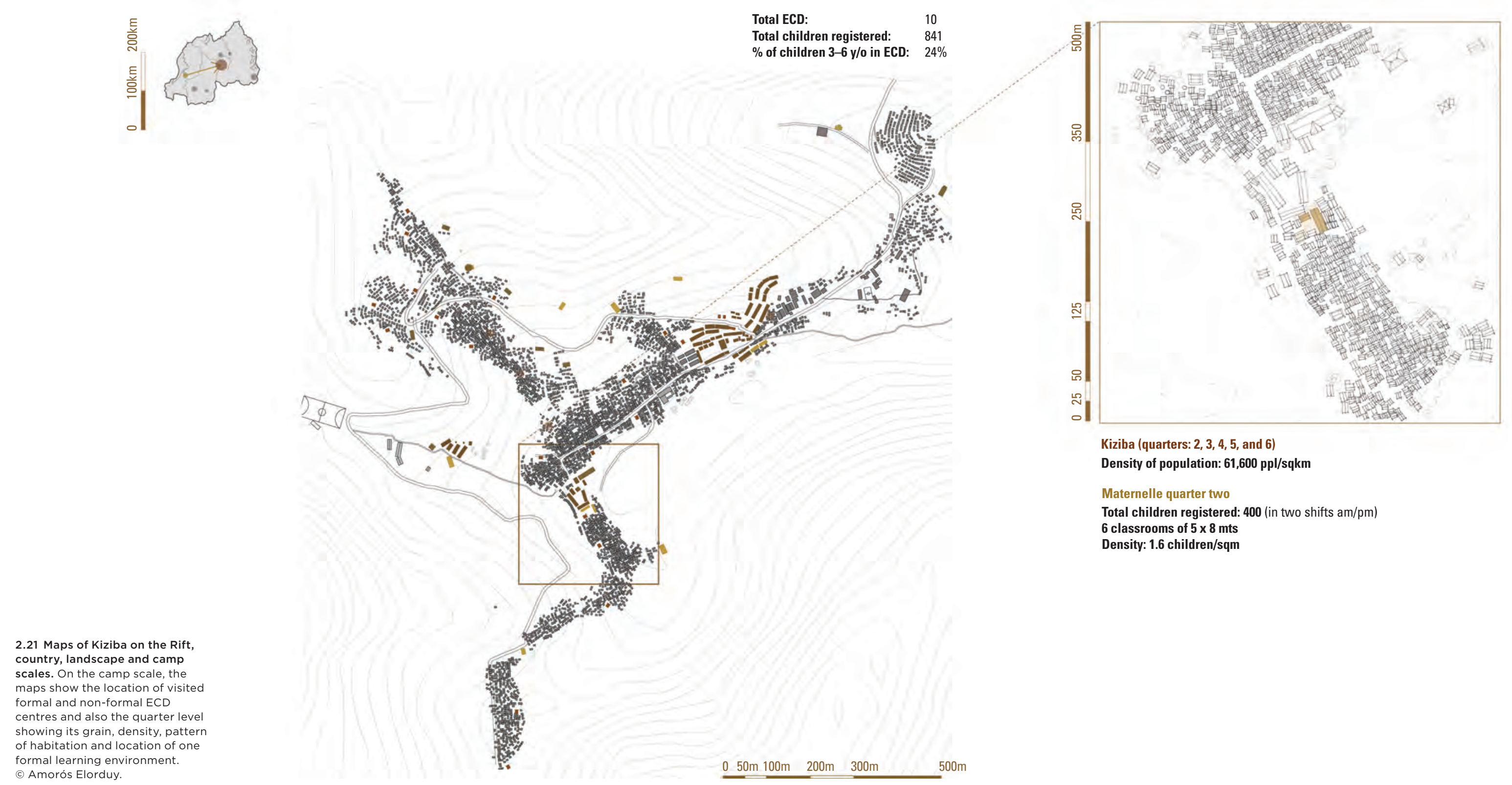

Hub and Main Transport
Kibuye ths walking dor

(4.5-5hs up)

$20 \mathrm{~km} \&>800 \mathrm{mts}$ elevation Lake Kivu
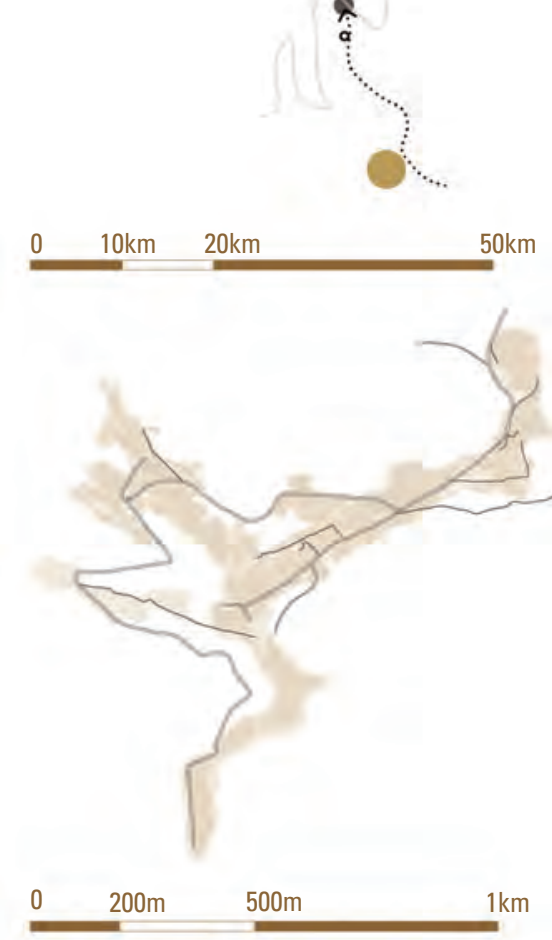

(-) Amorós Elorduy. 
land gets ever-steeper further downhill, the habitation density decreases slightly.

focused on direct cash exchanges, start-up For many years, Kiziba was one of the roughest and most marginalised of the Rwandan camps. Young people were abusing substances and causing trouble, mostly due to isolation and a lack of access to opportunities, such as further educabeginning of 2018, the reduction of funds from donor countries due to the European 'refugee crisis' and the Burundian refugee emergency affecting the region brought mportant policy and resource changes. A first-shock reduction of rations and a Alt to third-country resettement-due A alt to third-coduction of rations and a mainly to the regulations of the Urump for the popution and causating cours policies changed and aly with the newly signed Comprehensive With the newly signed Comprehensive Response Framework (CRRF). The Strategy for Economic Inclusion of The Strategy for Economic Inclusion of Refugees and the change from in-kind to cash hand-outs were two of the most signifcant alterations, ${ }^{143}$ followed by the adoption of the CRRF with its own national strategy in $2020 .{ }^{144} \mathrm{As}$ a result, the atmosphere the camp has improved significantly. More homes of Rwandan nationals are beginning to appear closer to the camp and on the two roads that lead to it. ${ }^{145}$ Camp managemen and the NGOs have built a new primary school and a higher education institution within the camp, and refugees are improving their homes to more permanent materials with the cash hand-outs and the recent access to start-up funding ${ }^{146}$ This change in policies has also triggered entrepreneurship with burgeoning small business and new NGO

$$
\text { raining and crowdfunding. }
$$

terms of formal and non-formal learning environments, in 2016, Kiziba had 10 non-formal ECD initiatives that were run in churches built by refugees and their direc local hosts. These non-formal ECD initiatives served 661 children. At the time, the camp also had two formal ECD centres, in quarters 2 and 4, which assisted 372 children In total, around 20 per cent of childre between three and five years of age were attending some ECD initiative In terms informal WASH facilities, Kiziba has the mainly this boo with in publicshow, ans 12 -squa no functioning public how and seven family members (fig. 221).

Kigeme: two hills, unplanned and planned created two new camps to host refugees fleeing Burundi's long civil war: Nyabihek and Kigeme. Most of these Burundian refugees repatriated between 2008 and 2009 This movement left Kigeme almost entirely dismantled, and it changed Nyabiheke's demographics to DR Congolese refugees Eastern DRC. ${ }^{148}$ In March 2012, a new guerrilla war brought thousands of new Eastern DR Congolese into Rwanda, ${ }_{149}^{149}$ repopulating and expanding Kigeme at the end of 2012 (fig. 2.22). ${ }^{150}$

The road that connects Butare ${ }^{151}$ with Thavu passing through the Nyungwe forest ${ }^{152}$ splits Kigeme across two hilltops. scenario all the camps that I analyse conjoined-In 2005, the governmen driven into the country by rebel clashes in

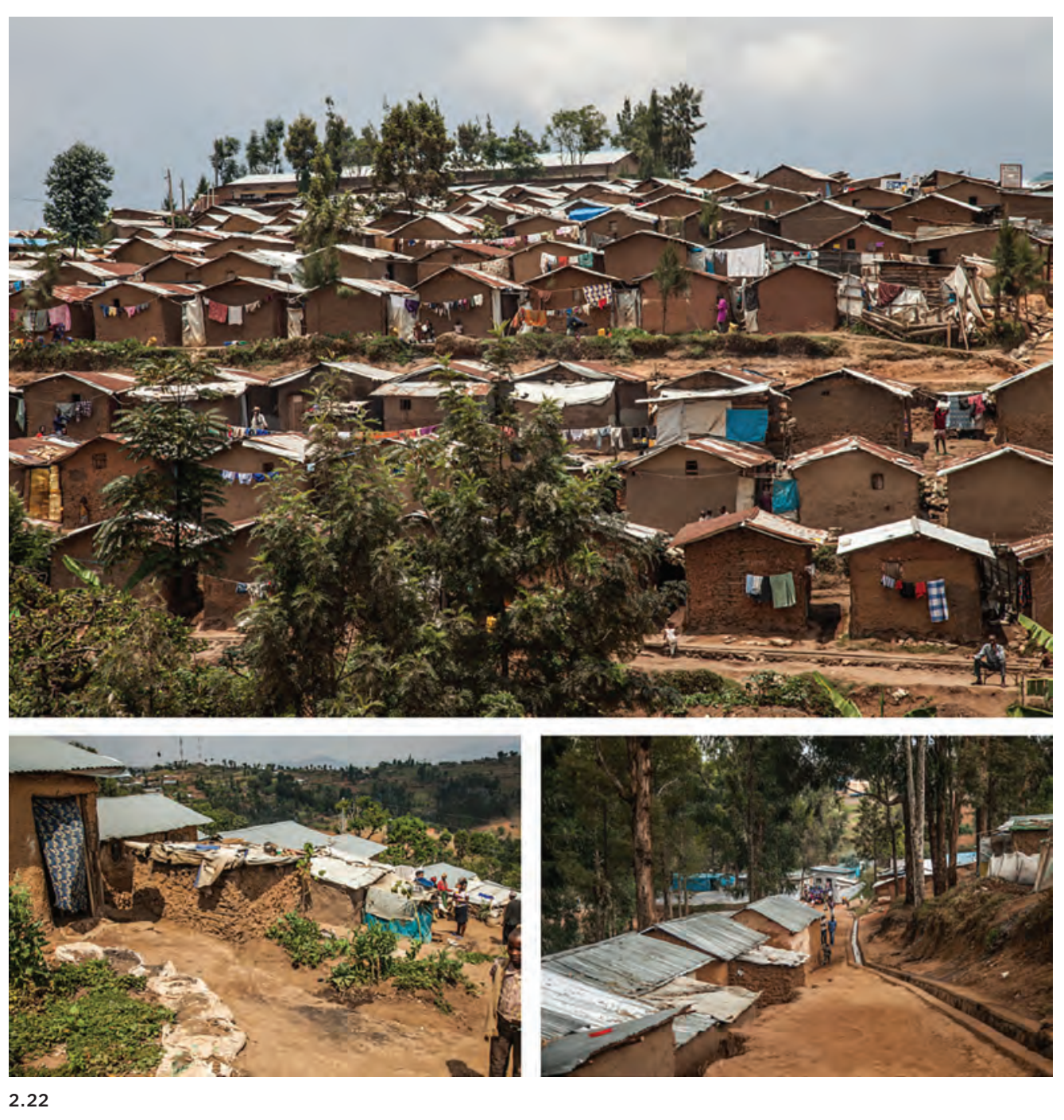

2.22 Kigeme refugee camp. path in Kigeme A. S
$\odot$ Amorós Elorduy. Top: general view of shelters at
Kigeme B. Bottom left: vegetable
apatch at Kigeme B. Bottom rigle patch at Kigeme B. Bottom right:
path in Kigeme A. September 2015
Kigeme A, on the northern hill, was the origino humanitarian planning. Between 2012 of Kigeme $B$ built on the southern hilltop. In February 2020 Kigeme hosted 19,845 fuces in eight 9 uarters spread over 34 hectares. The camp is close to the town nal camp established in 2005 with virtually and 2013, a UNHCR planner guided the plan of Nyamagabe, around a 30-minute walk, and to Kigeme's district hospital, about a five-minute walk. ${ }^{153}$ The camp's location contributes to a thriving black market, with currency flowing into the encamped familes and influencing the built environment. In terms of early learningenvironments, the camp has two formal ECD centres, one 
Kigeme
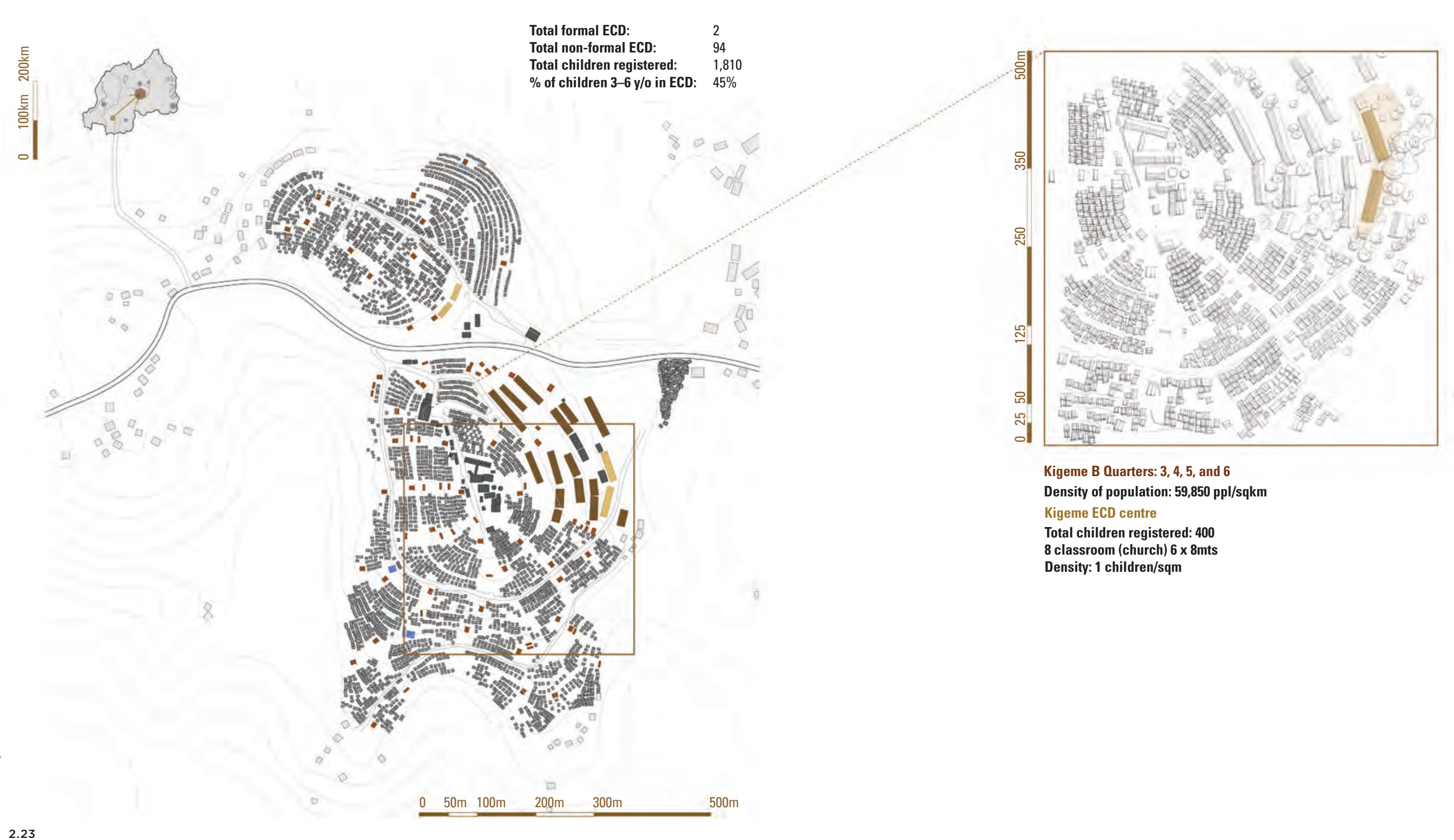

Host Community

...

Hub and Main Transport
BUTARE

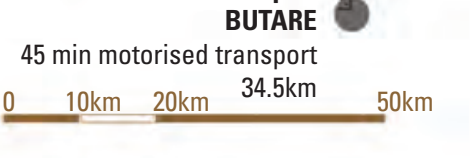

2.23 Maps and diagrams of
Kigeme on the Rift, country.

Kigeme on the Rift, country,
landscape and camp scales.

Onthe camp scale, the mas
show the location of visitited formal and non-formal ECD
centres and also the quarters

children registered: $\quad 1,810$

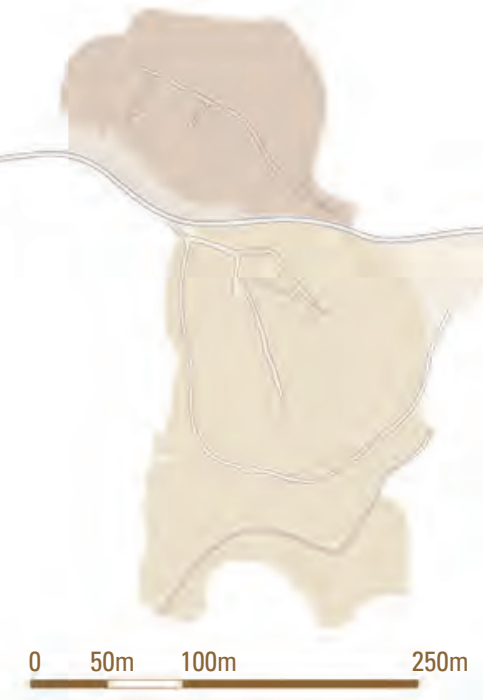


on each side of the road, serving 398 children. In addition, in 2016, Kigeme had 74 non-formal home-based ECD (HBECD) intiatives serving 1,222 children. The HBECD initiatives have taken place in Kigeme since 2012 and in Mugombwa since 2014. These initiatives are composed of groups of 10 mothers who each serve around 15 children aged with some material support from the NGOs. The ECD centres and the HBECD help around 38 per cent of children who are of ECD age. .54 $^{15}$

In terms of informal learning environments - specifically, WASH facilites - Kigeme on public latrines and phows Only certain have built their own latrines. In Kigeme B, WASH facilities are better built than in the unplanned and older Kigeme A, which has fewer latrines per people and in worse con ditions. In this camp, refugees extend their homes even up to second storeys in som homes even up to second storeys in som cases, and they have more furnishings than
those in the houses in Kiziba (fig. 2.23).155

Mugombwa: innovative planning yields similar outcomes-Eastern DR Congoles refugees kept entering Rwanda throughout the early 2010s. In October 2013, whe the Nkamira transit centre, located close to Gisenyi, was unable to sustain the large numbers of incoming DRC refugees, the UNHCR created Mugombwa refugee camp, located 18 kilometres south-east from Butare in the southern province (fig. 2.24). ${ }^{15}$

Mugombwa is the smallest and newest

of the DR Congolese camps in Rwanda. In

ebruary 2020, it hosted 10,420 refuge

in eight quarters. The planning strategy in
Mugombwa was to serve refugees and their direct local hosts simultaneously. This aim guided the choice of location and th camps master planning. For the first tim in Rwanda, a US architectural firm and higher education institution were involved in planning the settlement. ${ }^{1.7}$ Despite the new actors and goals, Mugombwa's morphology and materiality did not differ significantly from previous camp iterations. The most significant innovation in Mugombwa was having larger spaces between shelters move that a worker from the Cooperativ for Assistance and Relief Everywhere (CARE) Internation Rellef Ever

Regarding formal and non-formal learnts, Mugombwa is the only camp that Ihave included in this book and first camp in Rwanda, that planned for CDinceits in Rishment at a the camp's and was highy comTended by refuges and hy hicomworkers In rerms of non-format workers. In terms of non-formal learning HBECD in 1 , 2016, Mugombwa had 61 HBECD initiatives serving 739 children and one formal ECD centre serving 720 children In total, these initiatives served almost hal of the population of young children of ECD age. Mugombwa also shares its primary and secondary schools with the local people from Mugombwa town.

Regarding informal learning environments, particularly WASH facilities, the latrines and water access in Mugombwa like those in the other DR Congolese camps, are communal. However, the lower density of habitation and the better planningallows for more latrines per capita than in th more latrines per capita than in the older the UNHCR standard 20 people 215

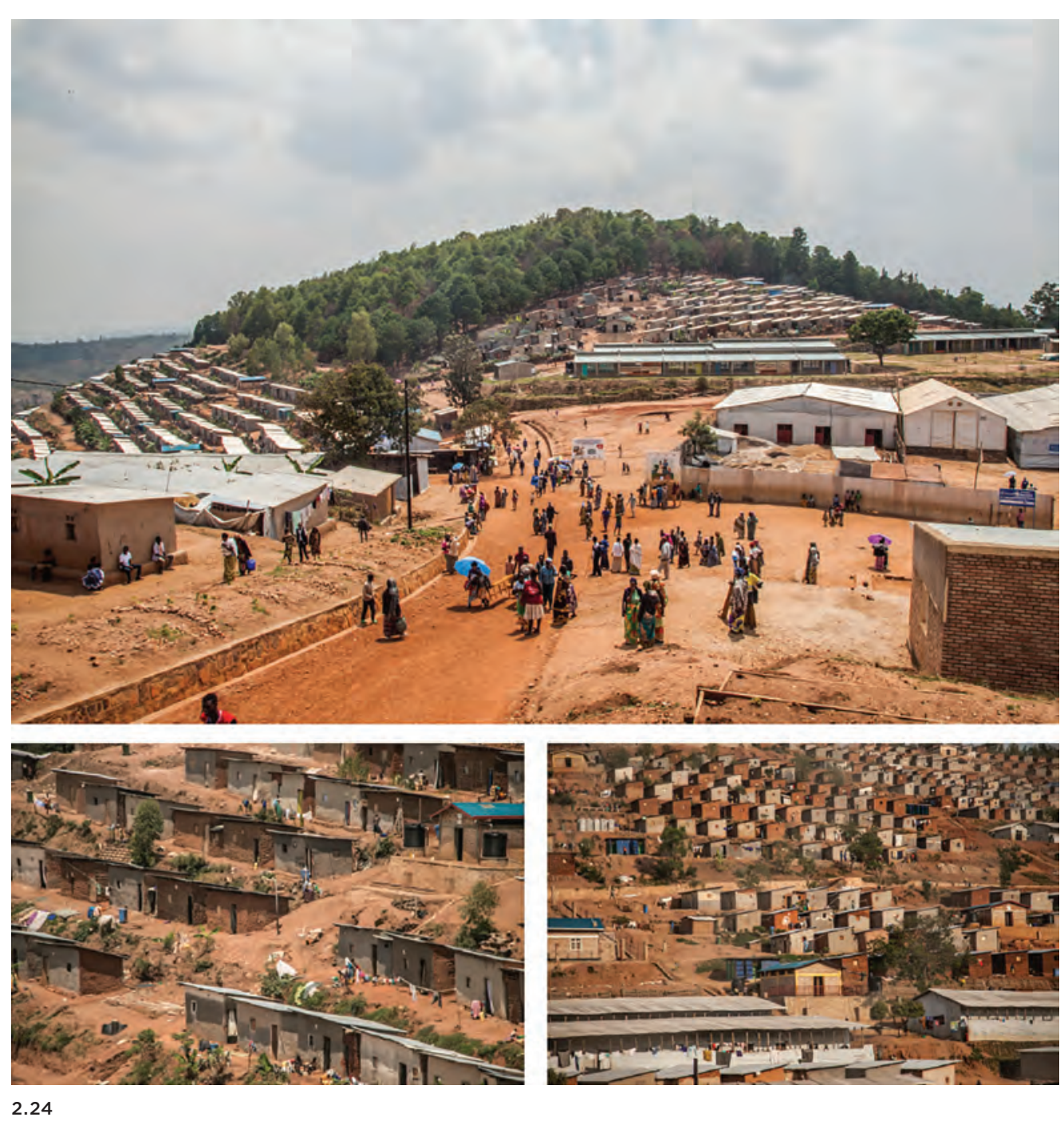

2.24 Mugombwa refugee camp.

The larger in-between spaces facilitated Some years on, homes have improved pavements, walls and drainage, and many hold commercial activities (fig. 2.25). the HBECD initiatives and the expansion of homes over time. Only four years after tered, had iron sheet roofs and kitchens.

interactive and static spatial characteristics-Dissecting and reassembling the physical characteristics of the seven camps described above, I have found patterns on the regional, landscape and camp scales

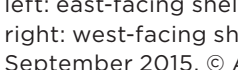
Septem
Elorduy. that might affect young children's learning. The three interactive and three static spatial characteristics, which I explain in 


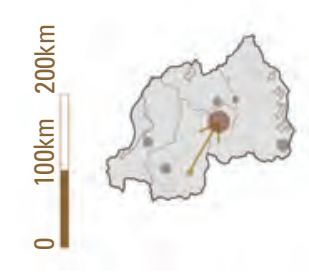

2.25 Maps and diagrams of
Mugombwa on the Rift, country,

landscape and camp scales.
the camp scale, the maps show

the location of visited formal and non-formal $E C D$ centres and also
the quarter level showing its grain. density, pattern of habitation and
location of one format tos

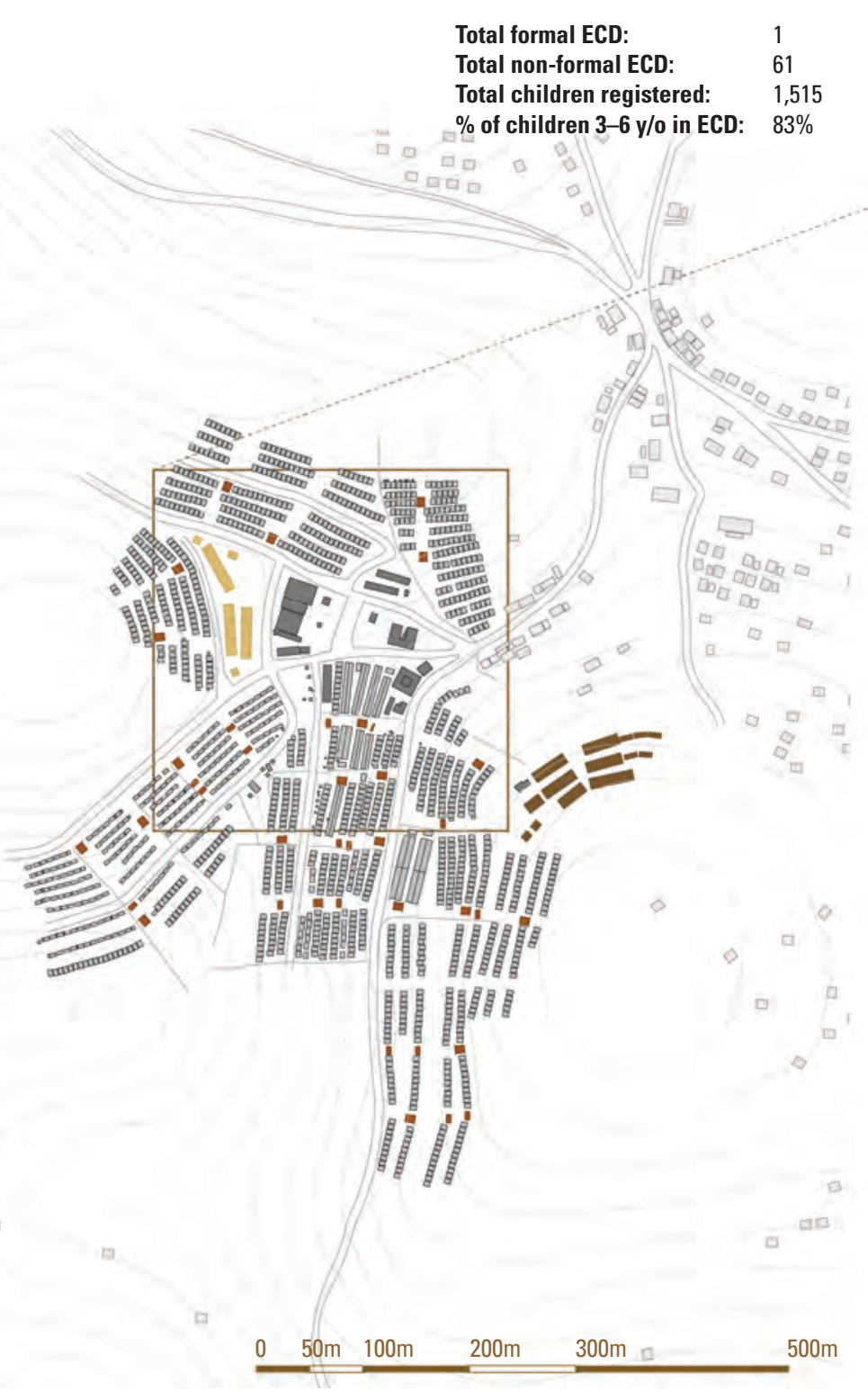

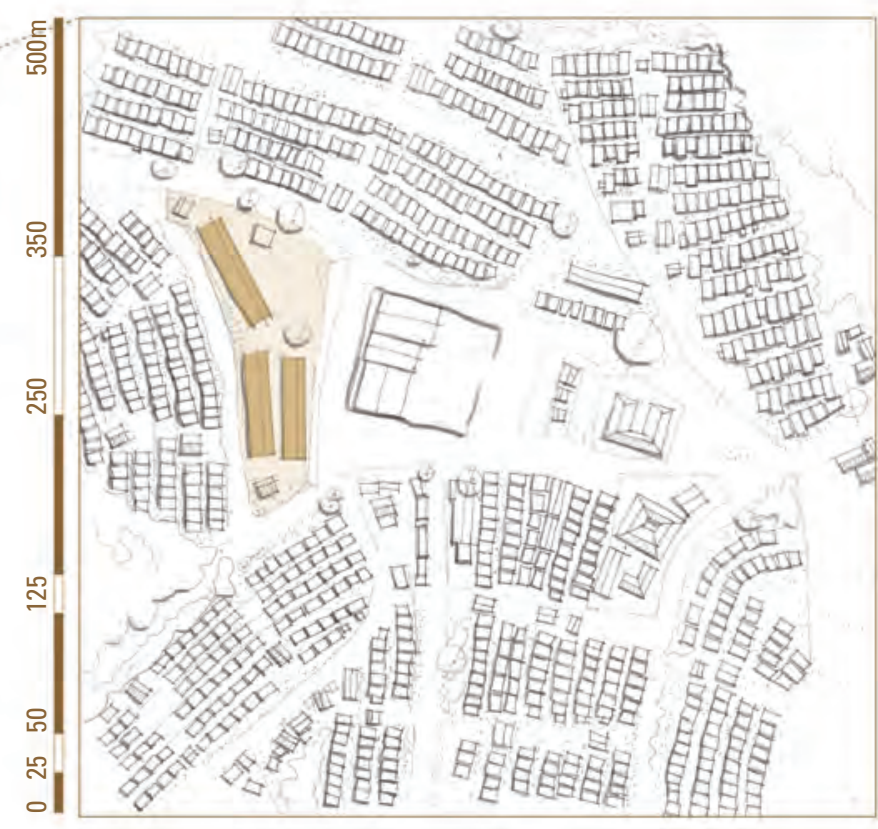

Hub and Main Transport

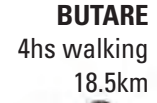

Host Communir Mugombwa town

$0 \quad 10 \mathrm{~km} \quad 20 \mathrm{~km}$

Mugombwa (all quarters)
Density of population: $38066 \mathrm{ppl} / \mathrm{sqkm}$

Total children registered: 600 (in two shifts am/pm)

12 classrooms of $6 \times 8 \mathrm{mts}$
Density: 0.52 children/sqm

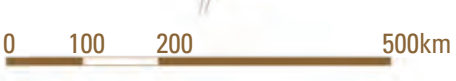



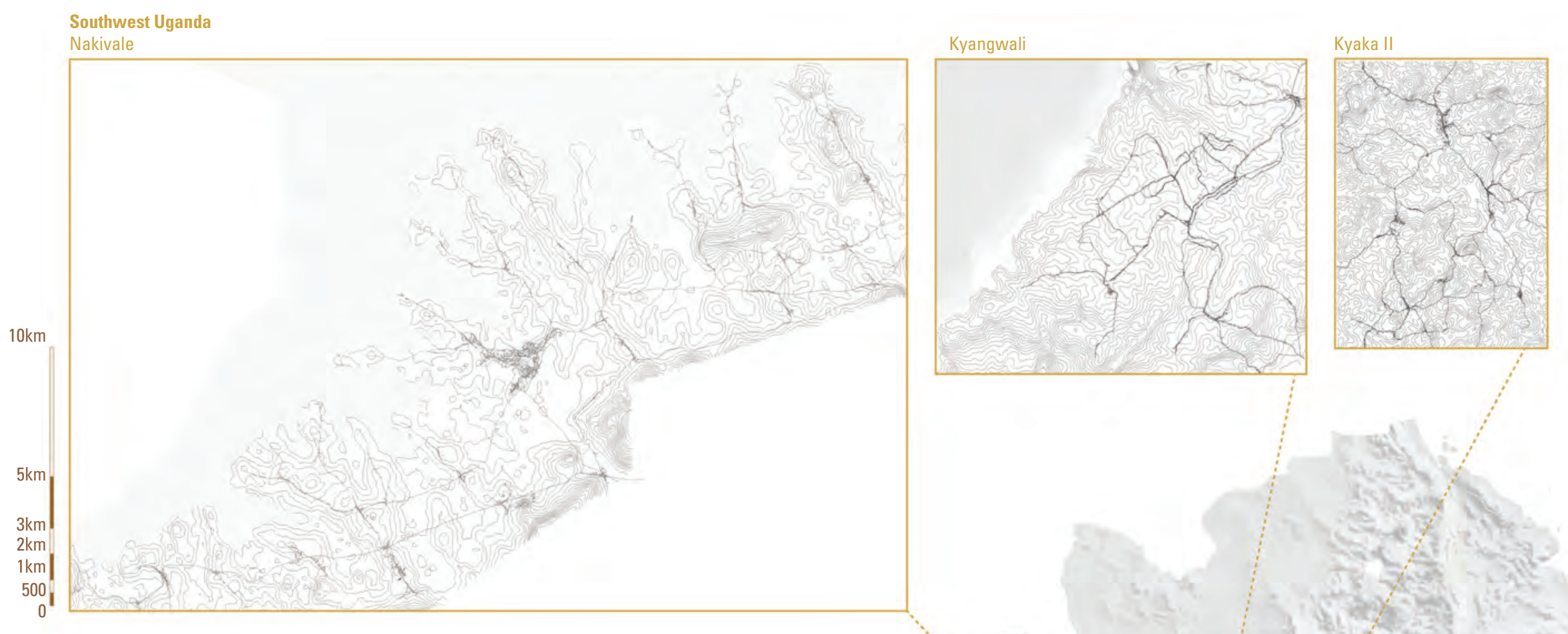

Northwest Kenya

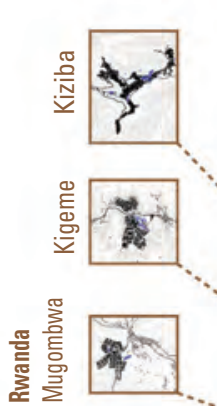

2.26 Location within East Africa,
detailed maps and dates of establishment of my seven case studies:
Nakivale (est. 1958) Kyangwali Nakivale
(est. 1964) and Kyaka II ( (est. 1983)

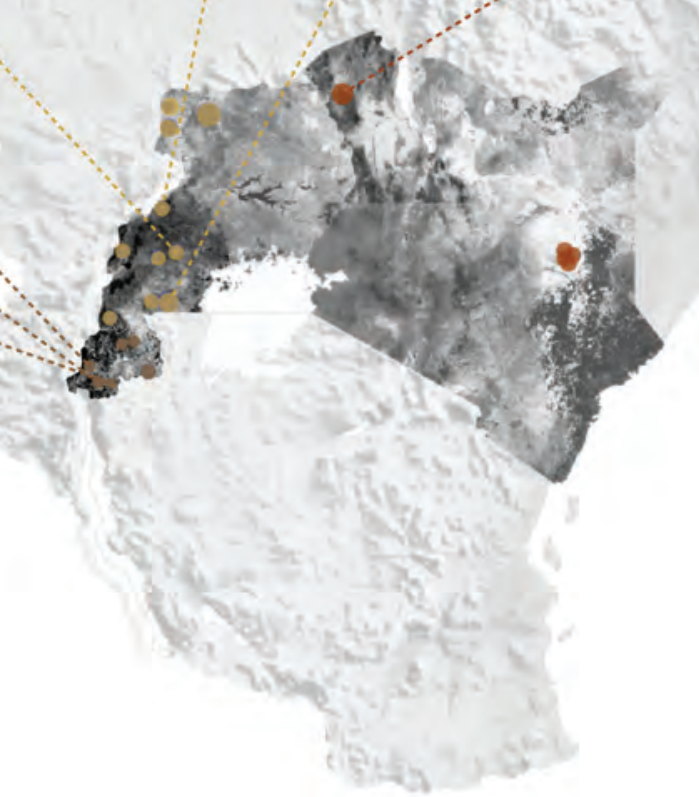



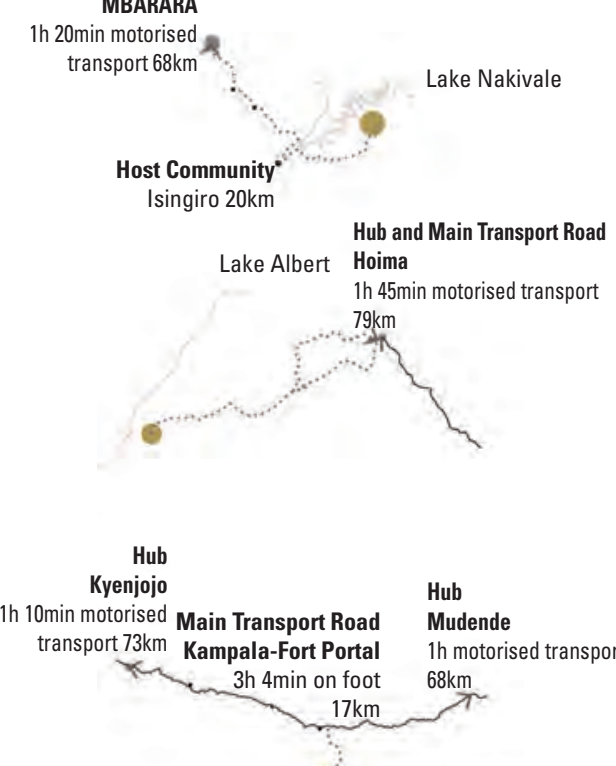

transport 68km Host Community"
Isingiro 20km Hoima<smiles>C1C2CC3C1C23</smiles><smiles>C1CCCC1</smiles>

(1)

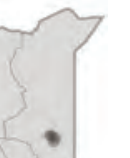

(ivise

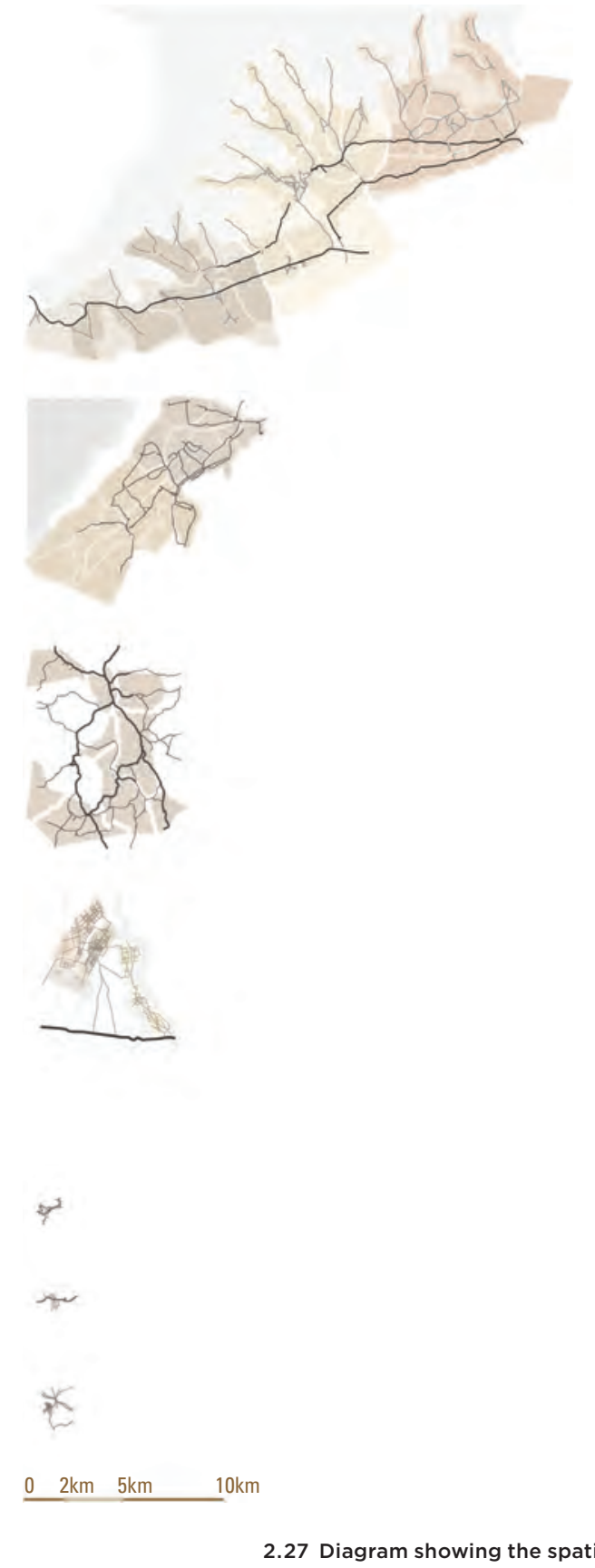

2.27 Diagram showing the spatial
relationships on the country, landKyangwali, kyaka II, Kakuma, Kiziba, Kigeme and Mugombw the following pages, are shared by all following are shared by all seven camps and could help unveil their evolution and map their influence on camps 列 help humanitarians, academics and host development of other camps in Easter Africa and better plan alternatives in order to improve young children's learning (fig. 2.26).

Interactive spatial characteristics

Growing heterogeneity and complexityLong-term camps are heterogeneous Long-ter assem taneously. In these camps, refugees child-rearing practices are multiple, so are the host coures are mile and policies thas govern policies that govern them, and the climates (fig. 2.27). Their sizes and population densities are many and varied. For example, in ties are many and varied. For example, in Rwanda, the Congolese camps are the size of a small town, have high population densities and are placed on the steep slopes of volcanic hills, sometimes reaching the 40 per cent slope. ${ }^{159}$ In contrast, the Southwest Ugandan camps occupy relatively large pieces of undulated and loosely planned land. They are conglomerates of fine-grain residential and agricultural uses sparsely populated, with an average 1.2-acre plot per family, ${ }_{100}^{16}$ while Kakuma in Kenya is designed like a grid on a dry plain with a coarse grain of segregated uses, ethnicities and classes. Heterogeneity is ubiquitous, even ithin the same country For example in the case of Uganda, the old, multi-ethnic and increasingly dry Nakivale has good soil for grazing cattle, but it is not suitable for agriculture and the construction of latrines and wells. In contrast, Kyangwali and Kyaka II benefit from a hilly topography with fertile soil and abundant rain-ideal conditions for agriculture and enough clay and grass to favour sturdy constructions.

Heterogeneity affects young children's learning both negatively and positively. A clear illustration of its adverse effects is evident in Tarach ECD centre in Kakuma in in the schedule, curricula that three decades can reve ili. rigins and training that their caregivers. The children who ares. The chifdren who attend Tarach represent f the of global standards fail to account for climatic, material, spatial, cultural and language variation. ${ }^{161}$ In Tarach, the primary language spoken is Arabic, which means that the Congolese children who attend the centre feel marginalised ${ }^{162}$ The standards do not contemplate child-friendly designs ${ }^{163}$ either, with one example of this being the windows, which are small and placed high up. The global standards and the short-term consultants that usually build centres such as Tarach ECD often seem unable to pre-empt certain variables. In Tarach, the unstable sandy soil and the years of use of building candy soil and the years of use of a building cause of broken toilets, cracked walls and 
Nakivale

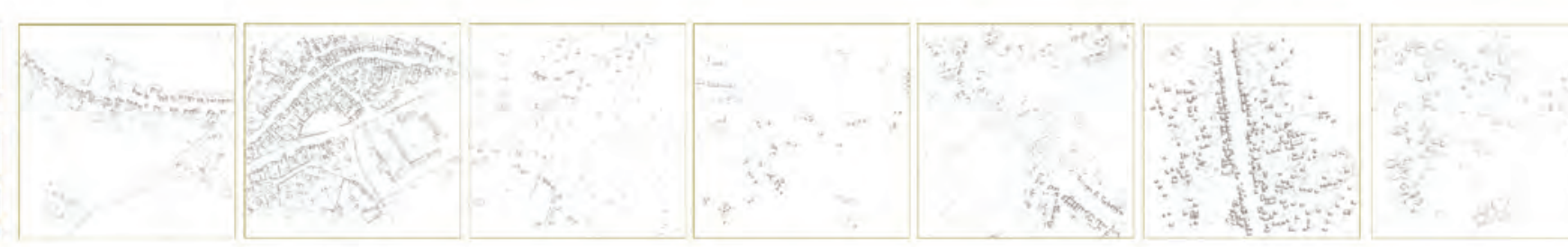

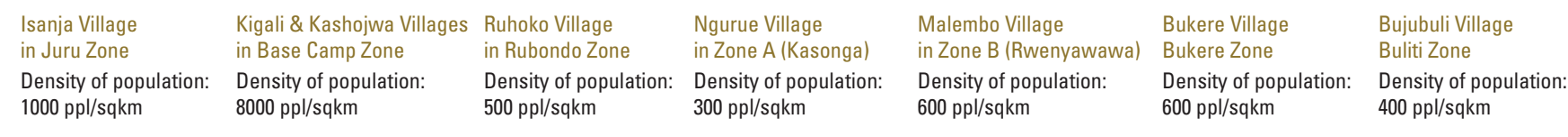

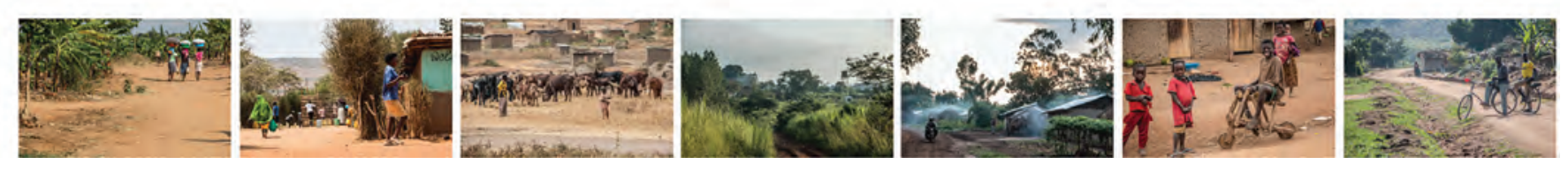

2.28 Infographic showing the
variability within the camp scal across my seven case studies (the
diverse villages and gaurters). diverse villages and quarters).
Specificilly it shows: three villages three zones (Ruhoko village in of Kigali and Kashoiwa vilteges in Base Camp zone, and Isanja
in in Juru zone); two villages at
Kyangwali, Ngurue in zone A an
Malembo in zone B two villages Malembo in zone B; two villages
Kyaka II, Bukere trading centre Kyaka II, Bukere trading centre
Bukere zone and Bujubulili in Bun zone; three zones at Kakuma,
per phase; the encounter of four per phase: the encounter of tour
quarters in Kiziba, quarters $2,4,5$ ters in Kigeme, uarters $3,4,5$
6 ; and the centre of $M$ agomb except quarters 7 and 8 . 9 Amorós rusted playground equipment. The example that feed it, the more difficult it is for the Karach applies to most ECD centres in stuc Kakuma. Afect of complexity for ECD is cosmopoli- straightforward solutions - their wsual tanism. Notably, in larger camps such as modus operandi. Kim Dovey ${ }^{165}$ and James Kakuma and Nakivale, the richness of Scott ${ }^{166}$ explain in their reflections of toppeople's origins, language and cultures down outlooks on social structures the enhance social interactions, openness and downsides of this type of 'seeing like a state'. children's learning through experience ${ }^{164}$ They focus on matters of invisibility, legThe intricacy of the long-term camps ibility and interpretation. Applied to the East ffects their legibility, with repercussions African refugee camps, complexity and the on their funding and maname on their funding and management. The state-like standpoint of the humanitarian

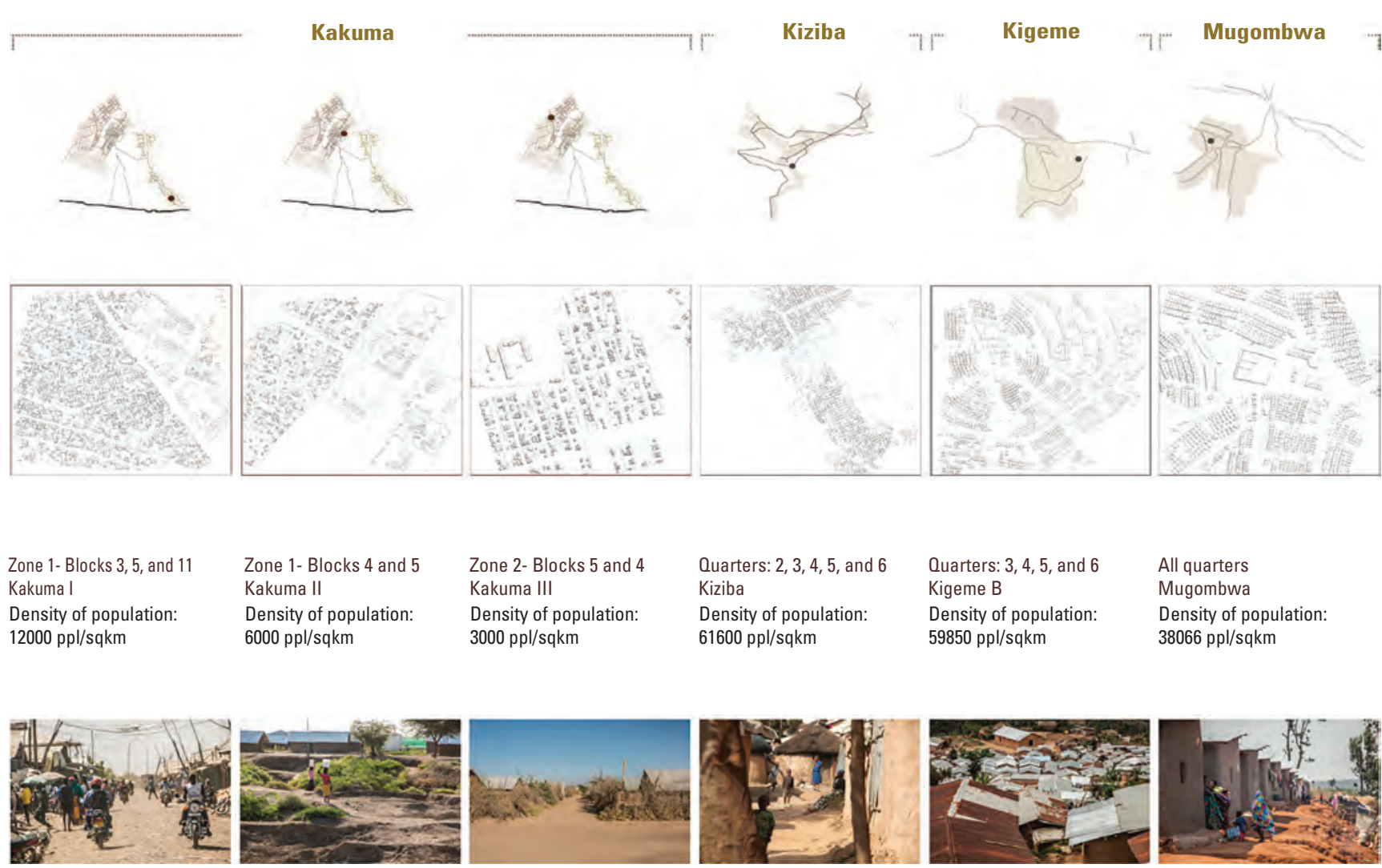

obligate the largely under-sourced and The appearance of formal ECD centres in understaffed managers to create general- the early 2010s contributed to the camps ised and simplified assumptions to make legibility. The formal learning avenues the camps more 'legible' to the outsiders and add up to the usually more invisible nonmore easy to run. This top-down approach formal and informal efforts that refugees and the lack of contextualised information and direct local hosts had been running for leads to generalising views, and it discour- years or decades. Formal centres literally ages donors, governments and academics put ECD on maps, reports, funding appeals, trying to understand the camps. NGO programming and national regulaIn an effort to count refugees, achieve tions by creating a building specifically Education for All goals 167 and improve the and only for one thing: young children's lives of children living in encampment, the learning. humanitarian efforts try to counterpoint Hence, formal ECD centres benefit the the complexity of the long-term camps. ECD effort and will continue to do so, as long as 
standardisation does not take away the richness of the preexisting non-formal systems. This coexistence can be seen in the hom based ECD and the formal ECD systems in Kigeme and Mugombwa explained in the chapter 'Refugee-led spatial interventions

Illegibility and being off the rada of the media and the international community have both positive and negative effects on young children's learning. The the lack of funds, resulting in broke the lack of funds, resulting in broke playgrounds, buildings and toilets that and hand-outs; and reduced resettlement programmes to third countries. However, reduced resources and management control trigger a higher number of spatial interventions led by refugees and direct interventions led by refugees and direct local hosts, including non-formal learning facilities. The Southwest Uganda camps are a good example, as their relaxed humanitarian control promotes the crea-
tion of numerous and varied non-formal learning initiatives. These improve the learning scenario for young children being more culturally relevant, nearb and for smaller groups. ${ }^{169}$

Currently, many of the non-form interventions go unaccounted for in humanitarian discourses of refugee education, contributing to the widespread assumption of refugees solely as victims, Dryden-Peterson points out this lack of Dryen-Peterson points out, this lack of going on since the 1960s. Mapping - and hence making legible and visible to the outsider - these non-formal interventions might improve life in the camps in the lon term. It will also contribute to providing more accurate image of refugees as people with some needs that can also lead an co-lead their own assistance and well-being. Moreover, acknowledging all the existing initiatives might allow better placemen of funds and efforts and enhance furthe collaborations between the humanitarian system and the refugees.

Co-functioning/interconnectedness-The long-term refugee camps located along the last African Rift work as co-depend structures $170 \mathrm{For}$. comps through a social looking at hese camps through a social-economic lens, to a re existing village or town despite relative isolation (fig 228). (tative isolation (fig. 2.28).

Camps can create benefits for their local counterparts, which usually undergo urba and economic growth, and their inhabit ants profit from the services in the camps. ${ }^{12}$ For example, in Kigeme, Mugombwa an the Southwest Ugandan settlements, camp services usually serve both refugees an their equally isolated and marginalised direct local hosts, ${ }^{173}$ bridging differences and strengthening their relationships. Hence, their interactions tend to be symbiotic, mutually beneficial and equitable, ${ }^{174}$ opening up options for the young refugees Healthy relationships between refugees and direct local hosts can affect young children's learning positively. They can increase children's access to essential goods and social services, provide economic opportunities services, provide economic opportunities social recognition in the host country.
Yet, camps can also create conflic between inhabitants and their neighbours. This tends to arise due to land ownership (explained in the following section) and unequal aid distribution, when the refugees reap benefits from humanitarian fund and services while their hosts, who are also marginalised and impoverished, do not. ${ }^{176}$ For example, in the case of the formal ECD centres in Kyaka II, refugees received scholarships but Ugandan nationals did not causing tension between both groups. In Kakuma, it is even worse, as ECD centres Kake only for refugees. Conflict rentres are ony for refuld children's free play options and increase their insecurity, affecting their learning through experience ${ }^{1 / 1}$ and their access to
goods and services. And services.

An example of the interconnectedness of the camps with a vast network of actors is the correlation between camp life and that in the countries of orign. Both Peteet and Sanyal ${ }^{1 / 9}$ observed connection to origin in the Middle Eastern camps. This relationship is evident in East Africa on the refugee-led constructions - both homes and commercial facilities - in the patterns of school attendance and religious temples.

Interconnectedness can be observed between different groups of refugees living in the same camp, enhancing children's openness to other cultures and strengthening their socio-emotional and language development, such as in Kakuma and Nakivale. However, these multiple origin can also create violent encounters. In such cases, children are forbidden to play freely on the streets. They can suffer abuse, kidnapping and violence in the common areas and on the camps' ou

areas and on the camps' outskirts, with repercussions on their physical and psychological development and preventing further learning. A clear example of this is Kakuma's streets and common areas. Kakuma can be insecure due partly to the poor relationship with neighbouring Turkana ${ }^{180}$ and partly to conflicts between the different refugees within the camp. In Kakuma, unlike in the other camps that I describe in this book, there is a night curfew to control insecurity.

$$
\text { Bonds exist even between the host and }
$$

untry. For example, the same Foply different policies or different refugee origins. That is the case ef Burundian refuges and DRC refuges in Rwanda, who receive very different in conficts andingesin the region muter or time On occasios, these conflicts implica the host coun the with repercussions for the roun, wis in repan cause in the refugees. This intricacy can cause insecurity for the easily locatcors I far as 2,000 kilometres as 作 Kakma and Nakivale - to find safety away co

Co-dependency and interconnectedness can also be observed between the camps morphologies and the landscape within which they reside. For example, in Rwanda, the Congolese camps are small clusters of dwellings located on hilltops that replicate the imidugudu-hill184 relationship present in other village formations in the country. These camps work like a hizome ${ }^{185}$ Once they reach a maximum surface area and population size, a new one sprouts up on another hilltop. These 
camps' relatively small size benefits young Most refugees in the East African Rift tend children's access to formal ECD facilities, to seek asylum within their neighbouring since their location is usually less than a countries, which are usually relatively poor, kilometre from any given household.

In contrast, the camps in Southwest Uganda follow a fractal growth along the ridges and valleys that criss-cross the topography. This growth behaviour involves an increase in the distance to ties. Still, these sparsely populated camps and their porosity are positive for young children, as they enhance co-dependent relationships between direct local hosts and refuges and among refuges. The a rease the num

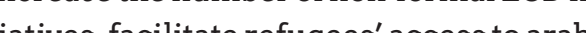
Tanes, facillate refug to red toduce overcrow oil stains on flat, arid and mostly valueless land, their growth eventually interrupted by dry riverbeds that seasonally flash flood by dry riverbeds that seasonally flash flood, destroying everything in their path. ${ }^{180}$ The long distances hamper young children's access to services and ECD centres. Th wide-open and unprotected streets - especially in its most recent phases - make parents wary, constraining children to play within their home compounds.

Interconnectedness can also be observed on larger spatial (regional) and temporal (years) scales, for example looking at the refugees' choice of fleeing routes and destinations. Regional political affairs, a family's economy and personal motivations, and the potential opportunities in aiven camp influence these selections. 'Refuges' choice of route and final location might affect young children's learning. 1 and have confly ging negative implications. On 列 languages and cultural upbringings at the formal ECD centres tend to be more similar between refugees, host countries' caregiver and their national ECD regulations over a short period they seem static Only the daily and aybe the seasonalchangesmigh become apparent However, whenobserving them over several years or decades, their the ent One example of this is the substantial population and land cover fluctuations population and land cover fuctuations that many camps suffer, especially those close to the borders such as Kyangwali, Nakivale and Kakuma. For example, Kyaka Il almost emptied in 1994. It then trebled its population $-5,000$ to 17,000 inhabitants - between 2005 and 2007, and then quadrupled it $-32,656$ to 123,086 inhabitants - from early 2018 to early 2020.

These fluctuations in population prevent proper planning and funding, obstructing formal refugee education and aid hand-outs, creating instability in the camps and triggering issues such as epidemics. Formal ECD centres at areas sensitive to fluctuations tend to be transitional tented structures, even after months or years of the camp's establishment. The areas of Mukunyu in Kyangwali, Ruhoko in Nakivale and phos II and IV in Kahoko in had these temporary ECD centres in 2016.
Ever becoming-Analysing refugee camps
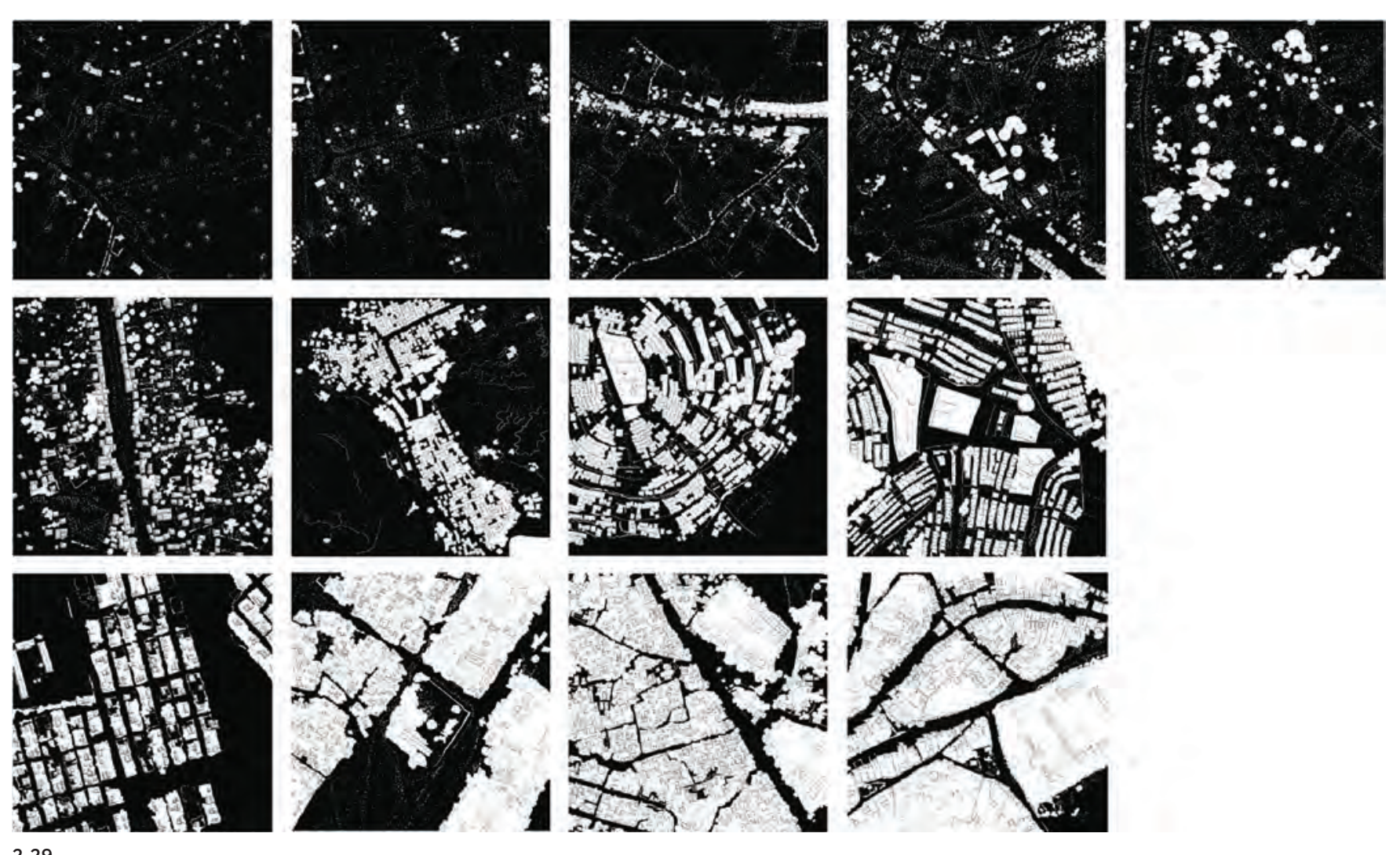

The unpredictability of these areas pushes the resource-scarce education cluster to

within them and over time depending on many human and non-human actors, espethe agency of refugees and direct cheap tented facilities. The hampered plan- local hosts. The resource-scarce and less ning in these 'buffer' zones is also reflected controlled camps tend to be more mallein the scarcity of water taps, WASH facilities able, as the refugees and their local hosts 2.29 Diagram of the open areas and the poor condition of the roads. These scantily planned facilities affect young children's learning and physical developmen mostly negatively, obstructing their access to proper content-based education and their learning through experience. . $^{188}$

Another example of the camps' have more agency to change the camps' spaces on the building scale. This malleability allows refugees to create and modify the spaces where children learn and spend most of their time: the homes, streets, open areas, community schools and religious temples In Kiziba, as humanitarKiziba, Kigeme, Mugombwa, Base Camp (Nakivale). $\odot$ Amorós heir material malian rou temples. In Kiziba, as humanitarthoritarian control and the 
international attention, refugees negotiate with their direct local hosts and create religious temples, mills and family homes on the outskirts of the camps, modifying the camps' boundaries. Both refugees and their direct local hosts use these temples These negotiated interventions benefit young children with direct content-based . the direct local hosts.

\section{Static characteristics}

Porosity-Porosity is present on all spatia scales. The nation states' borders located along the East African Rift are very porous, allowing for the relatively easy movement of goods and people, including refugees and rebels (fig. 2.29). The camps' borders are also porous; no fences or hard boundaries
exist in any of the camps at which I have exist in any of the camps at which I have worked. These two levels of porosity, in addition to the camps' relative closeness to national borders, increase potential incursions and attacks. Raids cause insecurity, with the abduction of both childre and adults. The camps at Kiziba, Kyangwa and Kakuma all have records of such situations. ${ }^{189}$ Insecurity might cause physical and psychological trauma to children, and even when not directly affected, parents might prevent them from playing on the cio- emotional, physical and intellectua socio

However, porosity at landscape an camp levels can be positive for young chil-

dren's learning. The highly porous and sparsely populated camps in Southwes Uganda allow children to create shortcuts through the landscape and play freely in th bushes and fields. In Rwanda, the unfenced homes and intricate streets facilitate the occupation of interstices for games and for community-organised learning activities, enhancing children's curiosity and opportunities for free play.

The case of Kakuma is particularly interesting in that it presents different levels of porosity, depending on the viewer reminder of the importance of alisation and the need for more contextusituated bits of nno more and richer situig may apper quite hem tay appear quite hermetic to a stranger in cial to the local young children who cre everybody in the neighbourhood. This duplicity strengthens young children's sense of community, safety and free-play options. In contrast, Kakuma phases II and III gain in visual porosity for strangers due to their open gridded roads, which become impermeable for young children due to their long distances and other risks. Parents living in these areas prevent children from venturing outside their home compounds. In these phases, the double-faced porosity has the opposite effects on young children's learning compared to Kakuma's initial phase..$^{190}$ In general, a high porosity at the camp and building levels coupled with high population densities enhance children's curiosity and learning-byexperience options. It may also encourage community activities and interactiourage neig around them. poor soil-lt seems that most of the conflicts that push refugees to flee their homes and many of the disputes within and around the camps are related to land, its scarcity and related resources. ${ }^{19}$ Tensions arise from the moment when governments and humanitarian agencies try to find land to establish a camp, raising issues of citizen rights and representation. Governmental power and geopolitics play a role. Particularly in East Africa, colonisation and lack of representation of certain groups - minorities and marginalised ethnic groups - affe recognition of rights. ${ }^{192}$

arise during the life of camp. Growing and fluctuating populions and unmarked boundaries tend to trigger these types of conflicts. For exmple in the 1980 s, due to land shortages and political turmoilin Uganda me Bahima pastoralists - moved to the surBaning par the the camp's refugees repatriated to Rwanda and the surrounding settlers moved withi the camp's unmarked limits to graze their herds or settle. Later that same year, when new Rwandan refugees arrived, friction and conflict took place. A similar situatio is recurrent in Kyangwali and Kyaka II. ${ }^{19}$ These types of disputes, which vary from camp to camp, significantly affect young children's mobility and security, preventing play and hence obstructing their learning by experience. ${ }^{194}$

Another dimension related to land, which I have found mostly on the camp and building scales, is the poor soil and the lack of land that hamper the building of proper constructions, especially
In fact, WASH is an endemic problem in ll the camps that I present in this book. For example, the sandy, unstable soil in Nakivale and Kakuma makes digging pits for the latrines difficult, especially for child-led families. In Nakivale, to circumvent this problem, refugees have resorted to building latrines on top of empty termite mounds due to their sturdiness. However, this practice prevents access for many young children and people with disabilities. In the Rwandan cases, the lack of land makes it unviable to have private WASH facilities - both latrines and showers - which consequently are public, scarce, overcrowded, dirty, unste chet child-friendly. Hence, most children ches on portunities for abuse and accidents Finally it is extremu accichts. many aid plans assums mest-case scen is the area is available and fertile, such as in Kyangwali and Kyaka II. Yet, even in such cases, not all refugees are agriculturalists, and even when they are, they tend to lack the tools, seeds and markets to place their produce. In most cases, the land is not fertile - such as in Nakivale and Kakuma - or big enough - such as in the Rwandan cases. I have hardly seen any refugees who can make agricultural profits or and lent to them.

As a consequence of the lack of agricultural profits and scant aid hand-outs, a large number of young children suffer from malnutrition ${ }^{197}$ Undernourishment affects in and physical development and consequently their learningabilites, 
social interactions and socio-emotional development. ${ }^{19}$

Finally, the extreme lack of land-Kizib in 2019 reached a density of around 65,000 people per square kilometre ${ }^{199}$ - combined with decades-long displacement makes overcrowding at the camp, the home and the ECD initiatives a real problem for young children's learning. Congestion affects children negatively, especially in homes ments noisy and lacking privacy and enough ments noisy and lacking privacy and enough
space. These home environments impact the physical integrity and the cognitive development of the young children and affect their lifelong learning. ${ }^{200}$

Isolation and proximity to the borderIsolation on the country and landscape scales increases the cost of goods and information affecting the refugees' access to food,
building materials and jobs for income genration. ${ }^{201}$ Lack of construction materials is reflected in inadequate housing, WASH and even educational facilities, affectin young children's learning. The distances to
major hubs also affect access to secondary and higher education and to proper health care. ${ }^{20}$

Moreover, being close to borders increases insecurity, the chances of raids in the camps and the likelihood of child abductions. This insecurity jeopardises refugee rity under the Convention on the Rights of the Child. ${ }^{203}$ According to the UNHCR's an OAU's guidelines, refugee camps should not be located close to a border ${ }^{204}$ which has loosely translated as a minimum of 50 hilometres from the border. ${ }^{205}$ Nevertheless, a standardised set measurement does not ensure a safe distance. Security from border incursions depends on geographical barriers, the porosity of the country's borders and other variables particular to each environment. The politics involved in land use, host nation security concerns an other aspects relating to the site selection of a camp become obstacles to achieving a secure site far enough away from the border. 206

Distance from the border is a clear example of how global standards, which are widespread in humanitarian practice, should be highly contingent on context, whether it be geographic, spatial, cultural, wher socio-economic or temporal. A post-strucsudy of contextualised approach to the is needed Kiziba Nakivale Kyangwali Kakum. Kiziba, Nakivale, Kyangwaliand Kakuma are all located close to a border Governments and the UNHCR have established even newer camps closer than the 50-kilometre standard, such as Rwanda's Mahama - establishedin 2015-and Kenya's Kalobeyei - established in 2016.20

Ever-changing, proto-urban, learning assemblages-The detailed maps of th long-term camps and their geographical and physical features provide an interesting and diverse picture of these settlements. Understanding the camps' interactive and static spatial characteristics - growing heterogeneity and complexity, co-functioning/interconnectedness, ever becoming porosity, land scarcity and poor soils, and isolation and proximity to thoor soils, an their effects on liveliby to the border - and their effects on livelihoods and especially camps grow/change. This information could make future refugee assistance strategies more adaptable and able to improv in ways that are beneficial to the people living there.

As I have explained, children extract some positive learnings from the long-term camps' built environments. They learn about openness from the cosmopolitan Nakivale and Kakuma. They develop their curiosity in the labyrinthic, dense and porous Rwandan camps and the old centres of Nakivale (Base Camp), Kakuma (phase I) Kyaka II and Kyangwali (trading centres). The increased presence of formal and The increased presere or formal and non-forma amongst paci dren, of attaining a for al educaton and of inproving her livingstion nutrition, health and cognitive stimulatio from an early age.

However, currently, the long-term camps are in general poor learning environments for young children. Geopolitics, international and national policies, geog raphy, socio-economics and the camps interactive and static characteristics are generally hampering young children's direct content-based learning and learning through experience. The current scenario creates mostly dangerous and harmfu environments for young children. The multi-scalar land scarcity and porosity, the ever-evolving conflicts and the locations of the camps create insecure environments that reduce children's access to health, education and essential goods, hindering their healthy physical and psychological development Moreover the humanitariansyste one-size-fits-all policies and approaches to learning are unsuitable for the varied . Language and cultural mishaps see many encamped children marginalised in the formal ECD centres. Finally, the lack of data on these complex and ambiguous long-term camps makes for an unappealing target to funders. Hence, ECD initiatives in the most complex and least researched camps are in extreme lack unds.

Camps do not usually get dismaned but rather evolve. A percentage of encamped refugees will come and go, as 列 borders will increasingly blur, triggered by sophisticated negotiations between the strained humanitarian system, the host government, the local authorities, the surrounding communities and the refugees. As the population grows in and around the ably become more problematic.

Gradually the camps will become more urban. If that is the envisioned future, humanitarian assistance should perhaps become more like acupuncture and less like major surgery to address specific problems. Moreover, projects and programmes should be accompanied with ongoing advocacy efforts to bring refugee rights to the same level as those for other humans.

For example, as Rwanda signed the CRRF, ${ }^{208}$ which emphasises the social and economic inclusion of refugees in national systems, the country is pushing refugees not only to become self-reliant but to eventually leave the camps ${ }^{209}$ This change from what was a highly paternalistic approach to a self-help approach is due not only to the 
CRRF but also to the decrease in humanitarian funding, the acknowledgment of the long-term camp problematic and the protracted conflict in DRC, as well as the tight
ethnic and cultural ties between Rwanda and its refugees. Could there be a possibility of shifting these camps into actual villages? As self-building is already taking place, what
would be required to achieve other types of autonomy? Could these camps also become attractive to locals and, with time, rather han a refugee settlement become just another umudugudu?

Further questions arise. Are the camps six spatial characteristics present in other long-term camps and newer settlements? If so, could we envision the routes that these newly built camps such as Mahama, Kalobeyei and Bidi-bidi ${ }^{210}$ will take? Would having this knowledge help in defining real alternatives to camps that improve young children's lifelong learning?

There is value in studying long-ter camps as a phenomenon in themselves, $d$ ferent from the generalising 'refugee cam Detailed spatial information through the lens of time has the potential to show evolutionary paths for other camps, shedding light on the impact of international visib ity and funding into the lives of encampe refugees and their direct local hosts, an elucidating some of the macro and micro politics involved in forced migration in different geographical areas. Humanitarians, governments, international institutions, academics and researchers, citizens and neighbours need to see long-term refuge caighbs in a holistic light and un refuge he complexity of interactions between cheme settlements. If long-term camps are considered real huma complex, they will be treated with the respect, dignity and care - in their design and maintenance - that any human-made settlement where millions of lives develop deserves. They will be treated as a place of human-not just humanitarian-relevance.

Nentury Africa from the Twelfth to the Sixteenth

2. The United Nations General Assembly

'Convention relating to the status of refugees'

Niane, Africa from the Twelfth to the Sixteenth

Century; Ogot, Africa from the Sixteenth to the
Eighteenth Century.
Slaughter and Crisp, 'New issues in refugee

Harrell-Bond, Imposing Aid; Harrell-Bond,

作

Harrell-Bond, 2-3.

Scott, Seeing Like a State; Harrell-Bond,

Daley, 'Refugees and underdevelopment in

Africa', 205; Kaiser, 'Structural adjustment

and the fragile nation', 1996, 227-37; Kayizzi-
Mugerwa and Levin, 'Adjustment and poverty', 1994.

Harrell-Bond, 'UN
good for children?

good for children?

ention Relating to the Status of

Refugees, signed in 1951 alongside the creation
of the UNHCR, was to coordinate action and ease refugee assistance allocation, initially just
for European refugees. The subseguent 1967 Protocol helped to define the term 'refuge', which became globally accepted, including in Africa, even before the signature in 1969 of the Refugee Problems in Africa. The UNHCR first became involved in the continent in July 1957, when refugee camps started to dot its geograas they substituted other pre-existing means of refugee assistance. The United Nations General Assembly, 'Convention relating to the status of refugees'; Loescher,' International recogni- governing the specific aspects of refugee independence of the UNHCR under Auguiste Lindt'; Kibreab, African Refugees; Stein and Clark, 'Refugee integration

ner, The United Nation

12. Chapter 12 ('Site selection, planning and shelter') of the UNHCR Handbook for Emergencies states: 'Avoid high population
density in settlements and in shelters Avoid very large emergency settlements; refugee camps should normally be considered as a last resort: Involve refugees in all phases of settle
ment and shelter planning and construction UNHCR, Handbook for Emergencies, 134, In the four editions of the Handbook for Emergencies, the first one, published in 1982, questions the effectiveness of ncamping refugees and is wary
of imposing such a settlement pattern. of imposing such a settlement pattern: '... as a the extent possible on local resources, materials and methods, and should, for example, avoid
regimented refugee camps. Solutions that can be readily implemented with existing resources and simple technologies should be sought, 3. Harrell-Bond, 'Camps: Litergature reviev', 1998 .
14. Harrell-Bond, Imposing Aid; Feldman et al., 'The failure of self-reliance', 2013 ,

The works of Lacey Gale and Wim Van Damme present three good illustrations of this shift in assistance strategies. Gale, "The invisible refugee camp', 2008; Van Damme, 'Do refugees and exclusion', 1995.

16. UNHCR, 'Population statistics'; Crawford,

17. Cosgrave and Mosel, '10 Things to know.

Gottwald 'Burden sharing and refug' 2010 ion'; Kreibaum, 'Their suffering, our burden? 2016; Rutinwa, 'Beyond durable solutions', 19

Century.
At the time, this signified 15 per cent of Malawi's population, which was one of the 'Incorporation and exclusion' 1995, 165. Zetter, Van Damme, 'Do refugees belong in camps?'

$1995,361$.
21. Marie and Shimo, 'Zambia initiative', 2002. Bakewell,' 'Repatriation and self-settled refugees in Zambia', 2000.
23. Turner, 'The barriers of innocence'' Landau, . . Malkki, 'The rooting of peoples', 1992; Holzer, The Concerned Women of Buduburam. crossroads of globalization', 477 .

27. Thanks to the Internet and new technologies, it
is easier to access information about the camps is easier to access information about the can imagery and open-source repositories.

28. Ever since the publication of the Alternatives to Camps policy in 2014 , many new 'camps' have
been built. In East Africa, two key examples Mahama in Rwanda and Kalobeyei in Northwest Kenya

29. The camps of Dadaab and, to a certain degree, Kakuma in Northwest Kenya attract a good deal
of attention from mainstream publications and academia alike. At the same time, the Rwandan or the Southwest Ugandan settlements are studied only sporadically, with the majority of relev
works developed around two decades ago 30. In 2016, Nakivale and Kakuma surpassed 100,000 inhabitants. Kyaka II, the small-
est camp in Uganda, housed around 40,000 est camp in Uganda, housed around 40,000
people. The biggest of the Congolese camps in Rwanda - Kigeme - had around 20,000 people. The densities of the Congolese camps in Rwanda were around $30,000-60,000$ people per
square kilometre, while the Southwest Ugandan camps had around $300-600$ peeple per square
kilometre. For more information, see: UNHCR, UNHCR Rwanda monthly population statis Y of Disaster
GCR and Office Management and Refugees', UNHCR and Office
of the Prime Minister Uganda, Uganda Refugee

Response Portal.
1. Lynch, 'The form of cities', 1954; Lynch and

Banerjee, Growing Up in Cities.
Montessori, The Absorbent Mind: Dew

'Experience and education', 1986

long-term refugee campsin the East African Riff.

ECD centres activities run for four hours a day. In most case studies, the activities were held

midday.
35. Amoros Elorduy, 'Learning in and through the

long-term refugee camps in the East African Rift.
36. Ward and Fyson Streetwork: The Ward and Fyson, Streetwork: The Exploding
School; Hart et al., Cities for Children; Nallari,
'The meaning, experience, and value of 
"common space"'; Karsten and Van Vliet,

37. Rasmussen,' 'Place for children', 2004; Chawla and Malon, 'N
dren's eyes'. place identity in the che chelopment of Early childhood development'; Bronfenbrenner, 'Contexts of child rearing: Problems and prospects; Gottfried and Gottfried, Home envchildren of middle-socioeconomic-status famiand house

'ós Elorduy, 'Learning in and through the

long-term refugee camps?

. Hallden, 'Children's views of family'; Chawla

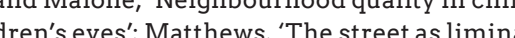

space', Zeiher, 'Shaping daily life in urban environments'; Ward, 'The child in the city', 1978 11. Ward; Ward and Fys

Exploding School.
4ynch. The Image of the

Lynch, The Image of the City
Baneriee, Growing Up in Citits

3. Smithson and Smithson, Ordinariness and
4.

Light, $45-6$.
4. In the 1960 s.

In the $1960 \mathrm{~s}$, Coombs acknowledged the imporformal schooling facilities. He introduced the notions of non-formal and informal lifelong poverty'; Coombs, World Educationa Crisis 5. David and Weinstein, Spaces for Children; Christensen and O'Brien, Children in the City.
4. The British Uganda Protectorate became inde46. The British Uganda Protectorate became inde-
pendent on 9 Occtober 1962 . The UNHCR began
its operations in the country in the early 1960 s.
The firstaccounts of fefugees in the country The first accounts of refugees in the country
date from the Second World Wat when it date from the Second World War when it hosted
displaced Europeans until 1945. In 1955 , Uganda started hosting Sudanese refugees and then those from neighbouring countries struggling for independence, including: Kenyans during 1959 Rwandan revolution, DR Congolese in the aftermath of Lumumba's assassination in 1961 and a number of Ethiopians and Somalis durin
the war for the Ogaden. In that time, Ugand's internal violence, triggered by Milton Obote and Idi Amin, created forced migration out of the country to Sudan, Kenya, Tanzania and further
afield. Marrui Africa Since 1935, 110; Jo Naggaga and Hovil, 'The phenomenon of forced migration in Uganda', 1:3
47. The refugee camps' managers in Uganda are refugee-elected representatives. The RWC is the equivalent of the local government system ther the most part, the refugees feel politicall $y$ disempowered. Omata and Kaplan, 'Refugee thelihoods in Kampala', 6 ; Refugee Law Project,

Act, constrained refugees' freedoms and huma rights. In 2006, the Ugandan government pub-
lished the Refugees Act 2006 and repealed the Cap 62 of the former Control of Alien Refuge Act. Government of Uganda, 'Uganda: Control of Alien Refugees Act'; 'Office of the Prime

50. UNHCR, Handbook for Emergencies. The emergency prepare
$16,17,19,136$ and 138 .

51. The overall number of encamped refugees has increased since data began to be recorded in the
early 1960 s. Bagenda, Naggaga and Smith, 'Land problems in Nakivale settlement'. the surface'.
Nationalities include those from Sudan, South Sudan, Burundi, Rwanda, Ethiopia, Eritrea, (including the district of Ituri in the Oriental province and the provinces of North and South Kivu). UNHCR Uganda, 'Statistical summ mary

54. The UNHCR lacks consistency in naming and tracking refugee camps and refugee-hosting regions in Uganda, making mapping and
keeping track of numbers difficult The oly refugee settlement in Western Uganda is Kyriandongo in the Kyriandongo District. The refugee settlements in Southwest Uganda, all
of which were established more tUan decades ago, are Nakivale and Orunchinge (Isingiro District), Kyaka II (Kyegegwa District), Rwamwanja (Kamwenge District) and Kyangwal (Hoima District). Sources: UNHCR and Office
of the Prime Minister Uganda, Uganda Refugee Response Portal. '
UNHCR Uganda, Statistical summary refugees UNHCR Uganda, 'Statistical su
and asylum seekers in Uganda'. hosted in settlements in Southwest and
Western Uganda in 2016. UNHCR Uganda
17. By 1963 , the Rwandan revolution, also known of the 420,000 Tutsi who fled Rwand 130,000 then Belgian Congo, Burundi, Tanganyika and Gganda. During that period, 78,000 refugees led into Uganda (contested figure). Prunier, The

58. The Ankole sub-region used to be the Ankole Kingdom before Milton Obote abolished Uganda's kingdoms in 1967. The Banyankole are
the region's main population Their language the Runyankole, is very similar to Kinyarwand the language of the Banyarwanda. The Bairu are sedentary agriculturalists, and the Bahin Banyankole. Bagenda, Naggaga and Smith 'Land problems in Nakivale settlement'; Niane, Africa from the Twelfth to the Sixteenth Centur

created in 1960 . However, Nakivale was esta lished in 1958 and 'officially recognized as a refugee settlement in 1960 through the Uganda Gazette General Notice No. 19', UNHCR Uganda,
'Nakivale fact sheet'. There are also conflicting sources on where the settlement is placed. It is located in the Isingiro District - not in the Uganda's Western region and in to be -in region'. Winter, 'Uganda - Creating a refugee
crisis', 1983; Bagenda, Naggaga and Smith, 'Land problems in Nakivale settlement: settle them away from borders is widely reco nised. It is a security issue for both the direct local hosts and the refugees due to abduction
and rebel incursions. UNHCR, Handbook for Emergencies. The emergency pre and response section, 16, 17, 19, 136 and 138.

1. Especially in the 1980 s and 1990 s, many refu列 'Uganda - Creating a refugee crisis', 1983,

62. Bagenda, Naggaga and Smith, 'Land problems in
Nakivale settlement'

Despite several contradictory sources about the surface area of Nakivale camp, spatial analysis confirms that in 2016 , it was 185 square kilome-
tres as stated by the UNHCR. UNHCR Uganda 'Nakivale fact sheet'

64. My calculations and those of UNHCR Ugand show that the average population per village Camp's villages were close tons. The Base Camp's villages were close to the 1,300 popu-
lation mark and Rubondo's around the 800 population mark. From the 79 villages that form
Nakivale, 63 were populated solely by refugees, clustered into 27 groups as follows. In the Juru zone, the villages were: Kahirimbi, Ngarama, Juru, Kakoma, Kankiniji, lsanja and Soaza. In th Kiyaza, Nyarugugu, Sangano, Base Camp. Kigali, Kashojwa, Kiretwa, Kabazana, Kasasa and Misiera. In the Rubondo zone, the villages Mirambira, Kyeibare, Kisura, Rwoma and
Rubondo. Data collected from the UNHCR's Nakivale base map.

5. Education was included in the humanitarian education cluster. The cluster began to incorporate ECD in 2009. UNHCR, 'Global strategy for 'The creation and developmentent of the global IASC education cluster'!

6. Data extracted from Windle Trust data se August 2016.

UNHCR Uganda 'Statistical summary refuge and asylum seekers in Uganda!

For example, the average distance children
must walk to access a formm/non-formal ECD centre in Nakivale's Base Camp is 500 metres, whereas in Rubondo, it is 1,200 metres.

69. The six camps established between 1964 and
1966 include Kyangwali and Kyaka I The dates of establishment of the Southwest Ugandan camps built before the 2000 s are unclear, since
the available sources contradict each other, and the available sources contradict each other, for some of them, including Kyangwali and Kyaka III I consider that Kyaka II was created in 1983 and Kyangwall in 1964 and was officiallly 'The coming of Rwandan refugees'. Matsiko, 'Museveni shocked at Kyangwali eviction'; Sein and Clark, Refugee integration'; UNHC Uganda, 'Kyaka II fact sheet'

70. Prunier, The Rwanda Crisis, 1959-1994. Leopold II of Belgium largely destroyed the fabrics of the diverse Congo basin societies
creating huge internal displacements. The country's independence, in addition to geopolitical and economic interests, unleashed conflict, particularly after the assassination of Zaire's
first Prime Minister, Patrice Lumumba, on 13 February 1961 and the subsequent government
under Mobutu Sese Seko. Between 1960 and 
1965, approximately 100,000 people were killed, displacement orand were forced into interna Central African Republic, Uganda, Rwanda, Sudan 'Forced migration in the Great Lakes and Horn

This establishment date is contest cited dates are 1964 and 1966 . I use 1964 because the second wave of refugee camp establishme ffter the Rwanda Revolution and the assassin tion of Patrice Lumumba in DRC

73. UNHCR and Office of the Prime Minister
Uganda Uganda Refugee Response Portal.

74. The Rwandan Batutsi genocide took place between 7 April and mid-July 1994. The end of the genocide happened when the Rwanda Patriotic former Batutsi refugees in Uganda, took pow over the country. When that occurred, hundreds of thousands of Bahutu fled the country Eastern DRC, Uganda, Burundiand Tanzania. Th tries returned to Rwanda. The RPFlater formed political party, which still rules the country today. Stearns, Dancing in the Glory of Mon
Prunier. The Rwanda Crisis, 1959-1994

5. Stearns, Dancing in the Glory of Monsters

Prunier, The Rwanda Crisis, 1959-1994.

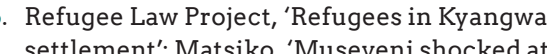

Kyangwali eviction:

77. In 2016-7, this camp hosted 36,713 refugees

This fast trebling in population is related to

well as to renovated conflicts and an Ebola out

break in Eastern DRC throughout 2019.

18. Over time, Kyangwali became a location for
vulnerable South Sudanese as the long dista with the South Sudanese border provided more protection for those refugees. Currently, the majority of the refugees in Kyangwali are D Burundians, Ethiopians, Kenyans, Rwandans, Somalis and Sudanese. Refugee Law Project,

Refugees in Kyangwali settlement',

. 'In 2013, more than 60,000 so-called encroacharmarked for refugees, were forcibly evicted from the Kyangwali refugee settlement in cennewartivals' Gerdner, 'Beneath the Conge',

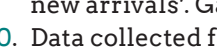
and contrasted with Kyangwali's base map an semi-structured interviews during the data

August 2016

villages of Kyangwali into area $\mathrm{A}$ (which has nine villages and the main administrative
office) and area $B$ (which encompasses

villages and a second administrative office in Rwenyawawa). Kupfer, 'Accessibility and quality of education for refugees', 3 . The villages in
area A are: Malembo, old Malembo Mukny, Nyamiganda, Kentome, Kitoro and Kagoma. The villages in area Bare: Nyampindu, Munsisa, Kinakyetaka, Mukarange, Kasonga, Kyebitaka,
Ngurwe, Nyambogo and Kituti Data collected from Kyangwali's UNHCR office and contrasted with Kyangwali's base map and semi-structure interviews during data collection fieldwork

2. Kyangwali's trade centres have a 'couple dozen
shops selling grains, imported goods, sodas, beer, and cigarettes. Regular trucks come from Hoima supplying these shops; in addition,
traders from Hoima and as far away as Kampal and Arua come during harvest time to purchase the agricultural production of the refugees'.
Refugee Law Project, 'Refugees in Kyangwali

3. Counting both formal and non-formal ECD initiatives. Data collected from the offices of Kyangwali's Save the Children and Action fieldwork from 17 to 21 August 2016 . These are now occupied

85. Datata collected through the analysis of the existing map of the camp and confirmed through semi-structured interviews WTh AAH

nel on 19 August 2016.

. 'March activiting a refugee crisis', 1983 settlement (Oart 2)'; UNHCR Uganda, 'Kyaka II

fieldwork was conducted in $2016-7$ when it hosted around 32,656. This steep increase was conflict and an intense Ebola epidemic in 2019. UNHCR Uganda, 'Statistical summary refugees and asylum seekers in Uganda'.

Bakiga, which are ethnone Batooro and the

tional Tooro Kingdom, located between Lala

Albert and Lake Edward. The Tooro Kingdom is currently a subnational constitutional monRutorro and it closely resembles Runyoro oken in the neighbouring kingdo Bunyoro. Mazrui, Africa Since 1935; UNHCR

Uganda, 'Kyaka II fact sheet'.
91. The nine zones in Kyaka II are Sweswe, Bulit,
Bukere, Mukondo, Ntababiniga, Kakoni, Bwiriza, Byabakora and Kaborogota. UNHCR Uganda, 'Kyaka III fact sheet'. Data
collected from KYaka I's UNHCR off Das contrasted with maps and semi-s interviews during data collection fieldwork

from 9 to 12 August 2016.

Das oplation stantiscR education sectio camp's field offices through semi-structured interviews with the NGO Windle Trust pers

nel on 10 August 2016 '
In Kyaka II, there are ' 0 water sources: 31 shallow wells, 20 boreholes and nine protecte
wells or springs as well as a water dam at Sweswe and a 7,500 litres mini water treatme structures to boost water sup ment'. UNHCR Uganda, 'Kyaka II fact sheet', 2

flict. cold war'; Kibreab, 'Forced Migration in the Great Lakes and Horn of Africa'; Pérouse de Montclos, Humanitarian aid, war, exodus, and 'Geographies of displacemen'

96. For more information on the South Sudanese conflict, see, for example: Jansen, 'The refuge camp as warscape', 2016; Merkx, Refugee
Identities and Relief; Martell, First Raise a F

97. Kenya has built 29 camps from the late 1980 to date: Thika from an unknown from September 1989 until 1995; Ruiru from 1991 until 1995; Walda from 1991 until April 1993; Mandera from 1991 until 1994; El wak from 1991 until 1994; Habaswein from
1991 until 1995 ; St Anne's from March 1991 until June 1997; Utange from May 1991 until April 1995; Majengo from August 1991 unt and ongoing; Hagadera from June 1992 ongoing; Hatimi from July 1992 until June 1997 Kakuma from July 1992 and ongoing; Dagahaley from August 1922 and ongoing; Jomvu from
January 1993 until lune 1997: Swaleh Nguru from August 1993 until June 1997; Marafa from 1993 until December 1995; Ifo 2 from
2011 and ongoing; Kambioos from 2011 until 促 aid, war, exodus, and reconstruction of identities', 2008, 292; UNHCR, 'Dadaab Refugee undate', UNHCR 'Kalobedaab tweekly

98. As Pérouse de Montclos explains, the same hosting and resettlement system contributed to the formation and crystallisation of many
refugee identities. Pérouse de Montclos 'Humanitarian aid, war, exodus, and reconstruction of identities', 2008. 99. These camps were Kwa Jombu, Hatimi,
St Annes, Swaleh Nguru, New Majengo, Utang These camps wer
and Habaswei. These camps were Hagadera, Ifo, Dagahaley

2. The coastal camps concentrated most of the Somali ethnic 'minorities': Kwa Jombu hosted and St Annes hosted Bravani; Swaleh Nouru hosted mostly Benadiri; New Malengo hosted a mix of all the above-mentioned minorities; hosted mainly low cast $S$ abs and Bantu. The rural camps hosted largely the major Ogaden Clans such as the Darood, the Rahaweyn, the Hawiye and the Isaak. The Bantu settled
both in the Dadaab's camps and in the coasta camps, and were later resettled to $K$ ac where they had more security, since most inhabitants were Sudanese. Perouse de reconstruction of identities', 2008; Ayiemba, 'Refugees in post-conflict reconstruction'. 103. Hyndman, 'Geographies of displacemen

104. Hyndman, 193

105. UNHCR Kenya,' Dadaab refugee

complex-UNHCR Kenya! of Kakutat June 2016

107. UNHCR Kenya, 'Dadaab refugee

108. Hyndman, 'Geographies of displacement', 199. 9. UNHCR,'Emergency handbook. Camp planning standards. (Planned settlements)';
UNHCR, 'Refugee children: Guidelines on protection and care preface'

110. According to datat collected during fieldwork
to Kakuma and from the literature, Kakuma 
was mostly devised from Nairobi. However, ho organisation has infortation rast becanse was involved in the planning of the camps in the 1990s. Not even the dates of establis ment are clear in the sources. Pérouse de

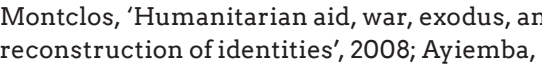
'Refugees in post-conflict reconstruction:

111. Hyndman, 'Geographies of displacement.
112. The Turkana people belong to the ethen groups known as the Eastern Nilotes. Apart
from grazing cattle, they carry out some subsistence farming in a number of irrigation
schemes along the two major seasonal rives schemes along the two major seasonal rivers,
the Turkwel and Kerio. Ministry of Planning and National Development, 'Turkana district

development plan (2002-2008)', 4.
This date is contested According

This date is contested. According to the
Department of Refugee Affairs (DRA) Department of Refugee Affairs (DRA)
Commissioner (semi-structured interview on
5 September 2016), the camp was established in 1991. However, publications suggest conflicting dates of establishment. Some st

after almost a refugees arrived in Kakuma of Gambella where they had been arriving
since 1983. Most of the refugees fled the fighting between the government of Sudan and the
Sudanese People's Liberation Army (SPLA). Most of the refugees who arrived in Kakuma were supporters or combatants of the SPLA.
They left Gambella camp after Mengistu Haile Mariam (president of Ethiopia who supported government of Meles Zenawit expelled the Sudanese refugees from the Gambella camp Some of them were the so-called Lost Boys who arrived in Kenya after a long trek across sou
ern Sudan. Many of these children had been recruited by the SPLA and arrived in Kakuma together. Jansen, The refugee camp as warscape', 2016, 431-8; $\mathrm{H}$,
displacement', 231-4.

15. Kakuma town is located on the eastern side of the seasonal Tarach River along the Lodwarfrom Oka, 'Unlikely cities in the desert', 2011, 226.

116. 'In 2002 the refugees were about 84,000 and by
May 2009 the number had dropped to 42,304 ' Ayiemba ,'Refugees in post-conflict to 42,304 Ayiemba, 'Re
struction', 8.
117. The refugees living in Kakuma are from Sudan, Ethiopia, Somalia, Sudan, Eritrea, Congo Brazzaville and Malawi. UNHCR, Statistical summary refugees and asylum
seekers in Kenya as of fanuary $31 \mathrm{st}$ 2018'. 118. Data extractedy from Kakumary's base map col-
lected during fieldwork in Kakuma from 2 to 10 September 2016.

119. During $m y$ fieldwork trip to Kakuma from
2 to 10 September 2016 both refugees and NGO workers reported attacks by Turkanas on refugees. The Turkanas on the other hand com plained about the help the refugees received
and the curtailment of their pastoral routes For example: 'These refugees are everywhere in our villages, collecting firewood, cutting trees, they are bathing and drawing water from Tarach River our only source of water, their
children have taken over our schools and they do not respect us. Something must be done to reduce their numbers because they are [a] refugees and host communities', 55
rest bet 120. Newhouse, 'More than mere survival', 2015 , $2300-1$; Crisp, 'A state of insecurity'.

According to he DRA Commissioner w at the Kakuma DRA Office on 5 .

September 2016.

The embryonic Kakuma phases II and IV, Kakuma phase III, were established to cater for the Sudanese refugees in 1999. What is now Kakuma phase IIII began to host refugees Rwanda, Burundi, Congo, Eritrea (since 1994), Somalia (since 1997) and Darfur (since 2008). Oka, 'Coping with the refugee wait', 2014, 26,

123. I gathered this information from informal conversations during fieldwork done in Kakuma more information, see UNHCR, 'UNHCR wel-

Comes Kenya statement',
124. The 12 ECD centres are: Trarach, Gilo and Lake
Turkana in Kakuma phase I- Mount Surat, Turkwell and Gambella in Ki Mount Surat, Shambele, Nasibunda and Mount Songot in Kakuma phase III; and Hope, Peace and Eliyes in Kakuma phase IV. These data wer 10 September 2016 .
125. The two Furaha centres, placed in Kakuma UNHCR, UNICEF and the NGOs in charge of education and child protection that began in 2016. They are fenced compounds that open after school to children of all ages and com-
prise a well-equipped playground, a referral
centre -including counselling rooms - and centre
toilets.

26. These are the first play-based ECD initiatives in the camp. They began in 2012 with the
activities of the NGO Waldorf Kakuma Proje programmes. The four Waldorf initiatives are based on the Western pedagogy of the same
name, which uses art as a means of learning and expression. Currently only the Kakum phase IV initiative has its own space; the oth three take place at the Mount Songot ECD and at two open areas in the protection and recep-
tion centres. Children come to the spaces for a few hours in the mornings and plant, pain make clay models and take part in other

27. The density of Rw

per square kilometre in 2018 was 430 people Berlanda, 'Umujyi:

ments in Rwan

es and human settle-

Regrouped Settlement Sites'.
. The Imidugudu Policy has been criticised

for forcing the regrouping of returnees and

midugudu. Other known villagisation proj in Sub-Saharan Africa are Tanzania's (beginning in 1967), Ethiopia's (beginning in 1975)
and Mozambique's (beginning in 1977) van Leeuwen, 'Rwanda's imidugudu programme', 2001, 625-30; Government of Rwanda and UNDP, '2014 National human development 'Uport'; Ministry of Infrastructure of Rwanda, ment policy in Rwanda'.
See Chapter and tarrell-Bond, 'UNHCR - Are
refugee camps good for children?'

Returnees mainly arrive in 8 Rm

waves: in 1994 and from 1996 to 1997 . These waves coincided with the end of the genocide returnees were the Batutsi refugees who had been hosted in Tanzania and Uganda, and they came back to Rwanda during the second half of 1994 after the Rwandan genocide. The second wave of returnees were Bahutu refugees who in Eastern DRC from mid-1994 when they Leeuwen,' 'Rwanda's imidugudu programme', and development', 2000 . are: Kiviziba estelese refugee camps in Rwand province in December 1996; Gihembe, established in the Northern province a year later; Nyabiheke, established in the Eastern province
in April 2005; Kigeme, originally established in the Southern province in 2009 and reopened in 2012; and Mugombwa, established in the Southern province in February 2014. Data
collected from semi-structured face collected from semi-structured face-to-face
interviews held with MIDIMAR representatives at camp level during fieldwork done in September 2015 and from UNHCR, 'UNHCR

In 2013, the strategy changed to some de and shelters were allowed more 'permanency' with elements such as iron sheeting roofs egy for settlement and shelter'. 135. Apart from the five Congolese camps, a new
camp, Mahama, was created in April 2015 to host Burundian refugees

136. UNHCR, 'Population statistics'.

Dancing in the Glory of Monsters; ; Prunier, rom Genocide to Continental War, Mamda

38. The First Congo War took place from December 1996 to May 1997. The Second Congo War began in August 1998 and officially ended
in July 2003 . However, conflict is still present

139. UNHCR and MIDIMAR, 'Economic inclusion of refugees in Rwanda', 19

protection KAP

141. UNHCR, 'UNHCR calls for calm'; Human Rights

UNHCR, 'Comprehensive refugee response

143. UNHCR, 'MIDIMAR-UNHCR joint strategy partners'; UNHCR and MIDIMAR, 'Economic 'Operational update - Rwanda 2017', 2 .

4. UNHCR,'Rwanda country refugee response

plan 2019-2020'
145. Data collected th

Data collected through observation and

informal conversations with camp managers
and NGO workers. Fieldwork trips developed 
30 August to 15 September, from 1 to 7 Octo and from 5 to 11 Noventer, 2017 , to 7 October

146. These data were collected through observatio and informal conversations in Kiziba from
30 August to 15 September, from 1 to 7 Octobe
and from 5 to 11 November 2017 .

147. Some examples are: start-up crowdfunding strategy run by the organisation Inkomoko,
direct cash transfers run by the organisation Give Directly, product launches with organistoves) and Bbox (solar energy mini grids) . MIDIMAR, 'Rwanda Ministry of Disaster

For more information on the rebel group $\mathrm{M} 23$,
see Stearns, Mai-Mai Yakutumba $44-45$

se Stearns, Mai-Mai Yautumba, 4 - 45 ,
MIDIMAR, 'Rwanda Ministry of Disaster

Management and Refugees

Belgian colonial rule. It is alsopital under National University of Rwanda and the Nation

Bukavu is the capital of 5

important transport hub and Kivu, an resource rich Eastern DRC. The road that connects Bukavu with Kigali is key for the entry
and exit of goods to and from Eastern DRC because the infrastructure and the roads in the DRC are in an extremely poor condition, and there are no
capital, Kinshasa.

153. My team at Active Social Architecture (ASA)
catil Kinsas. studio designed and built Kigeme hospital's maternity ward.

ties are explained in depth in

Chapter 3

Data collected hrough a multi-method qualiin various visits and fis maldwork observation Kigeme from 11 to 14 September 2015 and from 30 August to 15 September, and from to 7 October and from 5 to 11 November 201 respectively. These data were also col-
lected through my architectural work with humanitarian agencies in both camps from February 2011 to November 2014 .

56. These data were collected from MIDIMAR
and contrasted with information from structured, face-to-face interviews during structured, face-to-face interviews during
fieldwork done in Rwanda from 4 September to
1 .

7. The internationally renowned architect
Shigeru Ban had collaborated in the shelter design for Gihembe refugee camp in 1999. Ban

58. UNHCR 'Operationalters for UNHCR',

159. In 2016 , Kiziba had a surface area of 28 hectares, Kigeme of 34 hectares and Mugombwa of 24 hectares. Kiziba and Kigeme
had a density of 60,000 people per square

160. In 2016 , Kyaka II had the lowest density with kilometre 40 ind Nakivalitants per square with 600 inhabitants per square kilometre.
However, within Nakivale, there are big differences. The trading centres at Base Camp 1 and
Base Camp 2 had an average density of 8,000 people per square metre, and the densest
areas in Rubondo such as Ruhoko centre had an average density of 500 people per square Pence and Hix-Small, 'Global children in the shadow of the global child', 2007

Bühmann and Trudell, 'Mother tongue matters', Fafunwa, 'Rd . Koralek and Mitchell, 'The schools we'd like' Chiles, 'The classroom as an evolving land-
scape'; Dudek, Kindergarten Architecture.

164. Dewey, 'Experience and education'; Rasmussen, 'Place for children', 2004
eiher, 'Shaping daily life in urban

Dovey and King, 'Forms of informality', 201

UNESCO, 'The Dakar Fr

Pence and Hix-Small, 'Global children in the

Data collected through a multi-

tive approach from the Rwandan case studies in September 2015 and from September to studies in August 2016 and from Kakuma in

Kenya in September 2016.
170. Bonta and Protevi, Deleuze and Geophilosophy The two newest and best-connected camps
I have studied are both in Rwanda, while in general, the East African camps I have studied are isolated: Nakivale is 44 kilometres from Hoima, Kyaka II is 79 kilometres from Kyenjojo, Kiziba is 20 kilometres from Kibuye town and Kakuma is close to Kakuma town bu 119 kilometres from Lodwar, the next nearest qualitative approach during fieldwork in
September 2015, August and September 2016

172. For example, Kakuma town's population

2000: 'Prior to 1991 , Kakuma was a transport
2

and regional market town primarily settled by
Somali Isaak and Hawiye traders who domi-

nated the pastoral exchange, provided retail
and wholesale services to the local [Turkana pastoral communities and lodging/board-

Ing for drivers on the Kitale-Juba road'.

173. Usually, shared benefits take the shape of
transportation infrastructure, health and transportation infrastructure, health and
educational facilities and income-generating activities. UNHCR, Policy on alternatives to

camps. Data collected through a multi-method qualitacase approach during fieldwork in the Rwanda hrough a literature review: AVSI and InfoAd, Child protection KAP survey in Rwandan .

Kaplan, 'Refugee livelihoods in 76. Chambers, 'Hidden losers?', 1986; Chambers,
'Rural refugees in Africa', $1979,388-9 ;$; Rithi,
'Conflict amonst refuges' 'Conflict amongst refugees'

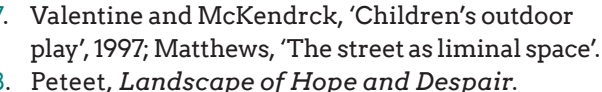

17. Peteet, Landscape of Hope and Despair.

180. Some refugees with access to cash emplo the Turkanas to collect and carry water and firewood for them and to clean their homes
According to refugees' and NGO workers' accounts, there have been instances when the Turkanas have raided their 'employer's's homes at night. The Turkanas see the refuges gees as responsible for their land eviction the obstruction of their cattle grazing and the increasing lack of water and desertificaresidents benefit from the job opportunities created by the flow of funds into the camp.
However, the Turkanas do not usually access those opportunitites and despise the camp
and their residents. These data were collected during fieldwork in Kakuma from 2 10 September 2016 and contrasted with the literature. Rithi, 'Conflict amongst refugees'
Emuria, 'Clashes between refuges and hos communities'.
181. UNHCR Rwanda, 'Participatory assessme

182. A good example of this is the Bahutu and Batutsi conflict that includes the nation states
of Burundi, Rwanda, Uganda and DRC. The conflict has lasted for centuries. A couple of publications that exp
and the Rwanda's involy Wars are: Stearns, Dancing in the Glory of Monsters; Prunier, From Genocide to Become Killers.

183. For example, some of the inhabitants of Nakivale come from Somalia, and some of the of Rutsuru and Beni in Eastern DRC. For more information, see the interactive maps at the

84. Imidugudu means 'villages' in Kinyarwanda
85. Guattari and Deleuze, Rhizome; Müller and Schurr, 'Assemblage thinking', 2016, 219.

tive approach, mainly using the spatial qualitysis of the maps that I made for the seven camps presented in this book and also collected and from September to November 2017, from Southwest Ugandan settlements in August 2016 and from Kakuma in Kenya in September 2016. As, for example, Uganda, Rwanda, Burundi, tural work in the Rwandan camps from 2011 unti1 2014, and qualitative data collected November 2017 .

189. Rebels had in the past abducted children to ing conflicts. Data collected through fieldwork in September 2015, August and September 2016 and September to November 2017 and con-

190. Data collected through the spatial, of the maps that I made for all the camps presented here and also collected during and September 2016 and September to November 2017 .

191. These land disputes tend to be raised with or the UNHCR. They do not usually result in violence between the refugees and their 
direct local hosts. Bagenda, Naggaga and
Smith, 'Land problems in Nakivale settlem Matsiko, Museven shocked at Kyangwal

192. Emuria, 'Clashes between refugees and hos, communities'; Bagenda, Naggaga and Smith,
'Land problems in Nakivale settlement'; Rogge, 'Afrca's resettlement strategies', 1981. 3. Bagenda, Naggaga and Smith, 'Land problems
in Nakivale settlement'; Gardner,'Beneath the surface.

19. For land conflicts in Uganda's refugee camp locals in Kyegegwa', Mutegeki and Basiime, 'Refugee camp chief killed in land dispute'
For example, Kiziba has an average of 45 5. For example, ceople per datine. Non or he toilets are specollected during fieldwork in September 2015, August and September 2016 and September to sis of the maps that I developed.

196. Anecdotal data collected through architectural work in the Rwandan camps fro lected through a multi-method gualitatives approach from the Rwandan case studies in September 2015 and from September to studies in August 2016 and fros Kandan cas

Kenya in September 2016.
97. AVSI and InfoAid, 'Child protection KAP survey in Rwandan refugee camps', $\mathrm{xi}, 21$ and protection and care preface, $1,14,23$ and 71. . UNESCO, 'Strong foundations'; UNICE

'Building better brains'.

square kilometres and had a density of 650 people per square kilometre, Kyangwal

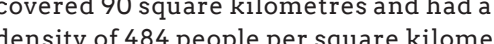
density of 484 people per square kilomettres and had a density of 400 people per square kilometre. Kakuma covered a total 9,000 people per square kilometre. Kiziba covered 28 hectares and had a density of 61,600 people per square kilometre, Kige 59,185 people per square kilometre and
Mugombwa covered 24 hectares and had of 38,066 people per square

poverty', 2004: Evans and Saegert 'Residential crowding in the context of inner city poverty', 7; Proshansky, Fabian, and Kaminoff, 'Placeenviry, 1. environment and cognitive development'.
Refugee Law Project, 'Refugees in Kyangwal settlement
20.ta collec

Date ase studies from 7 to 29 August 2016 . . United Nations, Convention on the Rights of

204. … for reasons of security, countries of asylum shall, as far as possible, settle refugees at a reasonable distance from the frontier of their country of origin'. UNHCR, OAU Convention lems in Africa.
205. UNHCR, Handbook for Emergencies. The mergency preparedness and response

6. For example, in Rwanda, the proximity to
the border, in conjunction with isolation and marginalisation, contributed to the attacks from 1996 to 1997. Since then there has been an effort to place the camps at a distance from the border. Nevertheless, Kiziba was still

placed 20 nore (the natural Eastern DRC). Anecdotal evidence collected through $\mathrm{my}$ architectural work with humanitarian agencies 1 . Cwanda from February 2011 September 2015, August and September 2016 and September to November 2017 the minimum 作 UNHCR, 'Comprehensive refugee 9. UNHCR, 'RW

plan 2019-2020'.
10. Mahama was established in April 2015 in Rwanda, Kalobeyei was established in established in 2017 in Northwest Uganda
Refugee-led spatial observed, imagined interventions

and speculated

Long-term camps, a socio-political These changes ripple through impactand humanitarian oxymoron, will not ing refugees, direct local hosts and the disappear or become thriving human humanitarian system.

settlements overnight.' Yet, they are Over the last decade, the humanitarian slowly morphing towards urbanity relief assemblage has tried to ch through the action of many different human and non uma reptitious spatial modifications led by The United (UNCR) hasput forwadpolicies the encampedrefuges and their diret local hosts are central in this evolution. and frameworks such as the Alternatives

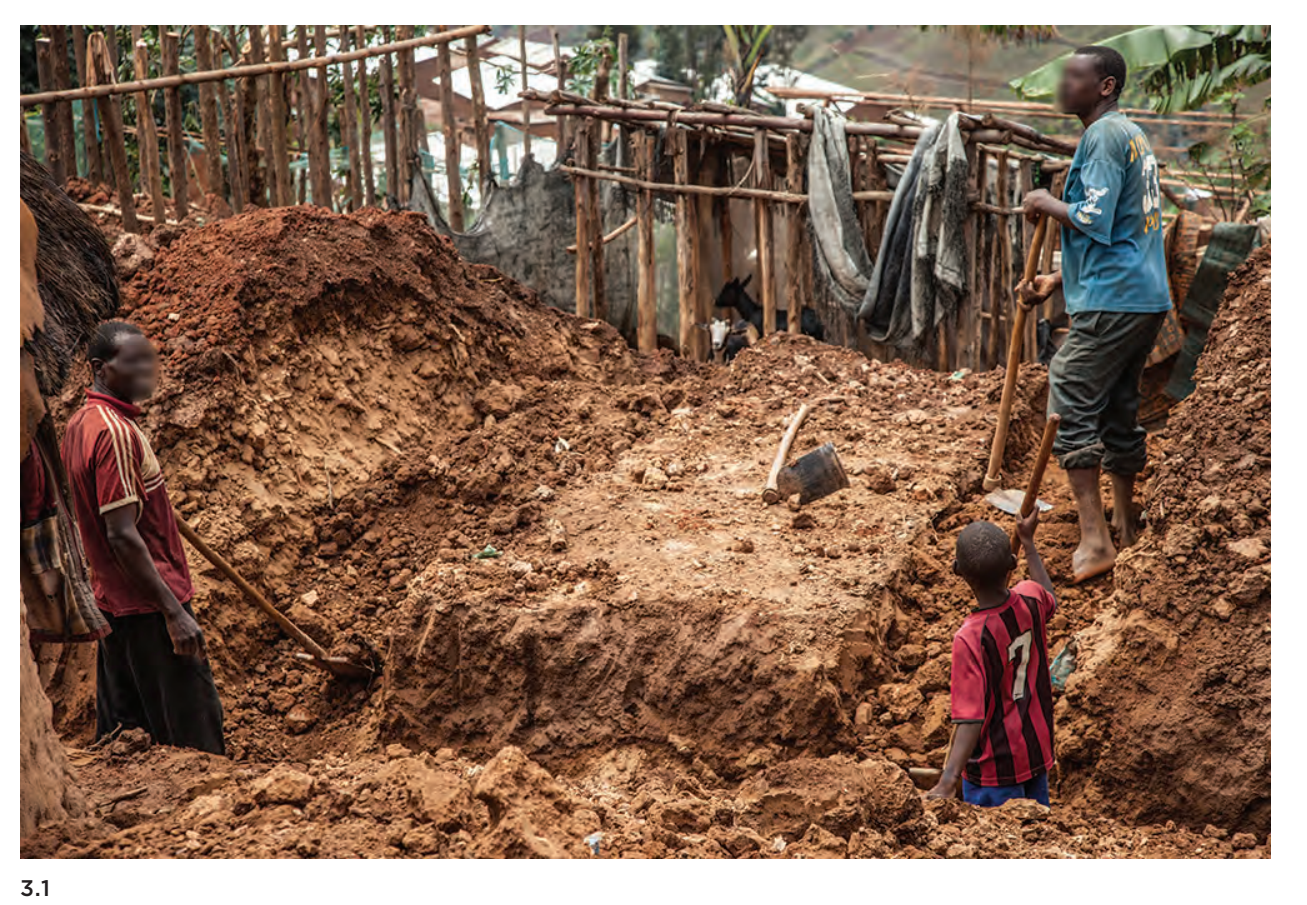


to Camps, which unfortunately still relies and contextualising research and includnoices in a collective experiment (n) Urban Areas ${ }^{2}$ and the Comprehensive of existing, albeit fairly invisible, power and Refugee Response Framework (CRRF), ${ }^{3}$ agency, including that of the built environwhich emphasise refugees' inclusion in ment, parents, young children, students of national systems. The humanitarian system architecture, artisans, refugees and their is embracing, alas slowly, the long-term direct local hosts.

character of most refugee situations and acknowledging their challenges.

However, the implementation of these policies is uneven across the globe. The UNHCR's position is highly political, placing donor agendas and international affairs cor all-being frefuges and direct local hosts. The UN agency also relies on governments and implementing partners to execute its policies. Moreover, these humanitarian strategies are overarching and general, usually based on partial data, with a blatant scarce representation of the

voices of refugees, direct local hosts and the experiences in the least visible cases-such as those in East Africa. Hence, as these
policies translate into action, they do not policies translate into action, they

lways achieve the intended goals.

Refugee studies have discussed extensively the power differentials that swing so fully in favour of donors and geopolitics. They try to understand how hierarchies and powers became so fixed in place, as Deleuze and Guattari say, so 'territorialised' and 'stratified'. 6 Will having better spatial data and situated bits of knowledge help in contextualising policy and decentralising power?

The goal of this chapter is to understand if and how architecture migh imbalances, even if slightly, by grounding
The power of place-making-The humanitarian approach to camp planning aims primarily to protect and preserve the lives of refugees, although in need of the lives efficiency and owing to political agendas does sowithout heir input Hence, encampment trategies fail to the the reampm terme experts, who are increasingly involve in the sustainabilin and efficin the sustainability and efficiency of the new and the long-term refugee camps, still tend to adopt a technocratic bid. The are usually delivering what they think is aligning with the power that subcontracts them. ${ }^{7}$ Due to time and budget constraints, and usually short-term appointments, they tend to lack contextual knowledge and largely disregard the social, political and economic implications of the physical containment of refugees, not to mention the impacts of the camps' spaces on children. They miss opportunities and create oxymorons.

Yet, surprisingly to many, in the seven the camps'built environ force reducing the camps' built environments, contrary to technicia bare the than 'neutral', technical expertise, unwittingly long-term camps that I present here, camp inhabitants are the main force reproducing

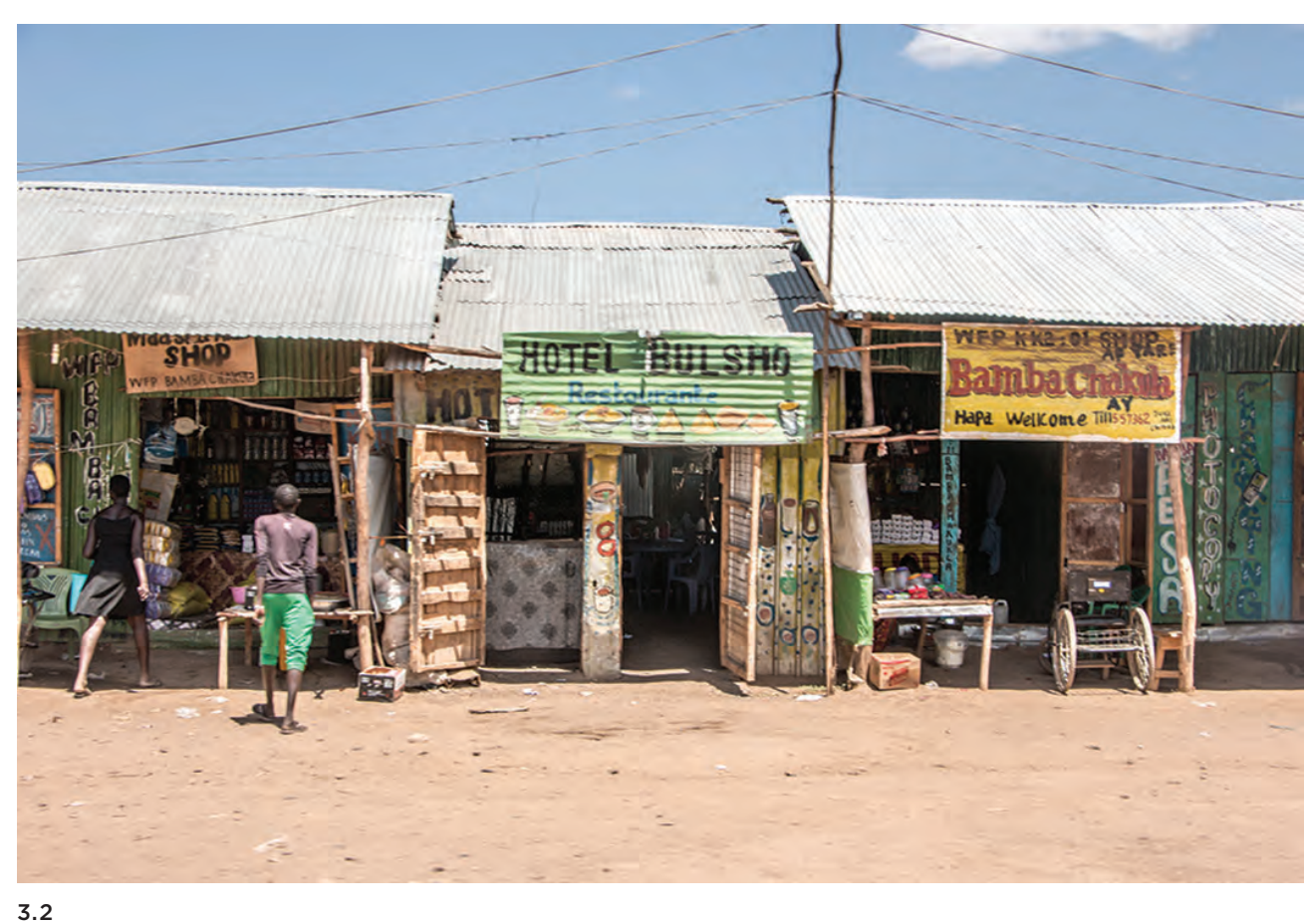

3.2 Commercial strip in Kakuma
phase III. Kakuma refugee camp phase Ill. Kakuma refugee cam
September 2016. A Amorós
Elorduy.

\section{the} sis of the camps that I started in Chapter 2 brings to the fore the variety of forces shaping the lives of encamped refugees, As in many human settlements and urban
areas around the world, different kinds of power exist. Some can only be observed when looking from diverse standpoints and considering different scales. As I unveil further in this chapter, these types of powe might not look like 'traditional' power but are effective in shaping the built enviro Refugees and their hosts are paramoun in the spatial reproduction of the long-term camps. Their role is vital, despite the inherent and often overwhelming 'traditinerpower imbalance in refugee camps and the lack of representation of refugees and their direct local hosts in managerial decision making. Refugees create exceptionally contextualised spaces as they inch their way to achieve their goals, counterbalancing the bleak, often heartless, humanitarian camp designs (fig. 3.2).

In this chapter, I present my efforts to understand how continuous surreptitious change takes place in the East African long-term camps. I show the exploration - developed with a team of local architects, artisans and refugees - of potential ways of harnessing that silent force to improve young children's learning. Moreover, my goal here is to flip the traMoreover, my goal here is to flip the traditional aid discourse. Rather than letting 
spatial interventions, this chapter tests a Incrementalism-I present proposals that potential refugee-led change with human- refugee respondents imagined and desire itarian technicians and other external in order to improve young children's learnactors as active participants. I aim to ing environments. For this purpose, I us employ what Edgar Pieterse terms 'radical the case of Kiziba refugee camp, and I catincrementalism':

'Surreptitious, sometimes overt, and multiple small revolutions that at unanticipate and unexpected moments galvanise into more profound ruptures that accelerate tectonic shifts of the underlying logics of domination.... A disposition and sensibility dominationes in deliberate actions onsility transformation but through a multiplicity of processes and imaginations, none of which assumes or asserts a primary signifiwhich assumes or asserts a pr

Moreover, in this speculative chapter explore how Lefebvre's 'transduction' might trigger a Freirean conscientious spatial change and might raise awareness of the role of place in young children's lear ing. This test will not resolve refugees'
existential struggle or radically change the current poor learning environments walls."1 However, it might provide a means to manage and tackle these problems by 'stumbling across what works and what does not'.

In the first section of this chapter Everyday Life Practices - I describ existing refugee-led spatial appropriations. I categorise them according to how the humanitarian system responds to them: with unawareness, permissbility or encouragement. In the second section - Refugee-Imagined Radical egorise the utopic interventions as they focus on formal, non-formal and informal learning environments. ${ }^{13}$ In the third section - Speculated Transversal Spatial improvement of young children's learnin and Kigeme refug some of the ethics, risks, limito explore opportunitions and of multi-authored and utopic devertont priations in these two Congolia appropriations in these wo Congolese refuge

The dissection of the observed spatial appropriations, the analysis and representation of the imagined ones and the tes of new spatial interventions bring to th fore the relationships between, and the agency of, the diverse groups of human and non-human actors that form the learning assemblages of the long-term camps. ${ }^{15}$ shows that encamped refugees and their direct local hosts are exercising their 'right to the city' daily: they are continuenvironments through 'radical incrementalism'. However, and as AbdouMaliq Simone expresses well, with this approach:

The point is not to suggest models or admire resilience. Rather, the point is to pursue the dogged work of trying to understand the larly as it is clear that residents, even in the Appropriations - I use participatory action research (PAR) to test 'transduction' in the environments, explicitly focused ously modifying young children's learning implications of desperate ways they may talk about thei lives, usually think about them as mor than survival alone. Yes, survival is the overwhelming preoccupation for many. But the pursuit of survival involves actions, relations, sentiments, and opportunities that are more than survival alone.... And thus the important work is perhaps simply to document these efforts on the part of the poor to give rise to a new moral universe, a sense of value, of potential, and of the unexpected to which people's attention, no matter how poor, is also paid ${ }^{16}$

Knowing who modifies the camps paces, and how and what young children spaces, and how learn from these, is timely, as new strategies for refugee assistance and refugee education are shaping up globally. In the long-term refugee camps in which I have worked, the humanitarian resources are dwindling and their traditionally topdown approaches to management are not meeting the increasingly interconnected and complex needs of the refugees and their direct local hosts. As policies and camp administrations adopt the $\mathrm{CRRF}^{17}$ and become more open to refugees and direct local hosts agencies, the prevalent refugeeled spatial appropriations gain relevance. Understanding these spatial modification and their effects on the camps' ecosystems can shed light on the potential future of refugee assistance and refugee early childhood development (ECD).

Extracting from urban theory-As I expressed earlier in this book, there is an extreme lack in this book, there is on space production in refugee camps, especially in East Africa. Yet, a recent 'urban turn' in refugee studies draws on urban theory literature to state the relevance of the built environment as a critical non-human actor in assistance strategies. In this urban theory literature, I identify four sets actors as spearheads of urban spatial transformations: international and national authorities, architects, universities and non-governmental organisations (NGOs), and local groups. Exceptionally significant for this chapter is the role of that last set of actors, described in the literature as covert, informal, survivalist, iterist,

The spatial actions of refugee camp inhabitants could be seen through survivalist lens, as expressed by Simone in the Weapons of the Weak: Everyda Forms of Peasant Resistance publishay Forms Contrary to the 'rebellions which hold Coridrary to the 'rebelins which hold pride of place in the archival record ${ }^{18}$ that pride elfinterest that drove 'non-spectacular forms of

The ordinary weapons of relatively powerless groups: foot dragging, dissimulation, desertion, false compliance, pilfering, feigned ignorance, slander, arson, sabotage, and so on.... Everyday forms of resistance make no headlines. [However, it] is largely in this fashion that the peasantry makes its political presence felt. For these reasons alone, it seems important to understand this quiet and ano action'.20 
Another lens to look at this refugee-led I I have found as well in the seven camps that ansformation could be that of discreetness and anonymity, reflected in the wor

Before 2005, it was rare to find litera'quiet encroachment ${ }^{21}$ :

"The notion of "quiet encroachment" describes the silent, protracted and pervasive advancement of ordinary people on quest for survival and improvement of the lives. It is characterised by quiet t, the atomised, and prolonged mobilisation with episodic collective action - open and fleeting struggles without clear leadership ideology, or structured organisation'.22

The post-structuralist look proposed y Bayat and other authors such as Roy nd Caldeira aligns with one of the most important authors in refugee studies and proponent of situated knowledges: Barbara ised' view of man, which wrongly assumes that once people are together, man's'soci nature' will quickly develop a social structure which will ensure the equitable and acceptable distribution of resources, no matter how limited those resources may be ${ }^{\prime 23}$ Harrell-Bond stated that the ove socialised view of man tends to romanticise the struggles of the oppressed -including refugees and the urban poor - a superficial view of flat characters. In her response to Gaim Kibreab's critique about her work Imposing Aid, Harrell-Bond stated that it is also self-interest that drives many of the survival actions of refugees She stated th refugees do not always develop a cohesive social structure of mutual help-something

\section{portray in this book} ture on refugee-led spatial intervention in long-term refugee camps, as refugeeled actions represented a challenge to the 'refugee as victim' view. Thus far Palestinian refugee camps in Lebanon are the source of the majority of incipient information on refugee-led spatial initiatives. In those camps, the politicised use of space has gained a highly complex and rooted dimension. ${ }^{24}$ An interesting study on the production 'f'place' in this study on the is anthropologist Julie Peteet's of Hope and Despair. In it, Landscap of Hope and Despair. In it, she states how 'refugees were the driving force in generatin tures and forms of tures and forms of external power. At one brief point in time, ... power shifted to the interior and gave leeway for Palestiniansto transform the camps in their image..25 Also, in her Squatting in Camps: Building and Insurgency in Spaces of Refuge, Romol Sanyal links refugee-led spatial modifications of the Middle Eastern camps with urban squatting employing Bayat's 'quiet encroachment of the ordinary ${ }^{26}$ to bridge urban theory and humanitarian space.

Yet, studies on refugee-led spatial production in East African camps are still almost non-existent. While studies that centre the view and voice of refugees and their direct local hosts started to appea in the region in the last decade, they focus mainly on economic and political aspects of the refugee-led spatial change ${ }^{27}$ Only couple of works and authors focus only space if
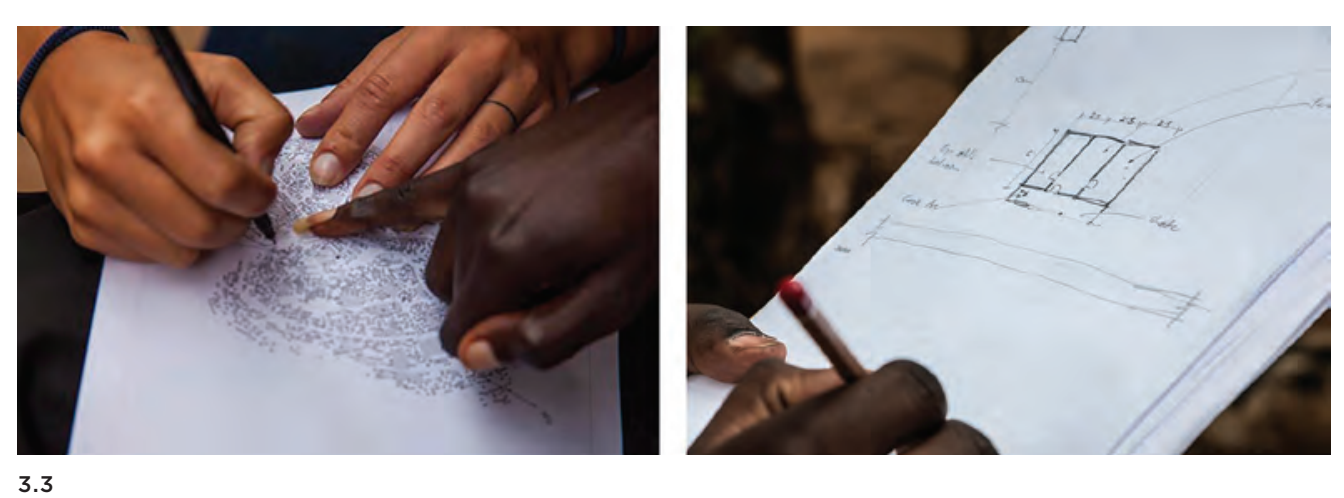

3.3 Sample of methods of spatia data collection. Map orientation (left) and sketching (right).
Randan camps, September 2015
๑ Amorós Elorduy.
Iyer Siddiqi. ${ }^{29}$ Both look at the visible and better-sourced operations in Northern Kenya This bookwants to contineturing the tide, providingenouhbase information and inciting local and regional researchers and built environment professionals to expand this research task in other camps in the region.

Observed quiet encroachment and everyday life practices-Through both everyday Ife practices-Through both permanent and transitory spatial appropriations, refugees repair, modify and adap all the available spaces to suit their needs. For example, children transform streets, interstitial spaces between houses and front yards into playgrounds; mothers appropriate these same spaces into temporary home-based ECD (HBECD) initiatives. ${ }^{30}$

n my work in the camps in Rwanda since 2011 and during fieldwork trips with my team of research assistants for this book (all students of architecture from the schools in the region), we photographed measured and sketched the spatialelements that research respondents identified as potential influencers for young child as learning in the camps - both positive and harmful. We specifically asked which features - such as additions to homes, schools and public areas - had refugees and direct local hosts developed, enquiring about the spatial evolution of the whole camp over time (fig. 3.3).

We concluded that refugees - and in some cases direct local hosts - are the main actors modifying the long-term fter the humantaran cast ost government establish the camp and do the main infrastructural works. They particularly take over when humanitarian resources dwindle, which they do in protracted complex crises and long-term refugee assistance operations. Because the majority of these inhabitant-led changes are mall scale, incremental and informal, they largely go unnoticed, especially if viewed from a top-down perspective-such as that of the media, the government and the humanitarian system.

Moreover, we learned that the humanitarian system mainly reacts to refugee-initiated interventions-by ignoring, allowing or encouraging those. In the coming sections Iillustrate those reations 


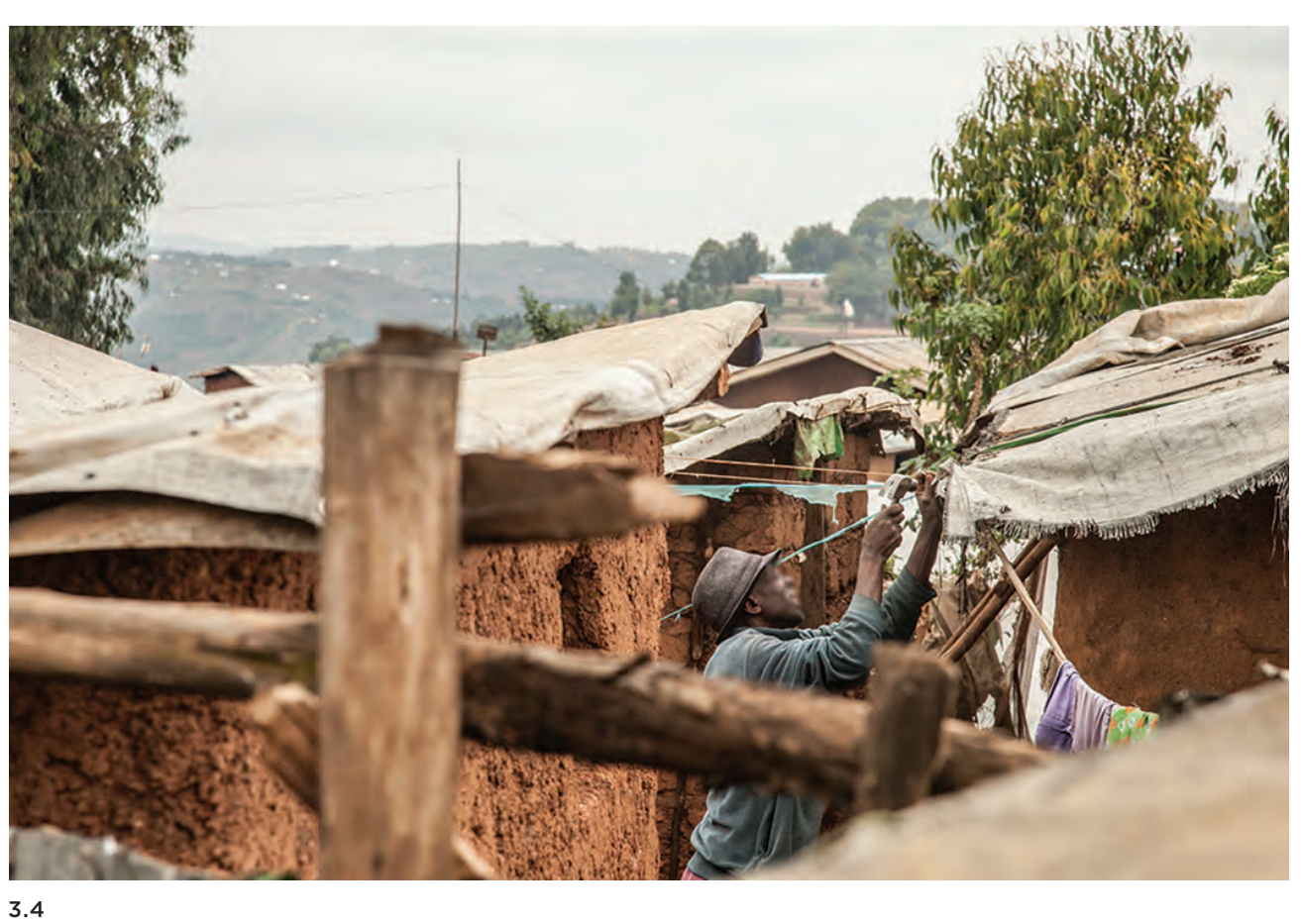

3.4 Man repairing the tarp roof to his home in Kiziba. Kiziba refug
camp, September 2017. O Amoros
Elorduy. ing les that are relevant for young children's learning. In this book, I do not document any refugee-led interventio blocked, banned, destroyed or met with blind opposition by the humanitarian system. That does not mean these do not occur. It can be hard to find these examples because, by their nature, most refugee-led initiatives are informal and unobtrusive, not leaving much in the way of evidence. their failures mostly invisible.

Unnoticed: the homes and WASH facilities-Days after a camp is established the first refugee-led spatial appropriations tart taking place (fig 3.4). These happen at the individual and family level with the construction, expansion and modification of homes, toilets and - if the land allows it - vegetable patches. ${ }^{31}$ Notably, the house are relevant in this book because they constitute the bulk of what I consider as informal learning environments, and they enhance the refugee's 'right to the city'. The humanitarian-government-media assemblage is not just unaware of home changes in the camps in East Africa. These supposedly powerful and in-control actors assume from the start that refugees will be in charge of making and modifying their homes (fig. 3.5).

All research respondents ${ }^{32}$ as well as ing environments ${ }^{33}$ identify then's learning envirnts paramiount to young children's learning, he literature on young children's learn-
Works examining the influence of the home's physical environment on child development began in earnest in 1979.3 For example, Harold Proshansky and Abbe stated that:

The home is a critical socio-physical settin in the life of the child because it is the aren in which most early learning occurs. Selfknowledge, knowledge of others, and knowledge of the environment all begin there. Many of these early self-perceptions there. Many of tis early self-perception and place-idention cognions will persist child is likely to have in later settings ${ }^{\prime 35}$

From an early learning perspective, the humanitarian system's failure to account for the homes as leaning spaces leaves the most critical hours and years of child development in the hands of the assemblage of parents and neighbours and of the built environment built by them. Refugee are indeed the makers of one of the most critical learning resources for young children in the camps. Being virtually in charge is empowering for refugees, but at the same time, it also means that policies, funding, humanitarian and governmen actors obviate this remarkable resource an role. The humanitarian system/host government binomial places elsewhere the materials, advocacy and other resources that would significantly help ECD at home. In the establishment of the long-term camps in East Africa, the diverse assemblages of UNHCR/host governments provide initial 'shelter infrastructure' which varies from case tocase For example, phases, Kiziba and Kigeme $\mathrm{A}^{36}$-the UNHCR teams of chnicians assembled (or helped refugees assemble) within the boundaries of the camps. ${ }^{37} \mathrm{~A}$ few months later, the UNHCR provided poles and tarpaulins to facilitate the construction of self-built mud houses with tarp roofs. Years later, ${ }^{38}$ they provided iron sheets that corresponded with the initial three-by-four-metre footprint of the original shelters. ${ }^{39}$

The recognition of permanence allowed and pressed refugees to make self-improvements to the shelters, transforming them into'semi-permanent' homeswith attached kitchens, extra roon Cous oust and presere present government provided each arring family with a plot of land and with poles and heir own. In the Ugandan context, the the humanitarian system/host government assemblage seems keener at distributing power. ${ }^{42}$ It allows refugees relative freedom to work and to move, and it provides them with some land in lusher areas than those offered by Rwanda or Kenya. This is in turn reflected in a broader range of construction materials and shapes in home structures. ${ }^{43}$ Refugees' spatial appropriations of their homes can be observed in real time a few weeks after a camp establishment. For example, in Mugombwa (Rwanda), the newest camp included in this book, the refugees promptly converted the initially tented structuresinto mudandine initially shelters with footprind and iron sheeting Now, seven years on, housings incorporate

especially learning through experience. 


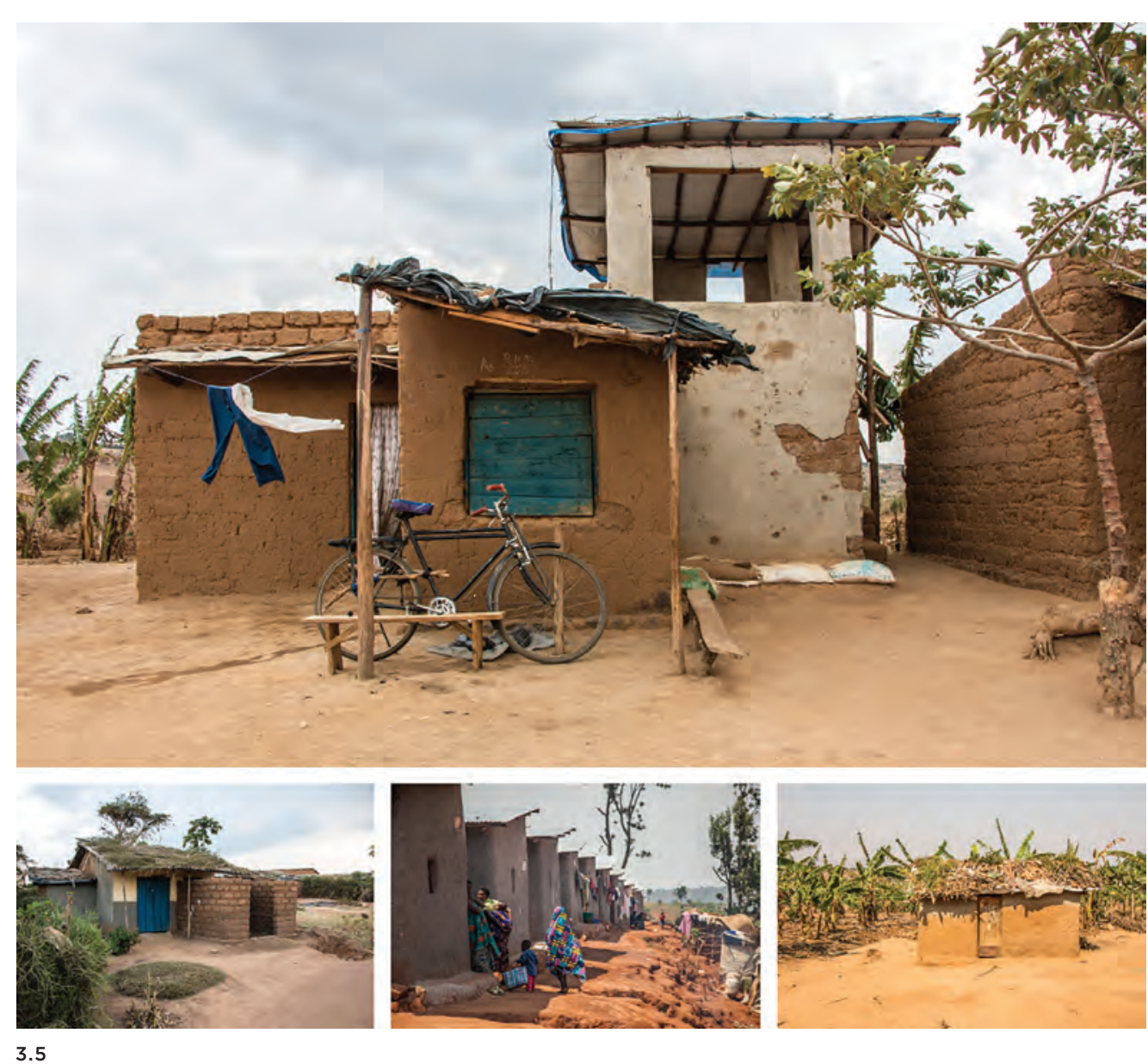

interior partitions, attached extra rooms unaccustomed eye, it is difficult to differenand kitchens, plastered walls and in some tiate between the outdoor area of one house cases kitchen gardens and fences. The and that of its neighbour (fig. 3.5). material evolution of Mugombwa includes The contextual assemblage of human businesses, churches and other more and non-human actors affects the homes' 'public' spatial appropriations done in con- transformations. For example, in Kakuma junction with NGOs. ${ }^{44}$ In older Rwandan in Northwest Kenya, homes and compounds camps such as Kiziba and Kigeme, the lack create a spatial quality variation between of planning, the scarcity of land and years of phases. As they grow older, they between of planning, the scarcity of land and years of phases. As the grow 45 der, they become come expansion have homes placed within denser and diverse At establishment, close proximity of each other-from 20 cen- all plots measure 10 square metres an timetres to a couple of metres apart. To the house one family, which is still the case in the recent III and IV phases. However, streets. ${ }^{49}$ The only fenced Congolese homes in Kakuma phase I, uses and time have I have found are those in Kakuma-the least divided some original plots to house up to safe of all the camps that I studied - where three families and have merged others to all inhabitants build tall fences around their become big and amorphous in order to host homes. Relatively safe streets can become churches and major commercial operations. incredible playgrounds and learning enviThe modified streets are narrow and curvy. ronments for young children. ${ }^{50}$ However, In an expression of their soft power and their when violent and armed conflict and inse'right to the city', Kakuma's refugees have curity are rife, parents prevent children over time transformed even the grain of the from leaving their compounds, which has camp's master plan to serve their needs. consequences for their understanding of The specific physicalcharacteristic the self-built homes-the number of rooms, style of openings, furniture flooring, ceiling and the exterior and the exing res in government policies, resource availability, family size, cultural backgrounds, traditions, climate and geography.

The different refugee origins provide a For example, Democratic Republic of Congo (DRC) refugees, who reside in all seven camps that I present here, ${ }^{46}$ tend to build similarly fenceless and small rectilinea houses. These mud homes, which comprise two to four rooms, usually have one space as a living and eating area, kitchen and bedroom, and the other space as a bedroom and storage, sometimes shared with animals. The Congolese usually build the extra rooms, attached to the home's main structure, out of wattle and daub or adobe bricks, ${ }^{47}$ and typically use them as a sleeping areas (fig. 3.6).48 Being fenceless reduces the adults' ability to control young children and allows passers-by to interact with the activities that take place in the front and back yards, which, in addition to the small bomes' interiors, prompts children to roam the the world and themselves ${ }^{51}$

One difference between Congolese ens. This var the Rwandan camps. These varianc s within DRC and to the availabilityo who con tukus half a metre to a metre awa from he house if space is availa 53 Those from further afieldin North Kivubind (the added kitchen usually attached to the main structure and generally with the same type of roofing as the main house.

Another illustration of this are the South Sudanese homes, represented in significant numbers in Kyangwali and Kakuma (fig. 3.7). In the Ugandan camp, they are made of several small and circular tukuls spaciously spread throughout the usually extremely well-kept home compound. Refugees expressed that the custom in their each child older than 12 years old, thus providing distinct sleeping arrangements for adults and children. Some of these homes had skirting bo some of these homes painted with mud, and separate tukuls for who come from areas close to Lave ${ }^{2}$ region was to build a separate tukul for

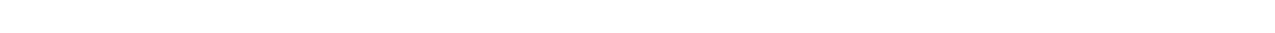




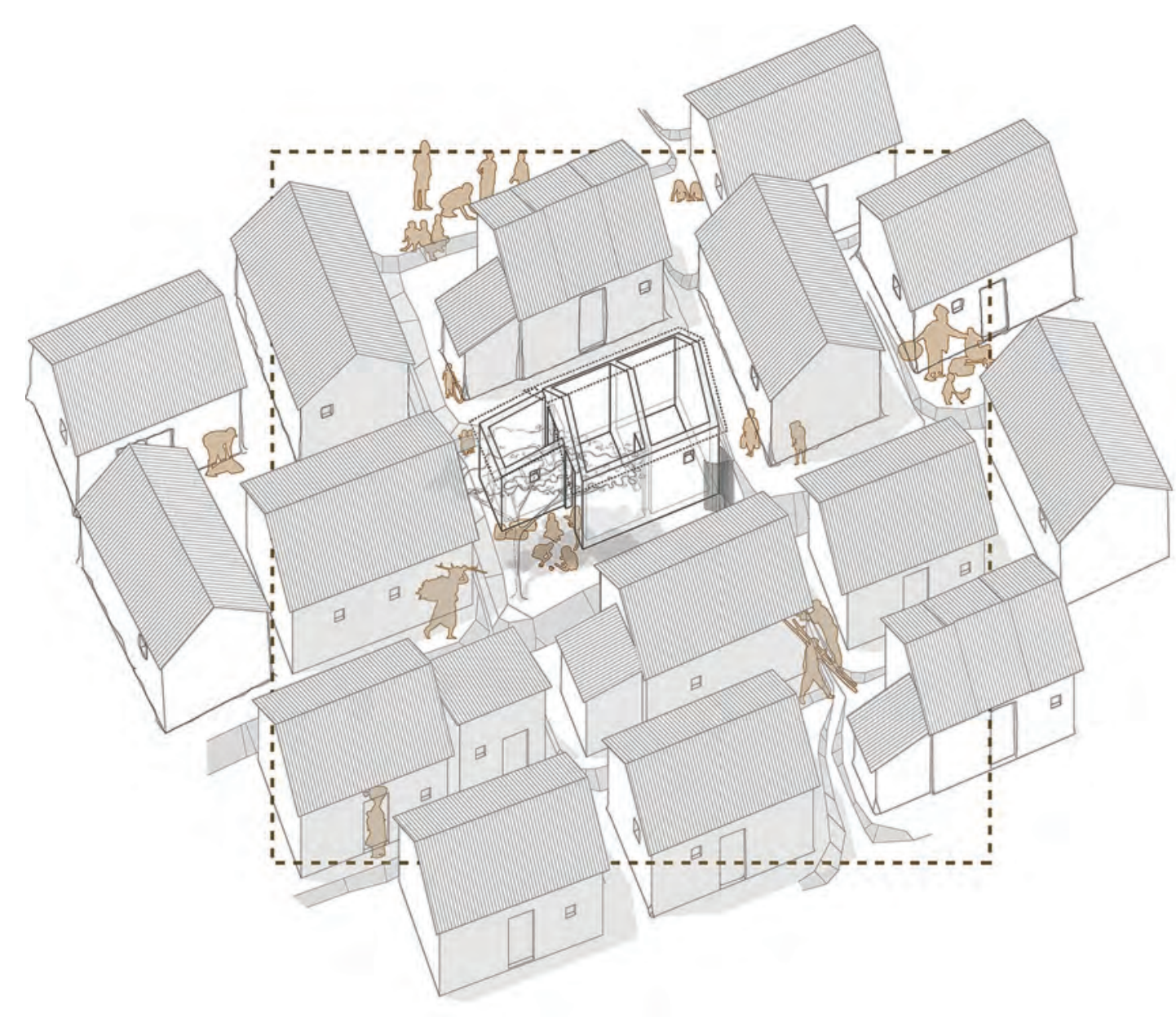

3.6

hens and grain storage. This separation soil - which consequently meant a lack and the abundance of space tends to benefit of construction materials and grass for children, as the alternative is overcrowded thatched roofs - force them to construct homes with shared sleeping arrangements rectangular homes.

with some reports of child abuse. ${ }^{54} \quad$ Assemblage thinking helps me to highThe South Sudanese families in Kakuma light the diverse effects of non-human actors o not build in this manner. Reasons such in home construction. Security, availability as lack of freedom, small. Reasons psuch in insecula as lack of freedom, smaller plots, insecu- of materials and climate create diversity, vity, UNHCR's provision of init al metal while cultural background, traditions, roof sheeting, desertification and sandy memory and family structure give more

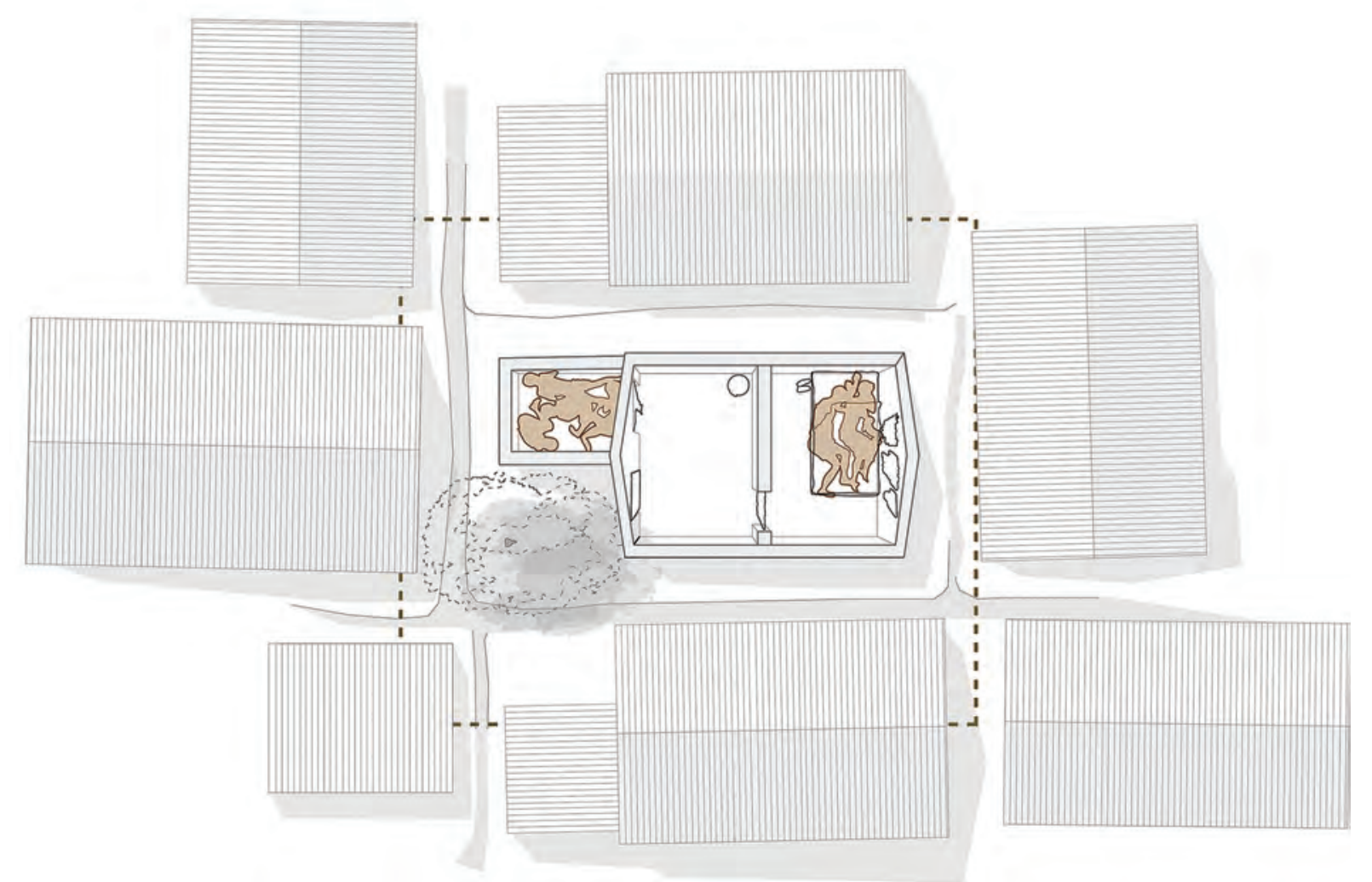

homogeneity. Some factors are territorialis- young children's learning and that the ing, while others are destabilising. Origins humanitarian assemblage largely obviates. ${ }^{55}$ and camps' contexts overlap, creating dif- Access to decent, child-friendly, secure and ferent assemblages and hence different safe water and sanitation facilities affects home structures. Homes are a complex children's everyday activities. They comexpression of refugees' 'right to the city' plain about the dire conditions of WASH $\begin{array}{ll}\text { and their right to adapt their surrounding } & \text { in all the camps in which I have worked. } \\ \text { built environments to their needs. } & \text { They criticise the terrible smell and lack }\end{array}$ They criticise the terrible smell and lack WASH facilities are another relevant
spatial modification that explicitly affect
and hence refrain from using them and 


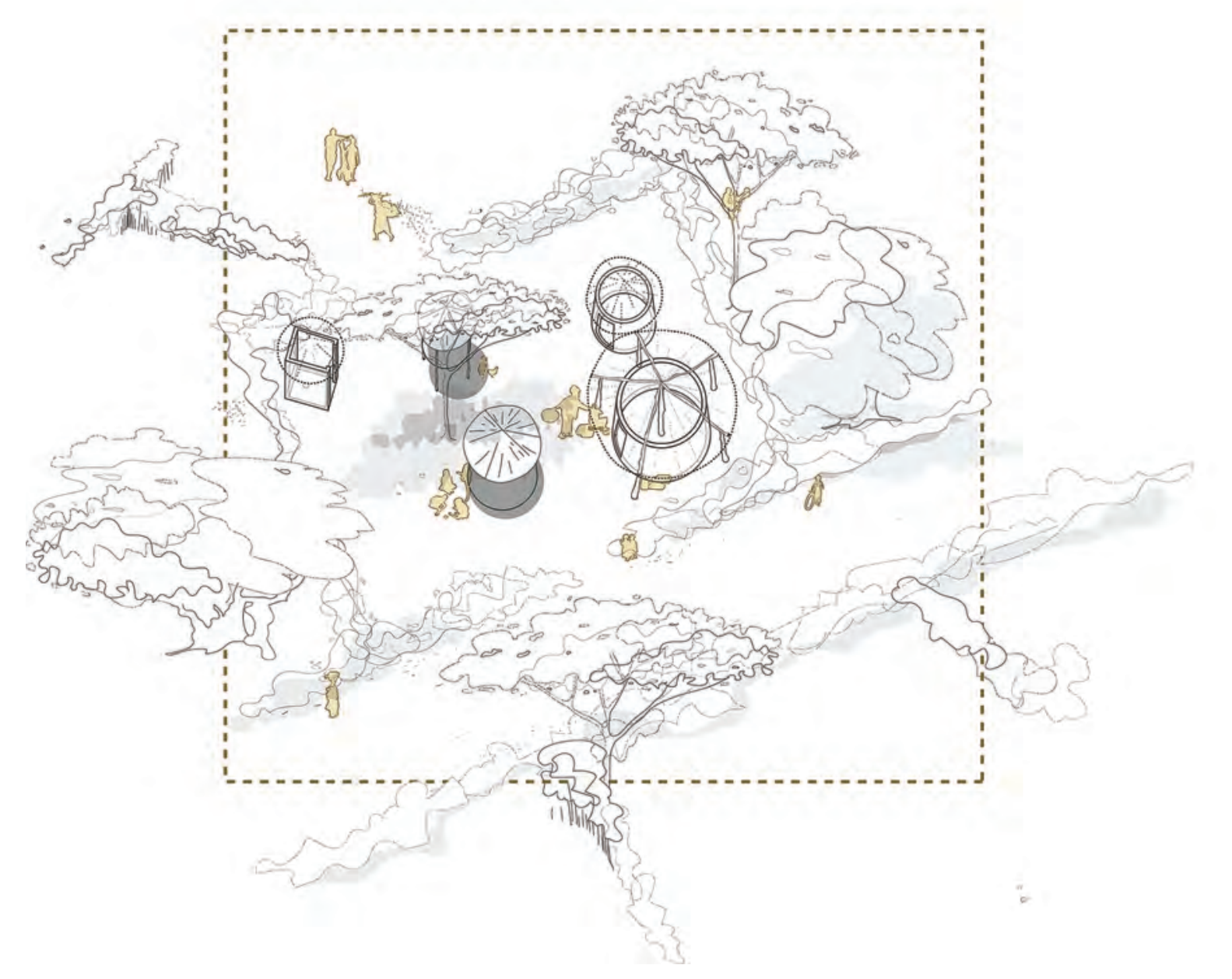

3.7 Diagrams showing the South
Sudanese refugee homes in the Southwest Ugandan refugee
camps and the main activities happening during the day and the
night within and around them. axonometric overview them. Left axonometric coerview of ham
in Ngurue village in Kyangw showing dally activities. Right: one house in Ngurue village in kyangwali showing the sleeping

xcuse themselves elsewhere - with risks host country's policies and the physical nvolved. Adults also complain about WASH characteristics of each camp. For example facilities, and even NGO staff agree with the in the camps of Southwest Uganda, each lack of sufficient and child-friendly WASH family must build its latrine within its allocated plot of land. The camp administration The overall adverse conditions of toilets, does not provide public latrines or help to showers and points of water access are due construct individual ones. In Kakuma the tion, their costand high maintenance, the of Kenya

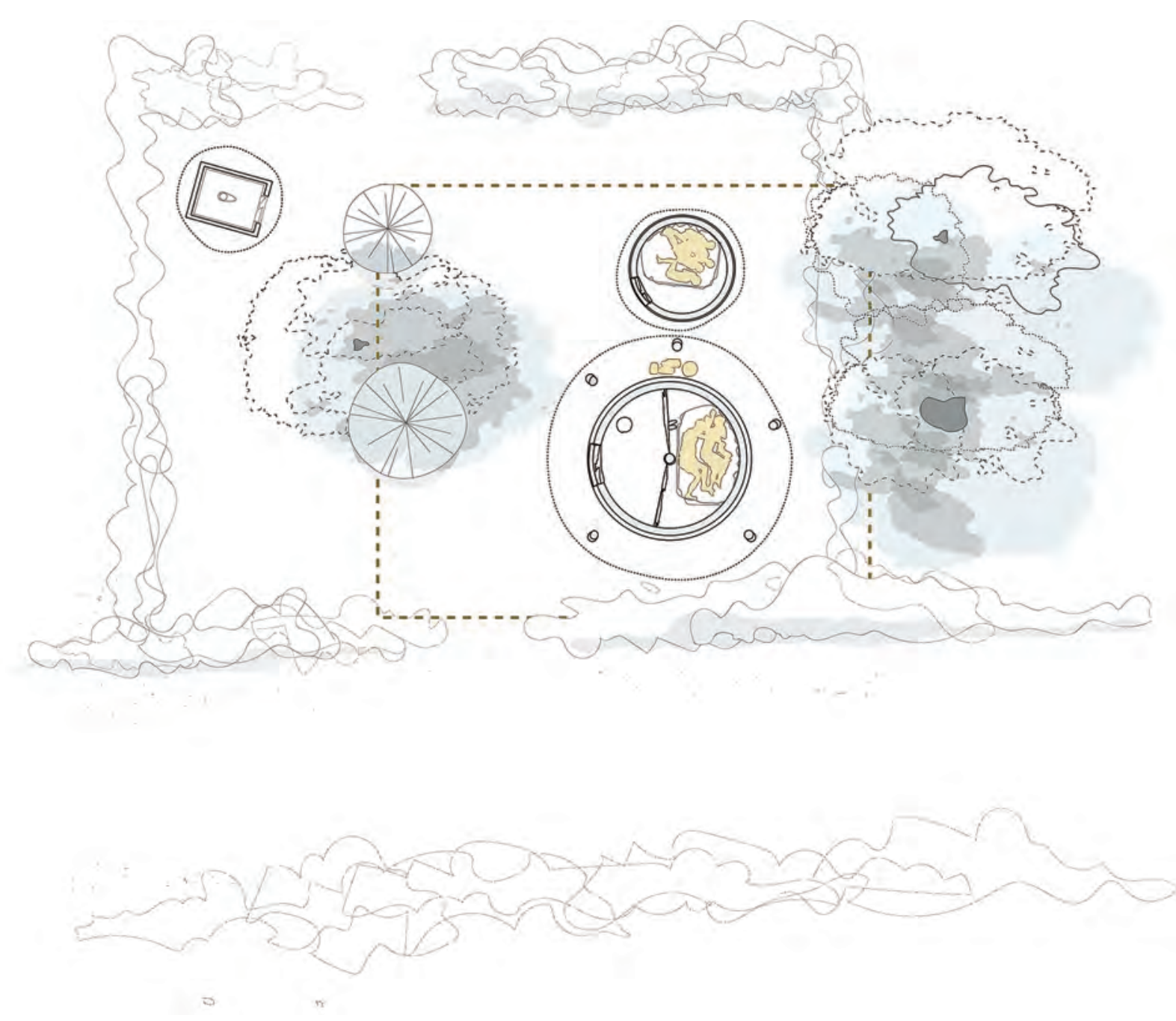

Committee provide one prefabricated case of Kiziba, and refugee-built ones are latrine slab per family, but only if the family exceedingly rare due to the lack of land. It had previously dug its latrine hole. Families is only in the areas that encroach outside unable to do so-usually the vulnerable, the boundaries of the camps in Kigeme widows or child-led households - remain and Kiziba where some families have built without a family toilet. ${ }^{57}$ In Rwanda, due private showers and latrines.

to the extreme lak of to the extre The corilities with requires more skills and tools, as well as one hole for every 45 people in the severe complex negotiations with direct local 
hosts, neighbours, camp managers and NGOs than is required for the expansion of the homes. They are not as widespread. Yet, their study brings to the fore sophisticated relationships and contextual and cultural characteristics of the various camps.

Allowed: religious temples, educational facilities and commercial structures- $-A$ few months after a camp is established, the assemblage of refugees and direct local hosts begin spatial appropriations their 'right to the city', refugees, somether 'ngh hosts and rarely but increasingly in coordination with NGOs, create and $\mathrm{n}$ coorthose built environment aspects that fall outside of the humanitarian clusters' mandates-elements that the refugee assistance assemblage does not consider essenti or life-saving, such as religious facilities, commercial endeavour ${ }^{58}$ and cultura relevant educational facilities (fig. 3.8).

In the camps that I have studied, the UNHCR/host government assemblag provides roads, water access, clinics an formal schools during camp establishmen Later, humanitarian-led refurbishments, expansions and new constructions are only punctual and depend on donor agendas and specific funding appeals. As there is not a coordinating body to manage construction works in the camps as a whole once the initial establishment phases are ove architectural interventions are usually one-off, not typically well coordinated and usually designed by NGOs' staff or shortterm consultants.
A clear illustration of the intersectionality of assemblages and the diversit of the power structures that exist can be found in Kiziba. Owing to lack of space within the camp boundaries, refugees negotiate with their direct local hosts to acquire or share the land adjacent to the camp to use for farming and to construct shared religious facilities. Over the years, the assemblage of refugees/direct local hosts have built at least nine churches and one madrassa-mosque outside the original camp boundaries, which serve all quarters 60 bnoundaries, which serve all churches and madrassas as som identify favourite spaces in the camps. Wo their at both the UNHCR and Minis the UNHCR and the Rwandan Refure Disaster Management and MINEMA) have confir MNIMA) have confirmed that these land transactions happen initially without quietly providing quietly providing spaces for non-forma learning for their children. ${ }^{01}$ Once th camp management notices these 'informal' transactions - usually when refugees have already erected a building - the renegotiate the ownership of the land with local and national authorities, and the camps' boundaries expand. ${ }^{62}$ Even the more restricted camps have porous borders, and the most destitute refugees have some degree or type of power over their 'managers'.

The Southwest Ugandan camps present good examples of the inhabitantrun educational facilities. The collection of camp planning strategies and government policies in the country and governrelationships between refugees and the

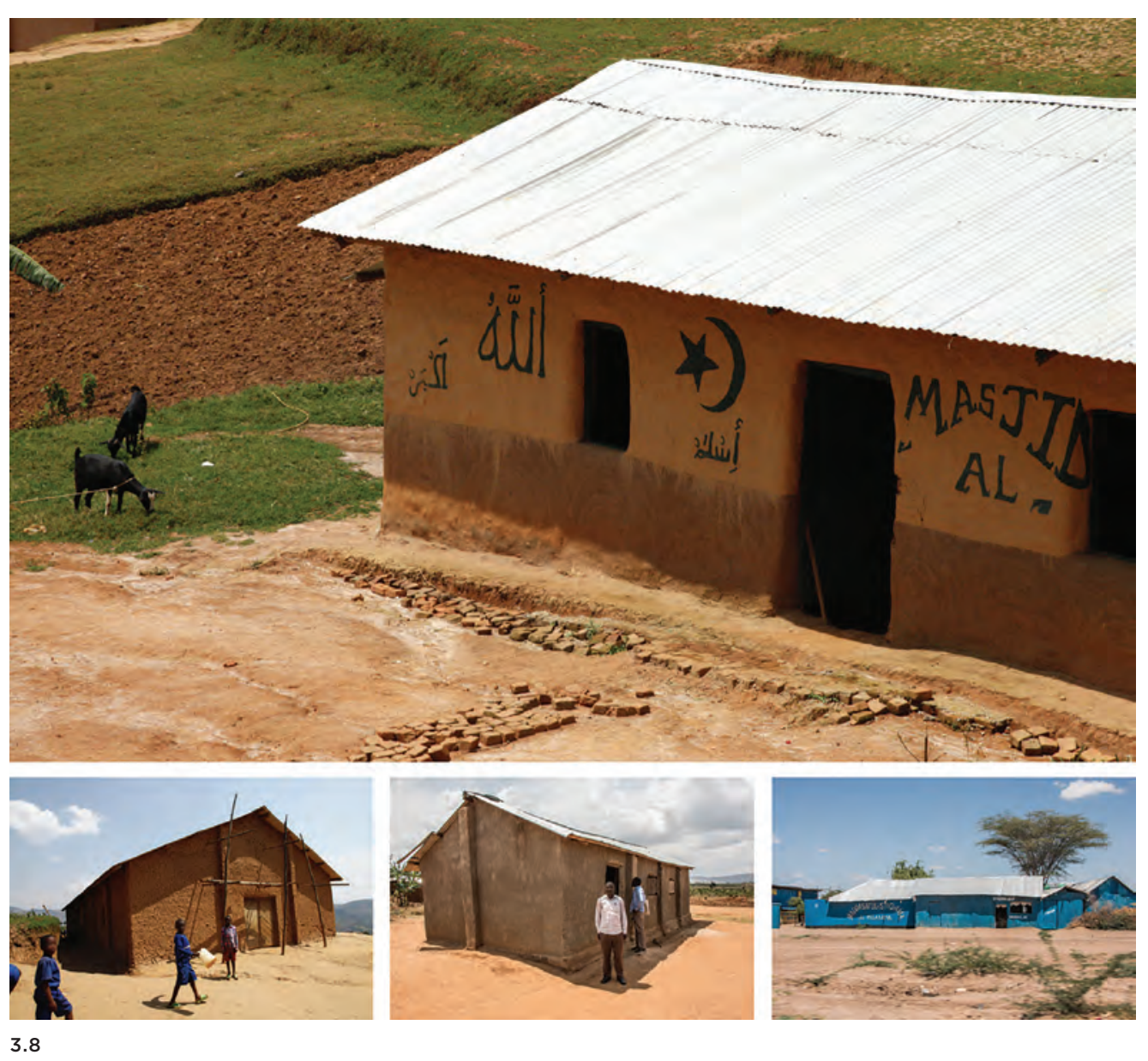

3.8 Religious facilities. Top:
mosque on Kiziba's out mosque on KIzlad's out-
skirts, Kiziba refugee cam Sestember 2015 Bottomp from
left to right: church in Kiziba's quarter 8, Kiziba refugee cam
September 2015 ; Isania Baptis church, Isanja village, Juru August t2017; mosague in Kakum
phase III, Kakuma refugee cam September 20
Elorduy. direct local hosts. Within the threshold shared between refugees and nationals, created by the ambiguous and porous I found - similarly to Kiziba - churches camp boundaries, refugee groups and sur- built by refugees and direct local hosts rounding Ugandan nationals have initiated that doubled as ECD facilities during non-formal content-based primary and weekday mornings. ${ }^{64}$ In Kakuma, where nursery schools. For example, in Kyaka people of Muslim religion are a majority, II, direct local hosts had built three of I found several madrassas and churches the seven ECD centres that my team and built within the camp fabric in clusters of I visited during fieldwork in 2016 and which joint compounds. In Kakuma, unlike in a ECD facilities ${ }^{63}$ In Nakivale, in the villages a shared initiative with the surrose was furthest from the camp centre and those semi-nomad Turkanas and NGOs. Besides, 

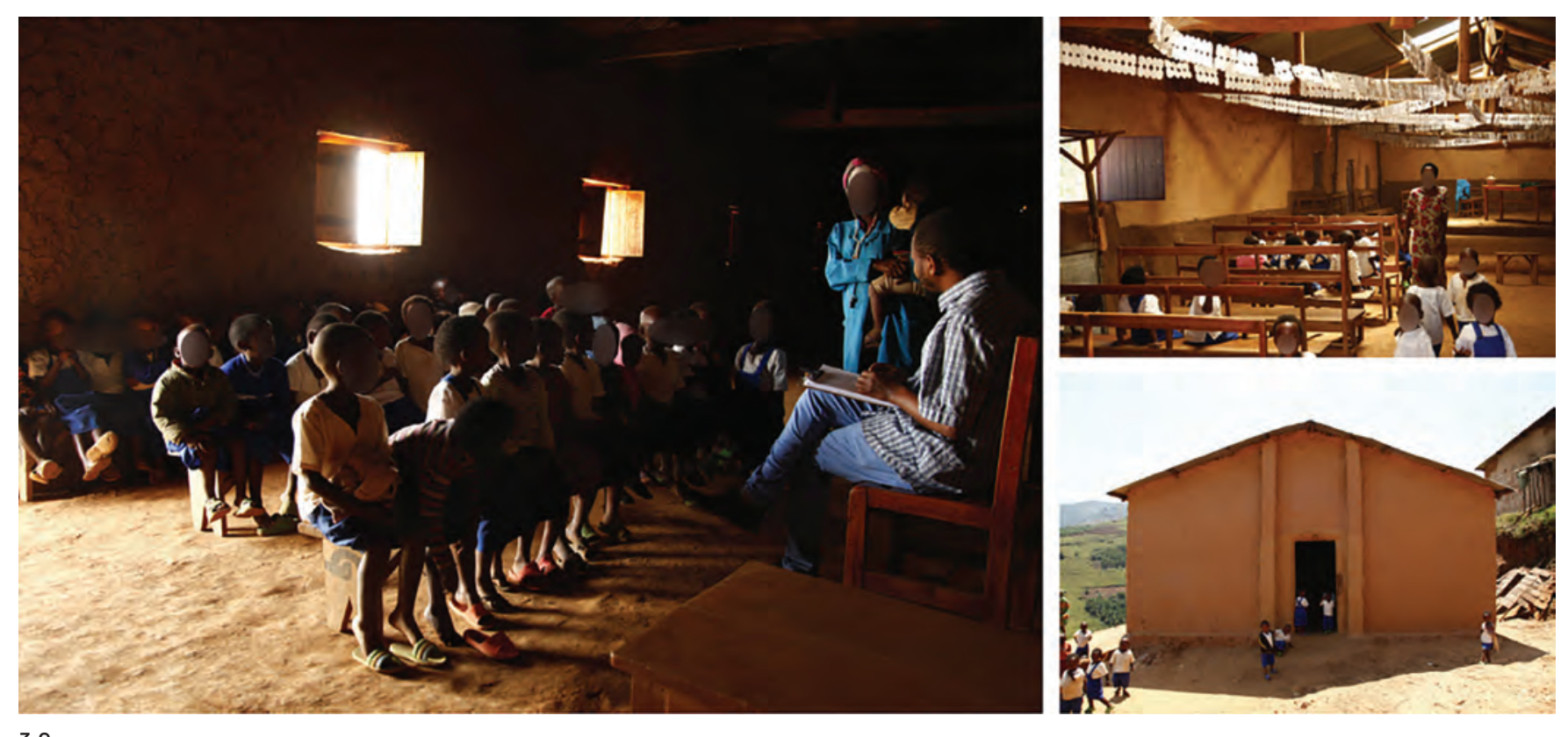

the humanitarian system does not count them as ECD provision

I classify the religious and self-built schools as non-formal learning environments. They provide a mix of learning by experience and content-based learning, which tends to be culturally adapted and
in smaller groups. These fall mainly out of the scope of the assemblage humanitarian system/host government mandate. Hence, they lack material resources and management support. Yet, religious facilities become and a tie to previous lives before refugeehood and encampment (fig. 3.9). They can 3.9 Kiziba's non-formal ECD ven become an element of empowerment and direct local host-built churches

for recome an element of empowerment Rwanda, the mere construction of religious temples has led to the inconspicuous an slow expansion of the camps' boundaries.

One of the most ubiquitous spatia propriations is the reconversion of homes into businesses and the construction of new commercial buildings (fig. 3.10). These are particularly apparent in the larger, olde and more cosmopolitan camp assemblages such as Kakuma phase I and Nakivale. These appropriations take place particularly along the main roads and close to the initially UNHCR-built markets ${ }^{65}$ and illustrate the variability among camps. In Kakuma, where refugees have more access to cash than those in other camps ${ }^{66}$ and where transport arteries and outside market hubs are further away. ${ }^{67}$ commercial facilities abound. Kakuma phase I is indeed an intricate network $\mathrm{commercial}$ local markets and urbentisting averi,
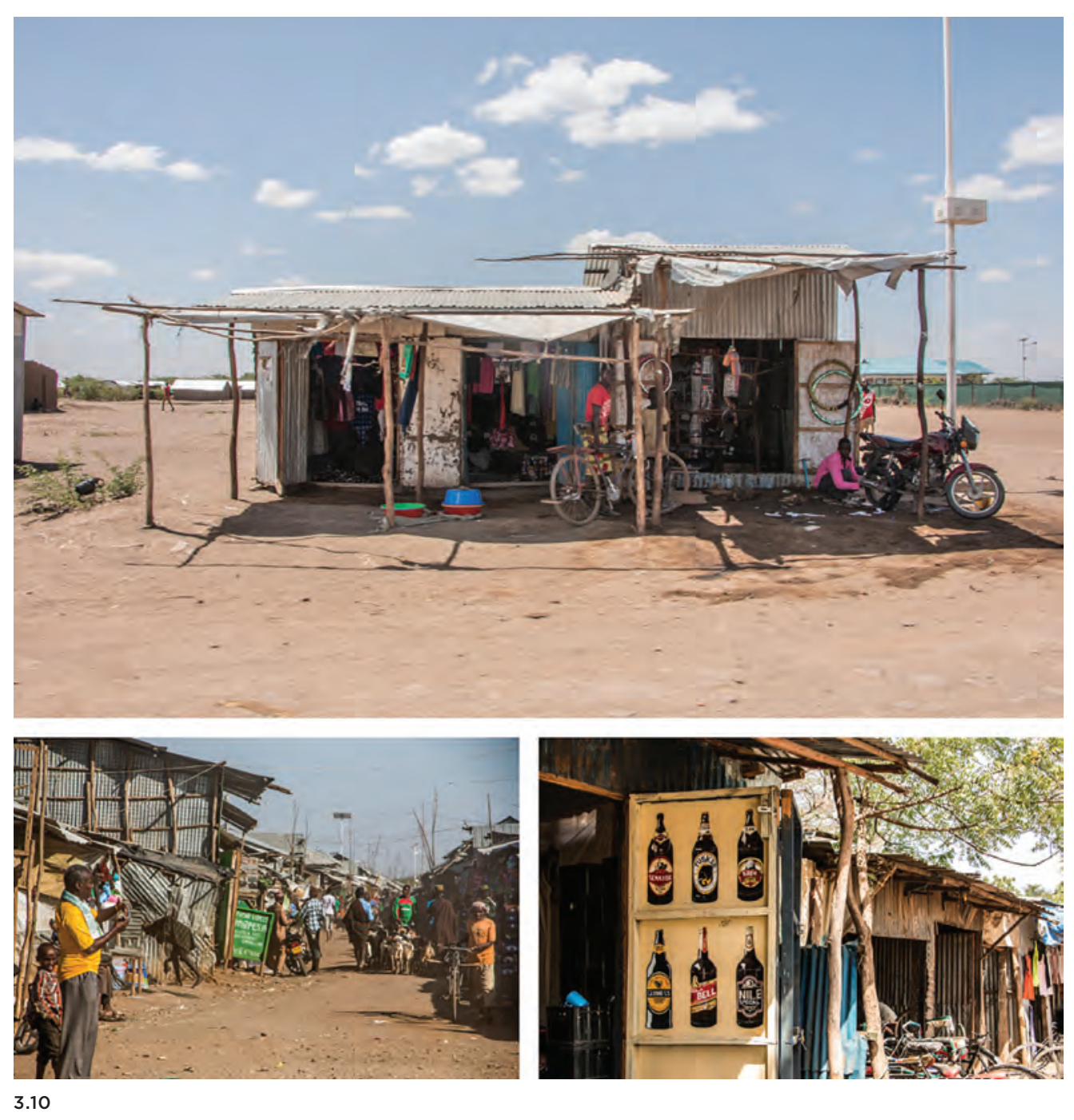

3.10 comm Kakuma. Top: small business
Kakuma phase Ill Bottom: two commercial roads in Kakuma Elorduy.

Mugombwa - and where refugees do not like the town-like trading centres as places receive cash hand-outs or remittances from to hang out and play - children in the abroad, commercial spatial appropriations Southwest Ugandan camps said they liked take longer to occur.

These allowed interventions act as stimuli These allowed interventions act as there, in their electricity-run radios and TVs, the varied people and the goods in the children in the larger and older camps in shops. However, with the rise in the comSouthwest Uganda and Northern Kenya mercial offer, the land value increases, and 


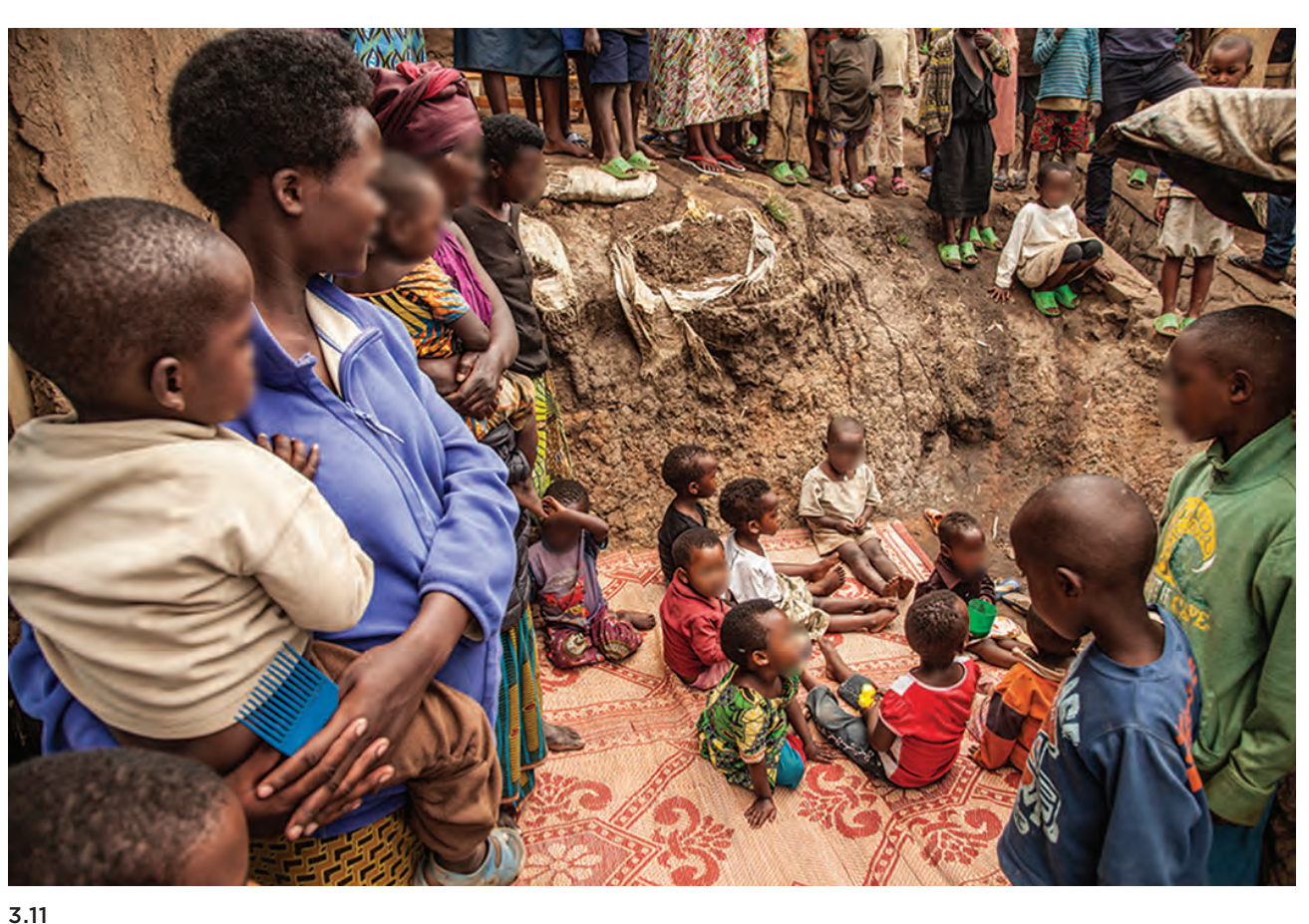

3.11 One of Kigeme's home-based
initiatives in quarter 5 K Kigeme initiatives in quarter 5. Kigeme
refuguee camp, september 2017 .

๑) Amorós Elordu refugees divide, sublet and expand homes. The front of shelters become shops, an open spaces become scarcer. Public toile become more crowded and dirtier. Hence, adults tend to keep children away from thes spaces.

Encouraged: the case of the home-based CD centres in Kigeme and Mugombwa, Rwanda-Since 2012 in Kigeme and since 2014 in Mugombwa, for a few hours each day, groups of 10 mothers - with some matespaces that exist between their homes in order to develop HBECD activities. ${ }^{69}$ These initiatives each serve around 15 children aged three to five years and take place from 8:00am to 11:00am (fig 3.11).
The nascence of the HBECD initiatives and their success is down to many factor In 2013, as Kigeme was expanded, the two existing formal ECD centres ${ }^{70}$ appeared to far away for many families with young children and were also overcrowded. Besides, some parents wanted to educate children according to their cultural conventions, and CARE Internationa $1^{71}$ - which was in charge of ECD at the time - had previous successful HBECD experience in rural areas outside the camps. ${ }^{72}$ This triggered the first test of HBECD activities in the Rwandan camps. At the end of that year, as Mugombwa was being established, Kigeme's successful HBECD experience ning to HBECD activities In Septom 2015 , a r

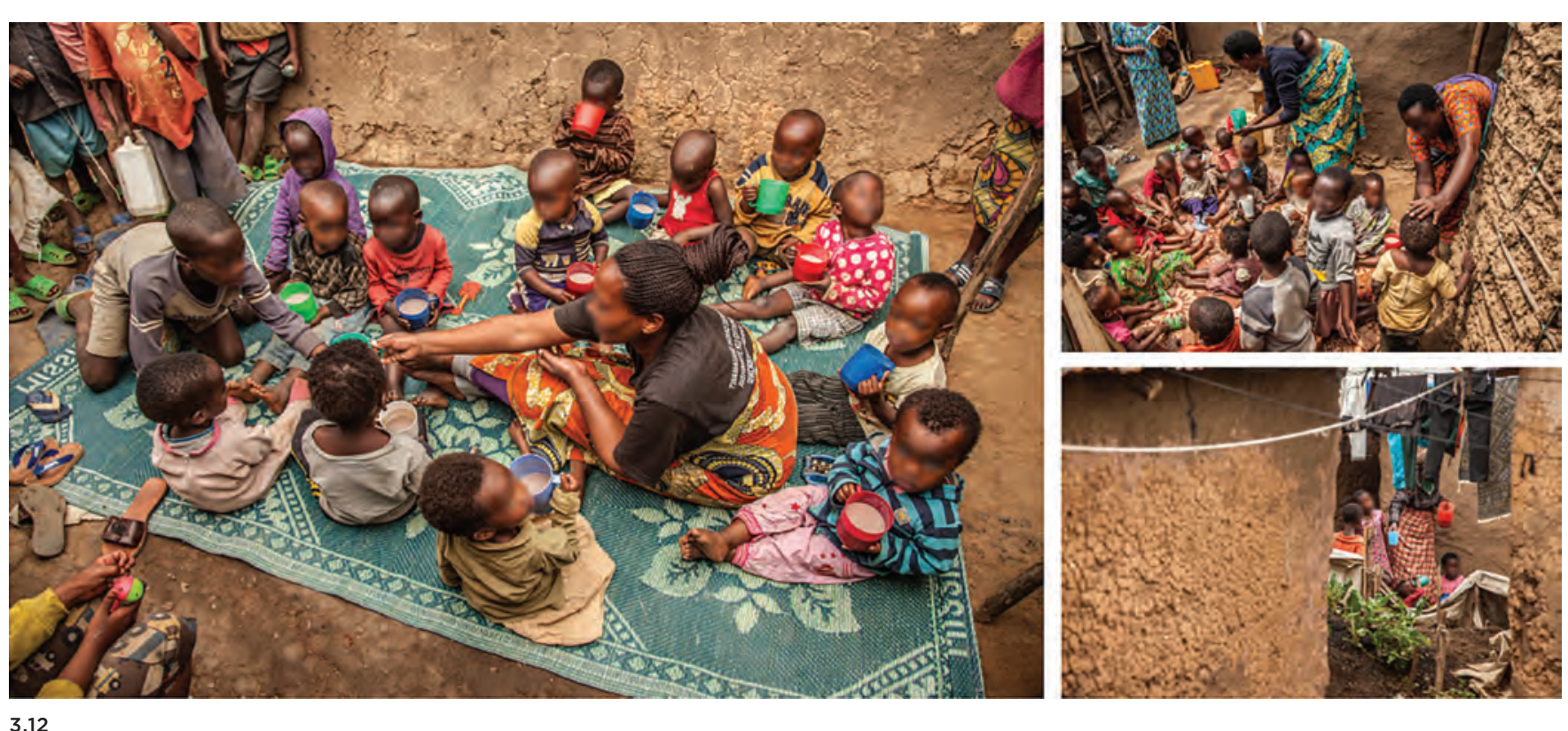

940 mothers in Kigeme rotated amongst a constellation of 94 HBECD initiatives - in 2017, there were 74 - occupying an average of 400 square metres in total and hosting 1,146 children between three and five years of age. ${ }^{73}$ In Mugombwa, around 600 mothers organised 61 initiatives - in 2017, there were
64 - serving 599 children in an occupied 64 - serving 599 children in an At each HBECD initiative, a locally made mat is placed on the floor to define the space and to provide a clean, horizontal platform for the four hours that the activities last these HBECD initiatives with sorghum for the daily porridge, some toys and floor mats. The

materials such as jerry cans, tarps and wooden poles. In Mugombwa, the mothers provide toilet paper turbans to distinguish the young children while they are taking part in HBECD activities (fig. 3.13). These turbans work as an added component of the pon and -making; by wearing them, children he HBECD.

The tremendous lack of space in both camps constrains these HBECD spaces to an average of four square metres. The damp mud floors are not adequate to spend several hours sitting on, and the initiatives lack enough toys, furniture and educational materials. There is no protection from the sun, the rain and passers-by unless the 3.12 Photographs of Kigeme
home-based ECD initiatives in quarters 4 and 5. Kigeme refugee
camp, September 2017. $\odot$ Amoros ridge for the young HBECD attendants in the space selected is fenced with found recycled the spaces for a few hours every day, and 

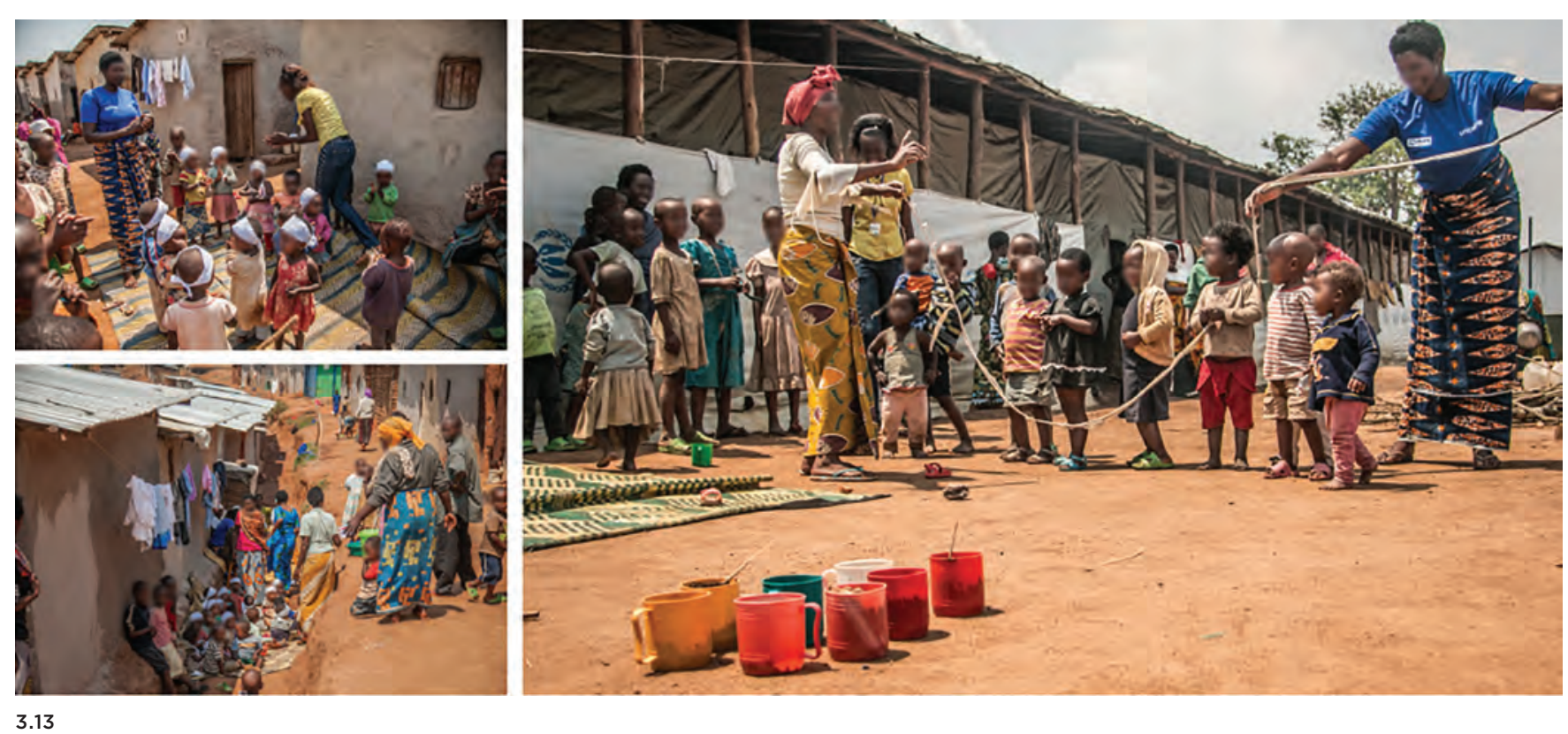

they prefer these to the centralised forma ECD. HBECD activities help decongest the overcrowded formal ECD centres, empowe mothers, entertain and stimulate young chidren and their older siblings, increase ties amongst neighbours and improve the ECD offer in these two camps.

Even in the HBECD cohesive operation, it is possible to observe the Congoles refugees' heterogeneity. While most appreciate the mother leaders' work, not all the neighbours are happy with the noise and the initiative's daily occupation of space. Likewise, not all the mothers are happy to volunteer one day a week to rotate and tak care of the children, despite the benefits is brings them. These differences are clear illustration of Harrell-Bond's criticis of the over-soci.
to refugees.
Quietly reproducing informal learning environments-Encamped refugees an their direct local hosts are continuously adapting to the built environments of the camps and are, in turn, adapting these to their needs, embodying their 'right to the city'. While none of the observed spatial appropriations has a political agenda at their core, in the cases that I present, a new degree of consciousness emerges when the assemblage of humanitarian system/host government notices the spatial appropriations and either allows or encourages them for their own goals, as sociologist Asef Bayat explains:

'[As] long as the actors carry on without being confronted seriously by any authority, they are likely to treat their advance as an ording are likely to treat their advance as once their gains ary exercise Hover, quarters 5,6 and 7. Mugombwa
refugee camp, September 2015 .
$\odot$ Amorós Elorduy. to become conscious of the value of their doings and gains, defending them often in collective and audible fashion? ${ }^{74}$

The humanitarian system has, for long time, been mostly unaware of thes appropriations. That is due in part to their consideration of the camps solely as humanitarian spaces, with the term 'urban' shunned from humanitarian narratives and the built environment considered of little importance, and also to the only recently
contested assumption that refugees are primarily vulnerable victims, duees are and apathetic. ${ }^{75}$ As sociologist Zygmun Bauman expressed:

$\therefore$ questions could be addressed to refuge life that are ordinary in urban studies but dy assemblies of the ruges, pas focase f their tight nentan pict sation and humantaranism dicourses, sation and humanitarianism discourses, but also because of the counterfactually assumed transitional nature of the settlements.?

An interesting remark is that refugee-led spatial appropriations seem to thrive in the most impoverished camps as humanitarian resources dwindle. While the unnoticed - homes and WASH facilities - are prevalent at all camps, the allowed-religious and commercial-flourish where humanitarian management is weaker and where resources shrink, especially for refugee assistance of complex long-term conflicts in so-called fragile states - such as DRC south Sudan and Somalia - where a large section of the inhabitants of long-term camps in East Africa stem from. Wealthier and highly visible aid operations tend to be more hierarchically controlled and provide better centralised facilities. In those, educational spatial appropriations-such as non-formal ECD centres - are fewer. Another noteworthy remark is that operations established after 2010, when the urban approach started to gain traction and the new alternatives to camps began to be promoted, tend to encourage spatial interventions.

Another interesting take from the observed sp wealthier and more internationally visible humanitari the past-toprovide advantages to refugees ated, causing divides betw in these cases, relationsips worsen, cons is the ees in the longterm camps in Sour Ures in the longterm campsin Southwest Jerand have developed more, and more sophisticated, relationships with their direct local ationships seem to be beneficial for all involved: national and local governments, refugees and direct local hosts, as well as humanitarians. In the last years, refugee assistance operations have tarted to include direct local hosts in their rategies, improving this trend.

Refugee-led spatial appropriations appear to provide what the resource-scarce humanitarian system is unable or unwilling o deliver through formal alternatives. Up until 2014, camp managements justbarely allowed the majority of the refugee-led spatial appropriations they noticed while 
in the last six years, many of these have holistic solutions devised together with refuraged. Camp management in gees, taking into account the assemblage of the region is opening up to more refugee- human and non-human actors that partake led spatial appropriations.

The humanitarian system's shift from in refugee assistance. detecting to allowing to promoting these pick only the elements of the Alternatives interventions is happening everywhere, to Camps or the CRRF that interest them even if it differs between contexts. Declining in order to keep control over the refugees. humanitarian resources, the failure of Newinterventions sometimes twist the ide encampment policies that force refugees' of refugees' capability to force them into dependency on aid and the recent austerity self-help while keeping them under similar measures and neo-liberal policies of many of tight sets of devised rules - camps, special the donor countries are triggering this shift. economic zones and other meths, specia For example, both Rwanda and Southwest tainment 79 These neo-liberalstrats of conFor exal ganda have changed from in kind to cash to igne the capable, hand-outs and nocolrage work the ance as they adhere to the CRRF put forward do not play on even ground. Approaches by the international community in 2016. that rely on physical containment are an Even if the val in cash is the same as or atempton refugees' hand even lower than - the former in-kind aid, freedoms, marginalising them and leaving access to money and the authorisation to them with minimal access to resources. work produces changes in the urban fabric Refugees are a heterogeneous constelof the camp as homes are refurbished and lation of often skilled individuals who ar shelters are turned into shops. The growing a key component of their own well-being urban development is clear in the highly Hopefully, the encouragement of refuisolated and impoverished Kiziba where new gee-led interventions that we see in the businesses sprouted up overnight with the long-term camps is a sign of the humaniarrival of cash hand-outs.

Embracing neo-liberal policies, the truly embracing that refugees are a neceshumanitarian system/host governments sary and active actor in their assistance. assemblage is increasingly focusing on However, the implementation of new conrefugees' self-help. It encourages spatial tainment strategies suggests that those appropriations and employs refugees' powerful actors are still reluctant to recagency to achieve its assistance goals ognise refugees' agency. To some degree, more efficiently. However, it is unclear it just does not compute in the normative whether these strategies will contribute to development/aid world view that poor, loosening the grip that agencies and gov- vulnerable and displaced populations can ernments have on refuges' freedoms. It be capable of contributing to and leading (t) refugees' human rights and will promote needing help defending their human rights and accessing food, money, shelter and education. The neo-liberal thought ties monetary and material capability with human capability

Moreover, in the East African case, the post-colonial hangover of the Security Council-dominated international community still ties Africans with need and dependency. The UNHCR's imposition of refugee containment for years - now embraced by host governments - was based on this view of the continent Forcing the establishment of camps in exchange of aid was an approch rooted in a lange of aid was an approach rooled in a lack of trust in new assumed helplessnes, Moreover, the paternalistic and patriarchal international form the majority form the majority of encamped refugees in the continent - with victimhood and dependence. The fact hat currently most of the literature, scholars and organisation working in humanitarian aid still hail from Europe and America and are funded by them only helps to continue this cycle. There is a need for more voices, particularly feminist and decolonising perspectives. There
need for more situated knowledges.

Refugee-imagined radical incrementaland 2017, my team and I asked research respondents which spatial interventions they would propose to make their camp a more stimulating mosaic of child-friendly learning environments. ${ }^{80}$ Their proposals focused on three main intervention areas: the camp/neighbourhood, the ECD initiatives and the home. I translated these proposals into drawings and photomontages and showed the proposals back to the refugee respondents and camp managers to discuss further whether the interventions were addressing young children's learning (fig. 3.14).

The camp/neighbourhood-The most prominent proposal - and the only one consistent throughout camps and respondents - was 'to have more young-children-friendly spaces with play equipment at the neighbourhood/village level' All adult respondents ${ }^{81}$ and a quarter of all child of their priority interventions 82

In general, children focused on experiential interventions that bring joy, cation. clearly and constenty proposed to have similar life to the 'com proposed to have Kakuma to 'commercialcentre of "township life"; access to election, "township life"; access to electricity, TV, "ind chested setting up a motorised transport system to get to school' ${ }^{83}$ Children in the Southwest Ugandan camps proposed 'having more, closer, bigger and better quality ECD centres and health centres'. In contrast, those at Nakivale suggested having more cows and

Adults instead focused on reducing accidents and improving the educational and WASH infrastructure. The adult respondents in the Rwandan camps (the most active in terms of camp proposals) wanted to 'secure slopes and other risk areas-ravines, dumpsters and open septic tanks-with handrails and paring'to 'curate 
Violence and physical abuse due to congestion, substance abuse, and hopelessness Harmful instects at home: jiggers, scorpions, larvae, etc. Climate and lack of weather protection at the home: (cold at night, hot during the day

Lack of space and light for reading and homework at home Homes' poor maintenance and structural integrity Lack of quiet and private space for napping at home Terrain: sloppy, with holes, open drainages, flashfloods cause accidents Sexual abuse at bushes or at the home due to congestion and other factors Road accidents involving vehicles Water management issues: lack of drinking water, soil erosion, flashfloods, floods, etc

Lack of enough and proper child-friendly toilets Lack of enough young children friendly playing areas Lack of books and didactic materials Lack of education Lack of uniforms Small and overcrowded Early Childhood Development Centres (ECD) Parental abandonment and lack of care and guidance Children are overworked by parents Parents don't see the value of ECD, lack of attendance Unaccompanied minors and children-led families Young girls' prostitution Lack of food and drinking water. Malnutrition Health problems, diseases, and lack of treatment Lack of clothes and shoes clothes, food, toiletries, etc.

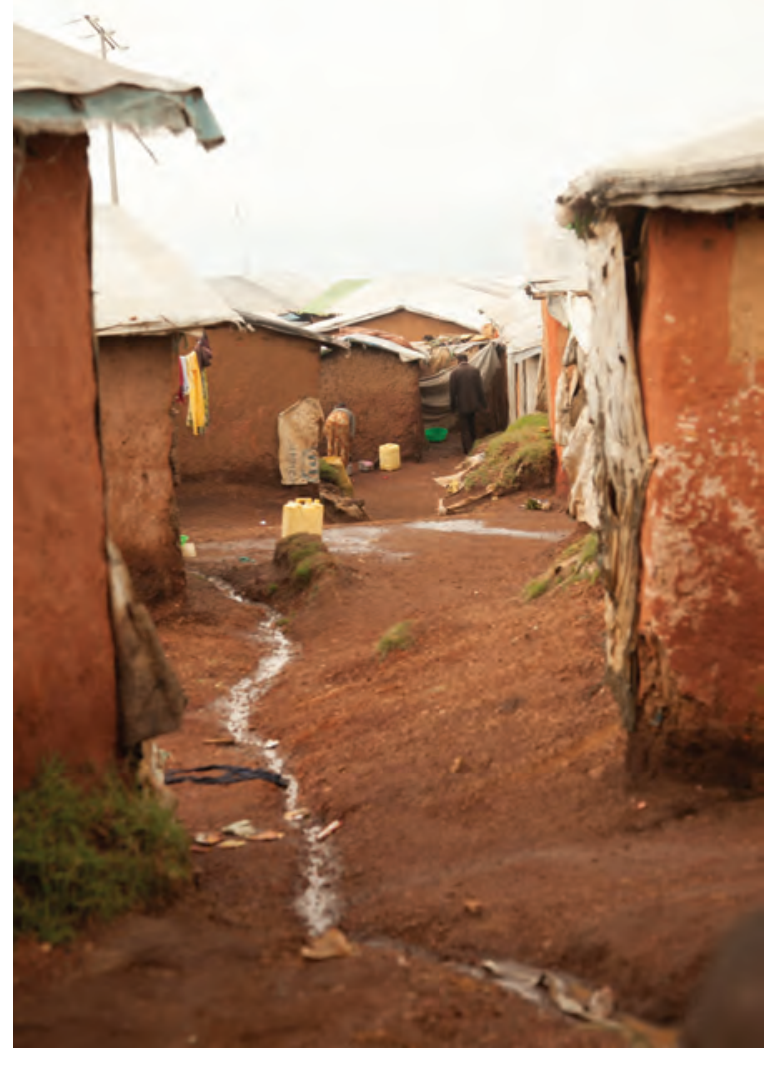

3.15

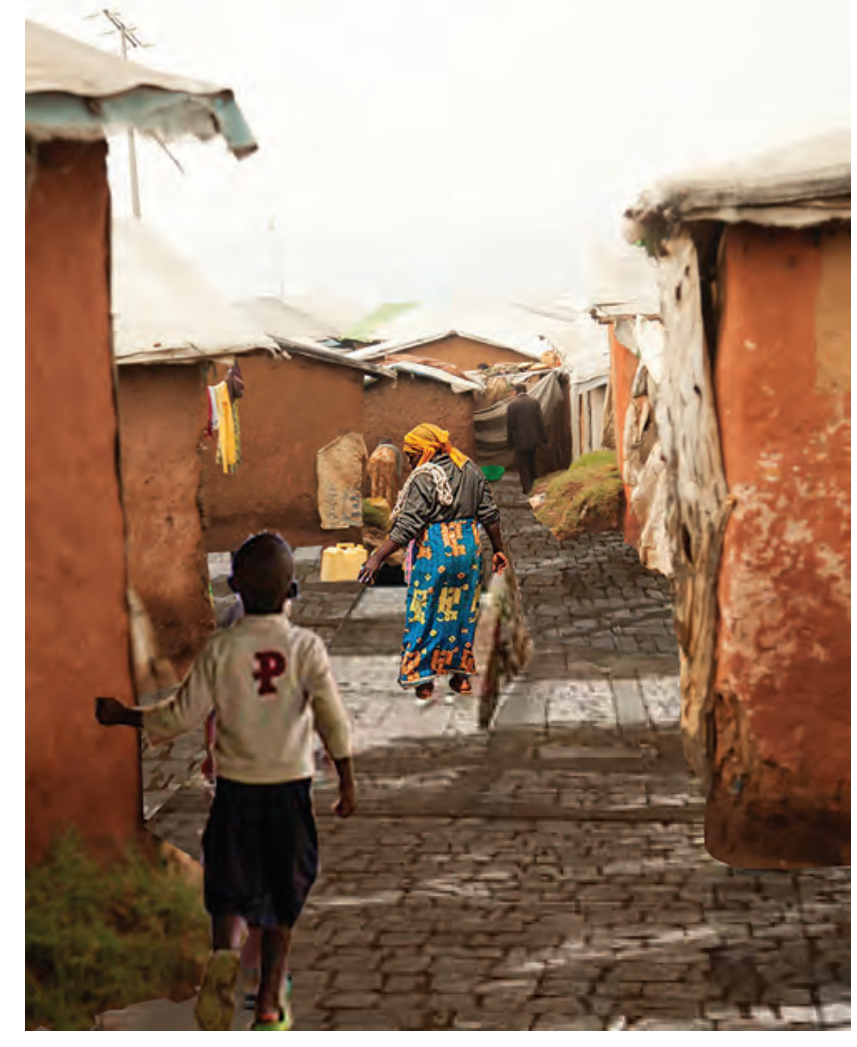

and make safer the paths that children use disengagement with common life, reinforcto access schools'; to 'cover and improve ing Harrell-Bond's opposition to the idea the stormwater drainages'; and to 'main- of the over-socialised view of man. ${ }^{86}$ As tain and make latrines safer'. In particular, useful as it would be to understand the trigKiziba's adult respondents suggested 'more gers for this seeming disinterest and how ECD centres that are good quality and more it compares to the diversity of the camps, easily accessible' (fig. 3.15). ${ }^{84}$ I do not have enough information to make Very few children in the Rwandan firm conclusions on this point. camps, few adult respondents in the Southwest Ugandan ones and almost none of The formal and non-formal ECD initiatives-The respondents who were actively drainage solutions Kiziba might show a certain disempowerment or initiatives - caregivers, mother leaders 
and young community mobilisers - gave answers geared towards improving the quality. They proposed stimulating an didactic', 'child-friendly designed', 'structurally sound and durable', 'sheltered from the sun and the rain', 'easy to maintain and clean' centres. These facilities could 'have openings for ventilation and light', be 'fenced for security' and 'have enough well-designed child-friendly playgrounds appropriately equip

The parents and guardians - less Thvolved in the ECD initiatives - focused on quantity: the size, position and security of the ECD spaces. All the parents and guardians except those in Kakuma phase througested building more child-friendy, high-qualy ECD cenires closer to the people. They also proposed improving the existingCD centrestoserve all neighbourhoods' and 'expanding the existing ECD centres to include more classrooms, a fence with a gate, green areas and access to water. Child respondents focused their ECDrelated proposals on the play and education materials available and on the provisio of food and water. In Kakuma phase III Nakivale and Kyaka II, children suggeste 'classrooms with sturdy wall materials with openings and good iron sheet roofs'.8 ${ }^{81}$ All the children in Kakuma, Kyaka II and Kiziba proposed an 'ECD kitchen with provisions of sweetened porridge'. The children at Kyaka II, Kyangwali, Kigeme and Kakuma phase III suggested 'access to water and clean toilets with hand-washing basins ${ }^{\prime}{ }^{99}$

The home-The home was central in the refugees' proposals for improvement. All respondents in Kakuma and Southwes well-furnished bedrooms'. The children wanted to 'have bed structures, mattresses, bedding and mosquito nets. It is striking that the Rwandan camps' inhabitants barely mentioned bedroom improvements when in more than half of the households, adults and children share overcrowded bedrooms that lack mattresses, ${ }^{90}$ and the bedroom can be a source of sexual and physical abuse of children (fig. 3.18).91

The adults in Nakivale and the children in Kakuma phases I and II Kiziba, Nakivale and Kyangwali suggested having 'cement floors inside the homes' Childron in II Kyanguli, Kigeme and Kakuma phases II and II also propose 'furniture and furmishing like towe carpets and surves' Childen living carpets and shelves. Children living in the Southwest Ugandan camps suggested for liguring 'sol for lighting and TV and agreed with the sug gestion by the children at Rwandan camps of 'building more easily accessible wate points to clean things and drink from'. Onl the children in Mugombwa and Kyaka II asked for 'nicer and cleaner latrines'. This point is interesting, since the quantitative analysis indicated that Kiziba's WASH facilies were the worst of all camps studied. All adult respondents across all camps suggested building 'bigger and better houses, inside and out'. This proposal indicates pronounced differences in perception between camps, since the size and quality of the homes vary greatly from quality o the hat are on average 20 square metres and the private or semi-private compounds are on

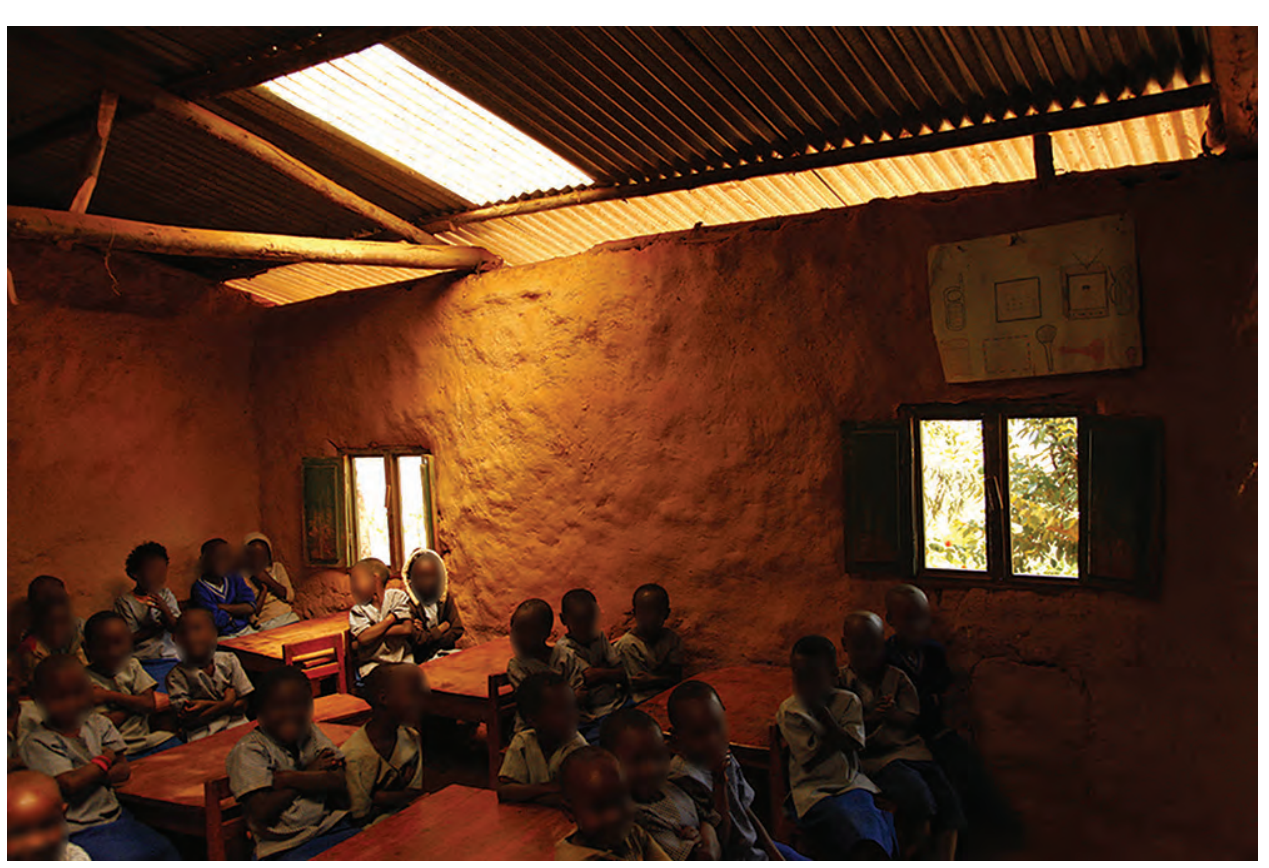

3.16 (A+B) Before-and-after
photomontage of the formal ECD centre in Kiziba quarter 8 , with new windows manufactured in
camp. $\odot$ Amorós Elorduy.

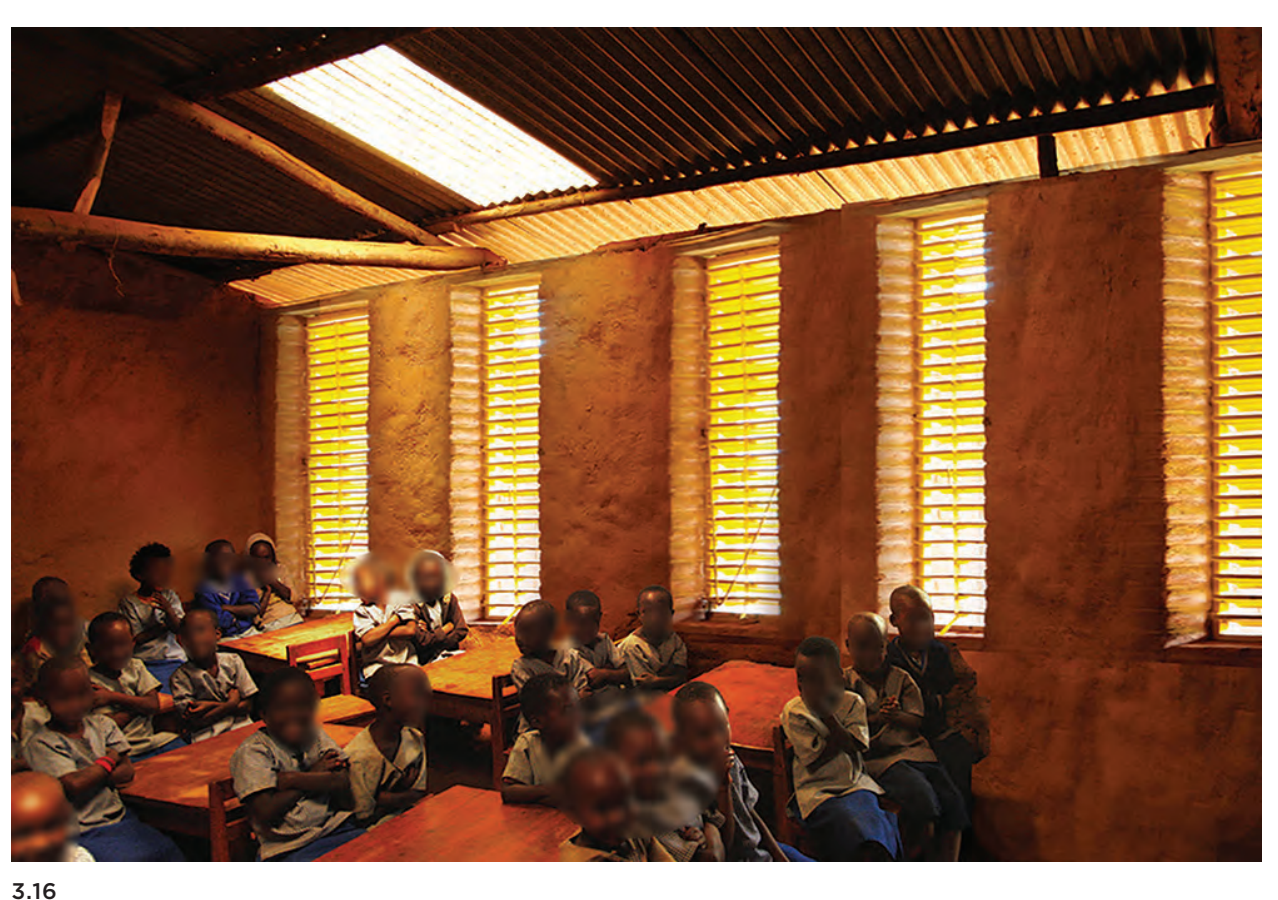




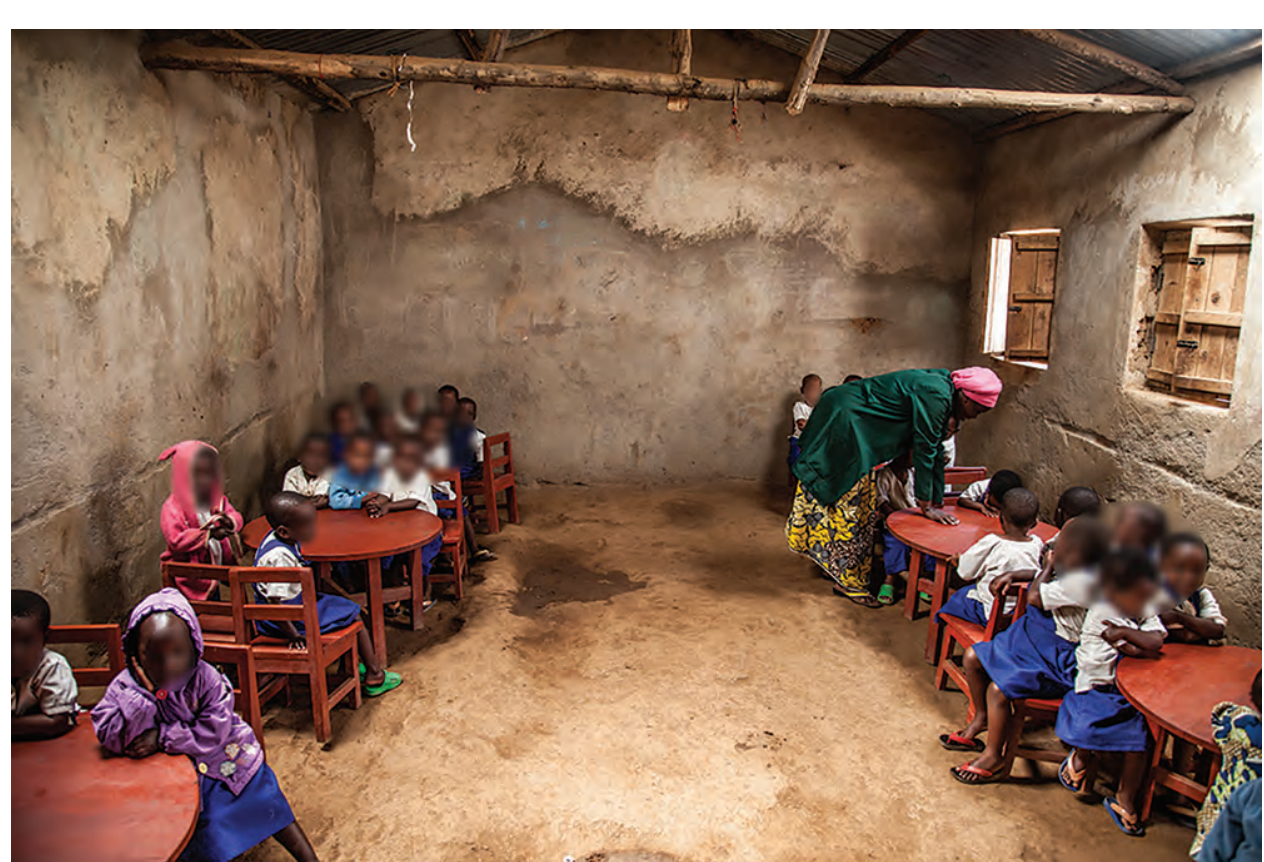

3.17 (A+B) Before-and-after photo-
montage of classroom interior in the maternelle in Kiziba quarter 4 the maternelle in Kiziba quarter
with new windows and ceiling.
0 -
80 square metres. The homes a the Southwest Uga riors that are 20-30 square metres. Their average plot size is 600 square metres for those who arrived before the 2000 s, and around 250 square metres for more recent arrivals. The homes on the Rwandan camps on average have two rooms, with interiors that are 12 square metres and shared exterior spaces that are three square metres. In fact, the adult respondents in the Rwandan camps suggest the 'need for a fence' 93

The collection of suggestions and proposals for the homes by both adults and children shows an appetite for better bedrooms and WASH facilities. While bedroms and While some recomment such as having to a hiove, others, such as having bex to achieve, others, such as having beds, mattresses, pavem, such and power, are all doable and achievable through diverse affordable strategies.

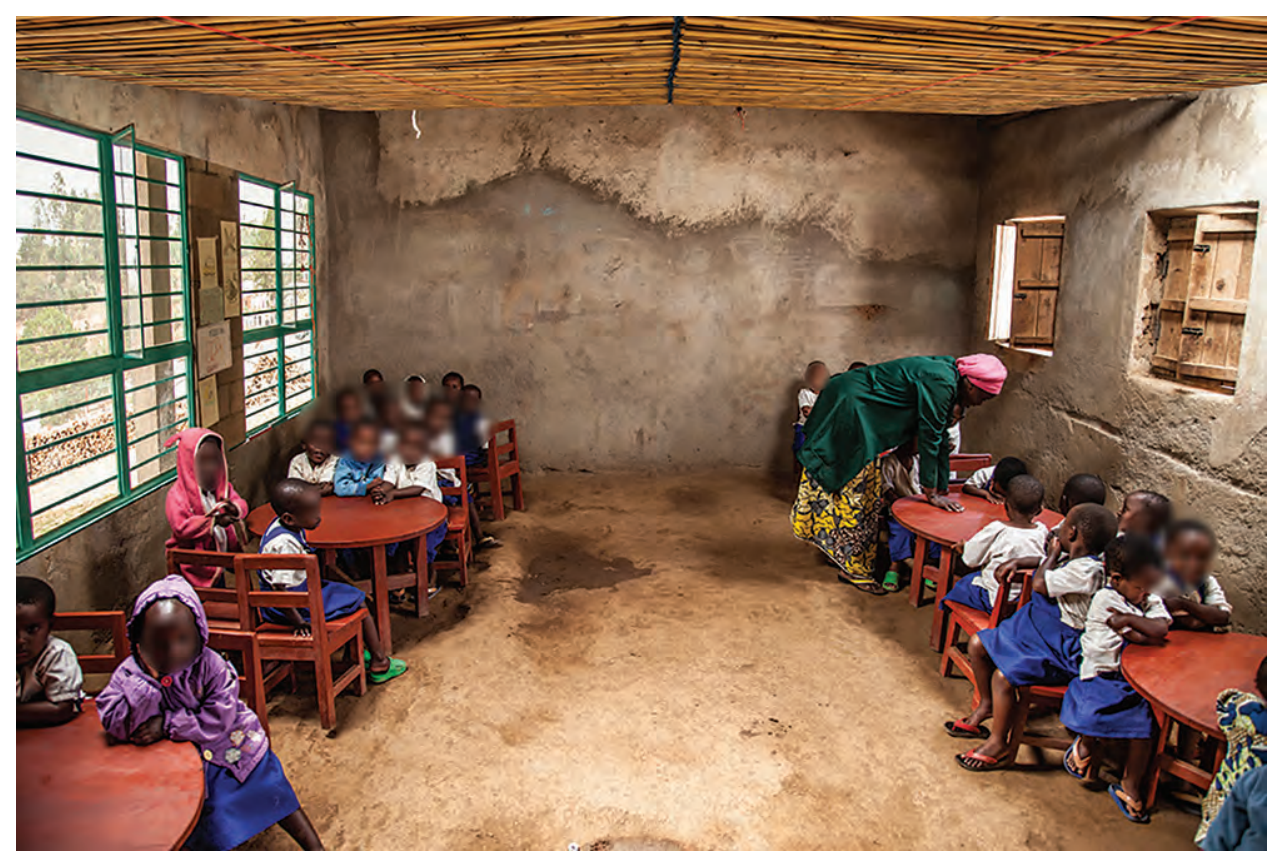

Illness. 94 Chronic anaemia, diarrhoea and parasites chus hookworms and jiggers are plome environments. All these negative influences have an impact on the brain and physical development of young children, affecting amongst other things their attention span neural connections.

Homes should be central in efforts to improve children's lifelong learning and their physical and socio-emotional wellbeing. Health education and protection initiatives that strive to be successful will gain insight by looking at the home as a ence for young children millionste milno re unpaved and children slep on the are unpaved and children sleep on the dusty floors of humid unventilated and overcrowded homes. Sexual abuse and gender-based violence sensitisation programmes will hardly succeed if non-family adults and children continue to share bedrooms and bed structures and access to safe oilets is not ensured. In contrast, small interventions such as paving homes, providing or fabricating bed structures on site as well as sturdy windows and doors, providing power and access to well-lit, secure, safe, clean and accessible WASH facilities can have critical positive effects in supporting those initiatives.

A mosaic of imagined utopias-Adults and children have a wealth of knowledge and chic of have a wealth of knowledge and ideas on how to improve their lives and medium and large 


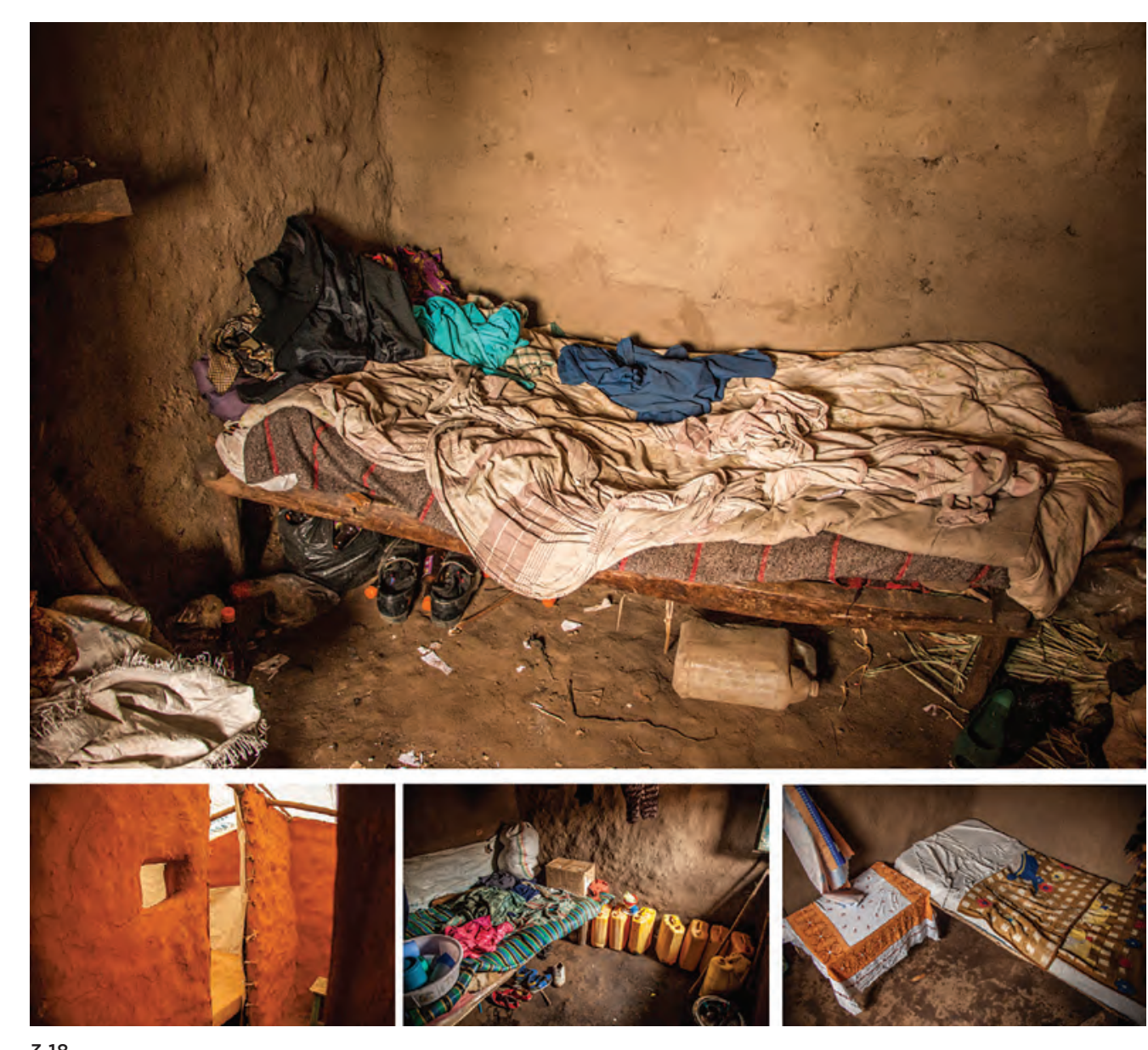

Recording and documenting these proposals can provide policymakers, camp managers, NGO workers, academics and refugees with a catalogue of options to begin improving young children's learning in these longterm camps. It is necessary and worthwhile to research potential ways of carrying out these interventions, supporting refuges and direct local hosts to dev cap them and camp management position.

Moreover, the refugee proposals corded\% open the door to a new understanding about the role of the refugee and of built environment technicians in the planning and maintenance of camps. They reveal refugees as capable of imagining and planning a better settlement that improves young children's learning and of meaninfully participating in discussions meaning ly participating in discussion ment The collection of the imained utopias described raises several questions related assumptions and cultural influences. Each proposal would require more time, information and in-depth research to understand the underlying causes of the different perceptions between groups of respondents and to investigate mean for their implementation.

Speculated transversal spatial appropriations-Participatory Action Research (PAR) methodologies rely on an iterative four-step cycle: gathering data, analysing four-step cycle. gathering data, analysing it, planning an action and carrying it out. I devinged this cycle in the past while camps camps. Wecollect an designedand built from the proses a d its analsis, learned the next ECD centre design a cyle for the next BCD centre design and construction. I continued with this strategy for the development of maps and visual information about the camps that I present here, the development of fieldwork trips, the analysis of the data and finally the PAR exercises. In 2017, I developed participator research with children and their suppor network of adults in Kiziba and Kigeme refugee camps. I chose these two sites due to budget, time, accessibility, th wealth of information and connections 1 had in both (I had worked in Kiziba since 2011 and in Kigeme since 2013) and their length of operation (Kiziba for 20 years and Kigeme for 12 years in 2017). PAR seemed relevant because the limited research about children in refugee camps recommends its use $e^{97}$ and because the educator Paulo Freire ${ }^{98}$ and UNESCO's Growing Up in Cities ${ }^{99}$ and MOST
Programmes recommend the use of PAR with children. ${ }^{100}$

Some of the strengths of using PAR in these two camps was their compactness, their relatively small size and their location among hills, which enable a comprehensive view of the camps from adjacent hills and roads. In both settlements, all residents and most PAR participants spoke Kinyarwanda and French, had a similar culture and upbringing (Congolese from Eastern DRC from three central provinces) and had milar ancestry and customary practices. During the PAR exercises, I tried to Dur the PAR exercises, Itried potentially be inver learning process carnents, cro localgra workers. I used arts and crafts, traditional and new technologies, and the diversity of disemine disseminate information, develop targeted actions, discuss and create new knowledge. Due to the obstacles involved in participaory research with young children living in refugee camps, to address ethical matters and for organisational reasons, I developed art-based PAR exercises.

$I$ chose to organise the PAR into three interconnected and sequential exercises: (1) the discussion about research findings amongst research participants, (2) the develpment of a spatial appropriation in Kiziba using participatory murals $s^{102}$ and (3) the development of a research-based public interest design (PID) studio with architecture master's (Pudents from Kigli's African Design Centre (ADC) and Kigeme's inhabitants. The exercises builtupon eachother and 


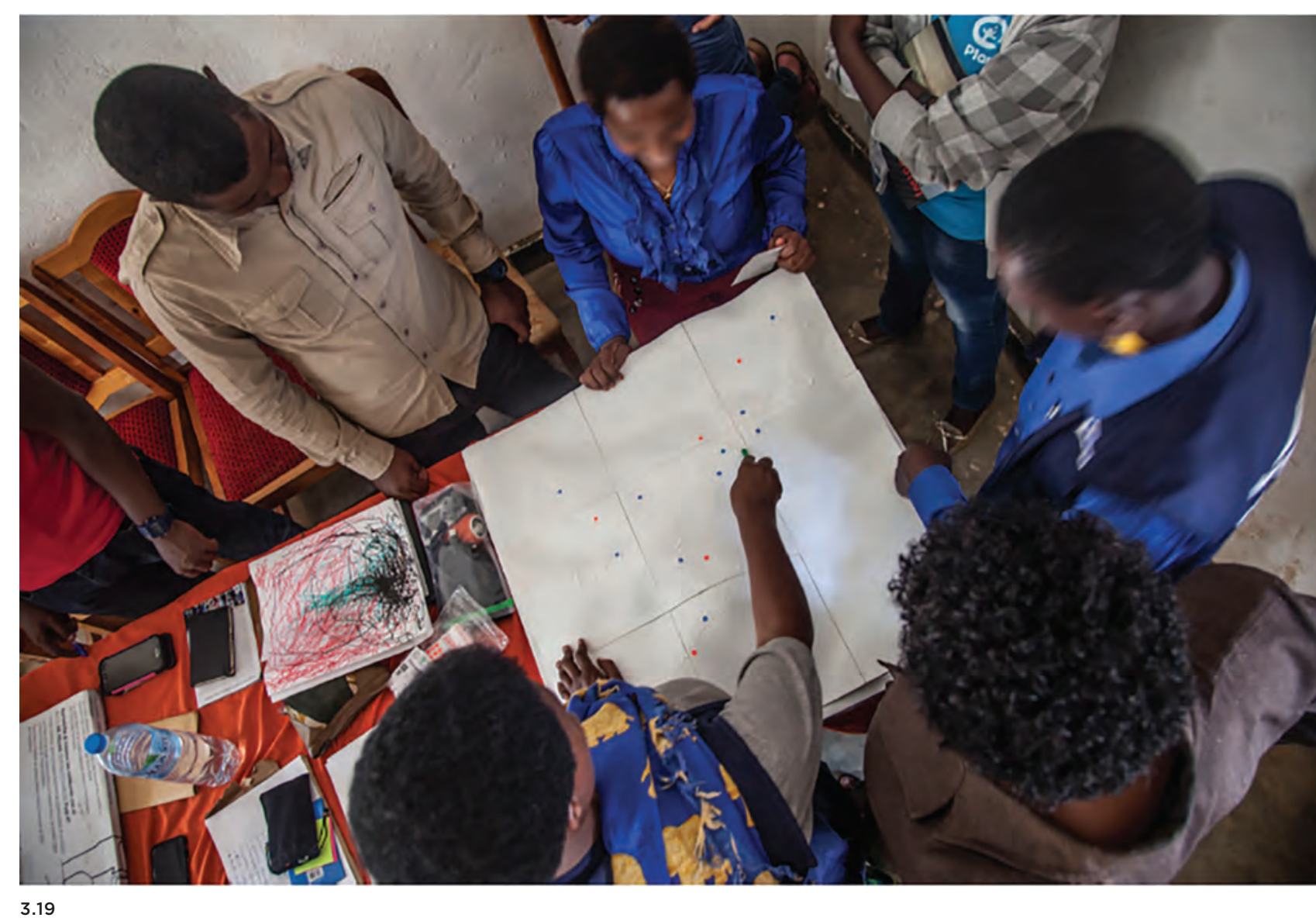

3.19

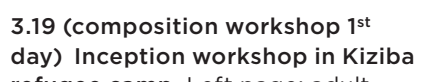

overlapped in time. The ADC fellows were representing the utopic proposals imagined involved in all PAR exercises, and hence the by the refugee respondents and a website. learnings from one exercise fed the following. needs-ln the long-term Congolese able to read it. I then showed the 3D-printed refugee camps in Rwanda, there is a lack physical model. This time, even the young of practice-amongst refugees and refugee participants - aged between three and five camp workers - in talking and think- years old - were able to locate their homes ing about the built environment. For that and their go-to play areas on it (fig. 3.19).

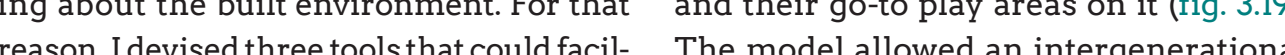
itate discussions amongt participants a 3D-printed model, printed photomontages the actors had their say. Finally, I showed
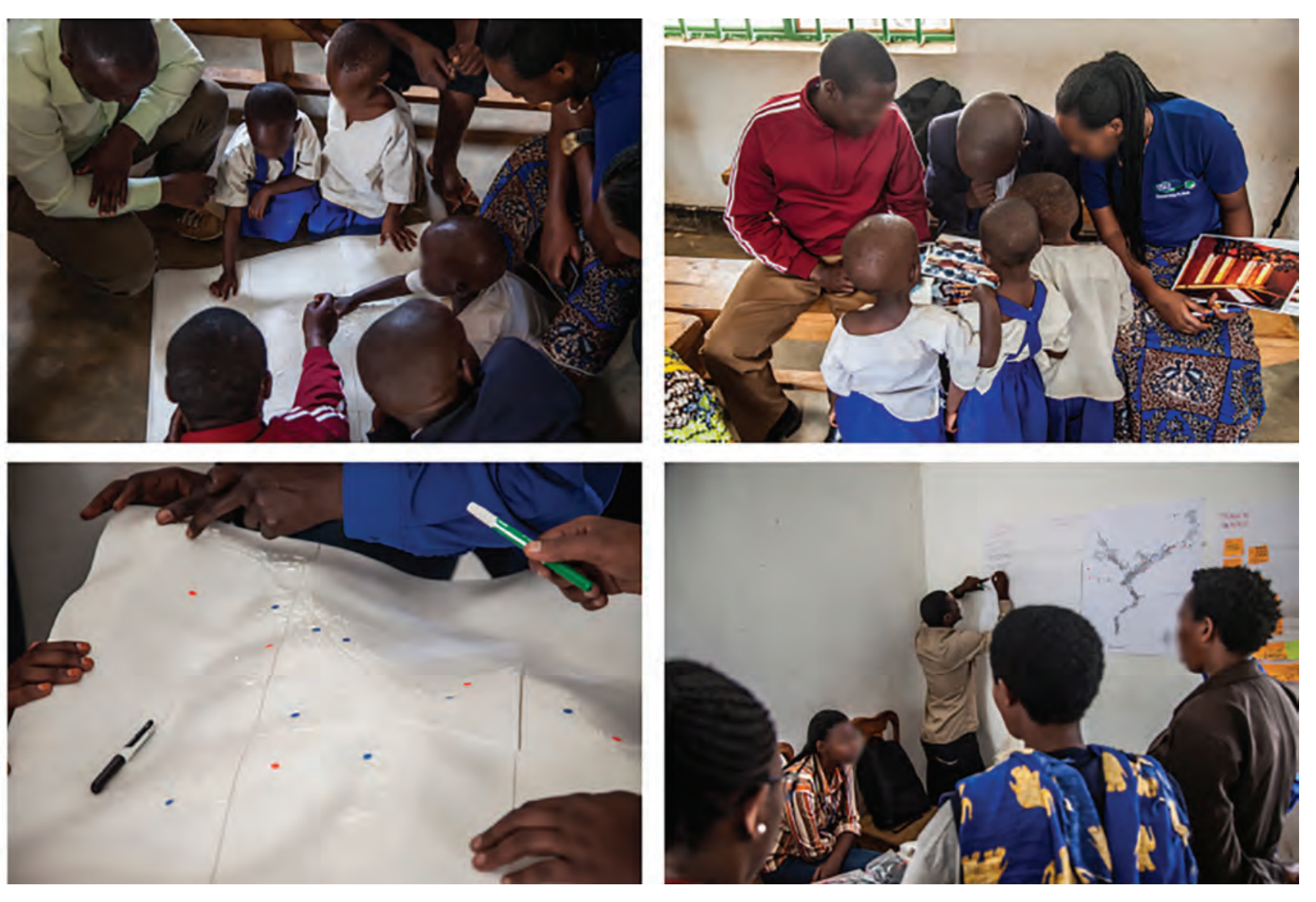

a few of the selected refugee proposals as using the 300-year-old Rwandan mural art photomontages, which displayed bigger tradition imigongo that stems from what is openings in the wattle-and-daub classrooms, now Rwanda's Eastern province. ${ }^{105}$ In the playgrounds made from local materials and Congolese refugee camps in Rwanda, many paths paved with river pebbles and gravel families already use mud and natural pigfound close to the camp. These images initi- ments (both materials used in the imigongo) ated a dialogue amongst participants about to decorate the interiors - and sometimes their diverse priorities and the potential of the exteriors - of their homes (fig. 3.20). the built environment and their skills to Many even imitate the traditional Rwandan improve daily life. ${ }^{104} \quad$ imigongo designs, in part because these im PAR 2: mural making-Next, the PAR immigrated into the North and South Kivu participants developed a series of murals regions in DRC at the end of the nineteenth 

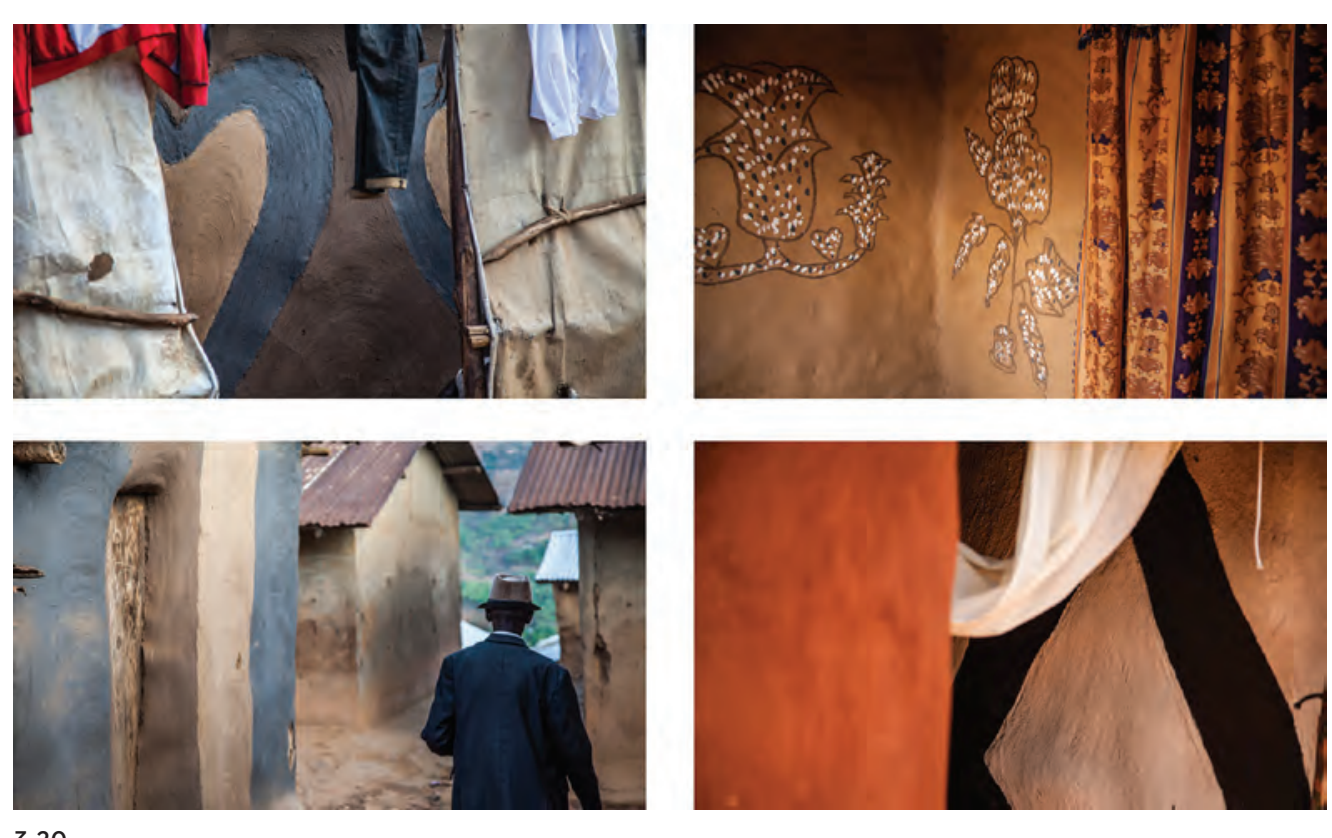

3.20

century and naturalised. They speak Kinyarwanda and share several commo traditions and culture..$^{106} \mathrm{As}$ well as thos reasons, we chose to do imigongo murals because arts and crafts have been tested in a variety of different settings as usefu elements of PAR to overcome language and cultural barriers in order to engage a variety of actors and to trigger change within public spaces in urban settings. ${ }^{10}$ Moreover, painted murals are used widely as educational displays in schools in the region and the camp, and most child respondents stated they liked them during our previous data collection fieldwork trips.

Two months were required to prepare all the paperwork and logistics to be able to develop the murals, ${ }^{108}$ which involved around 20 refugee participants ${ }^{109}$ and nine imigongo artisans.
The initial PAR exercise was also The first day of the two-week-long muralmaking activity. The site selection proces was a joint effort between all participants. After holding talks with the NGOs in charge of ECD, child protection and education, ${ }^{110}$ the group decided that the murals should contain didactic information about learning environments, raise awareness and trigger the development of child-friendly spaces (CFS) around the camp.111

The team used the 3D-printed model tocate all he main spaces where young children play. From the 30 initially selected sites, they pinpointed 10 for the potentia CFSs according to distances between locations, the need for at least one site per quarter and the qualities and risks of each site Following this, the whol risks of each site. Following this, the whole party visited areas and chose two sites with three to four murals in each to create synergies. ${ }^{112}$ The chose the maternelle in quarter $4-$ th formal ECD centre - and a space close to th market in quarter 2 where many children already played.

Next, all refugee participants learn from the imigongo artisans how to develop different traditional geometrical designs, make the dung and ash mixture, and apply it to walls and small wooden pieces figs. 321 and 3.22). Over the next five days, the team developed the first set of murals in the maternell's courtyard Children, caregivers parentsand courtisans chose the themes, the differen designs and how they might be organised designs and how the mist the artisans and adults deveped them. vided by the enclosed cou vided by the enclosed courtyard facl proted the learning of all participants and encourWed the children's involvement (fig. 3.23). We replicated a similar system at the neighbourhood location during the second week. Being in a public space incentivised curiosity and dialogue amongst neighbours and other camp inhabitants. This time, the neighbours selected the designs that would go on the walls of their homes from a set of traditional imigongo designs. Some of the neighbours were sceptical at first, hesitan about attracting even more children to the relatively quiet area, while others participated actively in the painting (figs. 3.24 and 3.25).

The murals' design and production sessions were active and creative. They incited informal conversations about the built environment, child development and the importance of CFSs. They also strengthened ties between the imigongo artisans, the refugees, the architecture fellows and he.
The murals triggered positive spatial change around them. At the end of the 12 days, the caregivers at the maternelle began to plant flowers around the paintings. In addition, most neighbours surrounding the other site used the remaining materials to paint the interiors of their homes with help from the imigongo artisans.

A couple of weeks after the completion of the murals, during informal conversations, the children highlighted that the maternelle was now 'much nicer' and they touched the murals every time they went in and out of the class The their parents and caregivers animals, colours, lose to the maret attacted neighours close to the market atracted neighbors rimplo po rtisan fromerals and pacicip surroundings. The creative for participatory activities seemed to be tangible and positive change and their close community. They increased the awareness amongst the munity about the relevance of (fig . 3.26). A few years after the intervention, most murals are still standing and have survived several rainy seasons, ${ }^{113}$ although I do not have information on the impact of the murals long term. Have they improved the children's learning situation in those particular spaces? Have the surrounding neighbours recognised those spaces areas? Have they triggered the creation 

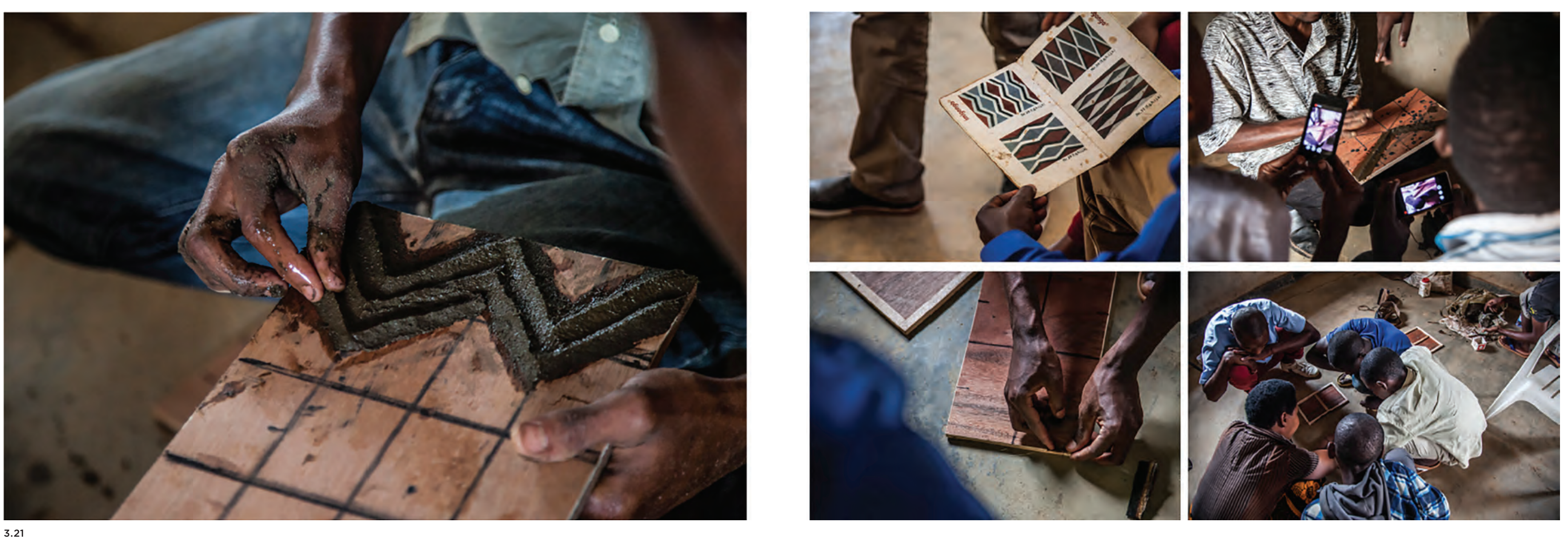

3.21 First day of learning the
imigongo technique teft imigongo technique. Let
page: applying the dung page. applying the dung-aned
ash mixture to a preprepared
wooden frame. Right page, from top to bottom and left to right
studying the different traditi imigongo designs and their
ings, ; reparing a wooden fram
with a ings; preparing a wooden
with a geometric framework
develop an imigongo desigh refugees filming the dung-arn-
ash application with their mo phones; and an imigongo artisan
teaching a group from the youth arts club. Kiziba refugee camp
6 September 2017 . $\odot$ Amorós of other child-friendly areas in other neighbourhoods?

graduates of architecture - from Rwanda, Uganda and South Sudants - and teans of -15 refugees from both camps (fig. 3.27)

PAR 3: PID-PID is a human-centred and The PID aimed to explore potential participatory design teaching practice that collaborations between schools of architecoriginated in the USA in the 1990s. PID ture and refugee assistance in the region. It studios emphasise topics and processes that engaged the refugee and student particienhance sustainable designs and include pants into trying varied methods of data ecological economic and social issues. 114 The collection and analysis, it fostered their PID studio Ideveloped from Septemberthrough creativity and innovation in dealing with November 2017 in the camps of Kiriba and complex issue and it helped them underKigeme in Rwanda involved three recent stand the ethics of a research project by applied architectural design with human camps; a two-month iterative design subjects. It was intended to help students research process where both refugees and and refugees master the use of architecture students worked together in a hypothetical and design as tools to create and transmit project to improve young children's learnnew knowledge, emotions and stories. ing in the case studies; and the presentation This PAR exercise required much of the findings to the broader refugee and prior planning ${ }^{116}$ The PID studio was com- humanitarian communities.

prised of initial desk-based research and During the two-week-long intensive the writing of a research proposal; a two- initial workshop the team decided to focus week workshop in Kiziba with field visits on devising a set of design guidelines for the week workshop in Kizito to Kigeme and Mutenance 

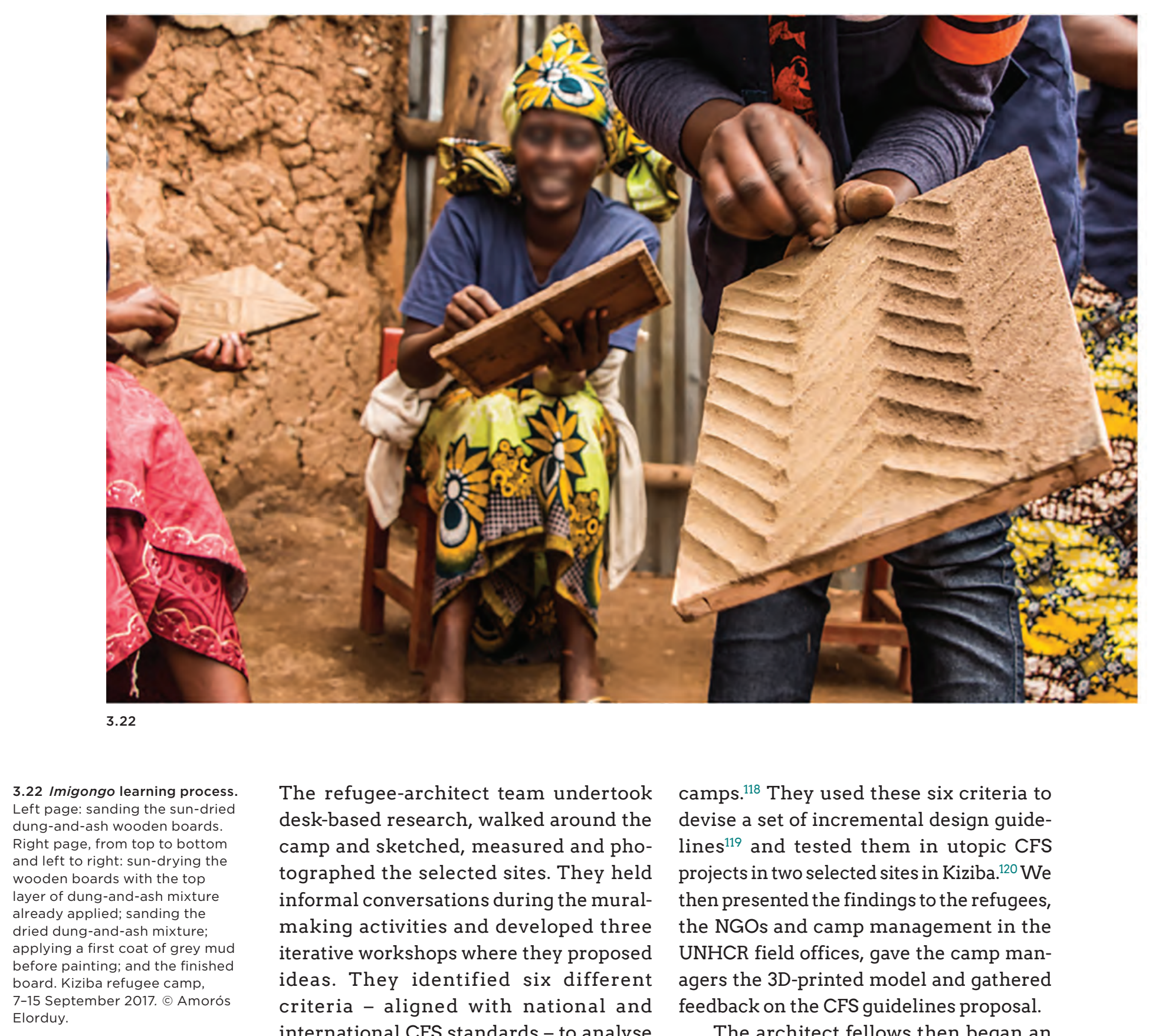

The refugee-architect team undertook camps. ${ }^{118}$ They used these six criteria to desk-based research, walked around the devise a set of incremental design guidecamp and sketched, measured and pho- lines ${ }^{19}$ and tested them in utopic CFS tographed the selected sites. They held projects in two selected sites in Kiziba. ${ }^{120} \mathrm{We}$ informal conversations during the mural- then presented the findings to the refugees, making activities and developed three the NGOs and camp management in the terative workshops where they proposed UNHCR field offices, gave the camp manideas. They identified six different agers the 3D-printed model and gathered criteria - aligned with nix diferent agers criteria - aligned with national and feedback on the CFS guidelines proposal. the existing and the potential CFSs in the intense two-week-long period of desk-based
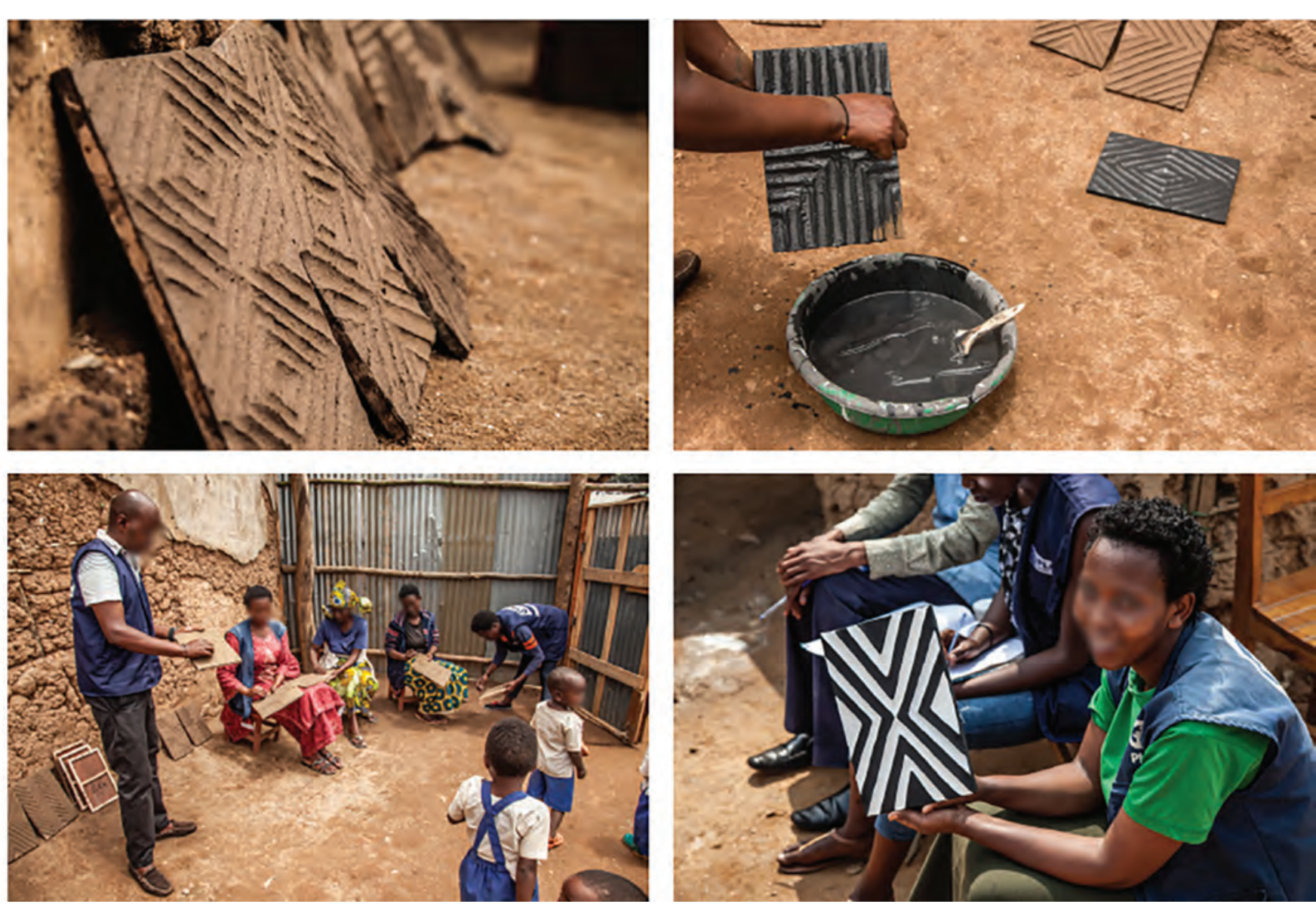

research, interviewed experts from PLAN refugee leadership and one worker from the International, the UNHCR and CARE NGO ADRA International and talked to refugees. They occasions. During those meetings, they decided to use the remaining two months held informal conversations while visiting to develop a set of standards and design a variety of HBECD sites, discussed design guidelines for the HBECD initiatives in options during the workshops and took conjunction with a group of refugees in design decisions together.

conjunction with a group of refugees in design decisions together.
Kigeme, the camp with the oldest HBECD
We visited, sketched and photographed initiatives. The fellows and their Kigeme 14 of the $74 \mathrm{HBECD}$ in Kigeme. We initiatives. The fellows and their Kigeme 140 the 74 HBCD in Kigeme. We listened counterparts 10 mity 

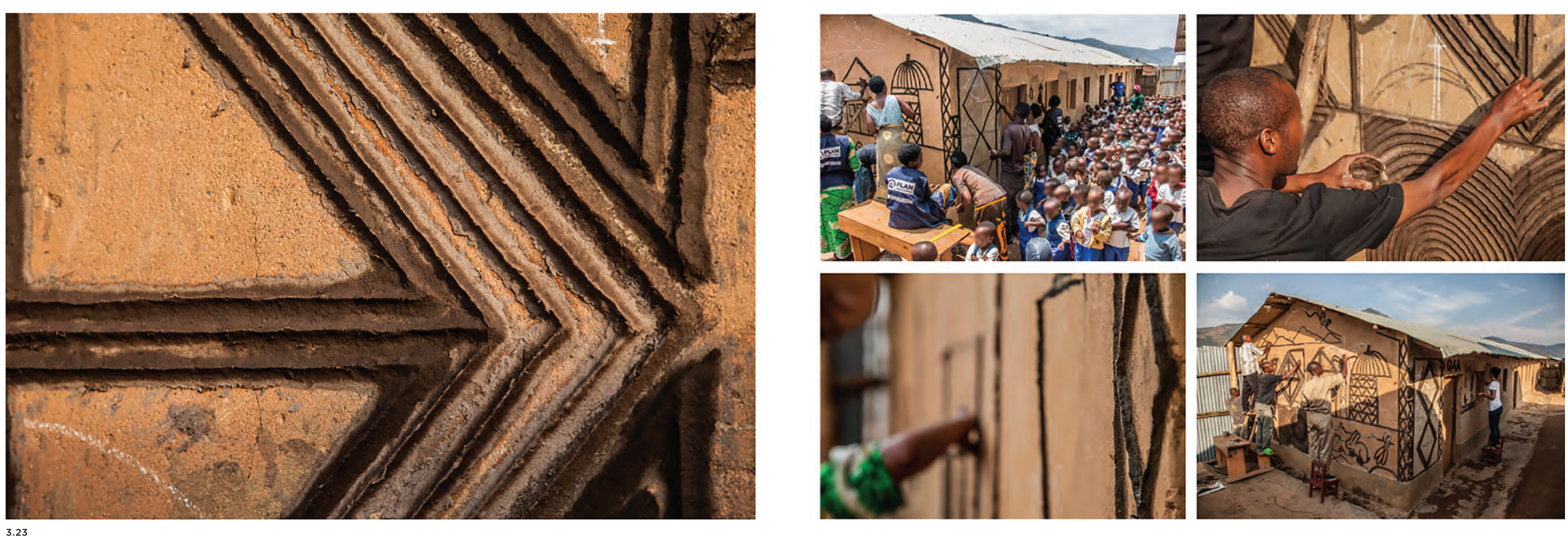

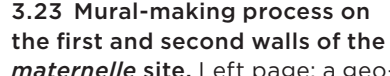
matemele site. Left page: àgeo-
metric piece a during the sun-drying process. Right page, from tom
bottom and left to right: usuli number of children surrounding
the murat-making process during

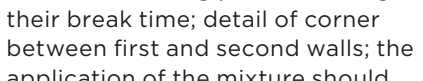

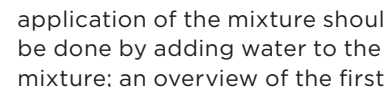

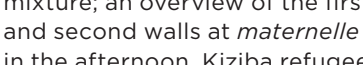

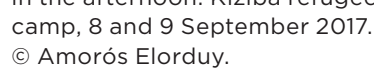

refugees and fellows then analysed the PAR triggers new knowledge and transpatial qualities, challenges and potential formation-Humanitarian actors do not ways to improve each of the HBECD visited. usually engage refugee adults - even less Using that information, they devised seven children - in initiatives that are connected overarching design guidelines with 26 to the built environment and to young specific elements that an HBECD site in children's learning. Despite the endemic Rwandan camp must, should and may lack of participation in the Rwandan have. They tested the guidelines and refugee camps, refugees participating projects: 0 in quarter 1 and one in quarter $5 . \quad$ to improve their camp through design and creative interventions. The iterative construction materials, amongst other character of the PID studio feedback ses- topics.

sions contributed to engaging refugee It was remarkably valuable but also participants in spatial and design-based challenging to develop participatory prodialogues. Throughout the process, the cesses in the Congolese refugee camps. This participants' knowledge grew on topics of was due to bureaucracies, security protospatial language and refugee camp issues cols and the humanitarian assemblage's with conversations of varied content and primary commitment to donors and host with conversations of varied content and primary commitm breadth. Refugees initiated discussions countries agendas rather than to their on circulation flows, rain and wind direc- refugee beneficiaries, as well as to what 


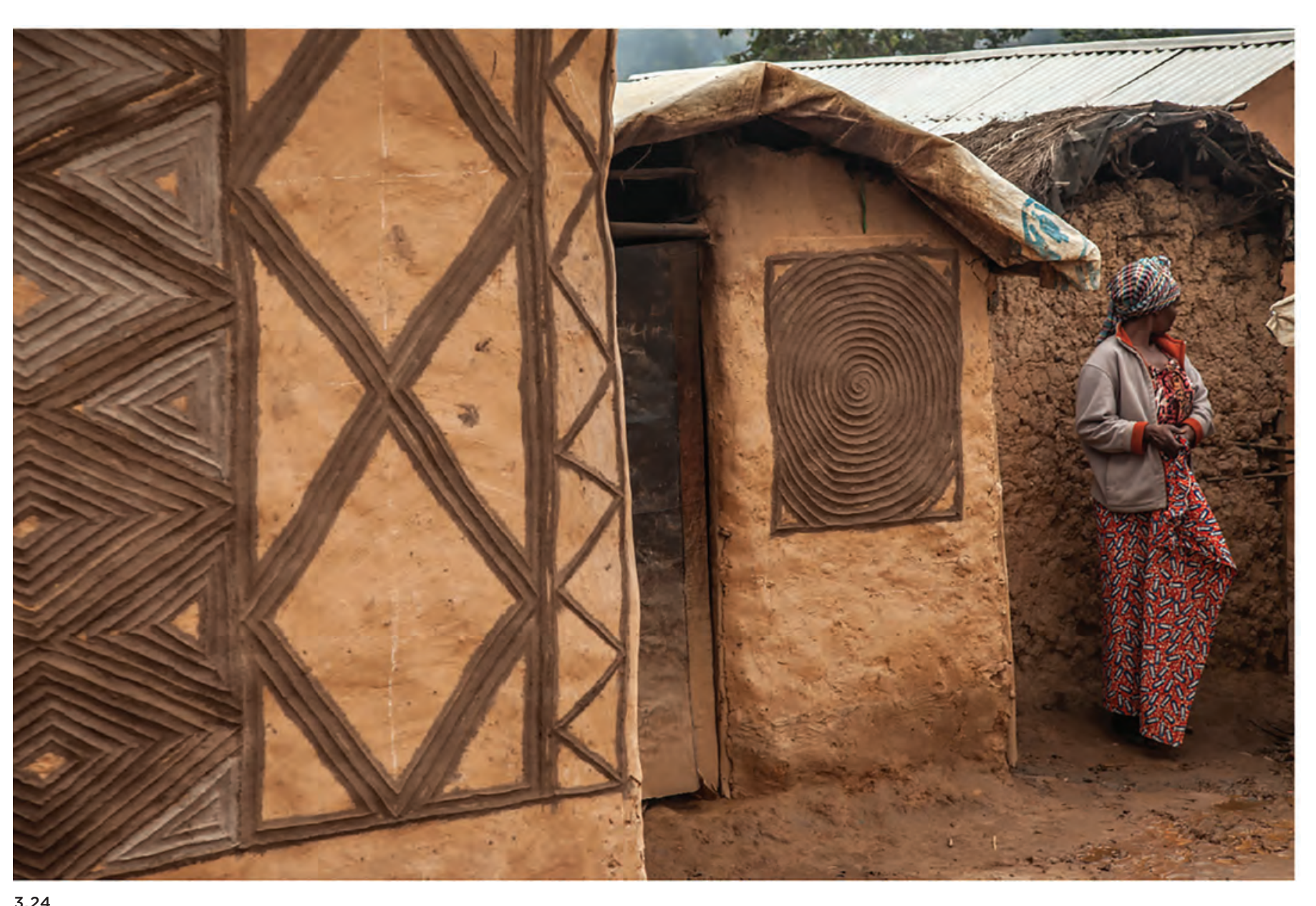

3.24

3.24 First steps of the muralsite. Left page two of thbourh at the neighbourhood mural during the process of sun--dirng
the dung and-ash mixture. Ri page, bottom left: the neighbouractivity. Bottom right: inigigongo
artisan, community mobiliser and owner of one of the homes Walls discussing the potential
outcomes portrayed in the phot 11 and 12 September 2017 . ๑ Amorós Elorduy.

call the 'anti-participatory ideologies' of focused only in Kiziba and Kigeme. This the humanitarian system. ${ }^{12}$ This attitude demonstrates how demanding it is to do adds to the extreme lack of information participatory research with young children vailable on the built environment and on and their support networks and to do it in young children's learning on the long-term these settings.

camps. It took me four years of work in the Rwandan camps as an architect in addition to the two-and-a-half years of fieldwork Two other obstacles to real participation in the camps were the encamped refugees' heterogeneity and research

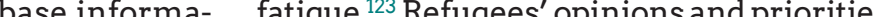
or to develop a rather small PAR exercise young children's learning stated a desire

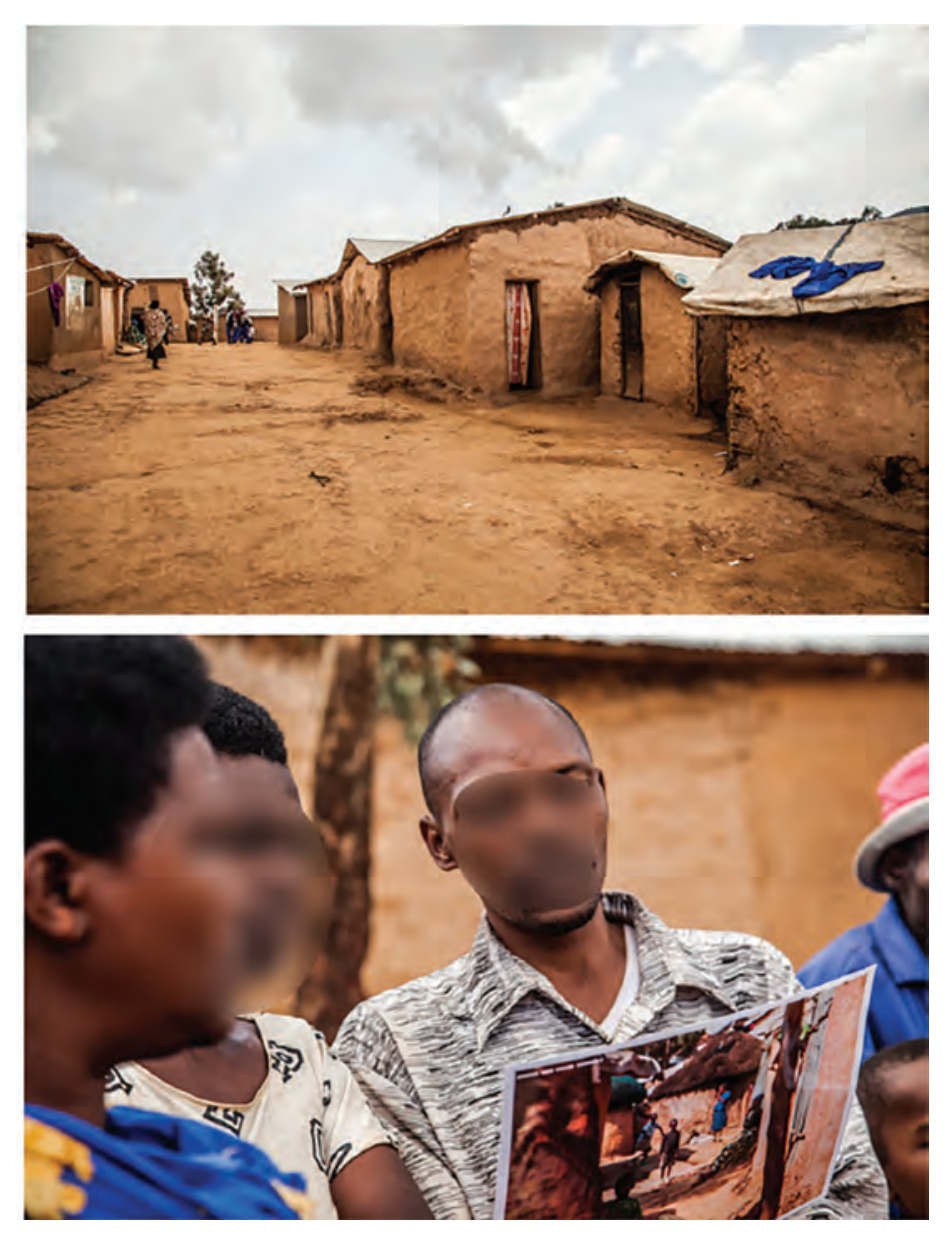

to have CFSs closer to their homes, while adjacent neighbours sometimes disliked the possibility of an increase in young children playing around their homes. Furthermore, repeated consultations that extract knowledge from refugees but that rarely end up contributing back cause fatigue and a refusal to participate in projects, especially amongst youth. ${ }^{124}$ This practice is sadly quite widespread in academic and humanitarian research. ${ }^{125}$
The values of the PAR exercises are multiple. The involvement of young architects and artists through an iteraive process improved the level of information available to refugee parents, children, caregivers and leadership on the role of space in young children's learning. The participatory exercises opened up new opportunities for the PID studio participants to authored spatial appropriations 125 PAR 

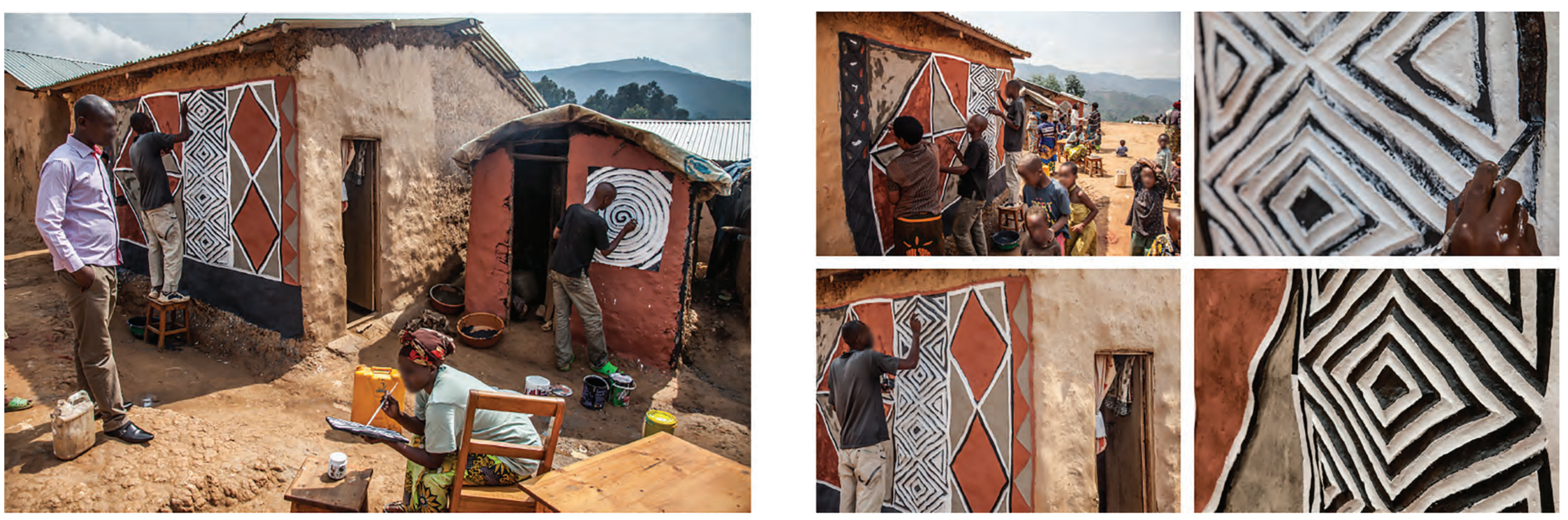

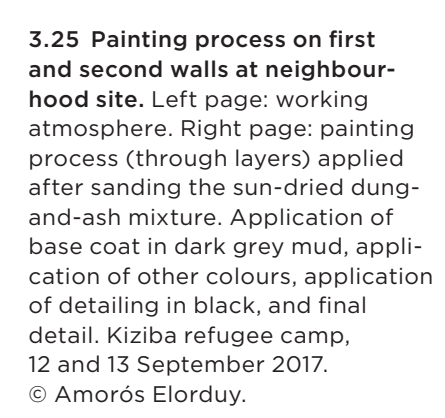

participants stated that they were pleased discussion processes afforded the incluto partake and had enjoyed and learned sion of more voices into the conversation. from the experience. They had had fun and These universal languages facilitated comfelt that their ideas were recognised and munication with a broader audience in a encouraged. These participants also gained universal language enabling their active new skills such as developing murals in the engagement. The PAR exercises might have migongo technique and design and tech- helped create some cracks in the barriers nical approaches to improve the HBECD built by assumptions that refugees are

The use of traditional and new technolbuilt by assumptions that refugees are vulnerable, apathetic and a homogeneous ogies, arts and crafts, and the design and show that the refuposed improvements spaces, evaluate their environments and long-term commitment to the initiated recommend thoughtful ways of improving spatial appropriations? them.

Even though 1 did not measure it, the exercises, I am unable to tell if and how the confidence to apply their social and ethical strategies used would work in other refugee and needs grew in most of the PAR parcamps. For example, would the 3D-printed ticipants, which were already some of the model technique work in the flat sparsely most active members of their communimodel technique work in the flat, sparsely most active members of their communipopulated and vast camps in Southwest ties. They transformed the murals, the CFS Uganda and Northwest Kenya? How and the HBECD designs that had initially 


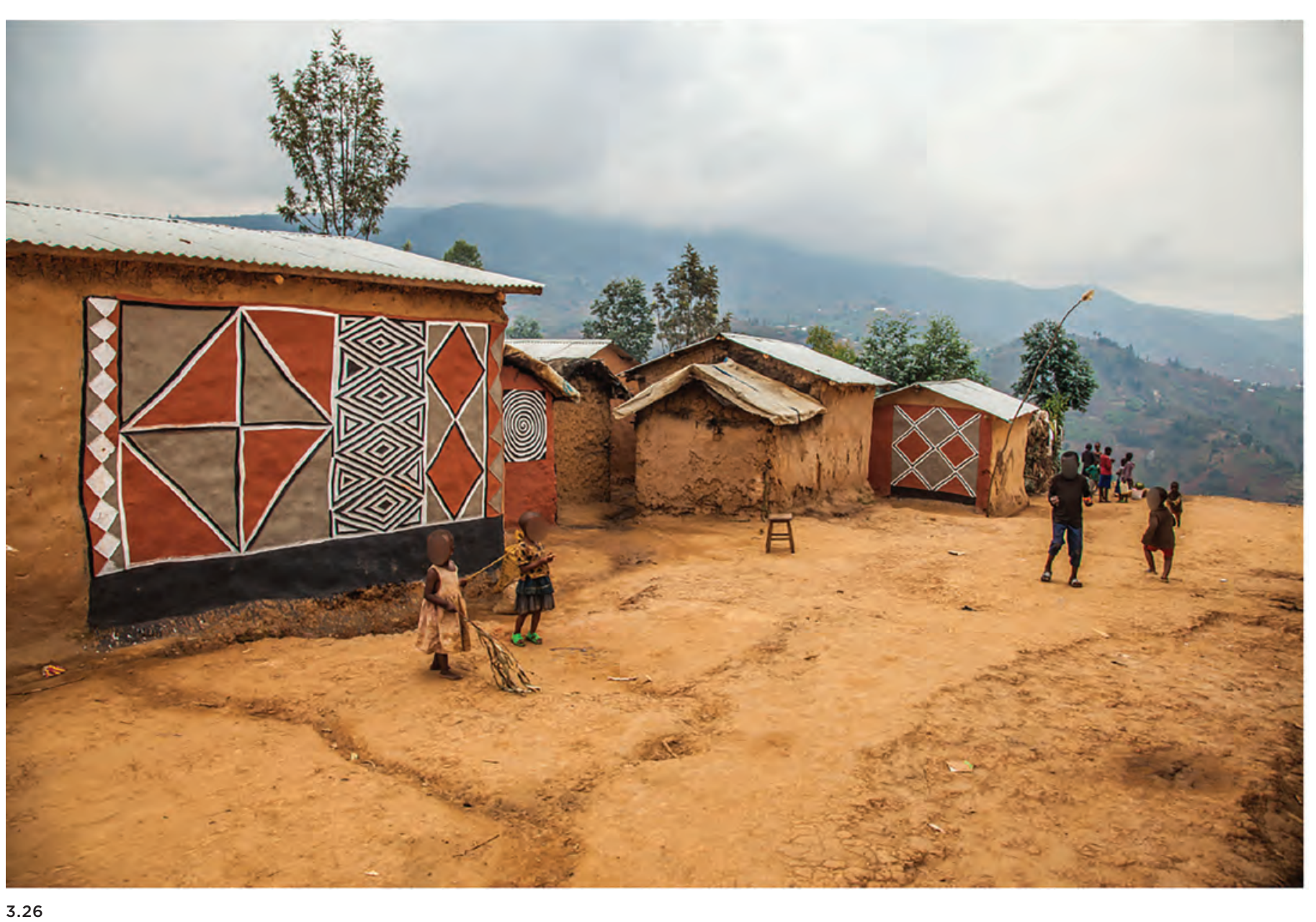

3.26

3.26 Finished murals. Left page:
neighbourhood site with its three murals. Right page, bottom left:
two walls at maternelle's entran
bottom right: mural facing matebottom right: mural facing mater-
nelle's playsround. Kiziba refugee camp, 15 september 201 .
$\odot$ Amorós Elordul. discussion points. Even if not quickly quali- very little leverage over the human and tatively evaluated and almost impossible to non-human actors who govern them. Yet, quantify, these discussions and informal they are the main characters modifying conversations during the PAR exercises the camps - a role that is mostly unrecsuggest their positive influence on the par- ognised, unpraised and hidden under ticipants' further empowerment. upon to participate in the camps' improvegenerally trapped in an extremely unjust system. Consequently, they typically have with marginalised populations have the humanitarian discourses of victimisation 政 entions elsewhere suggest that the involvement of local young artists and architects in participatory projects ment and development, and they are

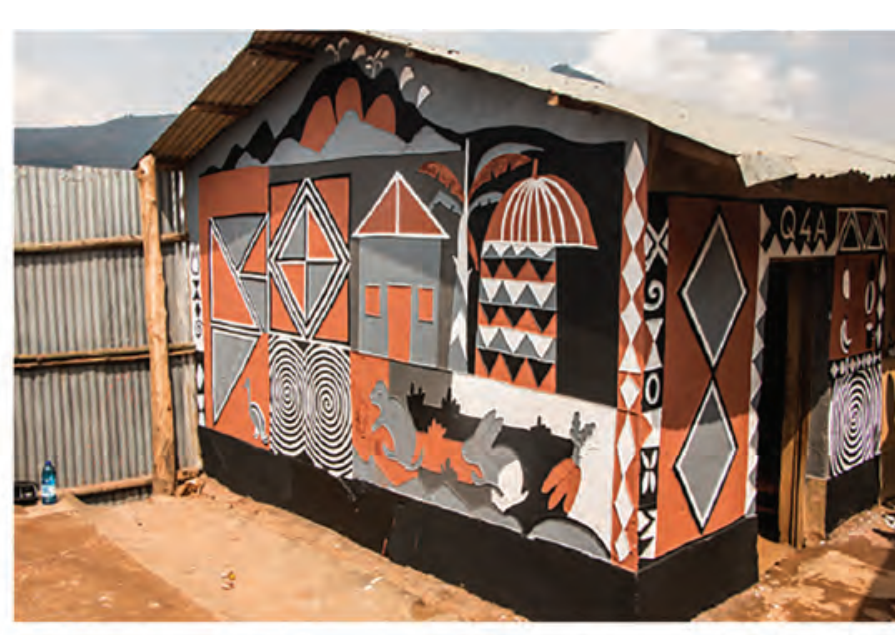

ख़ा

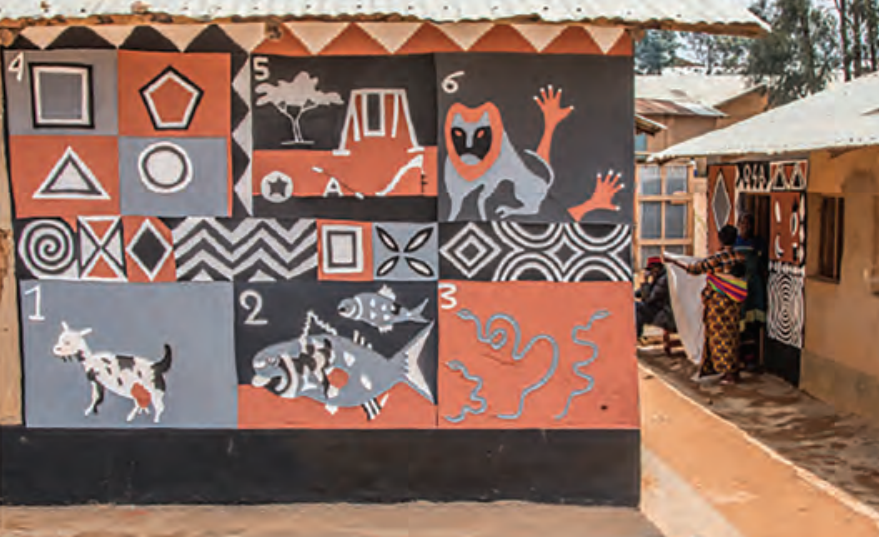

potential to increase pre-existing ethical, backgrounds and origins. The artists and social and political awareness amongst artisans were glad to see the similarities those participating. ${ }^{12}$

Each individual and group involved in the spatial appropriations highlighted in this chapter approached the same questions differently and asked different questions..$^{128}$ The students of architecture were mes- merised at the discovery of the camps in

their own countries and enjoyed the inter-

actions with people from such diverse (their own, to try something so different from what they are used to and to contribute to the improvement of other people's lives through their art Children and the rest of the refuge participants enjoyed the artistic ctivities. They liked being involved in the thought and design processes during the PID and the mural making having a say 


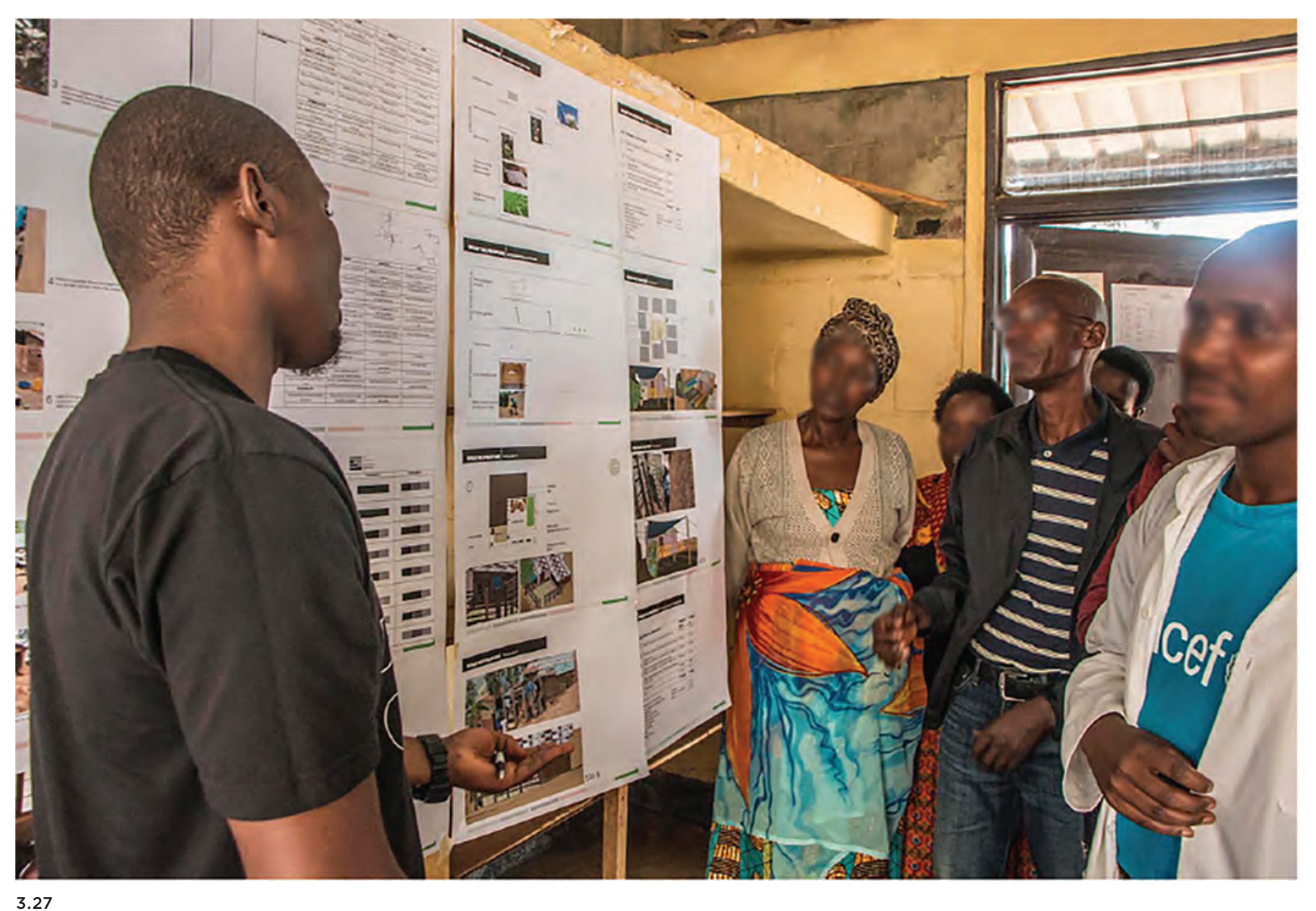

3.27

3.27 Public interest design studio
workshoops. Left page- discsussion workshops. Left page: discuss
around findings and potential design guidelines for hom
ECD psaces in the Rwand
refugee camps Kigeme camp, 6 November 2017 . Right
page: session to discuss the findpage: Session to discuss the fin
ings and the design guidelines
for future CFS in the Congoles refugee camps in Rwanda. Kirib
refugee camp 9 September 2017

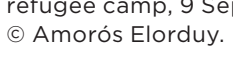

and contributing to a creative process. The example, it enables participation using immediate influence of the PAR exercises architectural tools and the use of an assemon participants - including the research blage thinking lens to create new spatia team - is the unveiling of a more positive knowledge. In our case, it has helped to sense of self, a better understanding of the unveil some of the complex realities of the needs of others, new social networks, new camps while including more voices in the skills and enjoyment. process and poter I have found limited refugee camp Conscious radical incrementalism-The studies where researchers had tried to dectign develop such substantive ways of making conscious radicaliciem
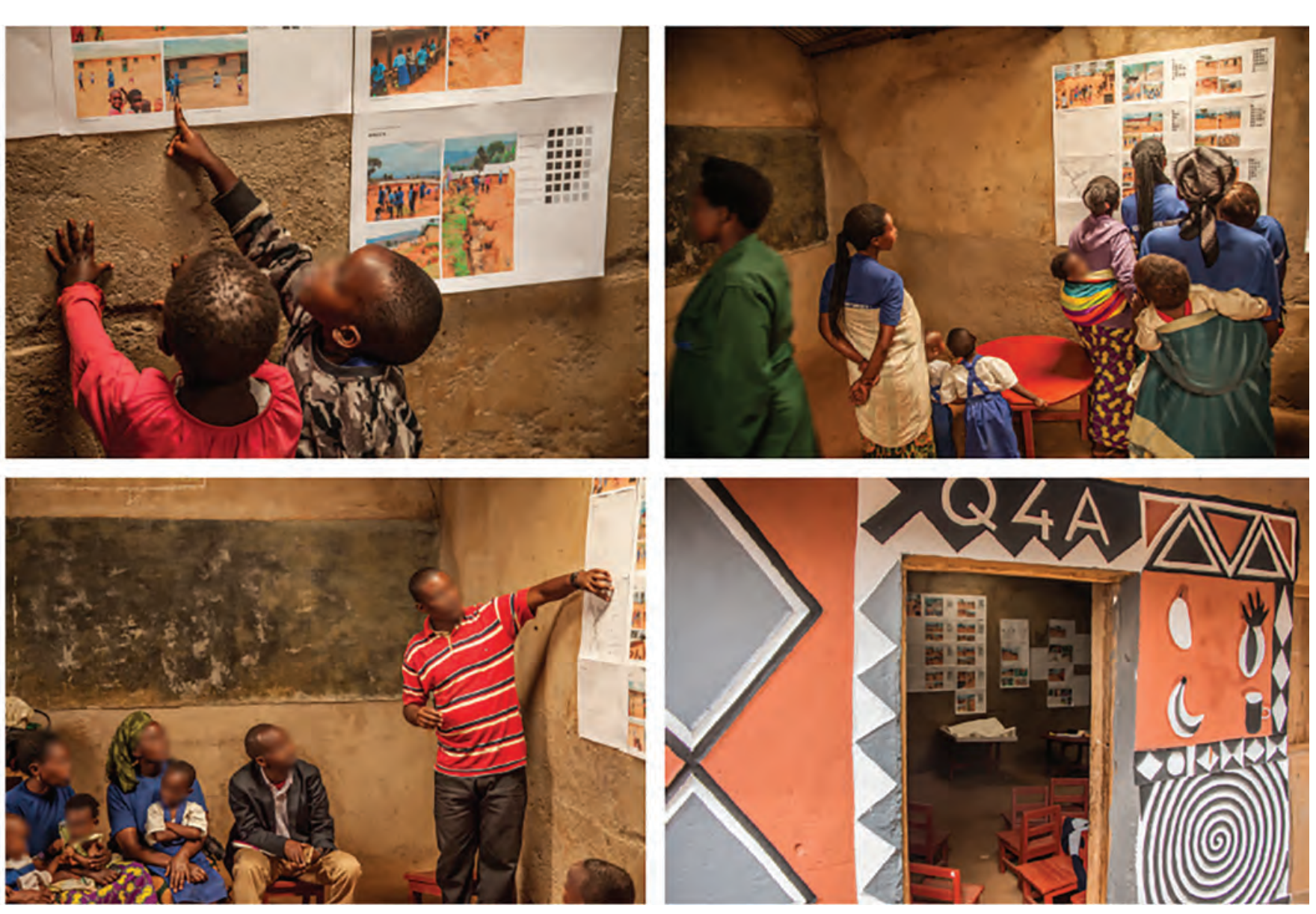

the people with whom they work. ${ }^{129}$ Too often, researchers and academics get hung up on changing the world with their ideas fabric with no agency and not enough skill. and findings, forgetting the opportunity Refugees continuously use their 'right to that lies in the research process itself. In the city'. They build and modify all of their my practice and research work, through homes, many of the schools and ECD iniresearch by architectural design, Itake spe- tiatives, and all the religious facilities, cific decisions, make great efforts and try which often double as ECD spaces. They also hard to crea a cycle from experience to create all the small shops that they also hard to create a cycle from experience to create all the small shops that exist in the theory to research to tangible outcomes, camps. They negotiate rent and acquire 
camp borders, expanding the footprint of the camps.

ventilation, dust-free and dry pavements

It seems evident that Colin Ward'sidea and mattresses, creating hodframes of the urban setting as a school without ments that foster children's safety, privacy walls could be attainable. ${ }^{130}$ Some ways of and enjoyment of family life.

transforming the camps' architectures into stimulating learning resources are the ones that I speculated about here, harnessing the refugees' knowledge of the camps them, bringing in refugees' varied cultures, imagination and wishes-especially those of children and their support networks-and employing local creative minds such as

Some organisations and individuals are already tapping into existing opportunities to transform the camps into stimulating learning environments. They do so to improve formal schooling such as is the work of Active Social Architecture (ASA) develop-
ing formal ECD centres in the Congolese ing formal ECD centres in the Congolese camps in Rwanda, ${ }_{1}^{131}$ to provide CFSs such as
the work of East African Playgrounds in the Southwest Ugandan camps and to improv home environments such as Opportunigee
in Nakivale or Creative Assemblages in in Nakivale or Creative Assemblages in Mugombwa. ${ }^{132}$

Stimulating environments might look sightly different in each camp setting. Specifically, in the Rwandan camps, safer streets will be those with proper storm water drainage, with handrails and proper paving in the steep areas. In the Kenyan camps, stimulating and secure streets would assimilate Kakuma phase I, smaller with more vegetation and shade, and where clusters of neighbours can take care of their younger members. Better homes could younger menbers Beter homes could ymprove
I have relished working with refugees and local artisans and students of architecure in different ways through the years. The speculations and interventions that describe in this chapter suggest ways of using the built environment as a valuable resource for learning. Through speculative actions based on observation of each specific settlement, architecture can transform the long-term camps and design the new alternatives to camps in order to culwate an environment conducive to young hildren's learning more effective chapter for the longterm campsis possible That is particularly true in Fost Africa as Uganda ${ }^{133}$ and ${ }^{134}$ bot refugees into national programming. If those in charge of ECD - both humanitarians and refugees - are able to learn the those, if they can value architecture an see it as an opportunity, it might be possible to transform the camps into 'schools without walls!

Since the early 1980 s, critics of the camp have different versions for the Handbook for and isolation are still the go-to strategy for

policy on refugee protection and solutions in urban areas'; UNHCR, UNHCR policy on refuge newR camps architectural qualities and harnes argued that they should be a last resort - advice Emergencies. However, physical containmen
3. UNHCR, 'Co
framework'.

(

See, for example, the new strategies in Rwand Uganda, and World Bank, 'REHOPE- Ref nd host population empowerment'; UNHCR UNHCR, 'Protracted refugee situations: The search for practical solutions'

Hyndman, 'Geographies of displacemen
Hyndman, Managing Displacement Deleuze, and Guattari, $A$ Thousand $P$ Herz,' 'Refugee camps in Chad'; Scott-Smith, 'The humanitarian-architect divide', 2017 .

Pieterse, City Futures, 6

sibilities, we need topias.... Transduction is an intellectual operation which can be methodically carried out an tion, the construction of "models" simulation as well as the simple statement of hypothesis. Transduction elaborates and constructs a mation related to reality and a problematic posed by this reality. Transduction assumes an incessant feedback between the conceptual framework used and empirical observations.
Its theory (methodology) gives shape to cert spontaneous mental operations of the planner, the architect, the sociologist, the politician and the philosopher. It introduces rigour in Writings on Cities, 21

10. "Thec The conviction of the must fight for their libppressed that they bestowed by the revolutionary leadership, Humankind "emerge" from their "submersion" and acquire the ability to "intervene" in reali
as it is unveiled "Intervention" in real ty torical awareness it-self-thus represents a step forward from "emergence", and results from the conscientizaçao of the situation. of awareness characteristic of all "emergence" Freire, Pedagogy of the Oppressed, 67 and 109. 1. Colin Ward and Anthony Fyson elaborate on the their book 'Streetwork: The Exploding School', 1973.

2. Pieterse, City Futures, 7

Amorós Elorduy, 'Lapping refugee spaces'; lon-term refugee cearning in and through the
14. Architects Constantin Petcou and Doina in their work ' $R$-Urban or how to co-product resilient city', 2015.

. McFarlane, Learning assemblages'

16. Simone, 'On cityness', $38-9$

(

Scott, 'Everyday forms of resistance', 1986, 42

of the Weak', xvi-xvi Bayat, "irom "dangerous classes" to "quiet
rebels", 2000; Bayat, The quiet encroachmen of the ordinary', 2007

2. Babls"' 2000, 545er,546 andasses" to "quiet

Harrell-Bond, 'Weapons of the weak', 2004, 1-2. In this quotation, Harrell-Bond actually refers and crisis theory relevant to understanding refugees in Africa?' That resonates as well with James Scott's work that Harrell-Bond chooses

24. Abourahme and Hilal, 'The production of

space'; Martin, 'From spaces of exception to "campscapes", 2015 ; Peteet, 'Producing place,
spatializing identity, 1948-68'.

25. Peteed "Bayat 'From "dape of Hope and Despair, 130. rebels"', 2000 .

27. Kagwanja and Pérouse de Montclos, 'Refugee city', 2009; Oka, 'Unlikely cities in the desert', 20

28. Jansen, 'The accidental city', 2009; Jansen, 'The

protracted refugee camp, 2015 toire non identifie'.

0. Fieldwork in Rwanda September 2015, September to November 2017, from Southwes September 2016 .

31. Fieldwork in Rwanda September 2015, September to November 2017, from Southwest September 2016.

2. Amorós Elorduy, 'Mapping refugee spaces'; Amorós Elorduy, 'The impact of humanitaria

3. Rodriguez and Tamis-Lemonda 'Trajectories of
the home learning environment' 2011: Halldén, the home learning environment', 2011; Halld
'Children's views of family'; Gottried and 'Gottfried, 'Home environment and cognitive implications of home environments'. 
34. Heft, 'Background and focal environmental con-
ditions', 1979: Gottfried and Gottfried, 'Home dit '

35. Proshansky and Fabian, 'The development

place identity in the child', 27 .

Dates of establishment: Kakuma phase I in 1992 Kakuma phase II in 1997, Kakuma phase III in
2009, Kakuma phase IV in 2014, Kiziba in 1996 and Kigeme A in 2005,

77. Many of these camps were not planned using

ute iron sheeting amongst refugees in 2013 . UNHCR, 'UNHCR's global shelter and settle-

ment strategy, 2014-2018.
Anecdotal evidence coll

ebruary 2011 to November 20 in Rwanda from hecked with data collected through fieldwork in and August and September 2016 .

0. In 2013, Kiziba and Gihembe had been running for more than 15 years and Kigeme $A$ an

In the 1960s and 1980s these $50 \times 50$ metres; currently, they tend to be to

$20 \times 30$ metres.
42. Rwanda began a shift in its strategy, aligning
with the CRRF and also owing to the drying up of international funding due to the European refugee crisis. UNHCR, 'Rwanda country

refugee response plan 2019-2020'. September-November 2017, from Southwest Uganda August 2016, and Kakuma in Kenya

September 2016.
4. In 2019, the NGO Give Directly began a programme of large direct cash disbursements to
refugees in Mugombwa refugee camp. Most of the refugees used this cash to make home Inprovements, some of those being pavements
In line with that and using the findings from $m$ PhD research (some of which is contained in this
book), I began a project with a local organisation book), I began a project with a local organisation more than 200 shelters in the camp and to train more than 20 masons on this cheap, local and

durable technique.
45. As gathered from the spatial analysis of the map GIS and based on satellite imagery and exist population data sets gathered from the UNHCC den mest phase and Kakua, Kakuma phase I is the akuma phase IV is the least

46. Congolese make up $99 \%$ of the inhabitants in

a construction technique structure and to support the mud from which
sulch the walls are composed

and the uses and functions of were collected through home caregiver questionnaires and focus group discussions (FGD)
carried out during fieldwork in all my Rwand case studies in September 2015 and from September to November 2017

In Wwanda, nost of he Congolese refugees are Banyamulenge. In Kyangwali, most are from
different ethnicities from Ituri and North Kivu provinces, who actually built fences around their homes and took their children to the ECD provided this information during a semi-structured interview on 20 August 2016 .

50. Ward, 'Children of the streets', 1986; Ward d Fyson, Streetwork: The Exploding Schood Ward, Caught in the Crossfire; Matthews, 'The street as liminal space'; Valentine and

52. Goma and Bukavu are the two major cities in North and South Kivu, respectively. Lake Kivu is

53. Thatural border between DRC and Rwanda.

since the Bye-bye Nyakatsi campaign took place in the early 2010s,

in Rwandan refugee cald protection KAP survey in Rwandan refugee camps'.

Consultative Group on Early Childhood Care ond Development and INEE, 'The path of mos

Amorós Elorduy, 'Mapping refugee spaces'.
This has changed in Kalobeyei where the latrines are now shared between several plots,
which provide all refunges with access to a toilet. However, as experience shows in other camps, shared toilet facilities suffer from poor

maintenance and increase the chances of abuse.
Usully market structure (a platform with a roof) or an open space for commercial use at the camp's establishment, providing the host country

Lutheran World Federation both had an engineer in their teams in charge of infrastruc-
ture. In Rwanda, UNICEF had either an architect or an engineer on its staff or a consultant who provided support to infrastructural needs education, child protection and health.

6. The NGO Global Help to Heal (GHH) has used
them to develop community-based ECD activties since 2014, and the refugees and direct local hosts teach Sunday school in them every weekend. Data collected hrough fieldwork Kiziba from 11 to 14 Sep
5 to 15 September 2017 .

1. For more information, see: Amoros Elordu East African refugee camps as learning

62. Data gathere

to-face interviews with the camp coordinatoKiziba refugee camp on 4 October 2017

These schools were close to the main roads in in other zones in the camp, there might have been more of this type of $\mathrm{ECD}$ centre. These showere able to pay a small fee Data collected through a multi-method qualitative approac during fieldwork
12 August 2016 .

\section{August 2016.
64. Amongst the 11 .} Rubondo onsery in Ruhoko village in the NGOS recognised these as ECD. Nakivale has three zones: Juru, Base Camp and Rubon 65. This type of spatial appropriation is particularly prominent in Nakivale's Base Camp neighbour

6. Examples of situations where access to cash include aid hand-outs in cash, access to NGO jobs and access to loans and rem
tances. Aid hand-outs are the aid that the provides regularly to each refuge family $\mathrm{H}$ tandouts used to be in-kind, such as food, construction materials and hygienic items, but now they are increasingly monetary due to the decreasing
funds of the humanitarian operations in the region. Guyatt, Rosa, and Spencer, 'Refugees vulnerability study Kakuma, Kenya', 23

67. Feldwor 'East African refugee camps as learning.

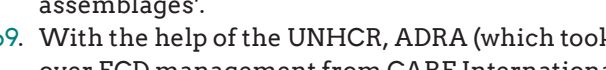
in 2016) provides the HBECD mother groups with sorghum for porridge and with some
toys and mats. ADRA stands for Adventist Development and Relief Agency.
70. In 2012, there was only one formal ECD centre, and it was located in Kigeme A.

Everywhere, formerly Coopenative for Relief Remittances to Europe. 72. Between 2012 and 2016 , the HBECD programmes in both camps were influenced by CARE's prior 'Nkundabana model' The HBECD programme was incorporated into national policy in 2007. CARE, 'A model geginning',
HBECD initiatives have

ted in Kigeme since its expansion in September 2012 and in the establishment of Mugombwa in October 2013 .
Bayat, 'The quiet encroachment of the ordinary',

Turner, 'Lukole (Tanzanie)'; Fresia, 'Performin repat' 76. Bauman, 'In the lowly
modernity', 2002,344.

modernity', 2002, 344.
7. UNHCR, 'Comprehensive refugee response

78. For example, in Rwanda, until 2017, direct local
hosts were not allowed to camps, and refugees were not allowed to work outside the camps. Since 2017, the policy and aid strateegy has shifted with MIDIMAR
and UNHCR's joint strategy on livelihoods encouraged to work. ONE UN, 'MIDIMAR and UNHCR affirm plan
Barbeletet al, How

onsure Ethiopia's "Jobs Compact" works for refugees'; Crawley, 'Why The law and policy of refugee cities, 2018 , three different areas to improve young children's learning: (1) the whole settlement - the streets, common spaces and WASH facilities, ties-ECD, pre-primary and maternelle.

81. Adult respondents include home caregivers,
community leaders, community mobilisers and community leaders,
ECD caregivers.

22. Only the children from Kabuma II and Nakivale did not mention it as a priority. Data gathered from game-based questionnaires
in all case studies: in Rwanda in September 2015, in all case studies: in Rwanda in September
in Uganda in August 2016 and in Kenya in

September 2016 . 
83. The newly established Kalobeyei uses a similar
master plan design as that of Kakuma phases master plan design as that of Kakuma phases
III and IV. Both those phases are the ones where children propose more changes, most of whic are aimed at making Kakuma phases III and IV become similar to Kakuma phase I (the initial grid-like planning of Kakuma phases II, III and IV means they are less dense and have less commercial activities than Kakuma phase I. Data to 10 September 2016

84. Kiziba is the only one of the three Rwandan camps that Istudied that does not have hom

5. Half of these respondents did not know wh. to suggest, and the others said they would not change anything.

6. Harrell-Bond, 'Weapons of the weak', 2004, 1-2 a new, well-equipped and child-friendly ECD centre, built in December 2014. For more inforspation see Amorós Elorduy, 'Mapping refuge in refugee camps'

88. Some of Kakuma phase III's ECD centres are
built from metal sheeting - the walls ar bill from meta sheethy - the walls and roofs - or are tented structures. In Nakivale an
Kyaka, most of the ECD centres, especially the community-run ones that use community-buil churches, are made out of wattle and daub. and playground spaces or facilities. Data collected through fieldwwork in Kakuma from 2 to 10 September 2016

Amorós Elorduy 'Lapping refugee spaces'; long-term refugee camps

90. The rooms are normally four square metres In size and are shared between five peoples
with no mattresses or proper bed structures. Fieldwork in Rwanda September 2015, September-November 2017, from Southwes September 2016

AVSI and InfoAid, 'Child protection KAP surv

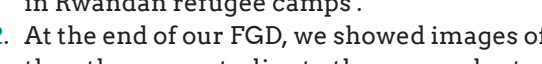
The residents of Kakuma and the Southwest Ugandan camps were shocked at the overcrowding in the Rwandan camps. Meanwh camps were impressed at the conditions in
Uganda due to the generous amount of ork in Rwanda September 201 September-November 2017, from Southwes
Uganda August 2016, and Kakuma in Kenya

September 2016 .
Most of the inhabitants in the Southwest itants have a fence and a secure door surrounding their home compound. This is particularly prominent in the congested
areas. Fieldwork in Rwanda September 2015 . September-November 2017, from Southwest Uganda August 2016, and Kakuma in Kenya September 2016 .

政 hildren's skin, as well as other skin illnesses
chis ons and respiratory illnesses such as asthma an the Rwandan cases in September 2017 rom from September to November 2017, from the Ugandan cases in August 2016 and from

Amorós Elorduy, 'The impact of humanitarian shelter', 2017; Amorós Elorduy, 'Learning in

96. Aside from spatial proposals, many of the

gestions from parents and children revolved around factors such as school fees, paying caregivers, having more toys, more scholas
tic materials and better food. However I Iam centring this study on the spatial and mate rial interventions only. Fieldwork in Rwanda September 2015, September-November 201

1. Chawla and Driskell, "The Growing Up in Cities project', 2006; Rigggio and Kilbane, 'The Cities', 2000, 201-5.

Freire, Pedagogy of the Oppressed.

. Lynch and Banerjee, Growing Up in Cities.

Transformations (MOST) Program
Thes

The PAR participants in Kiziba were: (1) three recent graduates of architecture, developing a
fellowship at the African Design Centre (ADC)
based in Kigali: (2) eight humanitarian workers and camp managers involved in Kiziba's education and child protection programmes, (3) one member for MDIMAR, two from UNHCR, one from $\mathrm{GHH}$ and one from Handicap
International; (4) 11 imigongo artisans, three

young adults organised by PLAN International (6) four young children from GHH's ECD Initiatives; and (7) myself. In Kigeme, the
PAR participants were: (1) the three, arche fellows, three humanitarian workers and cam managers involved in Kigeme's HBECD delivery: (2) one member from MIDIMAR, one from
UNHCR and one from ADRA (3) five mothor leaders who ran HBECDs and five communi obilisers; (4) refugee parents and young adults orga
(5) myself.

102. This activity entailed the creation of murats made from cow dung, ash and mud with the parents, caregivers, youn artisans and refuge

parents, caregivers, youth, and children.

some of the research findings to audiences lar from the camps: students and researchers, humanitarlan workers and institutions ties that had at that moment very little information about young chlidren's learn

term camps.
Data collected through a multi-method qualit

4. Data collected through a multi-meth
tive approach on 5 September 2017 .

In the early nineteenth century, King Karira

nique that uses the dung of young cal with ash to create relief on the wall's surface. This is later painted with mud, lime and burnt gated protrusion in Kinyarwanda. This art was later incorporated into the Banyarwanda kingdom and culture. After the Rwandan genoKodumuki, 'History of imigongo'.

6. Prunier, From Genocide to Continental Wa Hamdi, The Spacemaker's Guide to Big Placemaking with Children and Youth, 73-7.

108. This included: (1) presenting the idea to
UNHCR, the imigongo artisans, the NGO UNHCR, the imigongo artisans, the NGO MIDIMAR permission to access the camps an develop the murals in Kiziba; (3) organising funding through UCL Culture and the Beaco Bursary; and (4) putting together a team of
nine imigongo artisans from Rwanda's province, three young architect graduates on a fellowship in Kigali, an English artist and a Specifically, six mother

eaders, six comyoung people from the youth arts club. The paut of the activities after the first two dropped imigongo training. The youth arts club coordinator and the community mobilisers were left. lo contact them to ask them why they

11. PLAN International was the NGO in charge of
child protection - and by extension the CFS spaces - in the Congolese camps in Rwanda in
2017. Fieldwork in Kiziba from September to

the entry point for the PID studio and guided the first two-week intensive

112. That was a total of approximately six walls, metres.

113. In mid-2018, due to a school buildings at the maternelle in quarte
4 was destroyed However, the murals on the other locations are still standing, and the NGO
in charge of the maternelle is looking for funds . Feldman et al., 'Wisdom from the field'; Elliott The young architects were Victor Ikaremye (a of Rwanda), Lydia Kanakulya (a Uandan graduate from Ardhi University in Dar es Salaam) and Moses Mawa (a South Sudanes of Architecture). It trained them on ethics, information procedures and consent forms, photography, film and recording techniques cesses, FGD, questionnaire building and interview techniques. They were developing a
fellowship at the ADC based in Kigali. The ADC fellowship at the ADC based in Kigali. The ADC in three different refugee camps in Northern Uganda for 10 years. Victor Iyakaremye and Lydia Kanakulya, despite living close and had very limited knowledge of life in the camps. Mawa noted how different life in the Rwandan camps was from the one he had lived 6. In Nort to develop a sylla

to all the ADC fellows who could select my 


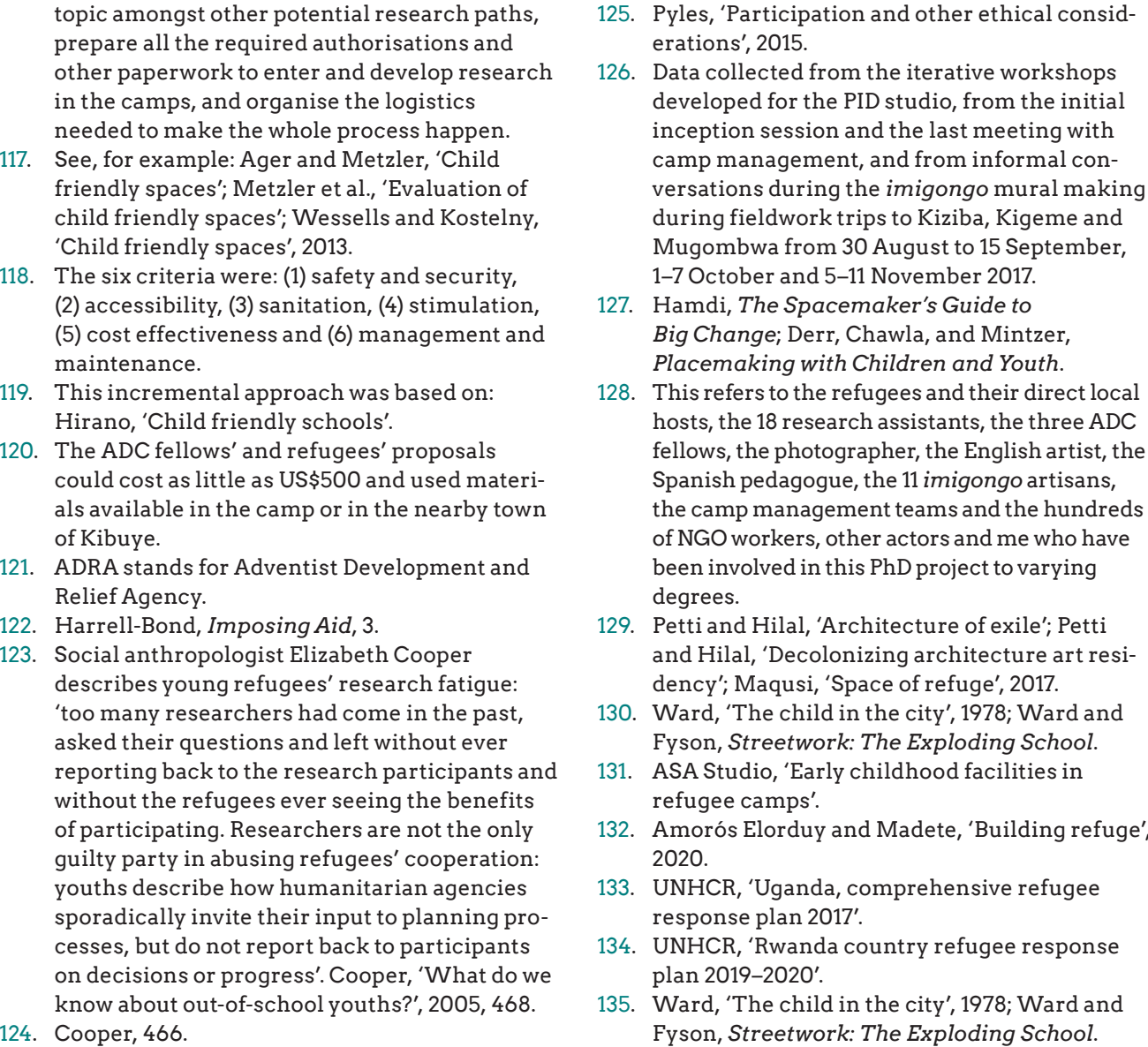

topic amongst other potential research paths, prepare all the required authorisations and in the camps, and organise the logistics needed to make the whole process happen
See, for example: Ager and Metzler, 'Child

friendly spass'. Agetzer Metler, 'Child friendly spaces'; Metzler et al..' 'Evaluation of
child friendly spaces'; Wessells and Kostelny 'Child friendly spaces', 2013.

8. The six criteria were: (1) safety and security,
(2) accessibility (3) sanitation (4) stimulation (2) accessibility, (3) sanitation, (4) stimulation,
(5) cost effectiveness and (6) management and maintenance.

19. This incremental approach was based on:
Hirano, 'Child friendly schools'

120. The ADC fellows' and refugees' could cost as little as US $\$ 500$ and used materials available in the camp or in the nearby town

12. ADRA stan

ventist Development and

Harrell-Bond, Imposing Aid, 3 .

describes young refugeses' research fatig too many researchers had come in the past, asked their questions and left without ever without the refugees ever seing the bents of participating. Researchers are not the only guilty party in abusing refugees' cooperatio youths describe how humanitarian agencies cesses, but do not report back to participants on decisions or progress'. Cooper, 'What do know about out-of-school youths?', 2005, 468

25. Pyles, Participation and other ethical consid-

26. Datac collected developed for the PID studio, from the initia 政 tions during the imigongo mural making during fieldwork trips to Kiziba, Kigeme and

7. Hamdi, The Spacemaker's Giver Big Change; Derr, Chawla, and Mintzer, Placemaking with Children and Youth.

128. This refers to the refugees and their direct local ellows, the rotortist Spanish pedagogue, the 11 imigongo artisans, the camp management teams and the hundreds of NGO workers, other actors and me who have

degrees. Ward, 'The child in the city', 1978; Ward an Fyson, Streetwork: The Exploding School. refugee camps' refugee camps'.
Lmorós Elorduy and Madete, 'Building refuge, 2020

UNHCR, 'Uganda, comprehensive refugee

4. UNHCR, 'Rwanda Ward, 'The child in the city', 1978; Ward and
Fyson, Streetwork: The Exploding School

Conclusions | through the eyes of an architect
With this book, I try to bring nuance, aid and early childhood development contextualisation and empathy to the (ECD), I hope that this book provides study and management of the long-term many practical learnings.

refugee camps in East Africa. I believe For starters, considering long-term that it is empathy that will help to change camps as proto-urban may be more mind-sets, decolonise humanitarian useful - for analytical and practical than merely seeing them as mately improve the leaning of millions humanitarian spaces, limbo and spaces of young children Assome the words of archit As somure hum

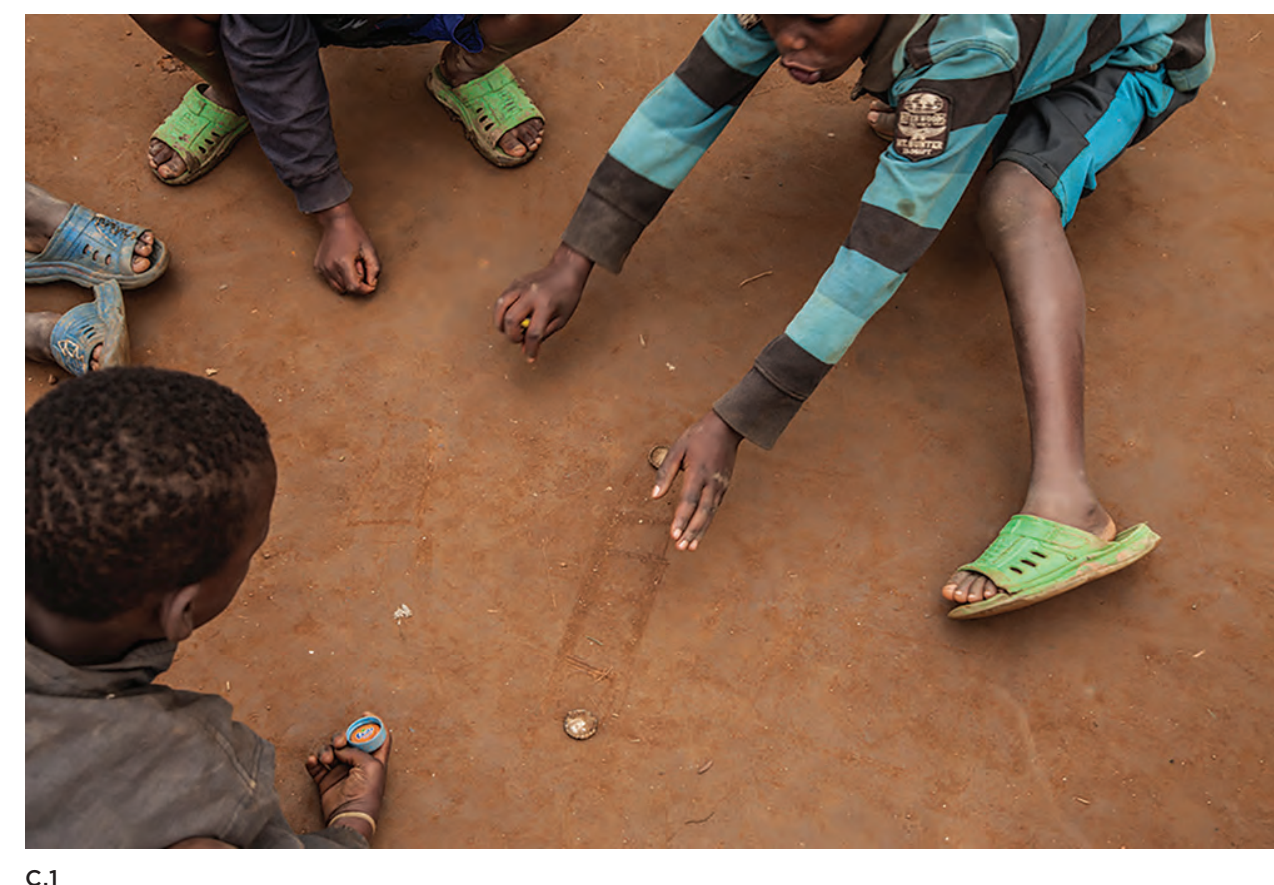


urban logics and assemblage thinking lens s a means to study and improve existing long-term refugee camps yields remarkable and useful results. In fact, gradually, academics, humanitarian practitioners and policymakers have been incorporating urban logics into refugee camp study and refugee assistance. For example, th Plan 2019-2020 gears towards converting camps into villages, ${ }^{1}$ which is in stark conrast to the country's early approaches th separated refugees from Rwandach nat that and deprived them of somand nationas doms. Acknowledging the power of the dom. Ack now urban will hopefully continue to change

Moreover consideringlongtercos

in their own right as different from recently established ones, valuing their urban-like characteristics and learning from the spatial qualities can shed light into the complex realities. Learning from the long-term camps can contribute to the transformation towards healthy huma settlements and inform new humanitarian strategies. Ideally, this new perspective can improve the livelihoods of refugees and the surrounding communities.

Through an urban lens, the built envronment gains centrality and agency. Treating the built environment as an active agent of camp life affords its inquiry and manipulation and gives planners, refugees and academics a relevant avenue to study and improve refugee assistance. Understanding the camps' growth patterns and having detailed, open-source and rer available spatial information might trigge more studies, improve their planning and management, and lead to more effective alternatives to them. One example of this is how the construction - and the appearance on maps - of formal ECD centres promotes awareness about ECD's relevance amongst refugees, direct local hosts, non-governmental organisations (NGOs), donors and local authorities. I expect that the maps, website and publications that I have developed might further enhance the discussion about the significance of the built and learning environments and about youn children's education in refugbout young triggering motion in refugee assista

Harnessing camps' spatial qualities can nsform and stimulatinglearning environments for young children Understanding the buit environment as an added educator for young child a the teachings of authers such as Ward ${ }^{2}{ }^{2}{ }^{3}$ or ${ }^{2}{ }^{4}{ }^{4}$ to can allow rew can allow rearchers and humanitarians camps physical environments on the lifelong learning of millions of children. It might give practitioners more tools to transform the camp from deprived and damaging into stimulating added educators.

Focusing on the built environment it becomes evident that refugees are the leading builders of these settlements. Together with their direct local hosts, they appropriate and reproduce the camps, particularly their shelters, commercial and religious facilities and many educational structures. Therefore, while the humanitarian system might we the facto ge the de facto government of these settlements, the refugees, their direct local hosts and home-based ECD (HBECD) in Kigeme and numerous geopolitical, climatic and socioeconomic actors. As refugees change their surroundings, they simultaneously adap to those in a continuous co-modification. This co-modification is especially prevalen in the older and most resource-limited camps, where aid hand-outs and humanitarian control are rapidly dwindling

The built environment of the home predominantly but also of the streets and othe common areas - what I classify as informal learning environments - are paramount to young children's learning In these stings, children acquire skills, behaviours, values chlld and know the lare influence of formal and non the infuence of formal and non-formal Unfort-based learning envir. Unfortunately, hese contexts have mostly adverse effects, which go unaccounted for, as the education cluster focuses principally on the formal ECD facilitie

Informal learning environments could improve with support to the refugee-led spatial upgrading. A child-friendly and stimulating home environment could be on where the pavements are dirt free, wher there is enough light and ventilation, and where the sleeping areas are safe, secure and comfortable. WASH facilities could positively influence young children when well-lit at night, clean, secure and used only by small groups. Moreover, children will significantly benefit from child-friendly neighbourhoods where streets are safer and designed for those shorter than 95 centmetres tall, where smaller playgrounds and child-friendly spaces (CFSs) dot the landscape and hereinitivessuch as the (aces for child stimulation.

Non-formal and formal educational facilities will serve better those who attend them if children and their support networks take centre stage, thus becoming contextualised. A step to achieving that would be to consider, fund and support the already existing initiatives led by refugees and direct local hosts. These enterprises tend to give more weight to cultural upbringings, are smaller and are closer to the diverse communities ${ }^{8}$ Moreover, humanitarian NGOs could learn from these grass-roots initiaives and supporteristing Parent-Techer Associach Associations in the choice of location, the facilites in those facilies incase thoser ave the public interest design (PID) studio in Rwanda - to have local and regional designers, engineers, artists and other experts involved, and even leading, the design and construction of learning environments, always with the children's well-being and timulation as the central goal.

Architecture can help to transform the long-term camps and create new alternatives to camps in order to cultivate more effectively an environment conducive to young children's learning, for example developing speculative actions based on the qualities of each specific camp, and developing interventions bearing in mind the six spatial attributes of the long-term camps - growing heterogeneity and complexity co-functioning/intercon and ever-bo-coming weak soils, and isolation and proximity to 
the border. If people in charge of ECD-both those imagined by the students of architechumanitarians and refugees - can value ture and the refugees during the PID studio rchitecture and see it as an opportunity in Kigeme and Mugombwa.

and harness the camps' architectural

qualities, if they practice meaningful par- Contributing to research by architectura ticipatory processes, it might be possible design-The series of which this volume

to convert the camps into 'schools without is a part is instrumental to those involved walls!

In my quest to unravel the long-term camp paradox, assemblage thinking has helped me substantially. It has reveale long-term camps as multi-authored evolving proto-urban learning assemblages. It has exposed the heterogeneity of the thas exposed the heterogeneity of the dependent and passive, many are active and self-motivated, others are resourceful entrepreneurs, some are vulnerable and oppressed victims, others are perpetrators and looters, and many are energetic and hard-working. ${ }^{10}$ Thinking through assemblage, the power and agency that refugees have becomes evident, which does not take away from the oppressive dominance th the humanitarian system/host governments assemblage imposes on them. In the long-term camps as in other urban settings, diverse levels and kinds of power and agency work simultaneously.

Using assemblage thinking, I have seen connections that might otherwise interactive spatial characteristics and the continuous spatial modifications tha refugees lead. Acknowledging the constellation and overlapping of asseme conallows action on these, such as the murals we dever in Kizibo It paves the way to create new and better assemblages such as in architecture with a social purpose the value of using design as an avenue to investigate social matters. Developing our work better, connect with our clients and the users of our buildings beter and understand our cultural, nat socia und politic their culural, natural, social year-on reste continued with that approach and aligned with ru win refugee campreserch tigates what Barbara Harrell-Bond called the anti-participatory ideologies and practices of the humanitarian system." It builds on refugees and migrant populations should in addition to the principle of causing no harm, benefit academia, policy development and refugee livelihoods.12,

Architectural tools have facilitated the translation and reassemblage of information into cartographic and pictorial representations of long-term refugee camps that did no exist before, and the collection of refugee accounts about the problems that youn children face in the camps. For example, mapping and spatial analysis allowed the discovery of trends, patterns and particularities of the interactive and static spatial chracteristics of the and static spatial the regeng-term camps in research through design has helped the teams that I work with and me to evaluate the idea that research on the subject of children's learning. The translation and interpretation qualities of tools such as models and photomontages have enabled and enhanced participatory processes. These instruments highlighted the relevance of space on young children's learning and brought this relevance to the current refugee-led spatial appropriations. The participatory action research (PAR) exercises that architecture, low- and high-tech tools art and crafts might allow the inclusion of various relevant actors in knowledge production cycles Specifically they afforded a collective process of spatial specurtion testing the Lefebrian tion ${ }^{14}$ through the creation of imigongo tion'through the creation of imigongo murals, he representation of imagined and the developos Kigeme and Mugombwa refugee camps to design CFSs and HBECD facilities.

The situated knowledges that created with the research by architectural design approach are vital tools to question underlying assumptions and generate new information. Through participatory research, facilitated with design tools, I included voices that are usually marginalised, both non-human (the built environment) and human (refugees and students of architecture), in knowledge production cycles. Including these actors usually bereaved of agency highlights their role in the development of contextualised theory policy and practice of refugee assistance and refugee education.

This type of approach to research and chitecture focuses on the process rathe than solely on the results. A relevant take on research by architectural design is, in se can be impactful and meaningful in many and varied ways. Focusing attention on the process and considering its relevance and effects can prevent issues such as widespread research fatigue amongst refugees. Moreover, this focus enables the researcher to gauge the research team's influence on the results. The research team becomes part of the assemblages that it studies. The choices that a principalinuestigator makes and the relationships she or he has with research assistants, regulations, translathics and logistics, all affect the results, The approach that I have taken is not The a r hach new. It has been widely applied in urban setlements acros the globels been used in refugee settlements in the Middle East. It could be replicated in new and long-term campselsewhere to decolofurther.

Situating refugee studies-In my quest to contribute-even to a slight degree, given my European background - to the decolonisation of the fields of architecture, ECD and refugee assistance, I made a special effort to help the careers and enhance the skills of young architects in the region. They were my research assistants throughout my architectural practice and my fieldwork. They have been invaluable collaborators. They might be involved in the future designing and building infrastructures or participating in drafting policy related to making better and afer places for refuges, their direct local hosts, as for refugees, their 
I also strove to include the voices learning source. This is a research body of young refugee children living in that is mostly yet to be developed. encampment and their support networks meaningfully, highlighting their role in Looking for real alternatives to campsmaking the refugee camps and ECD, and Suppose refugee children are to have a

harnessing their agency to trigger positive fair take on their futures. In that case, the change on both fronts.

This book demonstrates that more locally and regionally led research is needed - research that could better naviAfrican camps. Such studies could contribArican camps. Such stidies could contribpractise of refugee assistance and should practise of refugee assistance and should African universities and lead researies could improve the understanding of the camps. Also, at the policy and theory level there should be an effort to decolonise the field further. It is necessary to bring more voices into play, develop more situated knowledges and disseminate those. Some steps to achieve that could be to promote open-source publications, create accessible discussions and seminars, and move the centres of knowledge creation, collection and distribution closer to the refugee-hosing areas.

Research grounded on iterative, multstakeholder and participatory knowledge creation processes is necessary. Studies are needed that include local creative onstrated - arts and crafts can work as a universal language and as tools to involve more actors and create change in the longterm refugee camps. Investigations need to take into account parents', caregivers' and children's percetions, and acknowedge the whole built environment as a assemblage should consider banning th physical confinement of refugees in contained and isolated areas - planned camps, sttlements and special economic zones.

As politics and advocacy efforts work on that front new approaches should be taken for those camps and containment spaces that already exist: che long-erm caces that alre can provide relater, practitioners should provide real alternatives to camps which do inotrely on isolatinga Frome

From an architectural and urban standpoint, long-term camps could work as other urban hubs, placing relevance on the built environment with a body in charge of its with a holistic view of the whole. Power an responsibilities should be distributed an should include refugees, their direct local hosts and the local authorities. That does or international support should stop. Instead, power dynamics should change, as it happen in urban settlements across the globe.

With my work, I do not intend to provide linear solutions to clearly defined problems. I want to offer situated bits of knowledge that might be useful to policy and practice on refugee $E C D$, to the transformation of long-term camps in East Africa and also long-term camps in East Africa and also urban and architectural development, not mean that assistance to the vulnerable builtenviro ref res studies and the harnessing of the long-term camps' spatial characteristics highlighted in this book help envision a humanitarian strategy without
the forceful containment of people? An approach that promotes a participator decentralised and contextualised assistance? That promotes real alternatives to camps? Could the collaboration between local creative minds - higher education institutions for example - humanitarian organisations and refugees improve and contextualise assistance as we did with ou PAR exercises? Furthermore, could the support to as? Furthermore, could the support to already existing refugee-led strates and interventions contribute to better houng child More ituated howledes -and less More situated knowledges - and less overarching and generalising standard solutions - are what, in my opinion, will get us to an increasingly child-friendly and situated approach to housing and educational infrastructures in long-term camps and the rethinking of spatial strategies for refuge assistance.

This book presents an empathic approach to knowledge creation and nuanced image of seven long-term refugee camps in the East African Rift. It opens up the possibility for more contextualised responses to the spatial, socio-political and educational challenges they present. It has shown that ECD initiatives, camp planning and maintenance have the potential to affect young children's lifelong learning positively. However, this potential is now underused. I hope that the avenues that I have presented here to harness the built environment's potential as a positive added educator for young children are useful and used.

UNHCR, 'Rwand

Ward 2019-2020.

School; Ward, 'The child in the The Exploding

Lynch and Borerie, Growing Up in Cities. Chawla, Growing up in an Urbanising World, Chawla and Malone, "Neighbourhood quality in children's eyes'; Derr, Chawla and Mint
Placemaking with Children and Youth

Spatial appropriations take place through what Asef Bayat calls' 'quiet encroachment of the ordinary', AbdouMaliq Simone and James Scot
call 'everyday resistance', Teresa Caldeira calls 'peripheral urbanism' and Edgar Pieterse calls 'radical incrementalism'. Bayat, 'From "dangerous classes" to "quiet rebelel"', 2000; Scott, "

research:

IRIN, 'Food Aid 2018, .

. What, The chld in the city', 1978; Ward and

Slaughter and Crisp, 'New issues in ref research'; UNHCR, 'Emergency handbook. Camp planning standards. (Planned settlements)'.

, Bond, Imposing Aid, 3. Turton, Refugees,
forced migrants' Jacobsen and Landau,
refugee research'2003 Politique. Derr, Chawla and Mintzer, Placemaking with
Children and Youth: Unt and Bell, 'The impact of small-scale design interventions', 2014; Hamdi, The Spacemaker's Guide to Big Change. Ziliacus, 'With the Jarahieh Refugee School'; 'Space of refuge', 2017 . 
Assemblage thinking-Gilles Deleuze and host governments assemblage imposes on Félix Guattari presented the assemblage them.

theory in 1987 with the publication of Mille

Plateaux: Capitalisme et Schizophrénie.

Assemblage thinking rejects the interpreta-

tion of the social and natural worlds as made

up of finite and definable entities organ-

Built environment-In this book, I define the term 'built environment' as the human-

structures created to

structures. It considers conceptualisation a Co-constitutive-'Co-constitutive' is when

two or more events, actors or elements are to facilitate analysis Assemblage theory necessary for each other's creation and proposes instead that natural and social structure. One is necessary for the others formations are assemblages of complex con- to exist and be organised in a specific way. In figurations that are interrelated, composed our case, camp inhabitants and camp spaces of other complex configurations and in turn are co-constitutive; as they modify each create more extended configurations. ${ }^{2}$ other, they adapt to each other

Relativism is assemblage thinking's

main criticism. However, it has allowed Early childhood development-I use the me detail and contextualisation, opening acronym ' $E C D$ ' to refer to early childhood the door for the creation of situated bits of development from conception through knowledge. I use assemblage thinking as to six years of age in four main domains: a post-structural framework for analysing socio-emotional, cognitive, physical and social complexity, emphasising non-linear language development. The sustainable approaches to social systems based on development goals (SDGs) of the United mutability, exchangeability and intercon- Nations (UN) endorsed these four domains nectedness to contend both totalising and in $2015 .{ }^{4}$ As refugee assistance tightens relativist discourses. ${ }^{3}$ The assemblage lens its connection with development efforts, ${ }^{5}$ becomes emancipatory rendering visible this interpretation of ECD is likely to define diverse levels and kinds of power and refugee ECD for at least the next 10 years. ${ }^{6}$ $\begin{array}{ll}\text { diverse levels and kinds of power and } & \text { refugee ECD for at least the next } 10 \text { years. } \\ \text { agency, where refugees' power and agency } & \text { ECD initiatives in refugee camps ideally }\end{array}$ agency, where refugees' power and agency $\quad$ ECD initiatives in refugee camps ideally does not take awa from the oppressive inclue, 
learning education, as well as the provision of services to pre women, parents and other caregivers. For this research, I am focusing only on the 'early learning' piece of the ECD framework. Despite this conscious specificity, I nonetheless still use the acronym ' $E C D$ ' becaus of its prevalence amongst the education cluster ${ }^{8}$ leads on ECD (United Nations Children), and education implementin

Ecosystemic-This term emphasises the Exy interaction bet and the family, and the social, urbandual natural contexts. Originally, the term was used by Urie Bronfenbrenner and focused on the environment as a context for child development. It represented a broader conception of human development where the individual is as important as the context (spatial, temporal and natural) where it
develops. The term emphasises interrelat develops. The term emphasis

Long-term refugee camp-I define 'longterm refugee camps' as those that have lasted for more than three years and that host more than 5,000 refugees from 'protracted refugee situations' as defined by the United Nations High Commissioner for Refugees (UNHCR) in 2004.11 They are not to a study made in 1990, 117 camps had been established since UNHCR first started intervening in the continent, and of those, 59 were still standing ${ }^{12} \mathrm{From}$ the 1990s to date, in East Africa, camps have only been dismantled if requested by the host country. This is partly due to the protracted nature of some conflicts, as well as the camps being reoccupied over time by different waves of refugees stemming from diverse countries and conflicts.

Multi-scalar-Social and natural phenomenon take place and are constituted on different scales. They might act differently on each of those scales; continuity on one scale can be interruption at another. Scales can be spatial, temporal or socioeconomic. Doing a multi-scalar ar sociorefug a deepr and rich inhabitants allows phen anding of phenomenon - refugee camps - that has It might been quite flat and one-sided. It might help in the decolonisation of the refugee camp studies to bing in transdis-

Polyrhythmicthis book illustrates the simultaneous (two or more rhythms present) in the life of camp-the daily rhythms of life, the rhythm found in the spatial patterns and plans of the camps and the diverse rhythms of lifelong learning that children experience.

Proto-urban-I use the term 'urban' to mean 'within or of distinctly demarcated human settlements'. I specifically use the term 'proto-urban', borrowing from Manuel Herz, ${ }^{13}$ since the political community in these settings is not fully formed, an there is no real refugee representation in the camps' management At present, both the camps management. At present, both and national humanitarian organisation governance and the management of these spaces and people. The current structure prevents refugees' political participation within the nation states that host them
and the accountability of the humanitarian organisations that de facto govern them. These camps are not a polis, not yet. ${ }^{14}$ Besides, despite the move to recognise these as not just 'humanitarian' spaces or 'limbo', the humanitarian system/host government assemblage is reluctant to adm them as urban. That recognition could legitimise these spaces as permanent-as 'cities' and their inhabitants as citizens.

Radical incrementalism-Professor Edgar Pieterse of the A Por Cities meaning:

'Surreptitious, sometimesovert, and multiSurreptious, sometimes overt, and multple small revolutions that at unanticipated and unexpected moments galvanise into more profound ruptures that accelerate tectonic shifts of the underlying logics of domination.... A disposition and sensibility that believes in deliberate actions of social transformation but through a multiplic ity of processes and imaginations, none of which assumes or asserts a primary significance over other struggles.1.5

Refugee-In this book, the term 'refugee' aligns with the definitions found in the 1951 Convention Relating to the Status of Refugees and the subsequent 1967 Protocol. Article I, points 1 and 2, define a 'refugee' as:

$\therefore$...every person who, owing to a well-founded fear of being persecuted for reasons of race religion, nationality, membership of a particular social group or political opinion, is outside the country of his nationality and is unable or, owing to such fear, is unwilling to avail himself of the protection of that country, or who, not having a nationality and being outside the country of his former habitual residence as a result of such events, is unable or, owing to such fear, is unwilling to return to it.... Every person who, owing to external aggression, occupation, foreign domination or events seriously disturbing public order in either part or the whole of his coundry in either partior to seek refuge in of origin or nationality'

African states had been using the term 'refugee' even before the signature of the 1969 Convention Governing the Specific Aspects of Refugee Problems in Africa.

Right to the city-This notion coined by philosopher and sociologist Henri Lefebvre discussed how city space and inhabitants are co-constitutive and use their agency to modify each other. ${ }^{16}$ Furthermore, Lefebvre explained space as a complex social construction based on socially produced values and meanings that affected spatial practices of the everyday and the inhabitants' perceptions. $^{17}$

Transduction-Henry Lefebvre developed 'transduction' as a methodology aimed 'to encourage the creation of "experimental utopias" Framed by existing reality introduce "rigour in inentionandknowedge 
utopia" as a way of avoiding "irresponsible idealism" ${ }^{\prime \prime 18}$

Urban turn-The 'urban turn' is a relatively new study avenue in refugee camp studies. It conceives camps as what I call proto-urba spaces. Post-structuralist transdisciplinary authors are the leading proponents of this branch of works, which includes - in addition to humanities and social sciences academics - geographers, architects and urban planners since the early 2000 s. It includes a relevant representation of academics who aim at recolonising the field 19 Urban turn works are especially prevarent in highly visible cases, such as the Palestinis ale for fon comps over overlapping authorships of the long-term camp spaces. The urban turn approac renders visible human and non-human actors largely bereft of agency and over-
looked under discourses of humanitarian spaces and spaces of exception

Young children's learning-I define 'young children's learning' as the concepts, skills, values, knowledge and behaviou patterns that children acquire. Contentbased direct learning, incidental or indirect learning, and learning through experiencing the human-human, human-built environment and human-natural environment interactions are different means to assimilate knowledge.

Notes
1. Anderson and McFarlane, 'Assemblage and

geography', 2011, 124-7.

Deleuze and Parnet, Dialogues II, in de Landa,
'Both assemblage thinking and ANT have much to say about the spatial dimensions of power and concerned with why orders emerge in ways, how they hold together, somewhat precariously, how they reach across or mold space In 2016 , the international community comm ted to the SDGs, in which ECD was explicitly by 2030 , countries should 'ensure that all girls and boys have access to quality early childhood development, care and pre-primary education Global Education Cluster, 'Global education cluster 2015 report'; Global Education Cluster, Education cluster strategic plan 2015 to 2018 , the SDGs', 6 on, 'Refugee education: A global review', 478.

strategic plan 2015 cluster, $n^{\prime}$ 's Fund (UNICEF) und thed Nations (U) Organization (UNESCO) and of the different defCarly childhood emergencies, see: Woodhead Cappa “The formative year' 4 UNCSCF' 'Building better brains' 2014.

United Nations Office for the Coordination of Humanitarian Affairs clusters are 'groups of
humanitarian organizations, including but limited to the UN, in each of the main sectors humanitarian action'. OCHA, 'United Nations Office for the Coordination of Humanitari

IPs are public and non-public entities to which
the United Nations entrust resources funds an materials) to implement programme activities. agement of implementing pret of the manNations system organizations'

10. UNESCO's conception of ECD has its founda-
tions in four pillars established in socio-emotional, (2) cognitive, (3) physical apd (4) language development. UNICEF's conception of ECD is guided by six developmental language, (2) cognitive, (3) physcat, (4) socin language, (2) cognitive, (3) physical, (4) social,
(5) emotional and (6) approaches to learning.
Both UNESCO's pillars and UNICEF's domains e: (1) interpersonal, (2) intrapersonal, (3) logical-mathematical, (4) bodily-kinaesthetic

(5) musical, (6) linguistic and (7) spatial.
The UNHCR defines' tions' as 'refugee populations of 25,000 persons or more who have been in exile for five or more years in developing countries without imme solutions'; 'in protracted situations, refugee populations have moved beyond the emerge phase - where the focus is on life-saving protec solutions in the foreseeable future' UNHCR, 'Protracted refugee situations: Revisiting the problem', 2008; UNHCR, 'Protracted refugee 105-97; UNHCR, 'Protracted refugee situations',

12. Stein and Clark, 'Refugee integration and older refugee settlements in Africa?
13. Herz uses this term to refer to the long-term 'Refugee camps in the Western Sahara. Hert, 383. 'The accidental city' 2009, 11-2; Agier 14. Jansen, 'The accidental city', 2009, 11-2; Agier
and Lecadet, Un Monde de Camps; Feldman, 'What is a camp?', 2014, 244-52; Jansen, 'The protracted refugee camp', 20
15. Pieterse, City Futures, 6 .
16. Lefebvre, Le Droita La La Ville.

17. Lefebvre, La Production de l' I'space. 8. Lefebvre, Writings on Cities in Petcou and Petrescu, 'R-URBAN or how to co-produce a resilient city', 2015, 256.

Propologist Bram and ontological shift that occurred in refugee camp studies that associated long-term refuge
camps with urbanisation The geographers, architects, urban planners and urban theorists into the study of refugee camps brought with it this new perspective. Jansen, 
Acronyms

\begin{tabular}{|c|c|c|c|}
\hline \multirow{2}{*}{$\begin{array}{l}\text { AAH } \\
\text { ADRA }\end{array}$} & Action Africa Help & NCCK & National Council of \\
\hline & $\begin{array}{l}\text { Adventist Development } \\
\text { and Relief Agency }\end{array}$ & NGO & $\begin{array}{l}\text { Churches Kenya } \\
\text { non-governmental }\end{array}$ \\
\hline ANT & actor-network theory & & organisation \\
\hline ASA & Active Social Architecture & OCHA & United Nations Office \\
\hline CARE & $\begin{array}{l}\text { Cooperative for Assistance } \\
\text { and Relief Everywhere }\end{array}$ & & $\begin{array}{l}\text { for the Coordination of } \\
\text { Humanitarian Affairs }\end{array}$ \\
\hline CFS & child-friendly spaces & OPM & Office of the Prime Minister \\
\hline DRC & Democratic Republic of & & (Uganda) \\
\hline & Congo & PAR & participatory action research \\
\hline ECD & early childhood & $\begin{array}{l}\text { PID } \\
\text { cDGc }\end{array}$ & public interest design \\
\hline EFA & $\begin{array}{l}\text { development } \\
\text { Education for All }\end{array}$ & SDGs & $\begin{array}{l}\text { sustainable development } \\
\text { goals }\end{array}$ \\
\hline HBECD & home-based early & UN & United Nations \\
\hline IP & $\begin{array}{l}\text { childhood development } \\
\text { implementing partners }\end{array}$ & UNESCO & $\begin{array}{l}\text { United Nations Educational, } \\
\text { Scientific and Cultural }\end{array}$ \\
\hline MIDIMAR & Ministry of Disaster & & Organization \\
\hline & $\begin{array}{l}\text { Management and Refugee } \\
\text { Affairs (Rwanda) }\end{array}$ & UNHCR & $\begin{array}{l}\text { United Nations High } \\
\text { Commissioner for Refugees }\end{array}$ \\
\hline MOST & $\begin{array}{l}\text { Management of Social } \\
\text { Transformations and } \\
\text { the Fnvironment }\end{array}$ & UNICEF & $\begin{array}{l}\text { United Nations Children's } \\
\text { Fund }\end{array}$ \\
\hline
\end{tabular}




\section{Bibliography}

Abourahme, Nasser. 'Assembling and spilling-over: Towards an "ethnograhy of cement" in a Palestinian refuge camp'. International Journal of Urban and Regional Research 39 (2015): and Regior

The Nasser, and Sandi Hila 作 subjectification and the folding of polarity: The case of Deheishe Cam Palestine. Campus in Camps, 2008. Accessed 17 November 2020, http:// www.campusincamps.ps/wp-content -and-Sandi-Hilal_Deheishe-Paper.pd -and-Sandi-Hilal_Deheishe-Pap Agamben, Giorgio. Homo Sacer. Sovereign Power and Bare Life.
Stanford, CA: Stanford University

Stanford, CA:

Ager, Alastair, and Janna Metzler.

'Child friendly spaces: A structured

review of the current evidence-base. Uxbridge: World Vision Internation

2012. Accessed 17 November 2020

https://www.wvi.org/sites/default/fi
/CFS\%20Literature\%20Review\%20

final\%20Aug\%202012.pdf.

Agier, Michel. 'Afterword: What contem-

porary camps tell us about the world

to come' Humanity: An International

Journal of Human Rights,
Humanitarianism, and Development 7 (2016): 459-68.

Agier, Michel. 'Between war and city: Towards an urban anthropology of refugee camps'. Ethnography 3 (2002): 317-41.

Agier, Michel, and Clara Lecadet. Un Monde de Camps. Paris: La Découverte, 2014.

Amorós Elorduy, Nerea. 'East African efugee camps as learning assemblages. The built environment as an educational resource for encampe Youn' Univer ity Yc. University College London, 2018. Accessed 17 November 2020. https: discovery.ucl.ac.uk/id/eprint/10057316/ Amorós Elorduy, Nerea. "The impact of humanitarian shelter and settlements on child protection' Forced Migration Review 55 (2017): 41-3.

Amoros Elorduy, Nerea. 'Learning in and through the long-term refugee camps in the East African Rift'. In Refugee in a Moving World: Refugee and migrant journeys across disciplines, edited by Elena Fiddian-Qasmiveh, 362-81 London: UCL Press, 2020.

Amorós Elorduy, Nerea. 'Mapping refugee spaces'. Mapping

Refugee Spaces, 2017. Accessed 
17 November 2020. https://www mappingrefugeespaces.com.

Amoros Elorduy, Nerea, and Etta Madete. 'Building refuge'. The Architectural Review no.1477 (2020): 36-41.

Anderson, Allison and Marian Hodgkin 'The creation and development of the global IASC education cluster.' Paper commissioned for the EFA Global

Monitoring Report 2011, The hidden crisis: Armed conflict and education. Paris: UNESCO, 2010

Anderson, Ben, and Colin McFarlane. 'Assemblage and geography'. Area 43 (2011): 124-7.

Appadurai, Ariun ‘ 'Crassroots globaliza Appadurai, Arjun. 'Grassroots globalizaCulture 12 (2000): 1-19. in Sudio. 'Early childhood facilities in refugee camps'. 2013. Access activesocialarchitecture.com/refuge
. -camps-educ

-camps-educ.
AVSI, and InfoAid. 'Child protection KAP survey in Rwandan refugee KAP survey in Rwandan refugee
camps.' Milan: AVSI, 2013. Accessed camps.' Milan: AVSI, 17 November 2020. https://www.avs .org/upload/publication/0/24.pdf? _636348590910931508.

Ayiemba, Elias H. O. 'Refugees in postconflict reconstruction: A study of Kakuma and Dadaab refugees in Kenya'. In Conference on African Transnational and Return Migration in the Context of North-South Relations, 29-30. Coventry, UK. University of Warwick, 2009 .

Bagenda, Emmanuel, Angela Naggaga and Elliott Smith. 'Land problems in Nakivale settlement and the implications for refugee protec-

tion in Uganda'. Refugee Law Project

Working Paper 8, 2003. Accessed

17 November 2020. https://www

refugeelawproject.org/files/working papers/RLP.WP08.pdf.

Bakewell, Oliver. 'Repatriation and selfsettled refugees in Zambia: Bringing solutions to the wrong problems'. Journal of Refugee Studies 13 (2000) 356-73.

Ban, Shigeru. 'Paper emergency shelters for UNHCR - Byumba ru camp, Rwanda 1999', Shigeru Ban Archinects Disaster Religeru Ban Architects. Disaster Relief Projects, 1999. Accessed 17 November 2020. http./Www.shigerubanarchitects.com /works/1999_paper-emergency-shelter
/index.html.

Barbelet, Veronique, Jessica HagenZanker, Eva Ludi, Freddie Carver and Dirk Willem te Velde. 'How to ensure Ethiopia's "Jobs Compact" works for refugees'. Overseas

Development Institute, 2018. Accessed 17 November 2020. https://www.odi.org /blogs/10716-how-ensure-ethiopia-s -jobs-compact-works-refugees.

Basiime, Felix. '6 injured as refugees

clash with locals in Kyegegwa'. Daily Monitor Uganda, 23 November 2017. Accessed 17 November 2020. http:// www.monitor.co.ug/News/National/6 -injured-as-refugees-clash-with-locals -in-Kyegegwa/688334-4200532-3ef8lt /index.html. Bauman, Zygmunt. 'In the lowly nowhere-
villes of liquid modernity: Comments on and around Agier'. Ethnography

3 (2002): $343-9$
Bayat, Asef. 'From "dangerous classes" to "quiet rebels": Politics of the urban subaltern in the Global South'. Internationa Sociology 15 (2000): 533-57.

Bayat, Asef. 'The quiet encroachment of the ordinary'. The Chimumrenga Chronic 3 (2007): 1-8.

Berlanda, Toma. 'Umujyi: Cities and human settlements in Rwanda'. Proceedings of Sustainable Futures: Architecture and Urbanism in the Global South. Kampala Uganda, 27 - 30 June 2012, 136-41. Accessed

17 November 2020 . http://wwessed .org/berlanda.pdf.

Betts, Alexander, Gil Loescher and James Milner, Commissioner for Refugess (UNHCR): The politics and practice of (UNHCR) The politics and prefice of refugee protection. 2nd ed. London: Routledg 2012.

Betts, Alexander, Louise Bloom, Josiah Kaplan and Josiah Naohiko. Refugee Economies: Forced displacement and development. Oxford: Oxford University Press, 2016

Betts, Alexander, and Naohiko Omata Refugee Economies: Rethinking popular assumptions. Oxford: Refugee Studies Centre, University of Oxford, 2015. Bonta, Mark, and John Protevi. Deleuze and Geophilosophy: A guide and glossary. Edinburgh, UK: Edinburgh University Press, 2004.

Bronfenbrenner, Urie. 'Contexts of child rearing: Problems and prospects'. American Psychologist 34 (1979): 844-50.

Bronfenbrenner, Urie. The Ecology of Human Development: Experiments by nature and design. Cambridge, MA: Harvard University Press, 1979. Buhmann, Dörthe, and Barbara Trudell. Mother tongue matters: Local language as a key to effective learning'. Paris: UNESCO Division for the Promotion of Basic Education, Education Sector, 2008.

Bush, Kenneth David, and Diana Education in Ethnic Conflict: Towards a peacebuilding education for children Florence, Italy: UNICEF Innocent Research Centre, 2000.

Caldeira, Teresa P. R. 'Peripheral urbanization: Transversal logics, and politics in cities of the Global South' Society and Space 35 (2016): 3-20.

Cappa, Claudia. 'The formative years: UNICEF's work on measuring early childhood development'. New York Divisiof Data \& Analytics Section Division of Policy and Strategy, 2014. CARE International. 'A model beginning: CARE's early childhood development for Rwanda's most vulnerable children'. Geneva: CARE International 2015

Castle-Miller, Michael. 'The law and policy of refugee cities: Special economic zones for migrants'. Chapman Law Review 21 (2018): 303.

Chambers, Robert. 'Hidden losers? The impact of rural refugees and refugee programs on poorer hosts'. International Migration Review 20 (1986): 245-63.

Chambers, Robert. 'Rural refugees in Africa: What the eye does not see'. Disasters 3 (1979): 381-92. 
Chawla, Louise. Growing Up in an Urbanising World. London: Routledge, 200

Chawla, Louise. 'Growing Up in Cities: A report on research under way'. Environment and Urbanization 9 (1997): 247-52.

Chawla, Louise, and David Driskell. 'The Growing Up in Cities project'. Journa of Community Practice 14 (2006) 107-23.

Chawla, Louise, and Karen Malone. 'Neighbourhood quality in children's eyes' In Children in thilHome neighbourhood and community, edited by Pia nity, edited by Pia Christensen and RoutledgeFalmer, 2003.

Chiles, Prue. 'The classroom as an evolving landscape." In Children's Spaces, ing landscape." In Children's Spaces,
edited by Mark Dudek, 101-13. London Architectural Press, 2005.

Chkam, Hakim. 'Aid and the perpetuation of refugee camps: The case of Dadaab in Kenya 1991-2011'. Refuge Survey Quarterly 35 (2016): 79-97.

Christensen, Pia, and Margaret O'Brien, eds. Children in the City: Home neighbourhood and community. London: RoutledgeFalmer, 2003.

Consultative Group on Early Childhood Care and Development, and INEE. The path of most resilience: ECCD in emergencies principles and practice'. Paris: UNESCO, 2010.

Coombs, Philip H. World Educational Crisis: A systems approach. New York Oxford University Press, 1968.

Coombs, Philip $\mathrm{H}_{4}$ and $\mathrm{M}$, 1968.

Ahmed. 'Attacking rural poverty
How nonformal education can help' Washington, D.C.: International Council for Educational Developmen and World Bank, 1975. Accessed 6 April 20201. http://documents1 .worldbank.org/curated/en/65687146 8326130937/pdf/multi-page.pdf.

Cooper, Elizabeth. 'What do we know

about out-of-school youths? How participatory action research can work for young refugees in camps' Compare: $A$ Journal of Comparative and International Education 35 (2005) 463-77.

Crawford, Nicholas, John Cosgrave and Irina Mosel '10 thingsto kne and In Mosel. "lo things to know about refugees and displacement. the Hum Development Institute and Bricy Brief. London, 2015.

Crawford, Nicholas, John Cosgrave, Simone Haysom and Nadine Walick Protracted displacement: Uncertai paths to self-reliance in exile'.

Overseas Development Institute and the Humanitarian Policy Group, Commissioned Report. London, 2015 Crawley, Heaven. 'Why jobs in special economic zones won't solve the problems facing the world's refugees'. The Conversation, 2017. Accessed 17 November 2020. https:// theconversation.com/why-jobs-in -special-economic-zones-wont-solv -the-problems-facing-the-worlds -refugees-75249.

Crisp, Jeff. 'Forced displacement in Africa: Dimensions, difficulties, an policy directions' Refugee Surver Quarterly 29 (2010): 1-27.
Crisp, Jeff. 'A state of insecurity: The political economy of violence in refugee-populated areas of Kenya'. Africa Affairs 99 (2000): 601-632.

Daley, Patricia. 'Refugees and underdevelopment in Africa: The case of Barundi refugees in Tanzania'. PhD Thesis submitted in The Faculty of Anthropology and Geography, University of Oxford Trinity Term, St Anthony's College, 1989.

David, Thomas G., and Carol Simon

Weinstein. 'The built environment and children's development' In Spaces for Children: The built environment and child dopment, edited The child development, dited by Thomas $G$. New York: Plenum Press, 1987. David, Thomas G., and Carol Simon

Weinstein, eds. Spaces for Children: The built environment and child develThe built environment and child development. New York: Plenum Press,
Deleuze, Gilles, and Felix Guattari.

A Thousand Plateaus, translated

A Thousand Plateaus, translated
by Brian Massumi. Minneapolis:

by Brian Massumi. Minneapolis:
University of Minnesota Press, 1987 .

De Landa, Manuel. Assemblage Theor Edinburg: Edinburg University Press, 2016.

Derr, Victoria, Louise Chawla and Mara Mintzer. Placemaking with Children and Youth. New York: New York

University Press, 2018.

Dewey, John. 'Experience and educa241-52.

Diken, Bülent, 'From refugee camps to gated communities: Biopolitics and the end of the city'. Citizenship Studies

8 (2004): 83-106.
Diken, Bülent, and Carsten B. Laustsen 'The camp'. Geografiska Annaler, Series B: Human Geography 88 (2006): 443-52.

Diken, Bülent, and Carsten B. Laustsen The Culture of Exception: Sociology facing the camp. Abingdon, UK: Routledge, 2005.

Dovey, Kim, and Ross King. 'Forms of informality: Morphology and visibility of informal settlements'. Built Environment 37 (2011): 11-29.

Dryden-Peterson, Sarah. 'Refugee educaion: A global review' Geneva: UNHCR Policy Development and Evaluation Service (PDES), 2011.

Dryden-Peterson, Sarah. 'Refugee education: The crossroads of globalization' ducational Researcher 45 (2016): 73-82.

Dudek, Mark. Kindergarten

Archilecture: Space for the imagination. 2nd ed. London: Spon Press, 2000 Elliott, Emily Roush, and Leah Faulk

Kemp. 'Building social building: Public interest design as a catalyst for change'. In Globalizing Architecture: Flows and disruptions, edited by John Stuart and Mabel Wilson, 411-8. Washington, DC ACSA, 2014.

Emuria, Lotethiro Peter. 'Clashes between refugees and host communities: The case study of Kakuma Refugee Camp, 1992-2013'. Masters thesis, University of Nairobi, 2015. Accessed 17 November 2020. http:/ erepository.uonbi.ac.ke/handle/11295 193215.

Innead, Ennead Lab, UNHCR, and Stanford University. 'Rethinking 
refugee communities'. Ennead Lab, 2015. Accessed 17 November 2020. http://www.enneadlab.org/projects /rethinking-refugee-communities. Evans, Gary W. 'The environment of childhood poverty'. American Psychologist 59 (2004): 77.

Evans, Gary W., and Susan Saegert. 'Residential crowding in the contex of inner city poverty'. In Theoretical Perspectives in Environment-Behavio Research, edited by Seymour Wapne Jack Demick C. Takiji Yamamapner, Jack Demic Hiroufmi Min

Fafunwa, Aliu B. 'Education in the mother tongue: A Nigerian experiment'. Journal of African Studies 1(1974): 285.

Feldman, Ilana. 'What is a camp? Legitimate refugee lives in spaces of long-term displacement'. Geoforum 66 (2014): 244-52.

Feldman, Roberta, Sergio Palleron David Perkes and Bryan Bell. 'Wisdom from the field: Public interest desig architecture in practice. A guide to public interest practices in architecture'. Washington: American Institute of Architects, College of Fellows, 2014 Feldman, Sara, Meredith Hunter, Karen Jacobsen, Nicholas Crawford, John Cosgrave, Simone Haysom, Nadine Walicki, Humanitarian Policy Group and Way Forward. 'The failure of selfreliance in refugee settlements'. POLIS Journal 33 (2013): 4

Freire, Paulo. Education for Critical

Consciousness. London: Continuum, 1973
Freire, Paulo. Pedagogy of the

Oppressed. 30th anniversary ed. New York: Continuum, 2006.

Fresia, Marion. 'Performing repatriation? The role of refugee aid in shaping new beginnings in Mauritania'. Transition and Justice: Negotiating the Terms of New Beginnings in Africa 45 (2014): 41-63.

Fresia, Marion, and Andreas Von

Kanel. 'Beyond space of exception?

Reflections on the camp through the

prism of refugee camp through the

prism of refugee schools'. Journal of

Gale

refuge camp Durisible

Boreah "residuals" in Guinea'. Journal

(

of Refugee Studies 21 (2008). 537-52.

Uger, " "Beneath the surface of

Uganda's "exemplary" refugee set-

tlement, tensions simmer. Reuters,

2016. Accessed 17 November 2020

https://www.reuters.com/article/us

-uganda-refugees-landrights/be ...

andas-exemplary-refugee-settlemen

-tensions-simmer-idUSKBN13A1UW

Global Education Cluster. 'Education

cluster strategic plan 2015 to 2018'.

Geneva: Global Education Cluster,

2015.

Global Education Cluster. 'Global education cluster 2015 report'. Geneva Global Education Cluster, 2015.

Gottfried, Allen W., and Adele Eskeles

Gottfried. 'Home environment and

cognitive development in young chil-

dren of middle-socioeconomic-status

families' In Home Environment

and Early Cognitive Development

Longitudinal research, edited by Allen
W. Gottfried, 57-115. Orlando, Florida Academic Press, 1984

Gottwald, Martin. 'Burden sharing and refugee protection'. In The Oxford Handbook of Refugee and Forced Migration Studies, edited by Elena Fiddian-Qasmiyeh, Gil Loescher, Katy Long and Nando Sigona, 1-16. Oxford: Oxford University Press, 2014.

Government of Rwanda, and UNDP. '2014 National human development report. Decentralisation and human development: Accelerating socio-economic transformation and sustaining accountable governance'. Kigali: Government of Rwanda, 2015.

Government of Uganda. 'Uganda: Contro ( Contro of Alien Refugees Act, Cap. 64 of 1960 . Laws of 21. W Vol, 2, 1960 . Accessed 8 April 2021. https://www.refworld.org /cgi-bin/texis/vtx/rwmain/opendocp .pdf?reldoc $=y \& d o c i d=544448 \mathrm{~d} 84$ Government of Uganda, UN Uganda and World Bank. 'REHOPE - Refugee and host population empowerme Strategic framework - Uganda Kampala: Government of Uganda, 20 Accessed 6 April 2021. https://data2 .unhcr.org/en/documents/details 164166.

Grbac, Peter. 'Civitas, polis, and urbs: Reimagining the refugee camp as the city'. Working Papers Series No. 96 (2013): 1-36. The Refugee Studies Centre, University of Oxford. Accessed 5 April 2021. https://www refworld.or /pdfid/55c9f3504.pdf.

Guattari, Félix, and Gilles Deleuze.

'Introduction: Rhizom In

Thousand Plateaus: Capitalism and schizophrenia, trans. Brian Massumi, 3-25. Minneapolis: University of Minnesota Press, 1987.

Guyatt, Helen, Flavia Della Rosa and Jenny Spencer. 'Refugees vulnerability study Kakuma, Kenya'. World Food Program, United Nations High Commissioner for Refugees and Kimetrica, 2016.

Halldén, Gunilla. 'Children's views of family, home and house'. In Children in the City: Home neighbourhood and community, edited by Pia Christensen com Margaret $O^{\prime} B r i e n, 29-46$. London: RoutledgeFalmer, 2003

Hamdi, Nabeel. The Spacemaker's Guide to Big Change: Design and improvi-

arthscan New York Routledge, 2014

Earthe The sci, Donna J. Situated knowledges The science question in feminism of partial and the privilege. Feminist Studies 14 (2009): 575-99.

Harrell-Bond, Barbara. 'Camps: Literature review'. Forced Migration Review 2 (1998): 22-3.

Harrell-Bond, Barbara. Imposing Aid: Emergency assistance to refugees. Oxford: Oxford University Press, 1986. Harrell-Bond, Barbara. 'UNHCR - Are refugee camps good for children?' New Issues in Refugee Research, Working Paper No. 29. Geneva: UNHCR, 2000.

Harrell-Bond, Barbara. 'Weapons of the weak. Response to Kibreab'. Journal of Refugee Studies 17 (2004): 1-2.

Hart, Roger, David Satterthwaite,

Ximena De La Barra, Sheridan Bartlett and Alfredo Missair, eds. Cities for

Children: Children's rights, poverty 
and urban management. London: Earthscan, 1999

Heft, Harry 'Background and focal environmental conditions of the home and attention in young children'. Journal of Applied Social Psychology 9 (1979): 47-69.

Herz, Manuel. From Camp to City: Refugee camps of the Western Sahara Zurich: Lars Müller, 2013.

Herz, Manuel. 'Refugee camps in Chad:

Planning strategies and the architect's

involvement in the humanitarian

dilemma'. New Issues in Refugee

Research. Policy Development and

Evaluation Service, Research Paper

No. 147. Geneva: UNHCR, 2007.

Herz, Manuel. 'Refugee camps of the

Western Sahara'. Humanity: An

International Journal of Human

Rights, Humanitarianism, and

Development 43 (2013): 365-91.
Herz, Manuel. 'Refugee camps or

Herz, Manuel. 'Refugee camps or

ideal-cities in dust and dirt'. In Urban

Transformation, edited by Ilka Ruby

and Andreas Ruby, 315-22. Berlin: Ruby Press, 2005.

Hilhorst, Dorothea, and Bram J. Jansen. 'Humanitarian space as arena: $A$ perspective on the everyday politics of aid'. Development and Change 41 (2010): 1117-39.

Hilhorst, Dorothea, and Mathijs van Leeuwen. 'Emergency and development: The case of imidugudu villagization in Rwanda' Journal of Refugee Studies 13 (2000): 264-80. Hirano, Seki. 'Child friendly schools infrastructure standards and guidelines primary and tronc commun schools'. Rwanda Ministry of Education, Working Draft, 2009. Holzer, Elizabeth. The Concerned Women of Buduburam: Refugee activists and humanitarian dilemmas. thaca, NY: Cornell University Press, 2015.

Holzer, Elizabeth. 'What happens to law in a refugee camp?' Law and Society Review 47 (2013): 837-72.

Human Rights Watch. 'Rwanda:

A year on, no justice for refugee

killings' Human Rights Watch

23 February 2019. Accessed 17

23 February 2019. Accessed 17 /print/327730.

/print/327730.
Hyndman, Jennifer. 'Geographies of displacement: Gender, culture and po Thesis, University of British Columbia 1996.
Thesis, University of British Colur

1996.

Hyndman, Jennifer. Managing

Displacement: Refugees and the politics of humanitarianism. Minneapolis University of Minnesota Press, 2000. RIN. 'Food Aid 2018: The never-ending crisis'. IRIN News, 2018. Accessed 17 November 2020. http://archive irinnews.org/multimedia/food-aid -2018/index.html.

Isin, Engin F., and Kim Rygiel. 'Of other global cities: Frontiers, zones, camps' In Cities of the South: Citizenship and exclusion in the 21st century, edited by Barbara Drieskens, Franck Mermier and Heiko Wimmen, 170-209. London: Saqi Books, 2007.

Iveson, Kurt, and Ruth Fincher. ' 'Just

diversity" in the city of difference' The New Blackwell Companion to the
City, edited by Gary Bridge and Sophie Watson, 407-18. Wiley Online Library, 2012

Jacobsen, Karen, and Loren Landau. 'The dual imperative in refugee research: Some methodological and ethical considerations in social science research on forced migration'. Disasters 27 (2003): 185-206.

Jansen, Bram J. 'The accidental city: Urbanisation in an East-African Refugee Camp'. Urban Agriculture 2 (2009): 11-12.

Jansen, Bram J. 'The protracted

refugee camp and the consolidation of "human the consolidaInternational Journal of Urban and Regional Research (2015) Accessed 6 April 2021 . htps (2015). Accessed

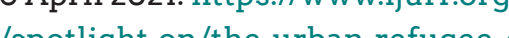
/spotlight-on/the-urban-refugee-crisis -reflections-on-cities-citizenship-and the-displaced/the-protracted-refug -camp-and-the-consolidation-of-humanitarian-urbanism/.

Jansen, Bram J." The refugee camp as warscape: Violent cosmologies, "rebelization", and humanitarian governance in Kakuma, Kenya'. A International Journal of Human Rights, Humanitarianism, and Development 7 (2016): 429-41.

Johnson, Laura C. "The developmental implications of home environments'. In Spaces for Children: The built environment and child development, edited by Thomas G. David and Carol Smith Weinstein 139-57. New York: Plenum Press, 1987.

Kagwania Peter

Antoine Pérouse de Montclos. 'Refugee camps or cities? The socio-economic dynamics of the Dadaab and Kakuma camps in Northern Kenya.'Journal of Refugee Studies 13 (2000): 205-22.

Kaiser, Paul J. 'Structural adjustment and the fragile nation: The demise of social unity in Tanzania'. The Journal of Modern African Studies 34 (1996): 227-37.

Karsten, Lia, and Willem Van Vliet.

'Children in the city: Reclaiming

the street'. Children, Youth and
Environments 16 (2006): 151-67.

Katz, Irit. 'Between bare life and everyday life: Spatializing Europe's migran camps'. Architecture Media Politics Society 12 (2017): 1-20.

Kayizzi-Mugerwa, Steve, and Jorgen Levin. 'Adjustment and poverty: A review or the African experience'. African Development Review 6 (1994)

Kibreab, Gaim. African Refugees: Reflections on the African refugee problem. Trenton, NJ: Africa World Press, 1985.

Kibreab, Gaim. 'Forced migration in the Great Lakes and Horn of Africa'. In The Oxford Handbook of Refugee and Forced Migration Studies, edited by Elena Fiddian-Qasmiyeh, Gil Loescher Katy Long and Nando Sigona. Oxford Handbooks Online. Oxford: Oxford University Press, 2014. https://doi.org 0046

Kodumuki. 'History of imigongo',

Kodumuki Wordpress, 2015 Accessed

17 November 2020 . https:/1 Accessed

wordpress com/history-ofimigongo. 
Koralek, Ben, and Maurice Mitchell. 'The schools we'd like: Young people's participation in architecture'. In Children's Spaces, edited by Mark Dudek, 114-54 London: Architectural Press, 2005

Kreibaum, Merle. 'Their suffering, our burden? How Congolese refugees affect the Ugandan population'. World Development 78 (2016): 2-29.

Kupfer, Meital. 'Accessibility and quality of education for refugees: A case study of Kyangwali refugee settlement' The School for International Training 2016, Independent Study Project (ISP) Collection, Paper 2346.

Landau, Loren. "The humanitarian hangover: Transnationalization of governmental practice in Tanzania's refugee-populated areas'. Refugee Surve Qunc 'Fr 21 (2002). 260-99. tatour, Bruno. 'From the world of science (1998): 208-9.

Lefebvre, Henri. La Production de l'Espace. Paris: Éditions Anthropos, 1974

Lefebvre, Henri. Le Droit à La Ville. Vol. 3. Paris: Éditions Anthropos, 1968 Lefebvre, Henri. Le Droit à La Ville Suivi de Espace et Politique. Éditions Anthropos. Paris: Seuil, 1972.

Lefebvre, Henri. Writings on Cities. Edited by Eleonore Kofman and Elizabeth Lebas. Oxford: Blackwell 1996.

Loescher, Gil. “The emerging independence of the UNHCR under Auguste

Politics: A perilous path Oxford

Scholarship Online. Oxford: Oxford
University Press, 2001. https://doi.org 10.1093/0199246912.003.0004

Loescher, Gil. 'International recogni-

tion of refugees'. In The UNHCR and World Politics: A perilous path. Oxford Scholarship Online. Oxford: Oxford University Press, 2001. https://doi.org /10.1093/0199246912.003.0002

Loescher, Gil. 'The new cold war and the UNHCR under Poul Hartling'. In The UNHCR and World Politics: A perilous path. Oxford Scholarship Onlin Oxford: Oxford University Press, 2001 https//doiorg/101093/0199246912003 0007.

Loescher, Gil. 'The UNHCR at 50:

Pressures and institutional autonomy' In The UNHCR and World Politics: A perllous path. Oxford Scholarship Press. 2001. Oxford University Press, 2001. https://doi.org/10.1093

Lomo, Zachary, Angella Naggaga and Lucy Hovil. 'The phenomenon of force migration in Uganda: An overview of policy and practice in an historical context'. Refugee Law Project Working Paper no. 1, 2001. Accessed 4 April 2021. https://refugeelawproject.org/files /working_papers/RLP.WP01.pdf. Lubega, Henry. 'The coming of Rwandan refugees and why Ugandans turned against them'. Daily Monitor Uganda, 23 April 2017. Accessed 17 November 2020. http://www.monitor.co ug/Magazines/PeoplePower/Rwandan -refugees-Mpororo-Batutsi-Hima 1689844-3899258-1d5rpnz/index.html. Lynch, Kevin. 'The form of cities'. Scientific American 190 (1954): 54
Lynch, Kevin. The Image of the City Cambridge, MA: MIT Press, 1960. Lynch, Kevin, and Tridib Banerjee. Growing Up in Cities: Studies of the spatial environment of adolescence in Cracow, Melbourne, Mexico City, Salta, Toluca, and Warszawa. Cambridge, MA: MIT Press, 1977.

Macgregor, Duncan. 'History of the

development of the East African Rift System: A series of interpreted maps through time'. Journal of African Earth Sciences 101 (2015): 232-52.

Malkki, Liisa H. Purity and Exile

Violence, memory and Exile: Violence, memory, and national cosmology among Hutu refugees in Tanzania. Chicago: University of Chicago Pr

Malkki, Liisa $\mathrm{H}$. The rooting of peoples and the territorialization of national identity among scholars and refugees' Cultural Anthropology 7 (1992): 24-44 Mamdani, Mahmood. When Victims Become Killers: Colonialism, nativism, and the genocide in Rwanda. Princeton NJ: Princeton University Press, 2020. Maqusi, Samar. 'Space of refuge: Negotiating space with refugees inside the Palestinian camp'. Humanities 6 (2017): 60.

Marie, Delphine, and Kelvin Shimo. Zambia initiative: Making refugees agents of development'. Conflict Trends, no. 2 (2002).

Martell, Pete. First Raise a Flag: How South Sudan won the longest war but lost the peace. Oxford: Oxford University Press, 2018.

Martin, Diana. 'From spaces of exceptio to "campscapes": Palestinian refugee camps and informal settlements in eirut'. Political Geography 44 (2015) $9-18$.

Matsiko, Haggai. 'Museveni shocked at Kyangwali eviction'. The Independent, Uganda, 20 September 2013. Accessed 17 November 2020 https://www independent.co.ug/museveni-shocked -kyangwali-eviction/.

Matthews, Hugh. 'The street as liminal space: The barbed spaces of childhood'. In Children in the City: Home neighbourhood and community, edited by Pia Christensen and Margaret O'Brien 101-18. London: RoutledgeFalmer, 2003. 1013. Ali Africa Since 1935: Ger, 203 history of Africa. Vol. Vul Edited by Ali Marri and C. Wondil. Edited by Ali Mazrui and C. Wondji. Oxfor Herma Crarlane, Colin. 'Learning assenblages'. In Learning the City. Knowledge and translocal assemblage, 15-31. Chichester, UK: Wiley-Blackwell, 2011.

Merkx, Jozef. 'Refugee identities and relief in an African borderland: A study of Northern Uganda and Southern Sudan'. Refugee Survey Quarterly, vol. 21. Geneva, Switzerland: United Nations High Commissioner for Refugees, 2000 Metzler, Janna, Kevin Savage, Marisa Vojta, Makiba Yamano, Alison Schafer and Alastair Ager. 'Evaluation of child friendly spaces Ethiopia field study summary report February 2013'. Mailman School of Public Health, Columbia University and World Vision 2013

MIDIMAR. 'Rwanda Ministry of Disaster Management and Refugees'. 2017. 
Accessed 17 November 2020. http:// midimar.gov.rw/index.php?id=69, Minca, Claudio. 'Geographies of the camp'. Political Geography 49 (2015) 74-83.

Ministry of Education Government of Rwanda. 'Integrated early childhood development strategic plan 2011-2016". Kigali: MINIEDUC, 2011.

Ministry of Infrastructure Government

of Rwanda. 'Updated version of the

national human settlement policy in

Rwanda'. Kigali: MININFRA, 2009.

Ministry of Internal Security

Government of Rwanda. 'Main ori-

entations of the Policy of Regrouped

Settlement Sites in the rural areas

Rwanda'. Kigali: MININTER, 1997

Development Government of Kenya

'Turkana district development plan

(2002-2008): Effective management

for sustainable economic growth and

poverty reduction'. Nairobi: MPND,

2001.

Montessori, Maria. The Absorbent Min New York: Dell, 1984.

Muggah, Robert. No Refuge: The

crisis of refugee militarization in Africa. London: Zed, in association with the Bonn International Center for Conversion and the Small Arms Survey, 2006

Müller, Martin. 'Assemblages and actornetwork: Rethinking socio-material power, politics and space' Geograph Compass 9 (2015): 27-41.

Müller, Martin, and Carolin Schurr.

'Assemblage thinking and actornetwork theory: Conjunctions, disjunctions, cross-fertilisations'. Transactions of the Institute of British Geographers 41 (2016): 217-29.

Mutegeki, Geoffrey, and Felix Basiime. 'Refugee camp chief killed in land dispute'. Daily Monitor Uganda, 2012 Nallari, Anupama. "The meaning, experience, and value of "common space" for women and children in urban poor settlements in India'. Thesis, CUNY Academic Works, 2014 Accessed 17 November 2020. https:// academicworks.cuny.edu/gc_etds $/ 80$. Napier-Moore, Rebecca 'Edu/gc_etds/80 relansere Rebecca. Entrenched relations and the permanence of longterm refugee camp situations'. Sussex Migration Working Paper No. 28 (200
1-21. Brighton: University of Sussex. Newhouse, Léonie S. 'More than mere survival: Violence, humanitarian governance, and practical mategovernance, and practical mate-
rial politics in a Kenyan refugee camp'. Environment and Planning A: Economy and Space 47 (2015): 2292-307.

Niane, Djibril T. General History of Africa. Vol. IV. Africa from the twelfth to the sixteenth century. Paris: Heinemann Educational and UNESCO, 1981.

OCHA. 'United Nations Office for

the Coordination of Humanitarian Affairs'. UN OCHA, 2015. Accessed 17 November 2020. https://www.unocha
.org/legacy/what-we-do/coordination -tools/cluster-coordination.

Office of the Prime Minister of Uganda. The Refugees Act 2006. Accessed 1 April 2021. https://www.refworld.org /pdfid/4b7baba52.pdf.
Ogot, Bethwell. General History of Africa. Vol. V. Africa from the sixteenth to the eighteenth century. Paris: Heinemann Educational and UNESCO, 1992.

Oka, Rahul Chandrashekhar. 'Coping with the refugee wait: The role of consumption, normalcy, and dignity in refugee lives at Kakuma refugee camp Kenya'. American Anthropologist 116 (2014): 23-37.

Oka, Rahul Chandrashekhar. 'Unlikely cities in the desert: The informal economy as causal agent for permanent "urban" sustainability in Kakuma refugee camp, Kenya'. Urba Anthropology 40 (2011): 223-62. Amathroping mata, Naohiko, and Josiah Kaplan. Refugee livelihoods in Kampala, Nakivale and Kyangwali refugee settlements. Patterns of engagement with the private sector'. Refugee Studies Centre, Oxford, Working paper Series no. 95,2013

ONE UN. 'MIDIMAR and UNHCR affirm plan to include refugees in Rwanda's national development'. ONE UN, 2017 Accessed 17 November 2020. http:// www.rw.one.un.org/press-center/news /midimar-and-unhcr-affirm-plan -include-refugees-rwanda's-national -development

OpenStreetMap. 'Humanitarian Openstreetmap team'. Participatory mapping toolkit, n.d. Accessed 17 November 2020. https://www.hotosm org/updates/participatory-mapping -toolkit-a-guide-for-refugee-contexts. Paulson Julia Education Conflict and Development Vol. 20 Oxford Studies in Comparative Education. Oxford: Symposium Books, 2011.

Pence, Alan R., and Hollie Hix-Small. 'Global children in the shadow of the global child'. International Journal of Educational Policy, Research and Practice 8 (2007): 83-100.

Pérouse de Montclos, Marc-Antoine.

'Humanitarian aid, war, exodus, and reconstruction of identities: A case study of Somali "minority refugees" in Kenya'. Nationalism and Ethnic Politics 14 (2008): 289-321.

Petcou, Constantin, and Doina Petrescu. 'R-URBAN or how to co-produce resilient city'. Ephemera: Theory and Politics in Organization 15 (2015): 249-62.

Peteet, Julie Marie. Landscape of Hope and Despair: Palestinian refugee camps. Philadelphia: University of Pennsylvania Press, 2005.

Peteet, Julie Marie. 'Producing place, spatializing identity, 1948-68'. In Landscape of Hope and Despair, 93-130. Philadelphia: University of Pennsylvania Press, 2009

Petti, Alessandro, and Sandi Hilal. 'Architecture of exile'. Campus in Camps, 2016. Accessed 17 November 2020. http://www.campusin camps.ps/architecture-exile..

Petti, Alessandro, and Sandi Hilal.

'Decolonizing architecture art residency'. DAAR, 2015. Accessed 17 November 2020. http://www .decolonizing.ps/site/.

Picker, Giovanni, and Silvia Pasquetti. 'Durable camps: The state, thetti. the everyday'. The state, the urban 
Pieris, Anoma. 'Encampments: Spatia tonomies of Sri Lanka's civil war. Architectural Theory Review 19 (2014) 393-413.

Pieterse, Edgar. City Futures:

Confronting the crisis of urban development. Cape Town: University of Cape Town Press, 2008.

Pieterse, Edgar. 'Grasping the unknowable: Coming to grips with African urbanisms'. Social Dynamics 37 (2011) 5-23.

Pieterse, Edgar. 'Introduction: Rogue urbanisms'. Social Dynamics 37 (2011)

Proshansky, Harold M., and Abbe K. Fabian. 'The development of place identity in the child'. In Spaces for Children: The built environment and child development, edited by Carol Simon Weinstein and Thomas $G$. David, 21-40. New York: Plenum Press, 1987.

Proshansky, Harold M., Abbe K. Fabian and Robert Kaminoff. 'Place-identity: Physical world socialization of the self? Journal of Environmental Psychology 3 (1983): 57-83.

Prunier, Gérard. From Genocide to Continental War: The 'Congolese' conflict and the crisis of contemporary Africa. London: Hurst, 2009.

Prunier, Gérard. The Rwanda Crisis, 1959-1994: History of a genocide. London: Hurst \& Co., 1995.

Pyles, Loretta. 'Participation and other ethical considerations in participator action research in post-earthquake

rural Haiti'. International Social Work 58 (2015): 628-45.
Ramadan, Adam. 'Spatialising the refugee camp'. Transactions of the Institute of British Geographers 38 (2013): 65-77.

Rasmussen, Kim. 'Places for children-Children's places'. Childhood 11 (2004): 155-73.

Refugee Law Project. 'Refugees in

Kyangwali settlement: Constraints

on economic freedom'. Refugee Law Project Working Paper no. 7, 2002

Riggio, Eliana, and Theresa Kilbane. 'The

International Secretariat for Child-

Friendly Cities. A global network for

urban children'. Environment

Urbanization 12 (2000): 2015.

refuex

refugees: The case of Kakuma

Univerty of Nairobi, 2015 . Accs,

University of Nairobi, 2015. Accessed

17 November 2020. http://erepository

/93371/Rithi_Conflict\%20Amongst\%20

193371/Rithi_Conflict\%2OAmongst\%20

Refugees\%20The\%20Case\%200f\%20

1992-2014.pdf?sequence $=3$.

Rodriguez, Eileen T., and Catherine S.

Tamis-Lemonda. 'Trajectories of the

home learning environment across the

first 5 years: Associations with chil-

dren's vocabulary and literacy skills at

prekindergarten'. Child Development 82 (2011): 1058-75.

Rogge, John. 'Africa's resettlement strat-

egies'. The International Migration

Review 15 (1981): 195-212.

Roy, Ananya, and Nezar AlSayyad.

Urban Informality: Transnational

perspectives from the Middle East,

Latin America, and South Asia.
Transnational Perspectives on Space and Place. Oxford: Lexington Books, 2004

Rutinwa, Bonaventure. 'Beyond durable solutions: An appraisal of the new proposals for prevention and solution of the refugee crisis in the Great Lake Region'. Journal of Refugee Studies 9 (1996): 312-25.

Rutinwa, Bonaventure. 'The Tanzanian

government's response to the

Rwandan emergency' Journal of

Refugee Studies 9 (1996): 291-302

Sanyal, Romola. 'Refugees and the city:

An urban discussion'. Geography

Compass 6 (2012): 633-44

Sanyal, Romola. 'Squatting in camps:

Building and insurgency in spaces of

refuge'. Urban Studies 48 (2011): 877-90.

Sanyal, Romola. 'Urbanizing refuge:

Interrogating spaces of displacemen

.

Regional Research 38 (2014): 558-72.

Scott, James C. 'Beyond the war of word

Cautious resistance and calculated

conformity'. In Weapons of the Wea

Everyday forms of peasant resist-

ance, 241-303. New Haven, CT: Yale

University Press, 1985.

Scott, James C. 'Everyday forms of resist-

ance'. Copenhagen Journal of Asian Studies 4 (1986): 33-62.

Scott, James C. 'Preface'. In Weapons of the Weak: Everyday forms of peasant resistance, $\mathrm{xv}$-xxii. New Haven, CT:

Yale University Press, 1985.

Scott, James C. Seeing Like a State:

How certain schemes to improve the

how certain schemes to improve the

Haven, CT: Yale University Press, 1998
Scott-Smith, Tom. 'The humanitarianarchitect divide'. Forced Migration Review 55 (2017): 67-8.

Siddiqi, Anooradha Iyer. 'L'historire architecturale d'un territoire non identifie'. In Un Monde de Camps, edited by Michel Agier and Clara Lecadet, 149-63. Paris: La Découverte 2014

Simone, AbdouMaliq. 'Cities and change', In For the City Yet to Come: Changing African life in our cities, 213-43.

Durham, NC: Duke University Press,

Simone, AbdouMaliq. 'Movement: The Zawiyyah as the city' In For the City Yet to Come: Changing African life in our cities, 119-35. Durham, NC. Duke Univis, P-35, Durham, NC: Duke University Press, 2004.

Simone, AbdouMaliq. 'On cityness'. In City Life from Jakarta to Dakar. Movements at the crossroads, 424 New York: Routledge, 2009

Skeels, Anna. 'March activities in the Kyaka II refugee settlemen (part 2)', 2012 (blog). Accessed 17 November 2020 https://www.elrha.org project-blog/march-activities-kyaka-ii -refugee-settlement-part-2/.

Slaughter, Amy, and Jeff Crisp. 'New issues in refugee research. A surrogate state? The role of UNHCR in protracted refugee situations'. New Issues in Refugee Research, Research Paper No. 281. Geneva: UNHCR, 2009. Smith, Linda Tuhiwai. Decolonizing Methodologies. London: Zed Books, 1999.

Smithson, Alison, and Peter Smithson. Ordinariness and Light: Urban 
theories and their application in a building project. Lond Stearns, Jason. Dancing in the Glory of Monsters: The collapse of the Congo and the Great War of Africa. New York Public Affairs, 2010.

Stearns, Jason. Mai-Mai Yakutumba: Resistance and racketeering in Fizi, South Kivu. London: Rift Valley Institute, 2013.

Stein, Barry N., and Lance Clark.

'Refugee integration and older refugee

settlements in Africa'. In 1990 Meeting

of the American Anthropological

Association New Orleans, 1990.

Turner, Simon. 'The barriers of inno-

cence: Humanitarian intervention and political imagination in a refugee cam for Burun ins Roskilde Universitet, 2001. Accessed 17 November 2020. https.//rucforsk.ruc . k/ws/portalines/portal/57417344/T Barriers_of.pdf.

Turner, Simon. 'Lukole (Tanzanie).

Victimes ou fauteurs de troubles:

Humanitaire et politique dans les

camps'. In Un Monde de Camps, edite

by Michel Agier and Clara Lecadet,

73-86. Paris: La Découverte, 2014.

Turton, David. 'Refugees, forced reset-

tlers and other forced migrants:

Towards a unitary study of forced

migration'. UNHCR New Issues in

Refugee Research, Working Paper no. 94. Geneva: UNHCR, 2003.

UNESCO. 'The Dakar Framework for Action'. Paris: UNESCO, 2000.

UNESCO. 'The hidden crisis Armed

conflict and education' EFA Glob

Monitoring Report. Paris: UNESCO, 2011
UNESCO. 'Management of Social Transformations (MOST) programme'. UNESCO, n.d. Accessed 77 November 2020. http://www.unesco org/new/en/social-and-human -sciences/themes/most-programme. UNESCO. 'Strong foundations: Early childhood care and education'. Vol. 11 Paris: UNESCO, 2007.

UNHCR. 'Camp planning standards

(planned settlements)'. Handbook for Emergencies. Geneva: UNCHR, 2015 Acces 17 November 2020 ht 2015. emergency.unhcr.org/entry/45582 /camp-planning-standards 45582 -settlements.

HCR. 'Comprehensive refugee York Dece framework. From the New On reclarat Gen to a global compact Un refugees', Geneva. UNHCR, 2016. UNCR. Dadaab refugee camps, Kenya UNHCR Dadaab bi-weekly update'. Nairobi: UNHCR, 2017.

UNHCR. 'Education. Field guidelines'. Geneva: UNHCR, 2003

NHCR. 'Global strategy for settle-

ment and shelter: A UNHCR strategy' Geneva: UNHCR, 2014

UNHCR. 'The implementation of

UNHCR's policy on refugee protection and solutions in urban areas'. Vol. 21. Geneva: UNHCR, 2012.

UNHCR. 'Kalobeyei settlement'. UNHCR 2016. Accessed 17 November 2020. http://www.unhcr.org/ke/516-kalobeye -settlement.htm

UNHCR. 'MIDIMAR-UNHCR joint strategy partners for economic inclusion of refuges' UNHCR 2017 Accessed 17 November 2020. htp//wWwinh .org/rw/12173-midimar-unhcr-join -strategy-partners-economic-inclusion refugees.html.

UNHCR. 'OAU Convention governing the specific aspects of refuge problems in Africa'. Geneva: UNHCR, 1969. UNHCR. 'Operational update - Rwanda 2017'. Kigali: UNHCR, 2017. UNHCR. 'Policy on alternatives to camps'. Geneva: UNHCR, 2014.

UNHCR. 'Policy on emergency prepardness and response.' Handbook for Emergencies. Geneva: UNHCR 2007 UNHCR. 'Population statistics' UNHCR, 2020. Access $17 \mathrm{Nove}$.NO 2020. Accessed 17 November 2020. https://www.unhcr.org/refugee

UNHCR. 'Protracted refugee situations' Geneva: UNHCR, 2004

UNHCR. 'Protracted refugee situation Revisiting the problem'. Geneva: UNHCR, 2008. Accessed 3 April 202 https://www.refworld.org/docid /486903142.html.

UNHCR. 'Protracted refugee situation The search for practical solutions'. In The State of the World's Refuges, 105-97. Geneva: UNHCR, 2006 UNHCR. 'Refugee children: Guidelines on protection and care preface. Geneva: UNHCR, 1994.

UNHCR. 'Rwanda country refugee response plan 201

UNHCR. 'Statistical summary refugees and asylum seekers in Kenya as of January 31st 2018'. Geneva: UNHCR, 2018.

UNHCR 'Uganda, comprehensive refugee response plan 2017
Humanitarian needs and requirements'. Kampala: UNHCR, 2017. UNHCR. 'UNHCR calls for calm and restraint after Rwanda refugee camp protests'. Kigali: UNHCR, 2018. UNHCR. 'UNHCR policy on refugee protection and solutions in urban areas, 21'. Geneva: UNHCR, 2009.

UNHCR. 'UNHCR Rwanda monthly population statistics'. Kigali: UNHCR 2017.

UNHCR. 'UNHCR's global shelter and settlement strategy, 2014-2018'. Geneva: UNHCR, 2014.

UNHCR. 'UNHCR welcomes Kenya state ment, urges for Somali refugees' UNHCR, 2016. Accessed 17 November 2020. http:// www.unhcr.org/uk/news/press/2016/11 /582d614a4/unhcr-welco ... -flexibility -timeframes-somali-refugees.htm ?query=Dadaab 2016

UNHCR Kenya. 'Dadaab refugee complex- UNHCR Kenya'. UNHCR 2018. Accessed 17 November 2020 http://www.unhcr.org/ke/dadaab -refugee-complex.

UNHCR, and MIDIMAR. 'Economic inclusion of refugees in Rwanda'. Kigali: UNHCR, 2016.

UNHCR, and Office of the Prime Minister Uganda. Uganda Refugee Response Portal. Refugees and nationals per district, 2018. Accessed 17 November. 2020. https://ugandarefugees.org /analysis/refugees-and-hosts/.

UNHCR Rwanda. 'Mahama refuge camp, one year on'. UNHCR Rwand 22 April 2016 . Accessed 17 Rwanda, 2020. http://www.unhcr.org/rw/93 
-watch-video-mahama-refugee-camp -one-year-on.html.

NHCR Rwanda. Participatory assess ment 2017'. Kigali: UNHCR, 2017

UNHCR Uganda. 'Kyaka II fact sheet'.

Kampala: UNHCR, 2014

UNHCR Uganda. 'Nakivale fact sheet'.

Kampala: UNHCR, 2014

UNHCR Uganda. 'Statistical summary

refugees and asylum seekers in

Uganda'. Kampala: UNHCR, 2017

UNICEF. 'Building better brains: New

frontiers in early childhood develop-

ment'. Geneva: UNHCR, 2014.

UNICEF. Transitional Learning Spaces

(TLS): Resilient design and con-

struction in emergencies, New York: UNICEF, 2013

United Nations. 'Convention on the Rights of the Child'. New York: United Nations, 2001

United Nations. New York Declaratio

for Refugees and Migrants. Vol.

16163. New York: United Nations,

2016. Accessed 17 November 2020.

http://www.un.org/en/development

/desa/population/migration

Igeneralassembly/docs/globalcompact /A_RES_71_1.pdf.

United Nations General Assembly.

'Convention relating to the status of refugees'. Treaty Series 606. New York United Nations, 1951.

UN Joint Inspection Unit. 'Review of

the management of implementing partners in United Nations stem organizations'. Geneva: UN, 2013.

Unt, Anna Liisa, and Simon Bell. “Th impact of small-scale design interventions on the behaviour patterns of the users of an urban wasteland'. Urban Forestry and Urban Greening 13 (2014) 121-35.

Valentine, Gill, and John McKendrck. 'Children's outdoor play: Exploring parental concerns about children's safety and the changing nature of childhood'. Geoforum 28 (1997): 219-35. Van Damme, Wim. 'Do refugees belong in camps? Experiences from Goma and Guinea'. The Lancet 364 (1995): 360-2.

van Leeuwen, Mathijs 'Rwanda's imi-

dugudu programme and earlier

experiences with villa earlier

resettlement in East Africa' Journal

of Modern African Studies 39 (2001)

623-44.

Vasquez, Carlos, and Anika Grafwerk. Compendium. Transitional learning spaces, design and construction in emergency. New York. UNICEF, 201 Vincent-Geslin, Stephanie, Yves Pedrazzini, Hossam Adly and Yafiza Zorro, eds. Translating the City: Interdisciplinarity in urban studies. Oxford: EPFL Press, 2015

Walter, Freith, and Francis Wrester

Early childhood development: The key to a full productive life'. The Journal of Childhood Development 23 (2009): 23. Ward, Colin. Caught in the Crossfire: Children and the Northern Ireland conflict. Belfast, UK: Appletree Press, 1987.

Ward, Colin. 'The child in the city'. Society 15 (1978): 84-91.

Ward, Colin. 'Children of the streets'.

New Society 77 (1986): 23.

Ward, Colin, and Anthony Fyson.

Streetwork: The exploding school.
London: Routledge and Kegan Paul, 1973

Wessells, Michael, and Kathleen Kostelny. 'Child friendly spaces: Toward a grounded, community-based approach for strengthening child protection practice in humanitarian crises. Natural helpers play a critical role in ensuring children's safety during and in the aftermath of crises' Child Abuse and Neglect 37 (2013): 29.

Winter, Roger. 'Uganda - Creating a refugee crisis'. Cultural Survival Quarterly June (1983): 1-13.

Wood, Stephen, and Kim Dovey 'Creative multiplicities: Urban Dorphe 'Creative creative clustering'. Journal of Urban Design 20 (2015): 52-74.

Woodhead, Martin. 'Early childhood

development in the SDGs'. Young Lives Policy Brief 28, January 2016. University of Oxford.
Zeiher, Helga. 'Shaping daily life in urban environments'. In Children in the City: Home neighbourhood and community, edited by Pia Christense and Margaret O'Brien, 66-82. London: RoutledgeFalmer, 2003.

Zetter, Roger. 'Incorporation and

exclusion: The life cycle of Malawi's Development 23 (1995): 1653-67.

Ziliacus, Ariana. 'With the Jarahieh

Refugee School, CatalyticAction demonstrates the true potential of (emonstrates the true potential of 2017. Accessed 17 Nes. Arch Daily, (2020. /with-the with-the-jarahieh-refugee-school -catalyticaction-demonstrates-the-t Zumt Poter 'A way of lookingat

things'. In Thinking Architecture, 9-27. Basel, Switzerland: Birkhauser, 1998. 

Index

Note: Page numbers in italics denote figures.

abductions, 80,82

Abourahme, Nasser, 19,20

Active Social Architecture (ASA) 2,146

ADRA, 135

Agamben, Giorgio, 14, 19

agency, 16, 18, 28

and assemblage

, 158 thinking, 20

of children, 158

lleability, 79-80

frefugees, 17, 18, 26, 96, 118-9, 145,

156,161

agents of change, 15,

Agier, Michel, 14, 1

agricultural refugee settlements, 26

agriculture, $26,36,41,81$

aid, 4, 19, 28, 119

Albert, Lake, 41

Alfajiri village, 48

Alsayyad, Nazer, 18

Alternatives to Camps, 17, 95-6, 118

Ankole region, 36

Appadurai, Arjun, 18

armed conflict, stopping children

leaving their compounds, 105

arts and crafts, 9. See also mural

$$
\text { making }
$$

assemblage thinking, 5-6, 17, 19-20, 21,

$$
156,161
$$

sylum seekers, 36

attacks on refugees, 36,80

Bahima pastoralists, 36,8

Bahutu refugees, 45

Bairu population, 36

Banyarwanda, 45, 129-30

Base Camp, Nakivale, 36-7, 39, 40, 74,

$$
79,104
$$

Batutsi, $35,41,45$

Bauman, Zygmunt, 16, 117

Bayat, Asef, 6, 116-7

bedrooms, 105, 122, 125

Beirut, 100

Betts, Alexander, 19

big data, 15

borders, proximity to, 8, 80, 82,$$
\text { 155-6 }
$$

camp, expansion, 110$$
112,146
$$

British Empire, 35, 49

British Protectorate of Uganda, 36

Bronfenbrenner, Urie, 162

Buduburam refugee camps, 18, 19

built environment, definition, 161

Bujubuli village, 47,2

Bujubuli zone, 48

Bukere village, 47, 74, 79

Bukere zone, 74

Buliti zone, $48,74,7$

burden,

Burden, refugee, 26

Burundians, 19, 45, 56, 57, 62, 77 
Caldeira, Teresa, 6, 100

camp planning guidelines, 2

campscapes, 18

CARE International, 66, 114, 135

cash hand-outs, 62, 118

change, agents of, 15,17

Chawla, Louise, 154

child development, 13, 103

child-friendly learning environments, 5 , 119-21

child-friendly spaces (CFSs), 130-2, 134,$$
141-2,146,155,15
$$

and agency, 158

Congolese, 73

and effects on encampment, 26

in Kyaka II, 45

in Kyangwali, 41

in Nakivale, 37

ttle tops on the

street, 153

and porosity, 80

proposals for improvements in the

camps, 119, 122

in Rwanda, 58

and WASH facilities, effect on, 155

children's learning, $8,19,21,83,164$

affected by relationships with local

hosts, 76, 77

affected by temporary facilities, 79

elements that home caregivers identi-

fied as problematic for, 120

and heterogeneity, 73

and homes, 125

and malnutrition and overcrowding

81-2

and porosity, 80

and role of place, 98

and WASH facilities, 107-8

See also lifelong learning, children's churches, 34, 110, 111-2, 111, 112

cities, 16, 17, 18. See also 'right to the city'

Civitas, Polis, and Urbs (Grbac), 1

co-constitutive, 18, 161. See also 'right to$$
\text { the city' }
$$

co-functioning, 6, 76-8, 155

collective experiment, 5, 8, 96

commercial buildings, 112-4, 117

community groups, 34

co-modification, 17, 18-9, 21, 155

Congolese camps, 56, 57, 66, 73, 77-8,

146. See also Kigeme; Kiziba

$$
\text { Mugombwa }
$$

Congolese children, 73

Congolese refugees, $41,45,57,58,62$,

$$
66,116
$$

and PAR, 128-30, 137

type of homes, 105,10

conscientisation, 8

conscious radical incrementalism, 144-6

containment strategies, 26,11

content-based learning, $4,33,79,80,83$, 112,164

Convention Governing the Specific

Aspects of Refugee Problems in

$$
\text { Africa, } 163
$$

Convention on the Rights of the Child, 82

Convention Relating to the Status of

Refugees, 163

Coombs, Philip Hall, 34
cosmopolitanism, 74, 83

country scale learning environments, 34

Creative Assemblages, 146

creative minds, 9, 146, 158, 159

cross-border conflicts, 36

CRRF (Comprehensive Refugee

Response Framework), 17, 62, 83-4,

$96,99,118,146$ curfew, night, 77

curiosity, and learning, 34, 80, 83

Dadaab camp, 19, 49

Dagahaley, 49

decolonisation, 18, 157, 162

Deleuze, Gilles, 19, 96, 16

development aid, 28, 118

Dewey, John, 34

Dinka Sudanese, 49

direct content-based learning, 4, 33, 80 83,164

direct local hosts, 28, 29, 34, 36, 96

and agency, 79-80

in Kenya, 50

in Kenya, 50 the spatial reproduction

of the long-term camps, $97,154-5$

and relationships with refugees, $76-7$,

110-11, 117

and 'right to the city', 98

displacement, long-lasting, 26, 28

donors, power differentials in favou

of, 96

Dovey, Kim, 74

RRC (Democratic Republic of Congo) refugees, $33,36,41,45,57,62,77$

from First Congo War, 58

and kitchens, 105

in Mugombwa, 66

Dryden-Peterson, Sarah, 76

East Africa, map, showing 66 long-term camps, 31

East African Playgrounds, 146

East African Rift, 1, 29, 32

Eastern DRC (Democratic Republic

of Congo) refugees See DRC

(Democratic Republic of Congo)

refugees

Ebola epidemic, 45
ECD (early childhood development)

centres, 34, 75-6, 77

built by refugees, 144

in Congolese camps, 146

increased presence of, 83

in Kakuma, 54, 55, 56

in Kigeme, 63, 64, 65, 66

in Kiziba, 60, 61, 62, 80, 121, 123

in Kyaka II, 45, 46, 111

in Kyangwali, $41,42,43$

in Mugombwa, 66, 67, 68, 69

in Nakivale, $37,38,39,41$

refugees' proposals for improvements,

refugees

Tarach, 73-4

temporary structures, 78-9

See also home-based ECD (HBECD)

ECD (early childhood development), definition, 161-2

(early childhood development) facilities, 1-2, 3, 4, 8-9

economic co-modification,

ecosystemic, 99, 156, 162

education, 15, 20, 28

ducational facilities, 110-11. See also

ECD (early childhood development)

centres

ducational programmes, humanitarian, $3-4$

Education for All goals, 75

empowerment for refugees, 112, 142

encroachment, quiet, $6,8,100,101-2$

Ethiopian refugees, 45,56

ever becoming, 6, 78-80, 155

everyday life, $6,8,41,101-2,107$

exception, space of, $3,11,1$

experience, learning by, 19, 79, 80, 81, 83, 164

and homes, 102

in religious and self-built schools, 112 
Fabian, Abbe K., 103

farming, 110. See also agriculture

fatigue, research, 138, 139, 157

Feldman, Ilana, 18

First Congo War, 58

fleeing routes, 34,78

floods, effect on housing, 56

formal ECD (early childhood develop-

ment) centres, 34, 37, 75-6, 77, 155

in Congolese camps, 78,146

increased presence of, 83

in Kakuma, 54,56

in Kigeme, 63, 64, 65, 66

in Kiziba, 60,61,62, 123

in Kyangwali, 41

in Mugombwa, 67, 68, 69

and refugees' proposals for improve-

d refugees prop

temporary structures, 78-9

formal learning environments, $37,41,45$$$
54,66
$$

in Kiziba, 60, 61, 62

freedom, 28, 36, 106, 118, 154

free play, 34,80

Freire, Paulo, 8, 127

Freirean conscientious, 98

funding

humanitarian, 3, 77, 84

lack of, 76,83

reduction, 62

short-term,

Garissa Counties, 49

geopolitics, 13, 81, 83, 96

Global Compact on Refugees, 17

governments, host, 18, 19, 20

Grace Orphans, 47

Grbac, Peter, 17

GRC approach, 146

GRC approach, 146
Growing Up in Cities (Lynch and

Banerjee), 127

Guattari, Félix, 19, 96, 16

Guinea (Conakry), 28

Hagadera, 49

Handbook for Emergencies (UNHCR) 26,49

Harrell-Bond, Barbara, 8, 14, 100, 116, 121, $137-8,156$

Herz, Manuel, 2, 17, 18-9, 162

heterogeneity, 6, 33, 73-6, 116, 138-9,

$$
155,156
$$

Hoima, 43

Holzer, Elisabeth, 18, 19

home-based ECD (HBECD), 66, 67, 76, 101,

$114-6,155$

and PAR, 135-6, 140, 141-2

(

child-friendly and stimulating, 155

decoration of, 130

improvements to, 146

in Kyangwali, 108-9

in Rwandan camps, 126

Homo Sacer (Agamben),

Horn of Africa, 32, 32

host countries, $6,28,34,58,73,78,137$

treating refugees differently according$$
\text { to origin, } 77
$$

hosts. See direct local hosts

housing, 56, 67. See also home

humanitarian aid, 19, 28

humanitarian assemblage, 17, 107, 137

humanitarian camp planning guidelines,

$$
20,21
$$

humanitarian educational programmes, humanitarian funding, 3, 77, 84

humanitarian institutional memory, 4

humanitarian refugee assistance prac-

tice, 17,153

humanitarian relief workers, 4, 35-6

humanitarian spaces, 6, 11, 17, 66, 117,

$$
153,163
$$

and urban turn, 13, 15, 100, 164

humanitarian system, 19, 20, 26, 28, 101-2, 116-7

humanitarian workers, 50, 66

human rights, 118

identity, 16, 18, 19, 103, 117

Ifo, 49

imaginative play, 34

Imidugudu Policy, 57

imigongo, 129-30, 132, 133, 134, 135,

$$
140,157
$$

artisan, community mobiliser and

home owner, 139

artists, 131

Imposing Aid (Harrell-Bond), 14, 100

incrementalism, radical, $6,8,98,119-27$

$144-6,163$

incursions, 80, 82

informal ECD (early childhood development) centres, 68. See also non-formal ECD (early childhood development) centres

informal economy, 19

informal educational system, 20. See also informal learning environments; non-formal learning environments informality, 17-8, 21

informal learning environments, 19,34 $37,116-9$

in homes, 102-3

in Kakuma, 56 in Kigeme, 66

in Kyangwali, 41

paramount to young children's learning, 155

in trading centres, 113

informal settlements, 18,20

insecurity, 34, 77, 80, 82, 83, 105

interconnectedness, $6,17,77-8,155$

ernational Bank for Reconstruction

and Development, 26

Isanja Baptist church,

Isingiro, 36

isolation, 8, 29, 62, 76, 82, 155-6

Jacobsen, Karen, 8

Jansen, Bram 2, 3, 15-6, 18, 100-1

Juru zone, 36, 39, 40, 74, 104, 111

Kagwanja, Peter Mwangi, 19

Kakuma, 6, 33, 49, 51-6, 51, 52, 53, 54, 55, $71,72,75$

and adults' proposals for improve

ments, 83, 121, 122

and children's proposals for improve-

ments, 122

commercial buildings, 112, 113

ECD centres, 34, 77

homes, 103, 104-5, 106, 125

latrines, $81,108-9$

and porosity, 80

and proximity to border, 82

religious facilities, 111-2

Kakuma phase I, 51, 52, 55, 56, 75,

and children's proposals for improve-

ments, 122

commercial buildings, 112, 113

commercial centre, 119

homes, 105 
Kakuma phase I (cont.)

and porosity, 80

safer streets, 146

Tarach ECD centre, 73-

Kakuma phase II, 55, 56, 75, 79, 119

and children's proposals for improvements, 122

commercial buildings, 113

and porosity, 80

Kakuma phase III, $21,52,55,56,75,78-9$

and children's proposals for improve-

ments, 119, 122

mosque, 111

open areas, 79

and porosity, 80

Kalobeyei, 49,82

Kashojwa village, 39, 74

Kasonga, $41,44,74$

Katz, Iris, 17

Kenya, 21, 32, 71, 101

camps, 18, 19, 20, 33, 49-56, 50, 82, 146

See also Kakuma

Kibreab, Gaim, 100

kidnapping, 34, 77

Kigali village, 39,74

Kigeme, 6, 21, 33, 62-6, 63, 64, 65, 72, 75

and children's proposals for improvements, 122

formal ECD centres, 65,76

home-based ECD, 114-6, 114, 115,

135-6, 155

and PAR, 127, 13

and PID, 132, 133, 157

public interest design studio

workshop, 144

Kigeme A, 62-3, 63, 66, 103

Kigeme $B, 63,63,65,66,75$ in-kind hand-outs, 118

Kinyarwanda, 58

Kiziba, $6,25,33,58-62,58,59,60,72,75$

and attacks, 80

and cash hand-outs, 118

and CFS, 134

children playing with bottle tops on the

street, 153

and children's proposals for

improvements, 122

classroom interior, 124

ECD centres, 61, 121, 123

finished murals, 142, 143

homes, 103, 107, 130

and imigongo, 132, 133, 134, 135

incepion

and land scarcity, 82,

and land scarcity, 82

latinnes and shower, 109

roof to his

and mural making, 136, 137, 138, 139

non-formal ECD in churches, 112

open areas, 79

painting process, 140, 14

and PAR, 127-32

pavement and drainage solutions in, 12

and PID, 133, 157

and proximity to border, 82

public interest design studio workshop

145

refugees create facilities in, 79-80

religious facilities, 110, 111

two neighbours rebuilding an old

shelter, 95

Kyaka I, 45

Kyaka II, 6, 33, 37, 45-8, 48, 71, 72, 73, 74

and children's learning, 83

and children's proposals for improve-

ments, 122

ECD centres, 46, 77, 111 and land scarcity, 81

population, 78

Kyangwali, $6,33,37,41-4,44,71,72,73,74$

and attacks, 80

and children's learning, 83

children's proposals for

improvements, 122

ECD centres, 42, 43, 78-9

homes, 108-9

and land scarcity, 81

and proximity to border, 82

Kyegegwa District, 37

Kyenjojo District, 45

lagga, 53, 56

acquiring, 110, 145-6

ownership conflicts, 36

scarcity, $6,81-2,83$,
Landau, Loren, 8

Landscape of Hope and Despair

(Peteet), 100

andscape scale, learning environments, 34

Latour, Bruno, 5

latrines, $37,41,81,108-9$

in Kakuma, 56

in Kiziba, 62

in Kyaka II, 45

in Mugombwa, 66-1

learning, children's. See children's

$$
\text { learning }
$$

learning assemblages, $6,8,82-4,98,156$

learning environments, 4, 6, 14-5, 19 ,

33-4

child-friendly, 5, 119-21

in homes, 102-3

in Nakivale, 37,4

Lebanon, 19, 20, 100,164

Lefebure, Henri, $6,14,18,33$

and transduction, 8, 98, 157, 163-4
Liberian refugees, 18,28

Liboi, 49

ifelong learning, children's, 8, 33-4, 82, 125,154

local hosts. See direct local hosts

long-term refugee camps

definition, 162

Lynch, Kevin, 34, 154

madrassas, 34, 110, 111-2

Mahama, 82

Malawi, 28

Malembo village, 41, 43, 74, 79

Malkki, Liisa, 16-7, 19

malnutrition, 81-2

Mandera, 49

map orientation, 101

mapping, 76, 156-7

maps

Arican continent showing the Eas African Rift with the current locations of internally displaced people and refugees, 12

East African camps, 31

Horn of Africa, Great Lakes and South

Sudan, 32

Kakuma, 51, 53, 54

Kenya, 50

Kigeme, 64, 65

Kiziba, 60, 61

Kyaka II, 46, 47

Kyangwali, 42,43

Mugombwa, 68, 69

Nakivale, 38

Nakivale, Kyangwali and Kyaka II, 37

Northwest Kenya, 71

Rwanda, 57,58

Uganda, 35, 70, 71

Uganda, Kenya and Rwanda, 72 
Martin, Diana, 18

material malleability, 79-80

maternelle, 131, 136, 137, 143

quarter two, 61

megacities, 16

memory, humanitarian institutional, 15

metropolis, 16

Middle Eastern camps, 18, 19, 20, 77,$$
100,164
$$

Mille Plateaux: Capitalisme et

Schizophrénie (Deleuze and$$
\text { Guattari), } 161
$$

Minca, Claudio, 17

Montclos, Marc-Antoine Pérouse de, 19

mosques, 11

MOST Programmes, 127

mother leaders, 34.116, 121-2

Mount Surat ECD, 55

Mozambican refugees, 28

Mudende refugee camp, 58

Mugombwa, 5, 6, 33, 58, 66-9, 67, 68, 72, 75 and children's proposals for improvements, 122

and Creative Assemblages, 146

formal ECD centres, 69, 76

home-based ECD, 114-6, 116, 155

homes, 103-4, 104

open areas, 79

and PID, 133, 157

Mukunyu, 41, 78-9

multi-scalar land scarcity and porosity, 83

multi-scalar studies, 15, 162

mural making, 129-32, 136, 137, 138, 139,

$140,141-2,143$

murals, 142, 143,

mutability, 17

churches, 111,111

and cosmopolitanism, 83

ECD centres, 39, 78-9

homes, 104

and interconnectedness, 77

moved to due to land scarcity, 81

and Opportunigee, 146

and proximity to border, 82

Nakivale, Lake, 36

National Council of Churches of Kenya (NCCK), 108-9

eighbourhoods, child-friendly, 119-21, 155 neighbouring communities, and refugee

$$
\text { camps, } 19
$$

neo-liberal policies, 118-9

'new deal', 5

New York Declaration for Refugees and Migrants, 17

NGOS (non-governmental organisations), $34,37,62,155$

Ngurue village, 44, 74, 79, 108, 10

night curfew, 17

non-formal ECD (early childhood deve -

opment) centres

increased presence of, 8

in Kakuma, 54

in Kigeme, 64

in Kiziba, 60, 62, 80, 112

in Kyangwali, 4

in Nakivale, 37

and refugees' proposals for

improvements, 121-2

in Southwest Uganda, 78

non-formal educational facilities,$$
76,155
$$

non-formal educational systems, 20

Nakivale, 1, 6, 33, 36-41, 37, 38, 40, 72, 73, 74 non-formal home-based ECD (HBECD), and children's proposals for

improvements, 119, 122
66, 67. See also home-based ECD

(HBECD) non-formal learning environments, 34 $45,54,62,66,112$

non-places, 3, 6, 11, 17

Northern Kenya, 33, 101

Northern Tanzania, 36

North Kivu, 45

Northwest Kenya, 19, 71, 78. See also

Kakuma

Norwegian Relief Committee, 108-9

Nuer, 49

Nugurue, 43

nursery schools, 111

Nyabiheke, 1,62

Tyamiganda, 43

OAU's guidelines, 82

Obote, Milton,

Oka, Rahul, 19

Omugabe, King of the Ankole, 36

open self-settlement approach, 28

Opportunigee, 146

igin, connection to, 77

over-socialised view of man, 100, 116, 12

painting process, 140,14

Palestinian refugee camps, 17, 19, 20 100,164

PAR (participatory action research), 8 , 127-44, 157

Pasquetti, Silvia, 16

Pearse, Andrew, 137-8

peripheral urbanisation, 6

Peteet, Julie Marie, 20, 77, 100

Picker, Giovanni, 16

PID (public interest design), 132-6, 137,$$
139,140-1,143,157
$$

Pieterse, Edgar, 6, 8, 98, 163

place-making, 13, 96-9, 100, 115

PLAN International, 135 planning, humanitarian, 20, 21 play, $34,80,81,122$

political co-modification, 18

political identity, 19

polyrhythmic, definition, 162

polyrhythmic assemblages, 33,156 porosity, $6,8,78,79,80,82,83,155$

post-structural learning environmen literature, 15, 34

post-structural urban theory, 17, 21

powe

differences, 20

power

power struggles, 28

primary schools, 11

Proshansky, Harold, 103

proto-urban, definition, $162-3$

proto-urban assemblages, 8, 15, 33

proto-urban learning environments, $8-9,14$

proto-urban spaces, $6,11,13,17$

$153-4,164$

public interest design studio workshop

$$
144,145
$$

quiet encroachment, $6,8,100,101-2$

radical incrementalism, 6, 8, 98, 119-27, $144-6,163$

raids, 80,82

Ramadan, Adam, 19, 20

rebel incursions, 36

refugee assistance strategies, 8-9, 17

refugee burden, 26,28

refugee camps, long-term, 27. See also

Ka kuma; Kigeme; Kiziba; $\mathrm{Ky}$ also

Kakuma; Kigeme; Kiziba; Kyaka II;
Kyangwali; Mugombwa; Nakivale 
refugee convention, 1951, 25 Refugee Protection and Solutions in Urban Areas, 96

\section{refugees}

Bahutu, 45

Burundian,

definition, 163

from Eastern DRC, 33

and ECD centres, 144

Ethiopian, 45, 56

and identity, 19

initiated interventions, 5, 79-80, 100 ,

$$
101,102
$$

leading builders of the camps,

154-5

Liberian, 18,28

location of and number, 30

map showing location of on East

African Rift, 12

negotiate with direct local hosts to

negotiate with direct local hosts to
acquire or share land adjacent to

camps, 110

paramount in the spatial reproduction

of the long-term camps, 97

and power, 156, 161

proposals for improvements in the

camps, 121-2, 125

and relationships with direct local

hosts, 76-7, 117

and 'right to the city', 98

role, $4-5$

Rwandan, 45

seen as vulnerable victims, 117

and self-help, 83-4, 11

Sierra Leonean, 28

Somali, $45,49,56$

South Sudanese, 56, 105-6,

108-9 treated differently by host according to

$$
\text { origin, } 77
$$

See also agency; Congolese refugees

Refugees Act, 2006 (Uganda), 35

regional scale learning environments, 34

relativism, 20, 161

religious facilities, 110, 111-2, 111, 117, 144

remote sensing technologies, 15

research fatigue, 138, 139, 157

rhythms, 33, 41, 156, 162

rights, $81,82,83,118$

'right to the city', 33, 98, 107, 110,

144,145

definition, 163

and informal learning environments,$$
102,116
$$

\section{Roy, Ananya, 100}

Rubondo zone, 36, 39, 40, 41, 74, 104

Ruhoko village, 39, 74, 78-9, 79

Ruiru camp, 49

Rwanda, 32, 36, 45, 57, 77-8, 8

Batutsi, 35, 41

changed from in-kind to cash handouts, 118

CRRF and the GRC approach, 146

Rwanda Country Refugee Response Plan, 2019-20, 154

Rwandan camps, 1, 19, 21, 33, 56-67, 58 , $128-44$

and children's proposals for improvements, 122

close to border, 82

formal ECD centres, 146

and growing heterogeneity and com-

plexity, 73

home-based ECD centres, 114- 6

homes, 103-4, 105, 106, 125, 126

latrines and showers, 109

maps, 72

and porosity, 80 refugees' proposals for improvements, 119,121

religious temples, 112

spaces for imaginative play, 34

83-4

Rwenyawawa zone, 41, 44, 74

Saharawi refugees, 19

Saint John Nursery, 47

Sanyal, Romola, 17-8, 77, 100

schools, 111, 112, 144

Scott, James, 6, 74, 99

self-determination, 28

self-help, refugees', 83-4, 118

self-settlement, 26,28

sensing

Shambele ECD, 55

shelter infrastructure, 103

shops, 113, 114, 118, 144

showers, 62, 66, 81, 108, 109

Siddiqi, Anooradha Iyer, 2, 18, 19-20

00-1

Sierra Leonean refugees, 28

Simone, AbdouMaliq, 18, 98-9

Situated Knowledges: The Science

Question in Feminism of Partial and the Privilege' (Haraway), 5

sketching, 101

Smithson, Allison, 34

Smithson, Peter, 34

soil, poor, 6, 8, 81, 83, 155

Somalia, 49

refugees, 45,56

South Sudan, 32, 32, 36, 49

refugees, 56, 105-6, 108-9

space

shared, 34

spatial analysis, 156-7 spatial appropriations, 99, 116-9, 127-44, 154,157

commercial buildings, 112-3

homes and WASH facilities, 101, 103-4 religious, educational and commercia facilities, 110

spatial data collection, 101

spatial language, 137

spatial rhythms, 33. See also rhythm spatial strategies of assistance, 9, 17,$$
21,159
$$

Squatting in Camps: Building and Insurgency in Spaces of Refuge

$$
\text { (Sanyal), } 100
$$

Sri Lanka, 20

Strategy for Economic Inclusion of Refugees, 62

streets, 34, 146, 155

Sub-Saharan Africa, 6, 25

Sudanese refugees, 51,56

survival practices, 6,99

sustainable development goa (SDGs), 161

SweSwe Zone, 48

Tanzania, 19, 28, 36

Tarach ECD centre, 55, 73-4

technological development, 26

temples, 80, 112

Thika, 49

Tindouf, 18-9

toilets, 37, 41, 103-4, 108-9. See also$$
\text { latrines }
$$

trading centres, 113-4

transduction, 8, 98, 157, 163-4

transversal spatial appropriations,$$
127-44
$$

Turkana County, 50-6, 77

Turner, Simon, 19

Turton, David, 8 
Uganda, 21, 29, 32, 81, 118, 146

Ugandan camps, 1, 15, 19, 33, 34-48, 35, 1

and adults' proposals for improve-

ments, 121, 122

and children's proposals for improve-

ments, 119

and co-dependency, 78

each arriving family provided with plot of land, 103

and growing heterogeneity and com-

plexity, 73

homes, 108-9, 125

latrines, 108

latrines, 108

and non-formal learning 76

and porosity, 80

trading centres, 113

trading 11,113

See also Kyaka II; Kyangwali; Nakival

Umubano refugee camp,

UNHCR (United Nations High

Commissioner for Refugees), 26,28

Commission $95-6,162$

and HBECD, 135

and Imidugudu Policy, 57

and Kakuma, 5

in Kenya, 49

and Kigeme B, 63

and shelter infrastructure, 103

in Uganda, 35

UNICEF, and Tarach ECD, 73

urban environments, 17, 34

urban informality, 18

urbanisation, peripheral, urban logics, 154

rban spaces, 17, 19. See also proto-urban

urban theory, 17, 99-101

urban turn, 6, 13-21, 99, 164

vegetable patches, 63,102

villagisation, 26,57

Between War and City: Towards an Urban Anthropology of Refugee Camps (Agier), 14, 16

Ward, Colin, 34, 146, 154

WASH facilities, 34, 41, 45, 66, 79, 81, 117

effect on children, 107-10, 155

in Kakuma, 56

in Kiziba, 62, 122

in Kiziba, 62, 122

and population growth, 83

and population growth, 83

and refugee-led initiatives, 102

and refugees' proposals for improve

ments, 125

Weapons of the Weak: Everyday Forms

of Peasant Resistance (Scott), 99

Western Sahara's camps, 18-9

World Bank, 57

young children. See children

young children's learning. See children's

$$
\text { learning }
$$

Zambia, 28

Zumthor, Peter, 


\section{DESIGN RESEARCH IN ARCHITECTURE}

\section{Series Editors:}

Murray Fraser,

The Bartlett School of Architecture, UCL Jonathan Hill, The Bartlett School of Architecture, UCL Lesley Lokko,

African Futures Institute, Ghana

At the beginning of 2020,66 long-term refugee camps existed along the East African Rift. Millions of young children have been born at the camps and have grown up there, yet it is unknown how their surrounding built environments affect their learning and development.

\section{Architecture as a Way of Seeing and Learning} presents an architect's take on questions many academics and humanitarians ask. Is it relevant to look at camps through an urban lens and focus on their built environment? Which analytical benefits can architectural and design tools provide to refugee assistance and specifically to young children's learning? And which advantages can assemblage thinking and situated knowledges bring about in analysing, understanding and transforming longterm refugee camps?

Responding to the extreme lack of information about East African camps, Nerea Amorós Elorduy has built contextualised knowledge - nuanced, situated and participatory - to describe, study and transform the
East African long-term camps, and uncover hidden agencies in refugee assistance. She uses architecture as a means to create new knowledge collectively, include more local voices and speculate on how to improve the educational landscape for young children.

With this book, Amorós Elorduy brings nuance, contextualisation and empathy to the study and management of long-term refugee camps in East Africa. It is empathy, she argues, that will help change mindsets, decolonise humanitarian refugee assistance and its study. Crossing architecture, humanitarian aid and early childhood development, this book offers many practical learnings.

Nerea Amorós Elorduy is an architect and researcher with extensive experience in sustainable, educational and health projects in East Africa. She is founder of the interdisciplinary design practice and think tank Creative Assemblages based in Kampala, and guest professor at the UIC in Barcelona. Her work has been internationally recognised with awards, publications and exhibitions.
Cover image:

(c) Amorós Elorduy

\section{¿UCLPRESS}

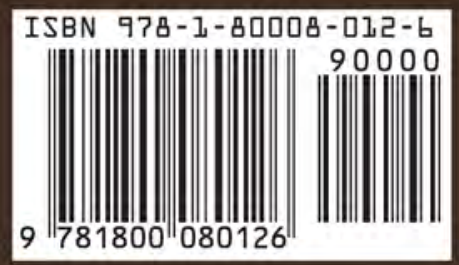

